\title{
Reading
}

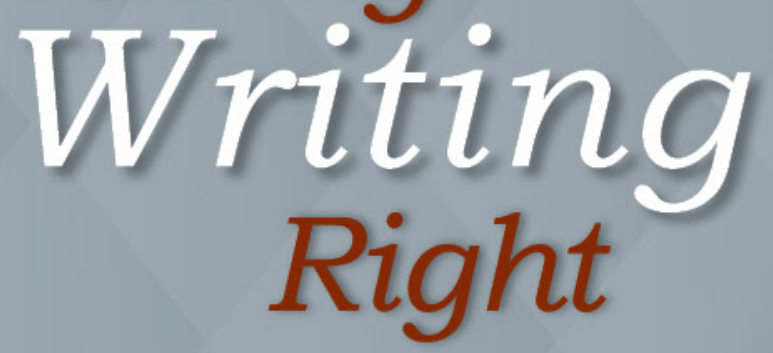

Essays presented in honour of Prof Elna Mouton

EDITORS Jeremy Punt Marius J Nel 


\title{
Reading Writing Right
}

\section{Essays presented in honour of Prof Elna Mouton}

\author{
EDITORS \\ Jeremy Punt \\ Marius J Nel
}

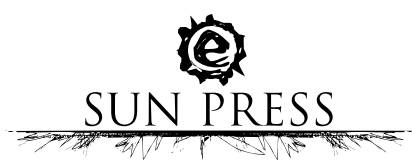


Reading Writing Right: Essays presented in honour of Professor Elna Mouton

Published by AFRICAN SUN MeDIA under the SUN PReSS imprint

All rights reserved

Copyright (C) 2018 AFRICAN SUN MeDIA and the authors

This publication was subjected to an independent double-blind peer evaluation by the publisher.

The editors and the publisher have made every effort to obtain permission for and acknowledge the use of copyrighted material. Refer all enquiries to the publisher.

No part of this book may be reproduced or transmitted in any form or by any electronic,

photographic or mechanical means, including photocopying and recording on record, tape or laser disk, on microfilm, via the Internet, by e-mail, or by any other information storage and retrieval system, without prior written permission by the publisher.

Views reflected in this publication are not necessarily those of the publisher.

First edition 2018

ISBN 978-1-928480-00-6

ISBN 978-1-928480-01-3 (e-book)

https://doi.org/10.18820/9781928480013

Set in Leitura News $9 / 13$

Cover design, typesetting and production by AFRICAN SUN MeDIA

Cover image: (C) Die Burger \& Leànne Stander

SUN PReSS is a licensed imprint of AFRICAN SUN MeDIA. Scholarly, professional and reference works are published in print and electronic format under this imprint.

This publication can be ordered directly from:

www.sun-e-shop.co.za

africansunmedia.snapplify.com (e-books)

www.africansunmedia.co.za 


\section{Table of Contents}

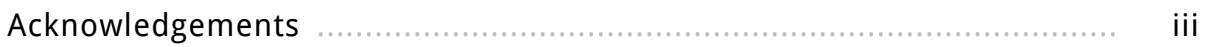

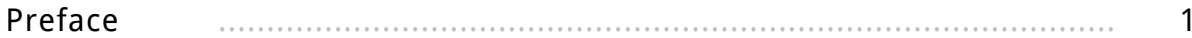

Prof DrJohn E Alsup

Introduction

Proff Jeremy Punt \& Marius Nel

\section{Section A | Right Reading}

Chapter 1 Reading Rightly? On Hermeneutics of Trust, Hope and Commitment

Dirk J Smit

Chapter 2 Reading from the Margins: Some Thoughts on the De-centered Reader

Bernard C Lategan

Chapter 3 From “one-way” Authoritative Discourse to Critical, Open Dialogue (s): Possibilities from Feminist Biblical Scholarship Maretha Jacobs

Chap ter 4 Further Interrogation of the Comparative Paradigm in African Biblical Scholarship: Towards an Analogical Hermeneutics for Interpreting the Old Testament in Africa

Louis C Jonker

Chapter 5 Experiencing the Fourth Gospel: Towards a Methodology of Biblical Drama Criticism

Cornelia van Deventer

Chapter 6 Tobit through the Lens of Trauma

Helen Efthimiadis-Keith

Chapter 7 Questioning the "natural given": Reading John 12:1-8 with a Gender-Critical Lens 


\section{Section B | Reading Writings}

Chapter 8 In Search for the Female Sage: A Decolonial Reading of the story of the Samaritan Woman (John 4)

Lilly SJ Nortjé-Meyer

Chapter 9 Living with integrity and wisdom? The rhetorical situation of the letter of James

Annemarie de Kock-Malan

Chapter 10 Reading the Tamar Story through the Postcolonial lens:

Reflections from Zulu women's Perspective

Slindile Thabede

Chapter 11 The perfect believer in Manly Religion (James 1):

Ancient Notions and Modern Effects

Jacobie M Helena Visser

Chapter 12 Where Heaven and Earth Meet: On Reading the

'Book of Nature' Rightly

Angelique Havenga

Chapter 13 The Pathos of New Testament Interpretation:

Reproof and Reconciliation in Matthew 18:15-20

Marius J Nel

\section{Section C | Readings and Writings}

Chapter 14 An Enigmatic Longing: Reflections on

Christian Spirituality

Denise M Ackermann

Chapter 15 On Leadership in Vulnerability:

Honouring Elna Mouton

Nico Koopman

Chapter 16 Funerary Customs in the FirstCentury

Mediterranean Culture Highlighting

the Role of Women

Birgit Taylor

Chapter 17 Plotting Pauline Travels in an Imperial Setting 


\section{Acknowledgements}

The editors want to acknowledge the financial contributions of the Dutch Reformed Church Curatorium as well as the Vice-Rector (Research, Innovation and Postgraduate Studies) of Stellenbosch University, without whom this volume would not have appeared. The support for the project and willingness to make resources available, through the friendly assistance of Doctor Pieter van der Walt as well as Prof Eugene Cloete, are deeply appreciated.

The Faculty of Theology also supported this project in many ways, including financially. We thank, in particular, the Dean's office as well Ms Escois Benjamin, Faculty Manager.

AFRICAN SUN MeDIA's willingness to consider this collection of essays for publication, as well as their valuable guidance and assistance throughout the process, has contributed in a major way to the quality of the book.

The editors also thank the contributors to this volume, who were eager to express their appreciation for Elna Mouton and her work, and whose contributions amidst busy schedules make this so evident. 


\title{
Preface
}

\section{"What time is it?" Nuni de in the New Testament}

\author{
Prof Dr John E Alsup
}

Congratulations Prof Dr Elna Mouton! ... from your friend and colleague, both in the settings of Stellenbosch, South Africa and Austin, Texas, USA, who has himself fairly recently become "emeritus" in the world of theological education. Joining me in this greeting of tribute are all your friends and colleagues here at the Austin Presbyterian Theological Seminary, especially President Theodore Wardlaw and Dean David Jensen. At retirement time we acknowledge with reluctance and yet with a degree of acceptance that it is "time" to do so. While we rejoice and celebrate, we also wrestle with the "timing" of it all. Hence, my contribution to your Festschrift is about "time." At the personal level, the expression in German is - to be sure apropos: Mit einem lachenden und einem weinenden Auge! (= "with a laughing and a crying eye!")

To be sure, the question of time has fascinated the imagination of thoughtful people for generations. From astronomers to mathematicians to chroniclers of historical phenomena and cycles of change to the younger generation, always asked "What do you want to be when you grow up?" (whenever that may be!) to the average adult person coming to terms with (or trying to do so) with the aging process when looking into the mirror, to Mister or Miss Average scrambling about to accomplish all the "to do's" while there is still time left before it is "too late" (complicated or helped by the construct of "daylight-saving time?"). We all - it would seem - are in a quandary over the question: "What time is it?" or more often "How late is it?" The optimists among us tend to reply: "It is never too late ... ", while pessimists and procrastinators say: "It is always too late, so why do today what you can put off until tomorrow!" This kind of futurist thinking demands a conversation about divine possibilities and opportunities to link up with God's purposes in history. There is a 
theological caution, it would seem, that arises whenever we speak about the future. We do well to be hesitant when speculating about what the future holds! (A Sunday school teacher by the name of Otto Stybor got me to wondering about such matters during my teenage years when he suggested that we might think of "history" as "His story".)

I am instructed in this regard by what we find in the linguistic options in Greek texts, ancient and modern: there is a refinement here of word usage on this topic of time and the future. First, the common word chronos (from which comes the English term "chronology") has as its contextual anchor the "movement" or "flow" of time as measured by the calendar ... days to nights to weeks to months and to years etc. - often expressed in connection with the seasons of the year. We often utter the familiar phrase “Time marches on!” Yet, as Prof Dr Mouton may remember from her visit to our horse ranch here in Texas, there is a type of time here called the "rhythm of the earth" that enables horses and humans to live together and interact respectfully and beautifully with one another as we live out a life of belonging to one another. It reminds me of the famous quotation from Winston Churchill: "There is something about the outside of a horse that is good for the inside of a human being." Prof Dr Punt and family also have such equine memories from their visit. What this special rhythm represents for humans who are open to learning from horses is that they live each day to the fullest without worries about tomorrow, confident, it would seem, that tomorrow will be just fine (not unlike Jesus' counsel in the Sermon on the Mount in Matthew 6:34: "Do not worry yourself about tomorrow for tomorrow will worry about itself. Sufficient unto the day is the evil thereof.").

When asked "How old are you?", Native American Indians replied by indicating how many summers they have experienced! In most places today a birth certificate offers a more precise answer ... or at least, so it would seem. We often call this "ordinary time." But is this all there is? When responding to affirmatives about all the good things coming from yesterday's blessings, Paul often introduces the caveat of pollo mallon ("how much the more," cf. e.g. Rom. 5:9, 10, 15, 17; 8:34, 11:12, 24; 14:13; 2 Cor. 5:9; Gal. 4:9; Phlm. 16, etc.), the (often) exceedingly more wonderful dimension of what breaks in unexpectedly into the chronological flow of things! What is that kind of time anyway when unmasked? Jacob Needleman offers an answer to this question in his provocative volume entitled Time and the Soul (New York, Currency/Doubleday, 1998). Quoting in part from Jeremy Rifkin, he asserts initially that we are:

overwhelmed by plans that cannot be carried out, appointments that cannot be honored, schedules that cannot be fulfilled, and deadlines that cannot be met. It is the new poverty ... our famine of a culture that has chosen things over time, the external world over the inner world. It has become the aching question of our era ... being busy, having many responsibilities, being involved in many projects or activities - is now being felt as an affliction. It is leading us nowhere. More and more it is being experienced as meaningless (vii-viii). 
Needleman's book, basically a pithy biographical novel, then moves from this initial observation about time and a sense of meaninglessness to a captivating engagement with metaphysical, theological insight. Eliot Appleman, essentially Needleman's chronologically prior self, is visited (as a divine gift) by the author in order to relive that which had been a former experience level, now from a "new now" perspective. Eliot encounters his future self, as it were, and tries to make sense of and act upon this encounter with the strange-yet-familiar future self. The past is now present and the future is now present for one and the same person in a time-warp of sorts. Needleman asserts: "Young Eliot feels the terror of being visited by a force infinitely beyond his comprehension; the terror of being seen by his own eyes; and then he asks provocatively: "Why are we afraid of being seen - by ourselves?" He continues: "Freedom from time - the approximate term for which is 'immortality' - awaits you; you are made for that, but you must search and search to receive in your life the winds of this immortality, this endless presence, that are constantly being sent to man from the centre of the universe." And he wants to call it a "good fear" that is "sometimes known to us as the experience of the uncanny ... Experiences that break through our ordinary sense of time ... " Needleman goes on to ponder this issue of time and other dynamics surrounding the profound quest for discovering answers to the question of "who you are." (There are echoes here, of course, from the ancient Greek traditions associated with the gnothi seauton (know thyself!) counsel by the Pythian oracle at Delphi to inquiries about future risks and associative consequences).

The reflections of Needlemann above lean, as it were, into the alternative discourse on time, which we have located in the alternative terminology and biblical thought world of chronos in Greek, which is "time" as kairos. In scripture it tracks a reality that has less to do with the "march of time" across the landscape of aging than it has to do with the encounter of "event draped in meaning" or some such thing. Let us call it event during and after which nothing can remain the same. A possible translation might be something like "destiny's hour" or "divine purpose manifest in history." These two types of time collide - if you will - and may go undetected and uninterpreted until the chronological time moves in its experiential stride to the "appointed hour" (of destiny) in which the encounter with the kairos of "divine purpose," if you will, produces the "new time" that is unimagined and "earth-shaking" (as we say) and that bursts on the scene. We know such moments, of course, as we sit in cancer wards, waiting incredulously and afraid, or in disbelief over the magnitude of natural disasters, or - in contrast - in maternity wards beholding the glory of new birth! For scripture this is - more often than not understood and spoken of in terms of the genre of "apocalyptic" (= pulling back the curtain to reveal what is otherwise hidden and thus unseen). To quote the Apostle Paul in 1 Corinthians 2:9f (paraphrasing the prophet Isaiah (64:4ff)): "Eye has not seen nor ear heard, neither has it entered into the heart of mortals, the things which God has prepared for those that love him. But (now) God has revealed them to us by His Spirit: for the Spirit searches all things; yes, the deep things of God." 
The literary genre in which the Apostle articulates this apocalyptic/theological understanding of time is the epistle, i.e. correspondence as surrogate for personal presence. This mode of "presence" takes very seriously the location of dialogue within the context of the church. It would seem that for Paul - and others - the church, as body of the risen Lord in a post-resurrection world, is seminal in many respects, not the least of which is certainly the issue of time! The eschatological "now" is nuni de, the new/now world of God's intention for creation ... a sobering and exciting notion of promise. Distinguishing itself from the genre of "gospel" which itself is to be distinguished from the genre of "biography", of course, and yet building on it, this epistolary genre opens the door to wise counsel (following aspects in oral tradition of such counsel as in the Sermon on the Mount? (... a provocative history-of-tradition question worth pursuing would be that of the relationship between the "it was said of old, but I say unto you" of the Jesus tradition and the nuni de of Paul and the tradition of faith development of apostolic congregations)), i.e. subsequent "parenetic guidance" (= admonishments, advice, etc. regarding the Christian life). The diction of this genre moves regularly from syntactical statements in the indicative mood (statements of fact) to those in the imperative mood (commands), i.e. appropriate new-faith conduct based on the prior facts or givens of God's revealed actions - particularly that of Jesus' resurrection - in history. To quote Prof Leonhard Goppelt in his Commentary on 1 Peter: "To live in society on the basis of Jesus' resurrection means to have an eschatological existence in history" and "as Christians they are 'foreigners' because they are to live this existence in history” (English trans. 67 and 156).

This brings into perspective another terminological refinement as pertains to the Greek term eschaton as the end or final "divine optic," so to speak, which sees time from the end to the beginning rather than the reverse order, which is our accustomed way to think of time's movement. Contrary to our view, we have here a view of chronological time turned upside down. It would be something like a kind of time that "marches backward toward and into chronos from the end toward the beginning; hence, "eschatology.

Another important aspect of the discussion of time in Pauline theological thought and diction is that which is raised by the title of this preface. It pertains to the content of the expression nuni de, noted above. While it is not a word for time per se, it draws attention to the contrasts within the relationships between three aspects of time, namely past, present and future, i.e. what was, is and shall be. The nun, of course, points to the "now of what is" and it sets itself apart, interestingly enough, from a certain aspect of the past-ness of what was, but weds - so to speak - the "is" with the "will be" of present and future. This "eschaton dimension" of time-reality is generally called in English the "eschatological now." The eschaton of God's future embraces the promises of God "from of old" - as the expression goes - pulling them forward into the present reality of time, while - at the same time - enabling future time to "reach back" into the present experience of the addressees of the genre in "parenetic 
address," thereby giving life and a compelling foundation to the behavioural guidance being urged. From the standpoint of "chronological time," it is as though the time reference of past event and future deliverance bend forward and backward simultaneously ... now as vivifying reality upon the present from both directions when mapping time upon the "flow chart" of chronos. The "now" becomes critical as a realisable focus: the past is no longer "over" and the future is no longer "not yet" ... rather both live within the present of God's new possibility.

At this juncture it is critical to specify what the particular (not general) past that "lives" in the present and the future has become. That is to say, we are drawn by virtue of lived life to raise the practical ethical issues of time that are so critical in a world like ours with all its nuclear dangers, natural disasters and the avarice, hatred and threats to "life and limb", as we say, from the unexpected assaults, driven by evil, of those who would do us harm for no other reason other than our skin colour, the way we part our hair, the views we hold on a variety of topics, or our confession of faith and the way we worship God! In point of fact, however, in the New Testament world things weren't much better with regard to the dangers that beset people like us. Creatures of God's creation and the giftedness of a habitat/ environment that God has provided, since the Garden of Eden, for them to enjoy has always been subject to corruption ... the experience of evil forces, lurking in every corner of our lives, has always been the bane of our existence.

Instead of assigning blame and ratcheting up the rhetoric of diatribe to which we have grown accustomed through the public news media and internet technology etc., Paul and the author of I Peter and other New Testament writers like them think and speak like apostles, like those sent by God with a message of hope, not unlike the prophets of old, but now (nuni de) with the declaration of "good news" for all creation after the resurrection of Jesus, i.e., the good news of euaggellion and its posture on time.

The post-resurrection perspective is important when comparing the apostolic confidence and diction of nuni de in the prophetic posture of Paul et al. vis-à-vis the oft-concomitant complaint of Old Testament prophetic longing: "How long, oh Lord, how long until your promises become our experience?" For the eschatological nuni de of Paul and elsewhere, the "new" that has come through the resurrection of Jesus Christ from the dead comes even now as God's new reality into the present from the future(!) of apocalyptic promises, e.g. in the Book of Revelation (cf. chs. 20-21), as well as into the present from the past, as much as from the nuni de of apocalyptic eschatology; the past was actually - as scripture would have it from the divine point of view - never anything other than present for God! The same can be said for the future in relationship to the present and past for God! And yet prophetic longing continues to ask: "and for us?" This business of promise and an empirical realisation is a thorny issue, to be sure. Accustomed as we are to the dominance of our thinking and speaking within the categories of existentialism and rationalism, it is quite foreign - as it were - for us to think and speak theologically, as the counsels of scripture and Needleman - in his style - prompt us to consider seriously. 
So, from whence or how does Paul derive the expression nuni de? First, this could be understood as a history-of-tradition question, by which we might attempt to trace lines of literary source-indebtedness among written biblical sources, their oral traditions, and their respective Sitze im Leben and inter-relationships. Even a brief exploration of New Testament and LXX Greek lexica and concordances (the Hatch and Redpath LXX Concordance is especially instructive here) makes clear, however, that, while the use of the term nun is hardly unique to Paul, the chronological flow of time in texts like Second Isaiah (ch. 43:1) or Job 30:1 and 9 hardly qualify as a source of indebtedness for the focal theological nuancing that constitutes the critical pivot point for the development of his correspondence with communities where his preaching and - presumably - conversations and clarifications in on-site dialogue were foundational for their very existence. First of all, it is important to acknowledge that the addressees of the writings containing the technical terminology of nuni de were congregations of Christians, which by and large were founded by Paul in his ministry of preaching and shepherding (often in absentia). Paul is not simply passing on the wisdom of prior prophetic wisdom. A first-hand "Apostolic calling" and "being sent out" is sui generis - as it were - for him as he attests frequently in reflection upon his encounter with the resurrected Lord Jesus (also chronicled as the Damascus Road appearance in Acts 9, 22, and 26 (cf. also in his own words from 1 Cor. 9:1; cf. also, 2 Cor. 5:16f: "Thus we - from the now perspective - know no one according to a physical perspective - even if we (once) knew Christ according to a physical perspective - but now ("nun") we no longer know (like this) ... thus if anyone is in Christ, there is a new creation; old things have passed away, behold, all things have become new"). Nuni de was for Paul clearly not merely a theological construct, but rather a personal, transformative reality.

This resurrection-contextual focus on the "but now time" of his own experience ("did I not see the Lord?" 1 Cor. 9:1) is also expressed in Philippians 3:10 as he seeks "to know" this Lord, that is (an exegetical kai in Greek) the "power of his resurrection," and that of the "but now" life of the congregation, that changed everything for both. Even when appreciating all other good and wonderful things in this life, Paul often proclaims the pollo mallon (= "how much the more") of nuni de! Worth pondering, of course, would be the possibility that pollo mallon (as suggested earlier with the reference to the gospel tradition of the Sermon on the Mount) is an echo of Jesus' "you have heard it said of old ... but I say unto you!" This would make sense, of course, for the continuation of apostolic discourse on the question - common to all the gospels - of the identity of the historical Jesus from the perspective of post-resurrection influences upon the development of gospel narratives, especially as regards Jesus' question at Caesarea Philippi (Mark 8:27ff and parallels): "Who am I?" Thus, he moves from the indicative mood of God's act of raising Jesus from the dead to that of the imperative mood of parenetic consequences of nuni de. 
It is consequential for Paul to then move, for example, to these powerful "so-what images" of inclusive table fellowship in Romans 12-15. This interpretive transition reminds me of an impassioned, prayerful appeal in Desmond Tutu's "An African Prayer Book" (110-113) entitled: "Reflections on Wholeness.” It reads:

Busy, normal people: the world is here. Can you hear it wailing, crying, whispering? Listen: the world is here. Don't you hear it, praying and sighing and groaning for wholeness? Sighing and whispering: wholeness, wholeness, wholeness? An arduous, tiresome, difficult journey towards wholeness. God, who gives us strength of body, make us whole. Wholeness of persons: wellbeing of individuals. The cry for bodily health and spiritual strength is echoed from person to person, from patient to doctor. It goes out from a soul to its pastor. We, busy, "normal" people: we are sick. We yearn to experience wholeness in our innermost being: In health and prosperity, we continue to feel un-well, unfulfilled. There is a hollowness in our pretended wellbeing: Our spirits cry out for wellbeing of the whole human family. We pride ourselves in our traditional communal ideology, our extended family. The beggars and the mad people in our streets: Where are their relatives? Who is their father? Where is their mother? We cry for the wholeness of humanity. But the litany of brokenness is without end. Black and white; Rich and poor; Hausa and Yomba; Presbyterian and Roman Catholic: We are all parts of each other, We yearn to be folded into the fullness of life - together. Life, together with the outcast, The prisoner, the mad woman, the abandoned child; Our wholeness is intertwined with their hurt. Wholeness means healing the hurt, Working with Christ to heal the hurt, Seeing and feeling the suffering of others, Standing alongside them. Their loss of dignity is not their loss: It is the loss of our human dignity, We busy, "normal" people. The person next to you: with a different language and culture, With a different skin or hair colour - It is God's diversity, making an unbroken rainbow circle. Our covenant of peace with God, encircling the whole of humanity. Christians have to re-enact the miracle of Good Friday; The torn veil, the broken walls, the bridge over the chasm, The broken wall of hostility between the Jew and Gentile. The wall between sacred and secular? There is no wall. There is only God at work in the whole; Heal the sores on the feet; Salvage the disintegrated personality; Bind the person back into the whole. Even if there are ninety-nine: Without that one, we do not have a whole. God, who gives strength of body, make us whole. ("An African Call For Life").

It would seem to be clear from this pastoral prayer's passion for God's gift of wholeness that faith's conviction is - fundamentally - that God is the only One able to define wholeness and to enable "working together with Christ" to heal the hurt, to see and to feel the suffering of others, to stand alongside those who have lost human dignity ... in short, to "re-enact the miracle," which is nuni de/Good Friday's Easter morning!

Finally then, in the spirit of shared dignity and the "re-enactment of Good Friday/ Easter morning," it is appropriate to conclude this exploration of nuni de in the New Testament thought-world with the shortest, yet perhaps in many ways most profound extant example of Paul's epistles: that which was written to Philemon. While certainly belonging to the Pauline corpus, it would appear that its authorship is actually a collective effort, or as we say today: "a group-send." At the beginning, Timothy "the brothered one" is mentioned as co-author and at the end Epaphras, 
Mark (the Gospel writer?), Aristarchos, Demas and Luke (the Gospel writer?) sign off with Paul at the end as well in pronouncing the grace of the (resurrected) Lord Jesus Christ upon the "spirit of you all." This plural - you all - is significant because the Epistle itself, while being addressed to Philemon "the brothered one" (as the head of the household), is also addressed to Apphia, the "sistered one" (= the wife of Philemon?) and to "Archippos" (= in Greek "Big or Alpha Horse"), our fellow-soldier, and to the "of you (singular ... the antecedent is of course Philemon) ekklesia ("church") of the household sort (in contrast to the "synagogue" sort?). A difficult lesson for Christian household dynamics (especially for those accustomed to 'being in charge!'), then as now, is that there is but one Lord of this household and all members thereof are douloi (servants) to one another (cf. for example, the hypotassomai structures of the household code tradition in Col. 3:12-4:6 and parallels).

Subsequent to the opening list of addressees in vv. 1-2, there follows in v. 3 the apostolic blessing: "Grace to you all and peace from God our Father and (from) the Lord Jesus Christ.” After this focus of address, there come assurances in vv. 4-7, which constitute a contextualisation of familiarity between all the parties mentioned in part one. Sometimes these parties have epithets of function within this exemplary house-church. V. 4 contains the "thanksgiving to my God" ... stemming from the Pauline lead voice of apostolic address, that launches a prayerful reminder statement about the constant concomitant recall of Philemon as head of this house-church in Paul's own prayer life. V. 5 focuses on that which has prompted this prayer of thanksgiving, namely, that Philemon's love and faith have been brought to Paul's attention. The singular pronoun ("hen") suggests that Paul sees love and faith as inseparable when directed to "the Lord Jesus" and when shared among "all the saints." V. 6 introduces a result clause: "that the common cause impetus that stirred your faith may accomplish the needed form of discernment about all the good at work among us for Christ." V. 7 continues: "For I feel a great joy and comfort as a result, dear brother, of your love because the compassions of the saints have found their peace (resting place: anapauo) through you."

A major shift in content follows then in v. 8, when the Apostle continues regarding the parenetic counsel prompted by the nuni de crisis hour that also exists for this house-church. The key word is epitassein, "to give orders, to arrange, shape, or structure something." In context it reads:

On account of the foregoing, I am feeling considerable confidence about my laying out what is the necessary thing for you to do. Yet (v. 9), on account of love, on the other hand, I am exhorting you, being such as I am, Paul, even a seasoned veteran, but now (nuni de) also being a captive of Christ Jesus, (v. 10) I am exhorting you concerning my 'offspring' Onesimus, whom I 'birthed' in my service of bondage (to Christ) (v. 11). He it is who once was of no use to you (Greek achreston), but now (nuni de) is of use (euchreston) to you and to me. (v. 12) He it is whom I have sent back to you, that is: the one whom I care for dearly. 
(v. 13) He it is whom I have wished to retain by my side for diakonia in order that, on your behalf, he might be useful in helping me in my duties as captive of the gospel." (v. 14) "But without your knowledge and willing consent, I was wishing to do nothing, in order that the good and helpful thing might not happen by constraint, but rather with your blessing.

An important moment for "time" and "transformation" has been reached here at vv. $15 \mathrm{ff}$ as the Epistle nears its conclusion. For one thing, like the formula "it is enough, payment has been made in full" in the gospel tradition (cf. Mark 14:41), apeches - drawing on the realities of various kinds of indebtedness between Paul, Philemon and Onesimus - opens the eyes of Philemon to the difference between "hour" time and "eternity" time, or (as earlier (v. 11)) nuni de time! New time, new perspectives on behaviour! V. 16 holds up for consideration a new definition for the "servitude of captives of the gospel" (cf. v. 13 above). Hence, v. 16 focuses on the emergence of a new creature shaped by the model of the resurrected servant-slave Lord Jesus, the One who is an "on behalf (of others) servant" - a "beloved Brother" (cf. also Rom. 8:29f). This is an invitation to Philemon to join up and to make common cause with the new day dawning: in receiving Onesimus, he/we are receiving one another in the Lord. Former errors and shortcomings will find new and helpful, redemptive solutions. These are blessed, apostolic pledges ... we all are invited to step forward ... echoes from the beatitudes! An interesting - though subtle - "seal on the deal," as it were, comes in v. 20 when Paul uses the "I would that and pray it will be so" form of the first person singular, $2^{\text {nd }}$ aorist optative mood, middle voice of the verb oninemi, from which comes the very name of Onesimus, which means to be helpful, of service, or useful. This apostolic, prayerful expression of name-interpretation is now placed on Philemon himself as epithet in the confidence that harks back to the joyful expression of compassions of the saints resting in love and comfort "through you" back in v. 7. Here, Philemon and Onesimus, in the "new now" of nuni de, share a common heritage and a new-now-future. Significant also is the accent on extending the oninemi supportive help of hospitality to those in need and doing those things that go above and beyond bare minimums in offering such specialised supportive help.

Wow, would that we had "the rest of the story", as we say, and could read Philemon's letter in reply to Paul! Some would say that we do in a way, in the Epistle to the Colossians (4:9) in which the service of diakonia became the last word in this drama ... the rest of the story? ... (Col. 4:9 "all things will be made known to you all there!") Amen.

Well, for now Prof Dr Mouton, God speed to you and all the best in retirement. I should have written more, but I ran out of chronos ... I had to go and feed the horses!

As before, your friend and colleague, John. 


\section{Introduction}

Proff J Punt E M Nel

This collection of essays aims to honour the scholarly work, academic contributions and research activity of Prof Aletta Elizabeth Johanna (Elna) Mouton, who retired as professor of New Testament at Stellenbosch University at the end of 2017. As is evident from all eighteen contributions, Elna's contribution to biblical scholarship generally, and New Testament scholarship in particular, has been influential and far-reaching, and often touched the nerves of those with whom she interacted. The contributors to this volume are academic colleagues from various institutions as well as past and current students of hers. All immediately agreed not only to contribute, but to write essays that relate in one way or another to Elna's scholarly focus on what she often called the "transformative potential" of biblical texts. Elna's many scholarly contributions, in conference presentations, scholarly writings and otherwise, clearly demonstrate her concern for accountable and responsible exegesis, and for exploring the ethical dimensions both in texts and in hermeneutics: reading writings right, with all its accompanying challenges and ambiguities, amidst liminalities of various shapes and sizes.

In the preface John Alsup from Texas in the United States and a long-standing friend of Elna Mouton's, already signals the connections between the academic concerns, faith commitments and human friendship that characterised Elna's life in so many ways.

In the first part of the book seven scholars demonstrate, often in engagement with Elna Mouton's work, important facets of reading rightly. The first two chapters directly engage Elna's hermeneutical approach to biblical texts. In the first chapter, and engaging Elna's work directly, a long-standing friend and later colleague 
of hers, Dirkie Smit, casts a light upon four aspects of her work that portray her concern with reading rightly. He shows also how her academic work is interrelated to her life's vocation, embedded in how she understands herself and her academic responsibilities across the spectrum of her involvement in intellectual, ecclesial and other intentional communities. In a related way, Bernard Lategan describes how Elna Mouton developed a very specific understanding of what an ethical reading entails. He explains how Mouton identified three interrelated levels of responsibility - and to even embodied these in her academic activities - including the need to account for the choices made during an interpretation of the text; discerning the pragmatic thrust of its content; and then applying these insights in the community and context in which and for which the interpretation is made.

Maretha Jacobs's reflection on Elna Mouton's kind of biblical interpretation points to what she identifies as the prominent aspects of Mouton's work, which Jacobs reads in conversation with other New Testament scholars: the theological hermeneutics of Dale Martin, Loveday Alexander's reflection on the kind of interpretation "God's Frozen Word" requires and the work of a few feminist biblical scholars. These comparisons lead Jacobs to consider alternative ways of viewing the Bible, their implications for biblical scholarship and for "opening up" the canon to other early Christian sources, and "dialogical biblical interpretations" of various kinds as ways of doing justice to cultural differences between the New Testament world and our modern world. In this way Jacobs situates and evaluates different ways of reading ethically.

Louis Jonker challenges the ability of the popular, comparative paradigm of interpretation of African biblical scholarship to produce right readings. The bias towards socio-historical textual analysis of the Bible in tandem with contemporary African socio-economic and religio-cultural realities, as well as splitting interpretation into two separate procedures of exegesis and application, creates problems for African biblical scholarship to read the Bible rightly. Jonker critically explores this paradigm and its dominance in African biblical scholarship, particularly in relation to the Old Testament. He argues that an analogical hermeneutic will be a more responsible basis for the comparative paradigm when applied to narrative texts.

Ancient narratives and stories have often been limited to their textual forms and only been allowed to serve as literature and products of countless translations. Cornelia van Deventer, however, seeks out the performance and experience of these stories focusing on the author of the first letter to the Johannine community, who makes this point when testifying of an experience of the divine. The author refers to

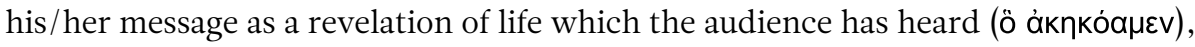

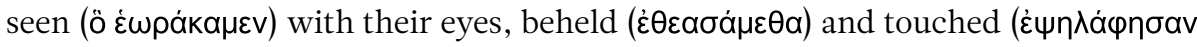
) with their hands (John 1:1). Van Deventer explores the means through which the Fourth Gospel, and potentially other narrative biblical texts, can be imaginatively 
experienced as drama and analysed accordingly by building on the existing methodology of narrative criticism with insights from the field of theatre criticism. The chapter seeks to transform readers into audience members who see, feel, smell, hear and taste the happenings of biblical narratives.

Reading the book of Tobit, slightly pre-dating the New Testament writings, through the lens of trauma, Helen Efthimiadis-Keith focuses particularly on Tobit's dysfunctional relationships and his subsequent recovery. In order to do so, she uses a Jungian psychoanalytic hermeneutic that regards all aspects of the text as manifestations of Tobit's psyche. Efthimiadis-Keith argues that the pervasive 'otherings' dominating the first section of the book represent Tobit's psychic fragmentation, regression and ailing relationships, while the effects of his psychic integration and recovery, spurred on by Tobias's marriage to Sarah and evident in transformed relationships, are illustrated in the last section of the book.

Amidst great strides forward towards the equality and dignity of all persons, specifically in terms of gender, many spaces within theology, faith communities and biblical scholarship (in Southern Africa and elsewhere) still remain ambiguous. Nina Müller van Velden questions traditional notions of the "natural given" of male dominance (often biblically motivated), since they continue to be a challenge for inclusion. The Gospel of John - regarded by many as offering a positive portrayal of female characters and demonstrating a welcoming stance towards women in the attitude of Jesus towards women - also contains such ambiguity in terms of gender. Positive strides towards inclusive notions are present in the narrative, yet traditional, patriarchal power relations are equally present, even in the character of Jesus. Muller van Velden proposes that it is precisely the ambiguous portrayal of gender relations in Johannine narratives, and John 12:1-8 in particular, that contribute meaningfully to contemporary discourses on gender and power relations, and thereby to the construction of open and inviting spaces for all.

The second part of the volume contains six essays which focus on reading specific texts. Lilly Nortje-Meyer presents a decolonial reading of the story of the Samaritan woman in John 4, partly based on an Afrikaans commentary on the Gospel of John which serves as intertexture that correlates with its social-cultural context. The original book by Erdman (1916) is an explanation of the Gospel of John, freely translated into Afrikaans. The ideology of the white Afrikaans male author has clearly influenced his view of the person of the Samaritan woman and her conversation with Jesus. The book serves as a cultural text that is central to the strategies of modern imperialism. The way in which Jesus and the Samaritan woman are interpreted demonstrates how these representations are governed by the politics of interpretation, theological persuasion and ideological motives of the coloniser. From a decolonial feminist perspective the story of the Samaritan woman in John 4 will be reread in a search of the female sage. 
Annemarie de Kock-Malan's contribution is situated in the midst of South Africa's multifaceted moral and social crisis, a society where poverty, gender-based violence, rape and HIV/AIDS are pervasive. These moral dilemmas in actual fact represent a deeper, primarily theological dilemma, since faith communities are not necessarily portraying their identity in Jesus Christ with integrity and wisdom, as alternative communities, as the letter of James suggests. The author of the letter of James perceived or anticipated a moral crisis in the historical situation of his audience. He reacts to this by arguing for alternative perspectives that his audience clearly did not see. This chapter investigates the "rhetorical situation" of the letter of James and the writer's reaction. The author of the letter of James challenges the dominant ideologies of the time in order to propose his own ideology or alternative perspectives as the alternative reality of God. The author speaks on behalf of the voiceless and marginalised in order to open the eyes of the audience to this alternative reality. The "rhetorical situation" of this ancient text is not identical to our situation, but the text holds a key that may help us to challenge our own situation in similar ways.

Following Elna Mouton's lead in the search for texts' transformative potential, Slindile Thabede reads Tamar's story through a postcolonial feminist lens in search of the subaltern's voice. She argues that Zulu women have so much to say about their marital oppression, and thus aims to allow these voices to emerge from the gutters of oppression in her rereading of the narrative. Zulu women's pain can become the new frontier for cultural reform, as it cries for new cultural norms that consider the reality of women and recognise that both males and females are equally important to the family and the society at large. Even though Judah needed sons to continue his tribe, it took Tamar's subtle intervention for him to achieve that. The postcolonial feminist lens may be helpful to Zulu women as they seek new ways to resist not only their patriarchal culture but also the oppressive powers of the colonial world in whose shadows they continue to live. Tamar's model of resistance may therefore be an important tool for empowering Zulu women to resist injustice.

Jacobie Visser pursues the gendered discourse - a particular focus in Elna Mouton's work - in James 1, showing how the Jesus followers are exhorted to live up to $1^{\text {st }}$ century CE Greek and Roman images of manliness: being perfect $(1: 4$,$) complete$ $(1: 4)$, lacking in nothing $(1: 4)$, being able to endure trials (1:12) and ready to be tested (1:12). The believers are considered blessed (1:12) and promised the crown of life (1:12) if they are able to adhere to these manly traits, but all in the name of being faithful to God. Visser in investigates the intersections of $1^{\text {st }}$ century masculinity and religion, as they are constructed in James 1, in order to expose the different elements involved and their intersectionalities. The effects of postulating religion and its discursive impact on contemporary attempts to re-masculinise religion are considered.

Taking her cue from Elna Mouton's involvement in teaching the spirituality course in the Master of Divinity programme at Stellenbosch, Angelique Havenga shows Elna's sensitivity to and awareness of the sacredness of time and space. For Elna, an essential part of our spiritual formation is learning to see that each moment and each place has the potential to be holy; that each moment and each place can convey 
the presence and glory of the Triune God; that each instance of chronos can become an instance of kairos. Inspired by Elna's mentorship and friendship over the years, Havenga explores this notion of the sacredness of time and space by specifically looking at how the sacrament of the Eucharist reconfigures our understanding and perception of the temporal and spatial dimensions of our earthly existence. Building on the thoughts of various theologians, she argues that the Eucharist - where we meet Christ and participate in the drama of his life, death and resurrection (in and through everyday bread and wine) - imbues people with what can be seen as a sacramental vision, which alters the way people see and live their lives in the space-and-time-bound realities of this world.

Marius Nel, one of the book's editors, engages with the topic of Elna Mouton's inaugural lecture, the pathos of New Testament Studies, pathos being the "persuasive power, reception and lasting effects in people's lives" of the interpretation of New Testament texts. In agreement with Mouton's emphasis on the importance of the pathos of New Testament interpretation, since it directly influences people's understanding of God and their own identities, Nel specifically focuses on the possible life-affirming or life-threatening pathos of interpreting Matthew 18:15-20 as an example. He argues that while interpreters should take responsibility for their interpretations of the New Testament, a possible life-threatening pathos of a specific interpretation of a text such as Matthew 18:15-20 cannot be used in a simplistic manner to negate the potential meaning of a text. It is instead important, as suggested by Mouton, to determine if the pathos of an interpretation of a specific text is in line with the grain or the intention of the text.

In the four papers constituting the third and final part of the volume, four scholars honour Elna's legacy by identifying how her work impacted on their very specific areas of research. Denise Ackerman touches on what arguably is one of the defining elements of Elna Mouton's work - and person - namely, spirituality. Ackerman described the ways in which we experience the enigma of longing will differ, depending on varied contexts, personal histories and faith traditions, but showing also those constants through time. Exploring the longing for the Holy One shapes the practice of prayer and increases the desire for silence and solitude. Exploring longing is not without pain and times of darkness, for there are no short cuts in the desire to deepen the relationship with God. Yet our longing does not allow us to turn away from mystery. We find that in the darkness of 'unknowing', truth about God is revealed. Ackerman argues that people cannot and dare not ignore that enigmatic longing which draws them ever deeper into life in Christ.

In his celebration of Elna Mouton's leadership, Nico Koopman not only identifies her leadership as situated within vulnerability, but also portrays such leadership as being aware that where vulnerability is acknowledged, accepted and affirmed, the way is paved for leadership that serves with humble assertiveness and leadership that seeks justice for all. Exploring vulnerable leadership, Koopman first explores 
vulnerability in terms of a Trinitarian anthropology. In the two last sections of his essay, Koopman shows how humble assertiveness and the quest for justice for especially the most vulnerable are two vital features of leadership in vulnerability.

Drawing on her own research expertise, Birgit Taylor examines the role of women in the funerary customs in the $1^{\text {st }}$ century Mediterranean culture. Among the funerary rites, the mourning customs are highlighted. The role of women in this context is discussed against the backdrop of public and private spheres of the prevailing culture. Funerary rites demonstrate that women played an essential role in the death and mourning customs in Ancient Judaism. Apart from preparing the body for burial, women grieved loudly in a lamenting act during a funeral procession, giving voice to society's grief. While in general the public domain may have belonged to men, in the funerary rites the domain of public mourning belonged to the women.

Finally, the contribution of the other editor of the volume, Jeremy Punt, links up with a theme which Elna Mouton often used to describe her and others' involvement in theological studies, namely the metaphor of the journey. He unpacks this notion in the Pauline letters and legacy, which as a whole are closely connected to travelling, with the apostle and others moving around and crossing boundaries of various kinds. These movements occurred at a time ( $1^{\text {st }}$ century CE) and in a context (Roman Empire) in which, on the one hand, travel happened more frequently than often thought, even if differently compared to today, and on the other hand, $1^{\text {st }}$ century travels were interconnected with issues of identity formation and acculturation which fed into the rich yet complex tapestry of $1^{\text {st }}$ century life not always or immediately evident in the texts of the NT. Among other considerations, one important aspect informing the broader picture of $1^{\text {st }}$ century travels was the ubiquity of the Roman imperial setting and its influence, aspects of which resonates in our modern context shaped by migration and other forms of people movement.

These eighteen contributions of fellow scholars and friends of Elna Mouton are indicative of the interests of these scholars, but also of their engagements with the different areas in which and themes about which Elna stirred up and promoted conversation, and challenged established ideas, in her committed, studious and earnest academic research work and scholarship, and in her persistent and ongoing endeavours, her persistent attempts to always read writings right! 
Section A | RIGHT READING 


\title{
Chapter 1 \\ Reading Rightly?
}

\author{
On Hermeneutics of Trust, Hope and \\ Commitment
}

\begin{abstract}
Dirk J Smit
Appropriating the perspective of the New Testament ... like mountaineering ... is a narrow road which calls for a hermeneutic of trust, hope and commitment.

(Mouton 2002:260)
\end{abstract}

\section{"True Proclamation of the Gospel"?}

Although we attended different schools in the same region, we knew one another at school and later as students. We met when we both represented our respective schools at an annual conference for potential youth leaders, sponsored by Die Burger, an Afrikaans newspaper. During our final school year we attended several activities of the Christian Students' Movement together. We were in fact together at such a weekend event in Riebeek West when the large earthquake struck the Boland area and caused major destruction in her home town of Ceres. As students at Stellenbosch University we knew one another very well and participated together in student life in many different ways.

I have many vivid memories of Elna Mouton from those early days, many of them quite remarkable. At the end of our final school year we were members of a stranddiensspan, groups of students who spent a few weeks during the December holidays keeping smaller children in seaside resorts busy during days and evenings by playing games, hosting cultural events and providing spiritual and moral instruction and guidance. One Sunday evening the whole group went on a picnic at a favourite spot in the countryside, alongside a dam, and sat together listening to the worship service on the 
radio. During the moments of silence at the end of the broadcast she said, suddenly and seriously, this was a good sermon, a true proclamation of the gospel.

I still remember the moment to this day and how surprised I was - shocked is perhaps a better description. To me it was completely unexpected; in the world from which I came such a remark would have been unthinkable, to say the least. We were still school children, so for her to comment on a service and sermon on the radio in such an authoritative tone, almost self-evidently evaluating the preaching, and using "true proclamation of the gospel" as the measure, completely surprised me. After all, what was "true proclamation of the gospel"? And what did she know about that? How did she recognise the gospel? How could she discern the spirit of the gospel in such a way and with such seeming self-confidence and authority? I was very impressed.

It would only be much later that I would learn that this task of discernment is precisely what Protestant churches are all about. According to the Lutheran confessional document, the Augsburg Confession, Article VII, this is what distinguishes the true church - that the gospel is preached purely and the sacraments celebrated properly, satis est, that is all that is needed for the church to be church. John Calvin and other Reformed believers would whole-heartedly agree, although Calvin added "and heard" (Smit 2008) - the gospel purely preached should also be heard, which is obviously what Elna Mouton was doing that summer evening in the vicinity of Uilenkraalsmond, although still at school, and indeed continuously afterwards on her interesting and rich life's journey.

\section{"The openness to be read and persuaded"?}

Her story has often been told, albeit still only in flashes and fragments, in introductions to her scholarly work, essays, lectures, interviews and, as she has alluded herself, her story is to a large extent the story of her life-long engagement with the Bible, with the stories and story of the gospel (see, for example, Mouton 1997:248; Mouton 2002:1-6; Mouton 2007b:37-39). Sometimes her own story would be reflected in her stories about the experiences of other Afrikaans-speaking and African women with the Bible (Mouton 1997c, 2002c, 2004, 2006b; Mouton \& Bezuidenhout 1998; Mouton \& Mwaniki 2015). Perhaps one could claim that her story is the story of a life-long search for the proper preaching of the gospel, but instead of 'proper' she would later use many other words, like accountable or responsible, and she would on occasion explain that accountable use of the Bible again calls for other words, such as integrity, credibility, relevance and authority.

Over many years we participated together in many activities that all formed part of her life-long search. Together we played leading roles in the formative and influential Bible Studies of the (Afrikaans) Christian Student Movement on the Stellenbosch campus (Smit 2008). Together we participated in the annual consultations of the Stellenbosch 
Centre for Contextual Theology (Smit 1990a, 1990b). Together we attended annual conferences of the New Testament Society of South Africa on hermeneutics (for example, Mouton 1994; Smit 1994). Together we would contribute to conferences on the uses of Scripture in ethics (Mouton 1997a, 1997b; Smit 1997). Together we collaborated with Bernard Lategan and his ongoing work on "hermeneutics and social transformation" (for example, Mouton 2006b; Smit 2006b). Together we prepared papers for the annual meetings organised by the Moluccan Theological Council in the Netherlands (Mouton \& Smit 2008, 2009). Together we were part of a conference on rhetoric and hermeneutics at the University of Pretoria with, amongst others, Elisabeth Schüssler Fiorenza as keynote speaker (Mouton 1996; Smit 1996) as well as a conference on reading the Bible in the Reformed tradition at the Centre for Theological Inquiry in Princeton (Mouton 2007c; Smit 2007). She often engaged themes from my own thinking, for example in contributions to two collections of essays (Mouton 2007a, 2011a). For her, one may claim, all these activities formed part of her life-long search for responsible or ethical reading.

When she decided to do her doctoral work on reading "ethically" (a New Testament document, in her case Ephesians, but only as one case study), she was concerned with precisely these questions (finally published as Mouton 2002). She had by then already made many life-changing discoveries, according to her own account, about the dangers hidden within these historical and human and culturally produced documents themselves, about the dangers of misuse of the Bible, about the importance of readers and their contexts, about the need for reading together with others and learning from and with them, for being formed together in community, about reading which is much more than merely using, closer to being read, being interpreted, being formed and transformed, about reading which is integral to learning and to teaching and to sharing, so that these processes cannot really be separated, about the need for (what she called) a multidimensional approach to our listening to the Bible, but not simply many approaches (or methodologies) alongside one another, in an eclectic fashion, all of them legitimate, but much rather an "integrated" multidimensional approach, "some kind of balanced integration," she wrote, "a coherent account" of how to engage with these Scriptures, since after all, we are concerned with hearing the gospel (Mouton 2002: 1-6, 7-52).

For sure, the literary form, structure and strategy provided relief and thrust, and had to be studied with the greatest of care and all possible skills, as she herself has often demonstrated in her meticulous attention to form and detail (for example, in Mouton 2002:53-122, but over the years repeatedly in many detail studies). Certainly, the historical background was indispensable for orientation and information, reorienting readers to gain some insight in the different reality and the moral world of texts from far away and from vastly different worlds, as she has so often argued in essays and papers. (In a brief summary of the so-called position of women in and with the New Testament, she would underline the deeply challenging consequences of these historical distances, Mouton 2002c.) Above all, however, the persuasive 
power of the rhetorical intentions of the documents should be allowed to touch and move present-day readers, as she has shown in her many scholarly contributions on rhetoric and reorientation and transformation, and on the communicative power of the documents themselves (for example, Mouton 1997a, 1997b, 2003, 2007b, 2007c). For that reason, structure and history and rhetorical strategy should all work together in order for contemporary readers to imagine for themselves the new visions which these texts can make possible - and that is the real challenge, for biblical scholars, the task, should they hope to be useful for church and academy (see her inaugural lecture, Mouton 2005; also Mouton 2008). Anyone familiar with Elna Mouton's life-work will immediately recognise the themes and topics, the questions and key words that occupy and fascinate her.

Perhaps one could pay tribute to this ongoing search throughout her life and work by highlighting four interesting comments that she made, although mostly in passing, so that it might be easy to miss them completely. All four already appear early on in important places in her dissertation, but all four represent guiding motifs and convictions underlying all her work, also in the years following the groundwork of the dissertation.

The first comment is found in the postscript to her dissertation and seems to articulate her final finding, the end result of all the detailed work in the preceding chapters.

Reading a New Testament document ethically has turned out to be much more than a matter of reading ... (R)eading a New Testament document ethically, ironically implies that readers are also being read by both texts and contexts to which they are responsible and accountable. I have been convinced that the openness to be read, and to be persuaded by the strange, alternative world of the New Testament, is the most decisive of all the moral choices readers have to make (Mouton 2002:258, her italics).

How do readers allow this, participate in this experience, share in this healing and liberating and transformative process of being read and transformed? For her, that remained the question of accountable hermeneutics, of reading rightly.

\section{“Exploring transformative potential"?}

In many ways and for many reasons, her life project therefore reminds one of the remarkable contribution to hermeneutics by the $4^{\text {th }}$ century North African scholar and bishop, Augustine of Hippo. After all, of Augustine too it was the case that, "(r)ather than the teacher of rhetoric interpreting the Bible, the Bible interpreted him” (Froehlich 2004:7).

For Augustine too, reading the Scriptures was about being read and being persuaded; for him reading the Scriptures was about being moved to love. His views on reading therefore became popularly known as his "hermeneutics of love," his “agapic reading” (Naugle 1998; see also Naugle 2008), or his interpretive "rule of charity” (Soul 2015). 
Augustine famously developed his views on hermeneutics in his De Doctrina Christiana, often translated as On Christian Doctrine, but probably better translated as On Christian Teaching, even sometimes translated as Teaching Christianity (see the discussion in Green 1995:ix-xiv) and it is interesting how Mouton also sometimes deliberately switches between notions of "reading” and "teaching” (see, for example, different published versions of Mouton 2012).

Augustine was, of course, deeply interested in, formed by, dedicated to and occupied by reading. From his autobiographical Confessions it becomes clear how significant reading was to him, from his own early education and later career, until the life-changing moment in the garden when he responded to the voice of a child singing "take, read" (Smit 2006), to his later career as bishop, preacher and teacher (Froehlich 2004).

It would be difficult to overestimate the influence and lasting impact of Augustine's views on the history of hermeneutics and reading of the Scriptures in the Western Church, including the reading of the Bible in the medieval and Reformation periods. For many centuries his discussion of the theme in On Christian Doctrine remained the unrivalled classic, the standard and norm (see, for example, the essays in Arnold \& Bright 1995; also English 1995 on its fundamental role during the Middle Ages).

It should therefore also not be surprising that there have been regular attempts to arguefor the continuing importance of his views even for contemporary hermeneutics in the church (see, for example, Froehlich 2004 and especially Andrews 2012) as well as in contemporary philosophical hermeneutics (see, for example, the essays of particularly Ramsey 2014 and Arthos 2014 in Troup 2014). Even, therefore, where contemporary readers and interpreters may no longer be conscious of Augustine's views and aware of his lasting impact on their own positions and practices, they may still be deeply influenced by his hermeneutics through his impact on the history of reception and on the tradition in which they also stand.

Augustine's On Christian Doctrine consists of four books. The first three deal with reading and the fourth one with teaching others what is being read.

"There are two things on which all interpretation of scripture depends: the process of discovering what we need to learn, and the process of presenting what we have learnt. I shall discuss the process of discove ry first, and then that of presentation," On Christian Doctrine, I.1.

In Book 1 he argues for the priority of love, in fact, for an ontology of love, and concludes with far-reaching assertions about the priority of love as the final purpose of all reading of Scripture. In Book II and Book III he develops his famous theory of signs - coming to grips with unfamiliar signs in Book II and coming to grips with ambiguous signs in Book III - and on that basis offers practical advice on how to read Scripture with this purpose of love in mind. 
In Book IV he considers how then to teach or proclaim this love found in reading Scripture. Although it is not a treatise in rhetoric, he does argue for the importance for Christian preachers and teachers to benefit from the wisdom and insights of rhetoric. It is in this context that he famously uses Cicero's distinctions between the three tasks of oratory, namely to teach, to delight and to move, or in his own words, to help audiences to listen with understanding, with pleasure and with obedience. For the Christian speaker - theologian, preacher, teacher - this threefold task involves, according to Augustine, the importance of the integrity of the speaker's own life, a concern with truth (rather than mere power and influence), and the need to pray for words that will communicate effectively. Again, the abiding presence of most of these motifs in Mouton's life and work is there for anyone to see - integrity, truth, prayer.

It is, however, in particular Augustine's introductory argument in Book 1 that is directly relevant for appreciating some of the dynamics that seem to be at work in Mouton's own reading of Scripture and in the tradition of interpretation in which she grew up and to which she still belongs.

In Book I he famously distinguishes between things to be enjoyed and things to be used - a distinction which he never really used again in his later writings. Human beings should (learn and therefore be taught how to) enjoy some things (which means cleave to them in love) and use other things (which means not cleaving to them in a similar way, but rather subordinating them to attain what they love).

There are some things which are to be enjoyed, some which are to be used, and some whose function is both to enjoy and to use. Those which are to be enjoyed make us happy; those which are to be used assist us and give us a boost, so to speak, as we press on towards happiness, so that we may reach and hold fast to the things that make us happy. And we, placed as we are among things of both kinds, both enjoy and use them; but if we choose to enjoy things that are to be used, our advance is impeded and sometimes even diverted, and we are held back, or even put off, from attaining the things which are to be enjoyed, because we are hamstrung by our love of lower things (On Christian Doctrine, I.7).

To enjoy something is to hold fast to it in love for its own sake. To use something is to apply whatever it may be to the purpose of obtaining what you love - if indeed it is something that ought to be loved. (The improper use of something should be termed abuse) (On Christian Doctrine, I.8).

For Augustine, God is to be enjoyed, and in order to do that believers should learn how to use those things which God gave us to assist us on this way - including one another, ourselves, but also the Scriptures. He uses the metaphor of a journey to illustrate his argument. Those travelling on their way to their homeland should not begin to enjoy the journey so much that they lose sight of where they are heading, since that would be perverse and a misuse of blessings along the road home.

Suppose we were travellers who could live happily only in our homeland, and because our absence made us unhappy we wished to put an end to our misery and return to our homeland: we would need transport by land or sea which we could use to travel to our 
homeland, the object of our enjoyment. But if we were fascinated by the delights of the journey and the actual travelling, we would be perversely enjoying things that we should be using; and we would be reluctant to finish our journey quickly, being ensnared in the wrong kind of pleasure and estranged from the homeland whose pleasures could make us happy (On Christian Doctrine, I.8).

His point is clear. The Scriptures are not intended to be loved in themselves, but (only) to be used for the purpose for which God gave them, namely to love and enjoy Godself and those in whom we love and enjoy Godself. The far-reaching implications of his point are surprising for many, however, and Augustine does not hesitate to spell them out very clearly and deliberately.

He goes into much detail on practical questions concerning love (how to love the Triune God; how not to love ourselves; how to love others "in the Lord," On Christian Doctrine, I.9-83), but the "chief purpose of all that we have been saying in our discussion of things is to make it understood that the fulfilment and end of the law and all the divine scriptures is to love the thing which must be enjoyed and the thing which together with us can enjoy that thing" (On Christian Doctrine, I.84), which means to love God and one another.

Everything else we should make use of and enjoy not with a permanent love but (only) with a transient love and enjoyment on our journey, as the means of our transport which we love and enjoy (only) for the sake of our destination (On Christian Doctrine, I.85) - and this includes the Holy Scriptures, which leads to his - for some - radical conclusion.

So anyone who thinks that they have understood the divine scriptures or any part of them, but cannot by their understanding build up this double love of God and neighbour, have not yet succeeded in understanding them (On Christian Doctrine, I.86).

The Scriptures are not there to be loved and enjoyed for themselves, but are given to us with their own distinctive purpose, namely to bring us to love God and neighbour. Whoever fails to read Scripture like this has failed in reading Scripture; in fact, Augustine does not hesitate to turn this claim around. Whoever fails to understand some linguistic, literary or historical detail in reading Scripture, but still reads them in such a way that the reading contributes to love of God and neighbour, has not made a fatal error. For sure, such readers must be helped, so that they do not develop bad reading habits, but their (mis)reading has achieved its proper purpose, like someone who has reached the right destination in spite of losing their way somewhat.

Anyone who derives from them an idea which is useful for supporting this love but fails to say what the writer demonstrably meant in the passage has not made a fatal error, and is certainly not a liar ... If (such a person) is misled by an idea of the kind that builds up love, which is the end of the commandment, they are misled in the same way as a walker who leaves the path by mistake but reaches the destination to which the path leads by going through the field (On Christian Doctrine, I.86, 88). 
Still not finished, Augustine argues that "there are three things which all knowledge and prophecy serve: faith, hope, and love" (On Christian Doctrine, I.90), so that people "strengthened by faith, hope, and love, and who steadfastly holds on to them, have no need of the scriptures except to instruct others" (On Christian Doctrine, I.93).

After all, if this is indeed the purpose of reading the Scriptures, the reason why the Scriptures have been given to us, then there should be no need for them whenever the purpose is being achieved, except for instructing those who still need them for the same purpose. This is why many, also in history (and here Augustine may be thinking of early Christian examples) "actually live without any texts of scripture" (On Christian Doctrine, I.93). According to Augustine, we thus have living proof that people may love God and neighbour without any need for the Scriptures.

In short, this is the sum of Augustine's hermeneutics in this brief instruction. It can indeed be called hermeneutics of love, but it could also be called hermeneutics of faith, love and hope.

So when someone has learnt that the aim of the commandment is 'love from a pure heart, and good conscience and genuine faith', they will be ready to relate every interpretation of the holy scriptures to these three things and may approach the task of handling these books with confidence. For when the apostle said 'love' he added 'from a pure heart', so that nothing is loved except what should be loved. He added 'good' to 'conscience' because of hope; for a person with the incubus of a bad conscience despairs of what they love and believe. Thirdly, he said 'with genuine faith': for if our faith is free of untruthfulness then we do not love what should not be loved, whereas by living aright it is impossible for our hope to be in any way misguided (On Christian Doctrine, I.95-96).

With these thoughts, Augustine contributed to an approach that would consciously reflect on what it means to "read rightly." Over the following centuries the details would differ and the answers would diverge, but the basic intuition and the fundamental ethos and pathos would remain, even when readers were no longer aware of Augustine's own contribution, argument and impact.

In recent literature, this fundamental question would again and again be raised by different scholars and in different ways.

One instructive example would be the discussion by the Princeton Old Testament scholar Patrick Miller of "The Rules of Faith and Love" in his essay called "What the Scriptures Principally Teach" (Miller 2004). Here he traces this intuitive question and hermeneutical approach from the Reformation (the essay's title is from the Westminster Confession), through the powerful claims of the 1528 Reformed Confession of Berne ("But where something is brought before us ... which brings us closer to Christ, and in accordance with God's Word is more conducive to mutual friendship and Christian love than the interpretation now presented, we will gladly accept it") and the similar sentiments of the 1560 Scots Confession ("We dare not 
receive or admit any interpretation which is contrary to any principal point of our faith, or to any other plain text of scripture, or to the rule of love," chapter 18) to the 1983 study of the PCUSA on the "Presbyterian Understanding and Use of Holy Scripture" ("No interpretation of Scripture is correct that leads to or supports contempt for any individual or group of persons either within or outside of the church. Such results from the interpretation of Scripture plainly indicate that the rule of love has not been honored").

Another instructive example from a different academic context would be the interesting so-called "Christian postmodernist" work of the Canadian neo-Calvinist philosopher James H Olthuis. James K A Smith and Henry Venema called the edited studies in his honour The Hermeneutics of Charity. Interpretation, Selfhood, and Postmodern Faith (Smith \& Venema 2004), inspired by some of his own essays, such as "Crossing the Threshold: Sojourning Together in the Wild Spaces of Love" (Olthuis 2004) as well as his seminal engagement with John Caputo in "A Cold and Comfortless Hermeneutic or a Warm and Trembling Hermeneutic?” (Olthuis 1990). Standing very consciously in the tradition of Augustine, Calvin, and Kuyper, Olthuis engages constructively with postmodern sensibilities by developing his own hermeneutics of charity. In the first of these essays (originally his Presidential Address to the Canadian Theological Society in 1993), Olthuis proposes to replace an ontology of being with a vision of love (very similar to what Augustine did in Book I of On Christian Doctrine). In the priority of love, he argued, agency returns, as a gift to be heeded. He then suggested that sojourning together (rather than settling or wandering) in the wild spaces of love is an apt metaphor for genuine postmodern theology, for theology crossing the thresholds - another of Mouton's favourite metaphors, for many years, together with "liminal spaces" and "situations of transition" or life in "the margins" (see, for example, Mouton 1997b, 2006b, 2007c, 2008; she even proposes a hermeneutic of liminality, Mouton 2003: 86-87).

The second interesting comment from Mouton's work is directly related to this long history of interpretation; perhaps one could indeed claim that it was her way of making the same point as Augustine and all his followers since the Reformation (for related discussion of the hermeneutic of Calvin see, for example, Opitz 1994; also Smit 2007; for her own understanding of the Reformation heritage, see Mouton 2007c:241). Similar words and expressions making the same point could in fact have been taken from many different sources in her oeuvre, since they all express an idea that is central to her work and that has therefore often been repeated, albeit formulated in slightly different ways. This idea refers to the task of "exploring the transformative potential" of the Scriptural texts, in her words. Already in the dissertation she described this hermeneutical challenge, for example, in the following way, by using words of Paul Ricoeur:

"What is indeed to be understood - and consequently appropriated - in a text? Not the intention of the author ... not the historical situation ... not the expectations or feelings of the original readers; not even their understanding of themselves as historical and cultural 
phenomena. What has to be appropriated is the meaning of the text itself, conceived in a dynamic way as the direction of thought opened up by the text ... (N)othing other than the power of disclosing a world that constitutes the reference of the text ... the disclosure of a possible way of looking at things, which is the genuine referential power of the text" (Mouton 2002:123, quoting Ricoeur, my italics).

These words - that readers should search for the dynamic way of the text, for the world disclosed by the text, for the possible way of looking suggested by the text - all show her closeness to the thought of her co-supervisor Bernard Lategan (see also Mouton 2006b; for Lategan's work, see the essays in Breytenbach, Thom \& Punt 2006; also Lategan 2012, 2015; Smit 2006b, 2012, 2015a and 2015b).

Particularly instructive was the deliberate and conscious way in which she would consistently use this tension (between the literary form, historical context, author's intention and cultural and ideological embeddedness, on the one hand, and the dynamic way, the world disclosed, the possible way of looking, on the other hand) as her way to deal constructively with several of the so-called difficult Scriptural texts from her feminist perspective - very much in the way already suggested by Augustine's cryptic remarks.

"Anyone who thinks that they have understood the divine scriptures or any part of them, but cannot by their understanding build up this double love of God and neighbour, have not yet succeeded in understanding them" - it is with such an imaginative hermeneutics of compassion, transformation and liberation that she reads the household codes (Mouton 2016c) and specifically Ephesians 5 (Mouton 2007c, 2011b, 2014b; Mouton \& Mwaniki 2015), Timothy's infamous text on child-bearing as a way to salvation (Mouton 2012; Mouton \& Van Wolde 2012), Paul's pronouncements that women should be silent (Mouton 2007c, 2011b), Matthew's story about the Canaanite woman (Mouton 2002b), Luke's story about the unnamed woman (Mouton 2007b, 2011a), John's implied household ethos (Mouton 2016b), and the stories in the Gospels about Mary and Martha (Mouton et al. 2008).

She would often find this potential for such a liberating way forward (again similar to Augustine) in what she calls the "theological thrust" or the "theological vision" of the text, which could then be used to critique the historical, cultural and linguistic form of the text, together with the ideological, patriarchal and oppressive function of the text, including the ethos and ethics of these texts, which have become so deeply problematic, terrifying and even oppressive for many contemporary readers. Again and again this would be her reading strategy.

She was continuously looking for the images of God at work in the texts, including the challenging and difficult ones, for the Christological thrust, for the vision of the Triune God (still in the spirit of Augustine), for the perspective of the New Testament, for the invitations and possibilities "to reimagine God" (see, for example, already her master's thesis, Mouton 1987; see also the important Mouton 1996:294-298 on 
Jesus as "the parable par excellence of the New Testament," as "the parable of God" who redefines and reorients our understanding of God; see Mouton 2011a:187-191 on reimaging God; also Mouton 2011b on "the theological framework"; also Mouton 2016a). "(T)he key to the transformative potential of the biblical narrative lies in the ongoing encounter with an awesome God” (Mouton 2007b:48). In her inaugural lecture she would call this the pathos of New Testament studies, "to facilitate and mediate the discernment of such an alternative world, a world characterised by God's radical, surprising yet paradoxical presence in Jesus of Nazareth and the Spirit” (Mouton 2005).

Again and again she would argue that this - searching for these liberating and transformative images of God in Christ through the Spirit - is the real task of interpretation, reading and teaching, otherwise our attempts to read would fall short of the theological thrust and vision of the Scriptures; we would not be reading rightly, one could say, with Augustine and his rule of charity in mind. This was the argument of her dissertation, but also the thrust and conclusion of many of her detailed exegetical essays since then.

\section{“To listen with all my senses"?}

It would, however, be another comment by Mouton, at the time seemingly made almost in passing, that would reveal the lasting impact of this tradition of interpretation even more clearly, if not in the form of any direct and conscious continuity and acknowledgement, then at least in the form of a remarkable similarity between her own intuitive approach and growing academic awareness and insight and this long hermeneutical tradition.

In the introduction to her dissertation she looked back - much like Augustine - on her own life story and reflected on the ways in which her intuitions and awareness were developed and transformed as the result of her rich life experiences. Already early on, she said, it became clear that interpretation would involve all of her senses and abilities and skills of sense-making.

As for my role - as a Reformed, Afrikaans woman in a traditionally African-animistic, patriarchal, Xhosa-speaking society, I soon learned to respect both its limitations and potential. My role, as I gradually understood it, was in the first instance to listen with all $m y$ senses, and to learn as much as humanly possible of the foreign - mainly oral - culture and language, before I could even think of teaching it effectively (Mouton 2002:1, partly my italics).

Over many years she would remain fascinated by this hermeneutical challenge, namely "to listen with all the senses." She would consciously reflect on this in many of her essays, papers, articles, Bible Studies and sermons. She would speak about this in interviews. She would very recently once more reflect at length on this when she responded as panel member to a paper by Piet Naudé during a conference 
commemorating the Reformation after 500 years (Naudé 2017). She clearly remained intrigued by the complex and variegated ways in which the message of Scripture is seen and envisioned, listened to and heard, felt and experienced and danced out (Mouton 2002:2), one could perhaps even add smelled and tasted. Reading Scripture, for her, is a form of celebration, of festivity, of sensory engagement to its fullest, of enjoyment, of healing, of being moved and touched and transformed.

This third comment, on attending to Scriptures with all one's senses - which unobservant readers could perhaps easily have missed at the time, mistaking it as merely a comment made in passing - would not only deliberately be developed in much more reflective detail over many years and in many contexts, but it would also further demonstrate remarkable similarity with the tradition of hermeneutics since Augustine.

Perhaps no one has done more to make the ways in which the tradition has listened to Scripture with all the senses more accessible than Karlfried Froehlich in his fascinating Warfield Lectures, recently published as Sensing the Scriptures. Aminadab's Chariot and the Predicament of Biblical Interpretation (Froehlich 2014; for a completely different, yet also fascinating account of the role of the senses, see McInroy 2014).

The predicament of biblical interpretation, Froehlich argues, is that the Bible needs interpretation. This was exactly the argument of Augustine's preface, in On Christian Doctrine - anyone who thinks that they can read and understand Scripture without rules, without instruction, without being helped and taught, without guidelines and hermeneutics, without perspective and orientation, is deeply misled and mistaken, Augustine said. In order to discern God's Word in all these human words, interpretation is necessary, says Froehlich.

He then provides an intriguing historical account of the history of biblical interpretation by showing how and why the standard fourfold sense of Scripture evolved and functioned. He provides his own translation of the well-known mnemonic verse from the $13^{\text {th }}$ century. "The letter teaches the deeds of the past, // Allegory that which to believe thou hast, / The moral sense what thou must do,// Anagogy the upward path to pursue" (Froehlich 2014:8-9), or in other words letter (and history) - faith (and doctrine) - ethics (and love) - ascent (and hope).

In the Middle Ages the metaphor of Aminadab's chariot (an allusion to the Latin Vulgate's version of the difficult Song of Songs 6:12) was widely used over many centuries to depict this one Scriptural sense (the single chariot) with its fourfold interpretation (the four horses). 
Froehlich then illustrates in a fascinating story how often and how widely (although diversely) these different senses of the meaning of Scripture were seen as hanging together with the five human senses. It is as if human readers of Scripture were engaged in sense-making by using the diversity of their five senses.

For him, "smelling the issues" had to do with a sense of what is at stake and of the need and importance of reading and interpretation (Froehlich 2014:1-21). "Touching the ground" had to do with coming to terms with the literal, which meant language and history, (literary) textuality and (historical) contextuality (Froehlich 2014:22-44). "Seeing the beauty" had to do with delighting in and believing the riches of the promises of what was read (Froehlich 2014:45-63), while "hearing the truth" had to do with listening to and faithfully following the direction of the orientation that was provided (Froehlich 2014:64-84). Finally, "tasting reality" had to do with experiencing the goodness, tasting the honey and the sweetness, delighting in and being nourished by, and with desiring for God amidst a felt absence, with longing for the beyond, forward-reaching, upward moving, with hoping to behold, with contemplation, prayer, worship, liturgy, and with a hermeneutics of affection (Froehlich 2014:85-114).

Although this may all sound strange to modern ears, Froehlich argues, it all developed from the one very basic conviction that there is a distinction between letter and spirit. Even when later figures, including Luther (in his later years) and other Reformers, and indeed Protestantism in general, rejected the elaborate scheme of the fourfold sense, they still affirmed the distinction between letter and spirit, and even when they claimed that the spiritual sense is not something in addition to the letter but in fact belongs to the letter, they still had to find ways to make sense of this spiritual sense of the letter - and in their own ways they thereby again affirmed different ways of discerning God's life-giving Word and Spirit speaking in and through the letter of Scripture (even though they vehemently denied and often ridiculed the fourfold meaning).

In the process, Froehlich offers fascinating discussions of - for example - Luther and Calvin, describing the latter's views on the believers' being mystically united with Christ as a classic example of the practice of biblical anagogy and therefore calling Calvin "an anagogical theologian” (Froehlich 2014:110-114).

Anyone familiar with Mouton's life and work will recognise remarkable parallels between some of her basic intuitions and convictions and many of the themes discussed in Froehlich's fascinating historical account. As an exegete, she is obviously very sensitive to the fundamental importance of "the letter," of respect for the texts themselves, as human writings, as literary and cultural products, as historical artefacts, as conditioned by ideology and power structures, as deeply problematic for us, she often speaks of the letter as "frightening" and "terrifying." 
She is keenly aware of language and signification and communication (Mouton 1987), and increasingly pays attention to rhetoric and the value of rhetorical criticism Mouton 1996). She has delighted, consciously and increasingly over the years, in the difficulties, and using all her senses helps her to deal with the riches, the diversities, the complexities, the difficulties, the multi-perspectives.

Like this tradition, she does not strive for simple solutions and for harmony; she prefers to stay on the thresholds, she looks from all sides, she observes, listens, smells, tastes, feels, enjoys, celebrates, delights. Like so many in the tradition, including Protestantism, she often reflects on the complex and reciprocal relationships between seeing and hearing, hearing and seeing (Froehlich 2014:63-67; Mouton 2007a; and again in still unpublished comments made during a conference commemorating the Reformation, 12 October 2017, in Stellenbosch, in which she said that seeing depends on hearing, in fact, that hearing is a form of seeing; also Mouton 2011a). On occasion she would argue for hermeneutics of seeing; on occasion she would plead for hermeneutics of listening (Mouton 2005, 2008:444-445); on occasion she would acknowledge hermeneutics of feeling and dancing (Mouton 2002:2-6).

She also appreciates the creative and integrative role of imagination in the reading of Scripture. What she described as "hermeneutic appropriation as an integrative act of imagination" has always been the key to her own hermeneutical approach (see, for example, Mouton 2002:165-258, especially 251-258, where she already developed criteria on how to practise this integrative act of imagination; she takes the expression "integrative act of imagination” from Hays 1990:45-46; see also Mouton 1997).

Ultimately, a hermeneutic of seeing gives priority to the imaginative possibilities of God's radical, liberating, healing love over the broken realities of our lives and the world. In this way it allows for moral confidence and hope instead of (absolute) certainty. The early Christians were overwhelmed and surprised by God's presence in the resurrected Jesus and the Spirit, even though they could not understand fully (Mouton 2007a:393-394, her italics).

As a feminist biblical scholar, she deliberately chooses the most difficult and challenging of pericopes to learn from those encounters - and even to teach about them - and she never suggests cheap and easy ways out of the difficulties. Again and again, she would conclude these discussions with an argument in the spirit that "anything less" than such an imaginative act would be a betrayal of the theological vision and thrust of the Scriptures itself. As early as 1994 she would already say:

As Christian believers in South Africa today we are challenged to allow the creative presence of God - the paradoxical in Christ experience - to redefine all relations by transcending every barrier (it is not necessary to repeat anything, but it will by now be clear that just about every single word in this formulation is loaded with significance and intent). 
She continued:

We are encouraged to identify with Christ in the triumph of his resurrection and exaltation, and to grow beyond all limited views of ourselves (in terms of sexism, racism, etc). To respect the transformative potential of Ephesians, would be to dedicate oneself to accomplishing the full potential of the body of Christ. Anything less would confine the God of Ephesians to the boundaries of an ancient canonised text in a way contrary to its own nature (Mouton 1994:375, my italics).

This last sentence would become the key with which she would unlock difficult pericopes again and again. "Anything less would run the risk of being incompatible with the rich world of discipleship that the New Testament projects, and of confining the living, life-giving and life-sustaining God of 1 Timothy to the boundaries of an ancient text in ways contradictory to its own theological thrust" (Mouton 2012:128, in the Scriptura version 2012:597; Mouton 2014b:181, 2014c:189-190; Mouton \& Mwaniki 2015:371). Anything less would betray the transformative potential of the Christological and Trinitarian God images often hidden behind and in these documents. Anything less would not be true proclamation of the gospel. Anything less would not be reading rightly. This is her hermeneutical key.

She is accordingly deeply conscious of the importance of prayer, worship and liturgy for reading the Scriptures (Mouton 2001, 2007a, 2014c, 2017). She appreciates the role of memory and hope in these processes of healing and transformation, and therefore prayer, liturgy and worship are so indispensable (Mouton 1997, 2004; 2007a; Mouton \& Bezuidenhout 1998). She often underlines the crucial role of sense-making (Mouton 2006b). She is convinced of the pastoral and moral, of the formative and indeed transformative role of Scriptural interpretation (Mouton 1997a, 1997b, 2017).

\section{"For a hermeneutic of trust, hope and commitment"?}

Hidden in these descriptions, however, may be an even deeper similarity between Mouton and the most basic intention of this long and influential hermeneutical tradition. After all, according to Froehlich, the deepest motive behind this tradition was the attempt to suggest "a dynamics of ascent" (following Steinmetz 2011). "The great advantage of the fourfold sense was its flexibility in serving the dynamics of ascent" (Froehlich 2014:120).

According to Augustine's account in his Confessionis (5.14.24), his eyes were opened for the first time to the beauty and power of Scripture through the sermons of Ambrose of Milan, who in turned followed Origen's "hermeneutics of ascent." The interpreter had to move upward from the literal sense to the true or spiritual sense, although over the years Augustine became increasingly convinced that the true sense was to be found without leaving the literal sense behind, the hermeneutics of ascent rather found the proper meaning in the literal sense (Froehlich 2014:53-57, 78-80). 
In Froehlich's account of the fourfold nature of interpretation in history, this hermeneutics of ascent plays a crucial role. In fact, in the whole history which he tells, using the metaphor of Aminadab's chariot, the idea of ascent is central. The three spiritual senses (see, hear, taste, or: faith, love, hope) as developed by medieval interpreters simply subdivided what the earlier tradition called the spiritual sense, and together they constituted an attempt to restore the dynamic of ascent in order to overcome the departmentalised situation of academic theology in and since the $13^{\text {th }}$ century, to build a bridge between biblical, systematic and pastoral theology, to shape and form, encourage and transform the Christian life, he argues (Froehlich 2014:123-124, approvingly appealing to Ellen Charry's instructive study of the pastoral function of doctrine in her book on the "renewing of your minds" Charry 1999).

This movement of ascent also explains the lack of clarity and consistency in the use of the so-called fourfold sense, he claims.

The point of all the fuzziness of boundaries and transitions between the senses, of course, is that the scheme was not meant to be tight, but rather serve as a teachable method. At bottom, it simply reflected the underlying assumption of interpretation as a fluid and dynamic movement - and not just forward but upward, from letter to spirit, from milk to solid food, from water into wine (Froehlich 2014:125, my italics).

Although she never uses the metaphor of Aminadab's chariot, the movement of ascent does indeed play a remarkable role in Mouton's work. Ascent, and even the ascension of Jesus, fascinates her and forms a crucial part of her Christological and theological vision (see, for example, Mouton 1993, 1994:375, 2014a).

In her case, however, she is particularly fond of employing the metaphor of a mountain. In fact, in one of the last public interviews with her, she wonders aloud why mountains hold such a strange fascination for her, and even the heading of the interview explicitly mentions the importance of mountains for her (Wiid 2017).

The fourth very interesting, almost remarkable, comment therefore already points to her earliest intuitions about such a hermeneutics of ascent. It was not fully developed at the time, but the metaphor of ascending high mountains clearly captured some of her most central ideas about the reading of Scripture. She closed the postscript of her dissertation with a personal account of a recent visit to the Swiss Alps, for a short retreat.

To me this sublime experience became very close to reading and being read by a text. As with reading, it is a gift and a choice to behold and absorb, to be overwhelmed by the splendour of these mountains; to allow them to penetrate one's senses in their multi-dimensionality: to see the marvellous detail of shape and colour, to feel the chill on one's face, to smell the cows and the wakening spring-field, to hear the wind, the birds, the silence ... To appreciate the thrust of these mountains - their depth, width, length and height - would expect from the 'reader' to rise beyond them, to look from a distance, to gain some perspective, but also to go back often, to walk the mountain paths and to 
spend the night there, to expose oneself to all their moods and challenges. Only then would it probably be possible to be persuaded by their inherent non-verbal strategy (Mouton 2002:259).

All the key elements of the first three comments are present again - the being read; the experience of being overwhelmed and penetrated and persuaded; the involvement of all the senses, seeing, feeling, smelling, hearing; the multidimensional communicative power of the thrust, the perspective, and the strategy, all together - but there is now also something more, namely the sense of height and moving higher, upwards, of rising up and above, of gaining distance and perspective, of ascent.

In the same way that Augustine's metaphor of the road as the way to the destination of enjoyment functioned, Mouton's metaphor of the mountain functions as the way to the destination of enjoyment of all the senses. For her, the movement at work in this metaphor is one of ascent, upwards, in the same way that the metaphor of the chariot functioned in the history of hermeneutics, according to Froehlich. In the very last paragraph and line of her dissertation, the mountain metaphor therefore leads her to a remarkable conclusion.

"For me as a reformist feminist reader, the ethical reading of the New Testament document has become a liberating and frightening experience ... However, the complexities involved in reading should neither paralyse us nor prevent us from taking decisions and acting. Appropriating the perspective of the New Testament ... is a slow, continuous, lifelong, more often than not cumbersome process. There is no instant way toward accomplishing it. Like mountaineering, it is a narrow road which calls for a hermeneutic of trust, hope and commitment" (Mouton 2002:260, partially her, partially my italics; when she uses this argument again, in the instructive Mouton 2003:87, she no longer includes the metaphor of the mountain).

She sounds almost like Augustine - if her trust means his faith, and her commitment means his love, then they are both arguing for a hermeneutics of faith, hope, and love. She also seems to convey something almost like the tradition of the fourfold senses - if her trust refers to "that which to believe thou hast," and her commitment refers to "what thou must do," while her hope refers to "the upward path to pursue," then indeed she is arguing for the same liberating and uplifting movement from the letter to the Spirit which this tradition was searching and longing for.

Of course, she could be part of this living tradition - since Augustine, through the centuries, through the Reformation, through Luther and Calvin, to contemporary Protestant hermeneutics - without being fully aware of their impact on her own life and thought.

After all, in his doctoral dissertation on Hans-Georg Gadamer, another mutual friend from our student days, Leon Fouché, convincingly showed the powerful ways in which the Wirkungsgeschichte, histories of reception, can affect us and help form us, often also and precisely without our knowledge and awareness (Fouché 2001). Sometimes we are influenced in ways which we do not fully understand and we stand in traditions of which we are not fully aware. 
When Elna Mouton therefore says in a recent interview that her own mother played a major role in her life and was in a way the first role model who influenced her own theological life and thought, her comment that Sunday evening many years ago, which I did not understand at the time, suddenly makes good sense.

\section{Bibliography}

Andrews, J A. 2012. Hermeneutics and the Church, in Dialogue with Augustine, Notre Dame: University of Notre Dame.

Arnold, D W H \& Bright, P (eds.). 1995. De doctrina christiana. A Classic of Western Culture, Notre Dame: University of Notre Dame.

Arthos, J. 2014. 'A Limit That Resides in the Word': Hermeneutic Appropriations of Augustine, in Troup, Augustine for the Philosophers, Waco: Baylor, 93-106.

Augustine. 1995. De Doctrina Christiana. Edited and translated by R P H Green.Oxford: Clarendon Press.

Breytenbach, C; Thom, J C \& Punt, J (eds.). 2006. The New Testament Interpreted: Essays in Honour of Bernard Lategan, Leiden: Brill.

Charry, E. 1999. By the Renewing of Your Minds: The Pastoral Function of Christian Doctrine, New York: Oxford University Press. https://doi.org/10.1093/ acprof:oso/9780195134865. 001.0001

English, E D (ed.). 1995. Reading and Wisdom. The De doctrina christiana of Augustine in the Middle Ages, Notre Dame: University of Notre Dame.

Fouché, H L. 2001. Hermeneutiek en Waarheid: 'n Kritiese Ondersoek na die Sin van die Wirkungsgeschichte in die Filosofiese Hermeneutiek van Hans-Georg Gadamer, unpublished doctoral dissertation, Stellenbosch: Stellenbosch University.

Froehlich, K. 2004. 'Take Up and Read'. Basics of Augustine's Biblical Interpretation, Interpretation, 58/1, 5-16.

Froehlich, K. 2014. Sensing the Scriptures. Aminadab's Chariot and the Predicament of Biblical Interpretation, Grand Rapids: Wiliam B. Eerdmans.

Hays, R B. 1990. Scripture-Shaped Community: The Problem of Method in New Testament Ethics, Interpretation XLIV/1, 42-55.

Lategan, B C. 2012. Teologie, Hermeneutica, si Transformare Sociala, Traducător: Cornelia Dumitru, Bucuresti: Curtea Veche Publishing. 
Lategan, B C. 2015. Hermeneutics and Social Transformation. A Selection from the Essays of Bernard Lategan, Stellenbosch: AFRICAN SUN MeDIA.

McInroy, M. 2014. Balthasar on the Spiritual Senses. Perceiving Splendour, Oxford: Oxford University Press. https: / / doi.org/ 10.1093/acprof:oso/ 9780199689002.001.0001

Miller, P D. 2004. What the Scriptures Principally Teach, The Way of the Lord, Tübingen: Mohr Siebeck, 286-296.

Mouton, A E J. 1987.

'n Eksegeties-Hermeneutiese Verkenning van die en Christoo-kernbelydenis by Paulus na aanleiding van Efesiërs 1:3-14. Unpublished MA thesis. Port Elizabeth: University of Port Elizabeth.

Mouton, A E J. 1993. Preaching from the Lectionary: Ascension, Journal of Theology for Southern Africa, 82, 78-97.

Mouton, A E J. 1994. Reading Ephesians Ethically: Criteria Towards a Renewed Identity Awareness? Neotestamentica, 28/2, 359-377.

Mouton, A E J. 1996. The Communicative Power of the Epistle to the Ephesians, in S E Porter \& T H Olbricht (eds.), Rhetoric, Scripture, and Theology, Sheffield: Sheffield Academic Press, 280-307.
Mouton, A E J. 1997a. The (Trans) formative Potential of the Bible as Resource for Christian Ethos and Ethics, Scriptura 62, 245-257. https://doi.org/10.7833 /62-0-620

Mouton, A E J. 1997b. The Transformative Potential of Ephesians in a Situation of Transition, Semeia 78, 121-143.

Mouton, A E J. 1997c. Die Verhaal van Afrikaanse Christenvroue: Uitnodiging tot Morele Vorming, Scriptura 63, 475-490.

Mouton, A E J. 2000. Leef Geloofwaardig!, Wellington: LuxVerbi.BM.

Mouton, A E J. 2001. A Rhetoric of Theological Vision? On Scripture's Reorienting Power in the Liturgy of (Social) Life, Neotestamentica, 35(1-2), 111-128.

Mouton, A E J. 2002a. Reading a New Testament Document Ethically, Atlanta, GA: SBL/ Leiden: Brill.

Mouton, A E J. 2002b. Die Kanaanitiese Vrou van Matteus 15. Hervormer in Eie Reg, Scriptura, 80, 220-225. https://doi. org $/ 10.7833 / 80-0-758$

Mouton, A E J. 2002c. Vroue in/en die Nuwe Testament, in C W Burger \& I Nell (eds.), Draers van die Waarheid: Nuwe-Testamentiese Visies vir die Gemeente, Stellenbosch: BUVTON, 327-328. 
Mouton, A E J. 2003. (Re-)describing Reality? The Transformative Potential of Ephesians in Changing Times, in A J Levine \& M Blickenstaff (eds.), A Feminist Companion to the Deutero-Pauline Epistles, New York: Continuum, 59-87.

Mouton, A E J. 2004. 'Remembering Forward and Hoping Backward'? Some Thoughts on Women and the DRC, in W Weisse \& C Anthonissen (eds.), Maintaining Apartheid or Promoting Change? The Role of the Dutch Reformed Church in a Phase of Increasing Conflict in South Africa, Münster: Waxmann, 283-292.

Mouton, A E J. 2005. The Pathos of New Testament studies. Of what use are we to the Church? Theologia Viatorum 30 (1), 50-86.

Mouton, A E J. 2006a. Van Eden naar Heden via Paulus, in Van E Wolde (ed.), Het paradijs, Zoetermeer: Meinema, 84-86.

Mouton, A E J. 2006b. Interpreting the Bible in Africa: Bernard Lategan on the Threshold of Diverse Theological Discourses, in C Breytenbach, J C Thom \& J Punt (eds.), The New Testament Interpreted: Essays in Honour of Bernard Lategan, Leiden: Brill, 177-198.
Mouton, A E J. 2007a. 'Seeing' With Reverence: Dirk Smit on the Ethos of Interpretation, NGTT, 48 (1 \& 2), 383-396.

Mouton, A E J. 2007b. The Reorienting Potential of Biblical Narrative for Christian Ethos, with Special Reference to Luke 7:36-50, in R L Brawley (ed.), Character Ethics and the New Testament. Moral Dimensions of Scripture, Louisville: Westminster John Knox, 35-55.

Mouton, A E J. 2007c. Surprised by New Contexts? Challenges of Reformed Exegesis from within Liminal Spaces, in W M Alston \& M Welker (eds.), Reformed Theology. Identity and Ecumenicity II, Grand Rapids: William B. Eerdmans, 230-241.

Mouton, A E J. 2008. Christian Theology at the University: On the threshold or in the margin? HTS, 64 (1), 431-445.

Mouton, A E J. 2011a. 'What is a Woman that You are Mindful of Her?' Aspects of Irony and Honour in Luke 7:36-50, in L Hansen, N Koopman \& R Vosloo (eds.), Living Theology, Wellington: Bible Media, 181-193, reprinted in NGTT 54 (3 \& 4).

Mouton, A E J. 2011b. Human Dignity as Expression of God Images? Perspectives from/on 1 Corinthians 14 and Ephesians 5, Neotestamentica,45 (2), 275-295. 
Mouton, A E J. 2012. Reading a

Pastoral 'Text of Terror' in

Africa Today? 1 Timothy

2:8-15 as a Context-Specific

Appropriation of the Creation

Story, in H J Hendriks, E

Mouton, L Hansen \& E le Roux

(eds.), Men in the Pulpit, Women in the Pew? Addressing

Gender Inequality in Africa,

Stellenbosch: AFRICAN SUN

MeDIA, 115-128. (see also

Mouton, A E J 2012. Teaching

a Pastoral 'Text of Terror' in

an African Context? Gender

Perspectives on God and

Humanity in 1 Timothy 2,

Scriptura, 111/3, 583-601).

Mouton, A E J. 2014a. 'Ascended

Far Above All the Heavens':

Rhetorical functioning of Psalm

68:18 in Ephesians 4:8-10?

HTS 70, (1), 1-9, Art. \#2058.

http://dx.doi.org/10.4102/ hts.

v70i1.2058 (originally published

as Memory in Search of Dignity?

Construction of Early Christian

Identity Through Redescribed

Traditional Material in the Letter

to the Ephesians, Annali di

Storia dell'Esegesi, 29 (2), 2012, 133-153.

Mouton A E J. 2014b. Reimagining Ancient Household Ethos? On the Implied Rhetorical Effect of Ephesians 5:21-33, Neotestamentica, 48 (1), 163-185.
Mouton, A E J. 2014c. The Heidelberg Catechism on Prayer: Relevance of a $16^{\text {th }}$ Century Confession for $21^{\text {st }}$ Century Households?, Acta Theologica, 2014; 34 (Suppl. 20), 174-193.

Mouton, A E J. 2016a. Jesus as Healer in the Gospel of Matthew: In Conversation with Alan Culpepper, In die Skriflig, 50 (1), 1-6, a2143.

http://dx.doi.org/10.4102/ids. v50i1.2143

Mouton A E J. 2016b. Torah Reimag(in)

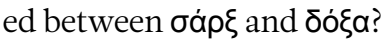
Implied Household Ethos in the Fourth Gospel, Neotestamentica, 50 (3), 93-112.

https://doi.org/10.1353/

neo.2016.0020

Mouton, A E J. 2016c. Mothering Salvation? Gender and Class in Early Christian Household Discourse, Neotestamentica, 50 (1), 1-8. https://doi.org/10.1353/ neo.2016.0032

Mouton, A E J. 2017. Spirituality and Transforming Worship? Individual and collective experiences of Jesus' presence (and absence) in John's Gospel, unpublished paper presented at Stellenbosch Winter School organised by Communitas, Beyers Naude Centre and Ekklesia, 13-15 June 2017, available web https:// communitas.co.za/wp-content/ uploads/2017/07/Handout_ Elna-Mouton.pdf. 
Mouton, A E J \& Bezuidenhout, R. 1998. Met God op Pad Tussen Herinnering en Hoop? Ervarings van NG-vroue met die Bybel, in W A Boesak \& P J A Fourie (eds.), Vraagtekens oor Gereformeerdheid?, Belhar: LUS, 207-216.

Mouton, A E J; Briz, M; Bekker, C; Büchner, E; Ludik, B \& Simpson, N. 2008. Moed om Mens te Wees, Wellington: Bybelkor.

Mouton A E J \& Mwaniki, L. 2015. From Patriarchy to Participatory Freedom? The Transformative Potential of the Ephesians Household Code in View of Changing Gender Roles in Kenyan families, in A E J Mouton, G A Kapuma, L D Hansen, \& T Togom (eds.), Living with Dignity: African Perspectives on Gender Equality, Stellenbosch: AFRICAN SUN MeDIA, 343-375.

Mouton, A E J \& Smit, D J. 2008.

Shared stories for the future? Theological reflections on truth and reconciliation in South Africa, Journal of Reformed Theology, $2(1): 40-62$. https://doi. org/10.1163/156973108X272649

Mouton, A E J \& Smit, D J. 2009. Jesus in South Africa - lost in translation?, Journal of Reformed Theology, 3 (3): 247-273. https://doi.org/10.1163/18725160 9X12559402787155
Mouton, A E J \& Van Wolde, E. 2012. New Life from a Pastoral Text of Terror? Gender Perspectives on God and Humanity in 1 Timothy 2, Scriptura, 111 (3), 583-601. http://dx.doi. org/10.7833/111-0-38

Naude, P J. 2017. Toward justice and social transformation? Appealing to the tradition against the tradition, HTS, 73:3, 8 pages. https://doi.org/10.4102/hts. v73i3.4350

Naugle, D. 1998. Agapic Reading: How to Read the Bible and Other Literature to Enhance Love for God and Neighbor, available on web (in different forms).

Naugle, D K. 2008, Reordered Love, Reordered Lives: Learning the Deep Meaning of Happiness, Grand Rapids: William B. Eerdmans.

Olthuis, J H. 1990. A Cold and Comfortless Hermeneutic or a Warm and Trembling Hermeneutic? A Conversation with John D Caputo, Christian Scholar's Review, 19, 345-363.

Olthuis, J H. 2004. Crossing the Threshold: Sojourning Together in the Wild Spaces of Love, in Smith \& Venema (eds.), 23-40.

Opitz, P. 1994. Calvins theologische Hermeneutik, Neukirchen-Vluyn: Neukirchener Verlag. 
Ramsey, R E. 2014. Love, and Interpret What You Will: A Postsecular Camus-Augustine Encounter, in Troup, Augustine for the Philosophers, Waco: Baylor, 77-92.

Saint Augustine. 1958. On Christian Doctrine. Trans. D W Robertson Jr, New York: Macmillan.

Smit, D J. 1988. Responsible hermeneutics. A systematic theologian's response to the readings and readers of Luke 12:35-48, Neotestamentica, 22 (1988), 441-484.

Smit, D J. 1990a. Ethics and interpretation - new voices from the USA, Scriptura, 33: 1628.

Smit, D J. 1990b. Ethics and interpretation - and South Africa, Scriptura 33: 2943.

Smit, D J. 1994. A story of contextual hermeneutics and the integrity of New Testament scholarship in South Africa, Neotestamentica, 28 (2), 265-289.

Smit, D J. 1996. Theology as rhetoric? Or: guess who's coming to dinner? Rhetoric, Scripture and Theology: Essays from the 1994 Pretoria Conference, S E Porter \& T H Olbricht (eds.), Sheffield: Sheffield Academic Press, 400-429.

Smit, D J. 1997. Liturgy and life?

On the importance of worship for Christian ethics, Scriptura: Christian Ethics in South Africa, 62:259-280.
Smit, D J. 1998a. Biblical Hermeneutics: the first 19 centuries, Initiation into Theology. The rich variety of theology and hermeneutics, S Maimela \& A König (eds.), Pretoria: Van Schaik, 275-296.

Smit, D J. 1998b. Biblical hermeneutics: the $20^{\text {th }}$ century, Initiation into Theology. The rich variety of theology and hermeneutics, S Maimela \& A König (eds.), Pretoria: Van Schaik, 297-317.

Smit, D J. 2006a. Neem, Lees! Hoe Ons die Bybel Hoor en Verstaan, Wellington: LuxVerbi.

Smit, D J. 2006b. Interpreter interpreted. A readers' reception of Lategan's legacy, The New Testament interpreted, in C Breytenbach, J C Thom \& J Punt (eds.), Leiden: Brill Academic Publishers, 3-25.

Smit, D J. 2007. Rhetoric and Ethic? A Reformed Perspective on the Politics of Reading the Bible, Reformed theology: Identity and Ecumenicity II, in W Alston and M Welker (eds.), Grand Rapids: William B Eerdmans, 385-418.

Smit, D J. 2008. On belonging: Doing theology together, Shaping a Global Theological Mind (ed.), D C Marks, Burlington: Ashgate, 153-162.

Smit, D J. 2009. En ook gehoor? Vrae rondom die Gereformeerde siening van die kerk. Maart \& Junie, NGTT, 50: 198-211. 
Smit, D J. 2012. Interpretarea e foarte importantă - o introducere, in B Lategan, Teologie, Hermeneutica, si Transformare Sociala, Traducător: Cornelia Dumitru, Bucuresti: Curtea Veche Publishing, 5-22.

Smit, D J. 2015a. 'Hermeneutics, what is that then?' - An Introduction, in B C Lategan, Hermeneutics and Social Transformation. Stellenbosch:

AFRICAN SUN MeDIA, 3-12.

Smit, D J. 2015b. Reading the Bible through the Ages? Historical and Hermeneutical Perspectives, Stellenbosch Theological Journal, 1(2) 175-194.

htpps://doi.org/10.17570/

stj.2015.v1n2.a08

Smith, J K A \& Venema, H I (eds.). 2004. The Hermeneutics of Charity, Grand Rapids: Brazos Press.
Soul, E. 2015. Augustine: The Text Means Love (Or You're Not Reading It Right, accessed at https://anglocatholicfire. wordpress.com/2015/08/22/ augustine-the-text-means-loveor-youre-not-reading-it-right/

Steinmetz, D. 2011. Taking the Long View: Christian Theology in Historical Perspective, New York: Oxford University Press, 3-14. https://doi.org/10.1093/ acprof:osobl/9780199768936. 003.0001

Troup, C L. 2014. Augustine for the Philosophers: The Rhetor of Hippo, The Confessions and the Continentals, Waco: Baylor.

Wiid, A. 2017. Elna het oor Berge en Drumpels Gereis, 22 August, e-kerkbode, kerkbode.christians. co.za/2017/08/22/elna-het-oorberge-en-drumpels-gereis.

Young, F. 2004, Augustine’s Hermeneutics and Postmodern Criticism, Interpretation 58/1: 42-55.https://doi.org/10.1177/ 002096430405800105 


\title{
Chapter 2 \\ Reading from the Margin
}

\author{
Some thoughts on the \\ De-centred Reader
}

Bernard C Lategan

\section{Introduction}

More than anyone of her generation, Elna Mouton has consistently insisted on the ethical nature of biblical hermeneutics. In this brief tribute to her in gratitude for her important and multifaceted contribution to biblical scholarship, I would like to highlight some of the challenges and opportunities of being - like Elna - a de-centred reader.

Elna has developed a very specific understanding of what an ethical reading entails. In her view, three interrelated levels of responsibility are involved: giving account of the choices made during the interpretation of the text; discerning the pragmatic thrust of its content; and subsequently applying these insights in the community and context in which and for which the interpretation is made (Mouton 2002:7).

This rich, inclusive understanding of the ethical dimensions of interpretation has very existential origins. Her personal experience, her exposure to and confrontation with totally different facets of the South African reality and her intellectual journey to explore these issues within the guild of biblical scholarship on a national and international level and in an interdisciplinary context, all made a distinctive contribution to the process (2002:1-6).

The enduring result is a critical consciousness which is no longer willing to take the text, its interpretation and its application at face value. But it is a critical attitude that leads neither to cynicism nor despair, but one which opens new possibilities through trust, hope and commitment (2002:260). As she eventually discovered, 
reading is actually a way of constituting oneself, of submitting oneself to being read, to be persuaded by a strange, alternative world and then to act in terms of this alternative reality (259-60).

But what was (and is) Elna's secret? Why did she see what others did not? Why did she discover dimensions which otherwise remained dormant in the text? Part of the answer may lie in the advantage of being a de-centred reader. To explain what is meant by this, we are obliged to make a short detour.

\section{The de-centred reader}

In a seminal essay dating back to 1986, Lars Hartman quotes a statement once made by his erstwhile teacher, Krister Stendahl: "My mother taught me that reading others' letters isn't nice”. Stendhal's intention was “to open the eyes of his audience to some of the hermeneutical problems which pertain to the fact that Christians read Paul's letters as if they were addressed to themselves rather than to their original recipients" (Hartman 1986:137). Although Hartman concludes at the end of his essay that present-day readers do have a right to read these letters, he alerts us to a very important reality: ninety-nine percent (if not more) of all readers of biblical literature were not the original, historically intended readers. This fact does not prevent later readers from doing their own reading (and what else do historians do - or can they do?), but it does point to the all-important reality of distanciation. Subsequent readers are removed from the original text in various ways: distance in terms of time, language, culture, experience, perception and many other parameters. Just as important is the fact that different readers from different times and social locations find themselves at different points of distanciation. Some may be closer in time or in culture to the original text and its context, others further away - and that goes for each of the different parameters. No wonder that so many reading strategies are aimed at overcoming this distance, to step into the shoes of the author, to eliminate or lessen the hiatus in time and other forms of strangeness, to merge the horizons of author and reader, or to read as the original, intended reader would. Although many of these strategies have made a considerable contribution to a better understanding of historical documents, in the end there always remains an unbridgeable gap, ranging in extent from a minor to a very serious nature. In this sense, all subsequent readers are de-centred readers, albeit to widely differing degrees.

It was only to be expected that this gap (of whatever nature and seriousness) should be assessed negatively, as a liability which should be remedied at all cost. Such is the power of and desire for "normal", "correct", "adequate" readings (which in fact are often code words for mainstream or dominant readings) that subtle breaks and inconsistencies in the text are missed, not to speak of more significant issues.

But what would happen if we view this apparent deficiency of not being a mainstream reader not as a liability but rather as a strategic asset? 
In this regard, Walter Benjamin offers some helpful insights. In his Theses on the Philosophy of History, ${ }^{1}$ he warns in the seventh thesis against the danger inherent in the strategy of empathy (Einfühlung). This happens when the historian, in the desire to bridge the historical divide, follows Fustel de Coulanges's advice to forget everything that has happened since and to "feel oneself into" (einfühlen) the earlier epoch. This may be a noble objective, but what is not fully realised is that the record of the earlier epoch already reflects the perspective of the dominant role-player(s) of this epoch. The historian thus (unwittingly perhaps) identifies, sympathises with none other than with the victor of the time (1980:696). This is in fact what a mainstream "reading" represents and this is what makes finding a different point of entry to the text, whether "from the bottom upwards", from the "outside" or from "the fringes" so important.

Benjamin's image of history thus is one of a woven piece of fabric displaying a distinct pattern and texture, both reflecting the perspective of the victor and the dominant actor(s). Although traces of the vanquished or marginalised are also evident in the design, these are not as conspicuous as the perspectives of the dominant. The warp and woof of the fabric of history therefore need different strategies of detection. Because the dominant pattern is the most obvious, history has to be "brushed against the grain" ${ }^{2}$ to feel the uneven traces left by the underplayed and hidden aspects of that history, that is, the experiences and perspectives of the vanquished and the marginalised. And for this, a "non-mainstream" consciousness, experience and perspective are needed.

The historical context in which Benjamin wrote his Theses is of course timespecific. Being shaped by Marxist thinking and initially sympathetic towards the ideals of historical materialism, he became increasingly concerned with the way these ideals were being implemented in practice by the politicians of his day. For him, the Soviet-German Pact of 1939 was a turning point in this regard. The fact that Stalin was willing to team up with fascism in this way was highly disturbing and opened Benjamin's eyes to deficiencies in the theory and practice of historical materialism. He learned that the best ideals do not automatically translate into the best practice - hence his suspicion about the dominant discourse and his growing tendency to "brush history against the grain" in order to detect these deficiencies and fault lines in mainstream (Marxist) thinking.

Despite the obvious differences, the metaphor of history as a garment, the product of a dense and complicated weaving process where power and domination determine the most prominent features of its pattern, can in some respects also be applied to a biblical text as the outcome of similar processes of selection, arrangement, highlighting and structuring which are involved in writing history. In this vein, the

Über den Begriff der Geschichte. Gesammelte Schriften 1-2. 1980. Frankfurt: Suhrkamp, 691-704 
corpus of early Christian literature can be likened to a tapestry woven with many threads, displaying certain patterns and exhibiting the characteristics of its time. It also reveals the presuppositions of its main exponents and reflects the power relations prevalent in that specific community. In other words, it represents the mainstream "reading" of the new movement - both as far as the content and the underlying assumptions of these documents are concerned. And the first, original, historical, intended readers naturally followed in the wake of this mainstream view.

There is another (rather uncanny) parallel between the situation of Benjamin and readers like Elna Mouton who read from the margins and who are therefore able to observe inconsistencies which are normally hidden from view. Benjamin himself shared the ideals of historical materialism and was therefore not unsympathetic towards the mainstream reading of history from this particular perspective. But precisely because of these sympathies he was able to detect discrepancies in this kind of reading of the tradition. In a similar way Elna and many readers like her share the fundamental precepts of the biblical tradition and are serious about a reading that will do justice to the intention of these documents. Such readers are sympathetic to much of what is contained in mainstream reading. But exactly because they read from a de-centred position, the unrecognised presuppositions, the embedded power relations and one-sidedness of much of mainstream reading become obvious to them. Because they read against the grain, the otherwise unnoticed aberrations, the loopholes and the absent voices are even more glaring to them.

The unintended or de-centred reader therefore faces a dual challenge. On the one hand, distance and unfamiliarity of varying degrees need to be overcome in order to come to grips with the main thrust of the text. On the other hand, looking from the "outside", from an oblique angle, brushing the text against the grain, have the advantage of feeling the uneven transitions, detecting subtle breaks, and thus discovering aspects which otherwise would have remained hidden. It is this advantage that the de-centred reader should utilise to the full.

It is in this context that Mouton understands herself as a "reformist feminist reader" (2002:260), that is, a distinctly de-centred reader. But this vantage point provides her with the opportunity to engage with the text in unconventional ways, which makes her reading much more than simply providing a translation, but leads to a comprehensive understanding that she calls an "ethical" reading of the New Testament.

\section{The temptation of single-cause reading}

All readers who understand themselves as being not at the centre of the received corpus of texts and who utilise the strategic advantage of being an "outsider" nonetheless face a unique temptation. Having an alternative, often unconventional and disruptive point of entry into the text can become the only lens through which 
the corpus as a whole is viewed, resulting in a very effective but severely limited approach. The temptation is to use one key to unlock all components of the corpus and to use one angle of attack to solve all "problems". The irony is that such a strategy not only fails to do justice to the complex matrix to which the corpus bears witness, but also weakens the effectiveness of the critique which is essential to unmask the biases which the corpus does reflect.

Mouton escapes this temptation by giving her project a much wider basis and a much broader scope. She uses the umbrella of ethics to cover a spectrum of readings - which enables her to question the assumptions of the dominant perspective without excluding her own perspective from criticism. She broadens the exegetical enterprise by providing space for historical, structural and ethical concerns. She furthermore avoids stagnation by recognising the dynamic, changeable nature of tradition and keeping the process open-ended. An alternative, newly imagined world remains a constant possibility, making the task of interpretation a way of life and an ongoing obligation.

One remedy for one-sided reading is therefore to read with others, to read in community, to develop a dialogical mode of reading (West 1999), to consider all possible angles and perspectives. Reading can be and often is an individual act, born in solitude - but it cannot remain there. It has to be shared to be effective and persuasive.

But is this enough in itself? In his extensive work on cultural studies and biblical criticism, Fernando Segovia traces the root cause of multiple readings back to the different social locations of real readers and the fact that each reading of necessity

constitutes a construction or re-presentation on the part of real readers: a re-creation of its meaning and a re-construction of its context on the part of readers who read and interpret from within specific social locations and with specific interests in mind. For cultural studies, therefore, this character of the text as 'text' ultimately makes a joint analysis of texts and readings of texts indispensable and imperative. There is never a text out there but many 'texts' (1995:9).

His reference to the need of "a joint analysis" seems to presuppose some kind of "reading with" and he indeed insists that the practice of cultural studies "calls for and demands dialogue, critical dialogue" (1995:17). But then he undercuts his own argument by stating that the question of validity in interpretation is problematic because the very criteria used in the evaluation of a reading in themselves are "constructions on the part of real readers" (1995:11). The basis on which the desired critical dialogue should proceed is therefore already undermined before the discussion has started. He merely states that the critical situation he envisages "is not necessarily one where 'everything goes' “(1995:11), but gives no indication how this result can be avoided. 
Accepting the reality of multiple readings caused by various forms of "distance" (historical, cultural, social location and the like) is just one step and needs to be augmented by forms of reading with, in dialogue, in interaction. The reader cannot be the only factor - there is also the counterfoil of the text and of history, and although Segovia is right that our understanding of both is always filtered through the lens of our own perspective, real dialogue proceeds on the assumption of a real possibility of persuasion and change - if it is to rise above the level of an "is/is not" debate.

As we have seen, Mouton offers a more substantive approach. But still the question remains - how can we get beyond mere associative reading ("this reminds me of ..., this makes me think of ... ”)? This question becomes more acute as the distance from the text - again in terms of history, culture, social location, hierarchy and the like - increases. How can we still claim that we are reading "in line with", following the extension of the text?

In this regard, it is worth revisiting a concept introduced by Helmut Köster and James Robinson already in 1971 when they choose the term "trajectories" for the title of their book Entwicklungslinien durch die Welt des frühen Christentums. ${ }^{3}$ The idea of a trajectory is eminently suitable for describing the dynamic, changing and ever-evolving nature of tradition in its course not only through early Christianity, but during the much older and longer preceding phases of biblical tradition. It also leaves room for the vicissitudes inherent in the process without losing the idea of continuity. As Hamerton-Kelly (1972:522) pointed out, categories like heresy and orthodoxy, history and kerygma, Palestinian and Hellenistic Judaism are so fluid that they are not very helpful for structuring the discussion on tradition and its historical development.

The metaphor of a trajectory is therefore an attractive alternative. Its usual meaning (besides technical and geometric usage) is the "path described by a projectile moving under given forces" (Fowler \& Fowler 1964:1377) and conveys a line of continuation through different time zones and changing landscapes - an apt description of the course of tradition in its various manifestations and historical changes over time. But the term also raises questions of its own. As Hamerton-Kelly (1972:522) rightly remarks, while Köster and Robinson emphasise the "trajectory", the "projectile" is never described. There is much talk about "ongoing linguistic translation in which the kerygmatic point is successively scored in ever changing historical circumstances" (Köster and Robinson 1971:28), without making clear what this "point” really entails.

The distinct contribution by Mouton is her refusal to separate "projectile" from "trajectory" by integrating content and form. She quotes Ricoeur with approval that "what is to be appropriated is the meaning of the text itself, conceived in a dynamic way as the direction of thought opened up by the text" (Mouton 2002:123). The 
"thrust" (her term for "trajectory") of the structural dimension of the text has content, a content which leads to "moral action" (243). This enables her to combine the thrust of the structural dimension (30) with the persuading strategy of the rhetorical dimension (48) and the orienting perspective of the historical dimension (32) to arrive at pragmatic conclusions and ethical implications $(113,119)$.

\section{Not only a wandering viewpoint, but a wandering reader}

Mouton therefore illustrates that the reader (as Segovia (1995:14-15) has reminded us) is a dynamic and flexible participant who can change positions and inhabit different perspectives and different reading strategies. The unintended reader can become an informed reader, a historical reading can be complemented by a structural or text-immanent reading and so forth. Within certain limits (the contemporary reader can never become a first reader, for example), readers can (and do) don different hats, assume different positions and use a variety of readings.

In doing so, she avoids being pinned down to a single position or having to fulfil a pre-ordained, prescribed role as reader. In fact, her strategy allows her to navigate the full scope of the text and to explore all its aspects. Being a de-centred reader does not imply being boxed in or condemned to a fossilised position. The "wandering viewpoint" of Iser (Iser 1980; Botha 1988) enables the "wandering reader" to take the stage. The apparent relegation to the margins of the text is in fact the eye of the needle through which the decentred reader must pass to gain her freedom and access to the full reach of the text.

It is thus in no small measure ironic that the uninvited guests (read: uninvited readers) gathered from "outside" and from unlikely places (Luke 14:21-24) end up by being the guests of honour at the feast. There is nothing that prevents the decentred reader from exploring the perspective from the centre or to participate in "mainstream" reading - not only as a theoretical possibility, but as a pragmatic outcome. In Elna's case (and hopefully she has opened the door for many others to follow) this meant not remaining at the margins, but reaching right into the heart of the enterprise, occupying spaces previously forbidden (women in office) and assuming roles that for a long time remained gender-restricted (dean).

Could this be a possible trajectory for the injunction not to despise the day of small things (Zech 4:10) - ages after it was first pronounced? 


\section{Bibliography}

Benjamin, W. 1980. Über den Begriff der Geschichte, Gesammelte Schriften, I-2. Frankfurt: Suhrkamp, 691-704.

Botha, J. 1988. Iser's wandering viewpoint: a reception-analytical reading of Luke 12:35-48, Neotestamentica, 22(2): 253-68.

Fowler, H W \& Fowler F G (eds.). 1964. The Concise Oxford Dictionary of Current English, Oxford: Oxford University Press.

Hamerton-Kelly, R G. 1972. Review of Trajectories through Early Christianity, Theology Today, 28(4):521-523.

Hartman, L 1986. On reading others' letters, Harvard Theological Review, 79 (1-3):137-146. https://doi.org/10.1017/ S001781600002040X

Iser, W. 1980: Interaction between text and reader, in S Suleiman and I Crossman (eds.), The Reader in the Text, 106-119.

Köster, H and Robinson, J M. 1971. Entwicklungslinien durch die Welt des frühen Christentums. Tübingen: Mohr. (Trajectories through Early Christianity Philadelphia: Fortress)
Mouton, E. 2002. Reading a New Testament Document Ethically, Atlanta: SBL.

Segovia, F F. 1995. Cultural studies and contemporary biblical criticism: Ideological criticism as a mode of discourse, in Segovia and Tolbert, Reading from this Place, 1-17.

Segovia, F F and Tolbert, M A (eds.). 1995. Reading from this Place. Social Location and Biblical Interpretation in Global Perspective, Volume 2, Minneapolis: Fortress Press.

Suleiman, S and Crossman, I (eds.). 1980. The Reader in the Text: Essays on Audience and Interpretation, Princeton: Princeton University Press.

West, G O. 1999. The Academy of the Poor. Towards a Dialogical Reading of the Bible, Sheffield: Sheffield Academic Press. 


\title{
Chapter 3
}

\section{From "One-way" Authoritative Discourse to Critical, Open Dialogue(s)}

\author{
Possibilities from feminist \\ biblical scholarship
}

\section{Maretha Jacobs}

\section{Introduction}

Elna Mouton's ethical reading of biblical texts comprises a multidimensional approach to biblical interpretation. Though critical of patriarchy in biblical texts and their history of interpretation, her work is mostly also a meticulous endeavour at extracting/producing transformative meanings even from explicitly patriarchal biblical passages such as the household codes in the deutero-Pauline writings. She thus attempts to guide these into the present in a transforming, life-giving way (Mouton 2003, 2011, 2014). This applies, inter alia, to her work on the letter to the Ephesians, on which much of her work from early on focused.

In order to avoid absolutism, and relativism, she implements a number of strategies from different fields of research. These figure almost as constants in much of her work: Van Gennep's and Victor Turner's concept of liminality, which includes the elements of risk and creativity, the metaphoric nature of language and some insights from feminist biblical scholarship, or gender studies, to name a few prominent ones. As is still mostly the case with biblical scholars, the focus in her work is exclusively on canonical writings. Apart from, or related to, her kind of biblical interpretation, she is known for her involvement in the broader African context, including the Circle of Concerned African Women Theologians, which led to the publication of the book Living with dignity: African perspectives on gender equality, which was awarded the Andrew Murray-Desmond Tutu prize in 2016 (Brümmer 2016; see also Mouton 2006:177-198). 
Linking up with the issue of "ethical interpretation", and feminist biblical scholarship or gender criticism as one of the components present in her work, in this chapter I mainly, though not exclusively, link up with a number of insights from feminist biblical scholarship. ${ }^{1}$ Some of these are related to the views of scholars from other strands of biblical scholarship, for example, contemporary reflection on the origin and nature of the biblical canon from the perspective of media studies (Kelber 2010:71-99) and an emphasis on the active role of the interpreter in biblical interpretation (Martin 2006:1-5). The aim, as Elna Mouton exemplifies in her own way, is to contribute to a less rigid, more just and humane kind of talk on the Bible and religion, including that which takes place outside of the academy. This may hopefully contribute to a more just and humane dispensation not only for "traditional" insiders of the Christian churches/tradition, but also for different kinds of "others" (e.g. gay persons), who were in the past often excluded by biblical discourses and their interpretations.

Feminist biblical scholarship has during the past few decades become an extensive scholarly field, which implies that only aspects of it can be touched on briefly here. ${ }^{2}$ In the process numerous and diverse feminist voices appeared on the scene who, by focusing on a variety of issues not previously in the centre of scholarly attention, "has forever changed the character of the academic and theological debate" (Castelli 1994:78). Only since the 1990s has substantial work in this field been done in South Africa (Nortjé-Meyer 2015).

With its roots in the women's movement of the late $19^{\text {th }}$ century in the USA, thus outside of the academy, and in response to the realisation of the use/abuse of the Bible and its authority against women struggling for emancipation (Schüssler Fiorenza 1994:1), feminist biblical scholarship from its inception was intended to make a difference to the lives of real persons. Initially the focus was especially on women and slaves, who experienced different kinds of exclusion. Questions of race, sexual orientation, etc. would later become part of the agenda. Like feminism in general, feminist biblical scholarship was and is still concerned with change of different kinds, be it political and social change, or changes in the cultural imagination and the definition of humanity (Schneiders 2000:8, 9; see Reinhartz 1997:32 specifically with regard to biblical scholarship). This would later be extended to include a theological agenda directed towards saving the earth (McFague 1993). The aim here is to link up with

\footnotetext{
The issue of feminist biblical scholarship and its relation to - or for some, mutation into - gender criticism is not taken up here. Moving away from essentialism, the term "gender criticism" is nowadays more commonly used and implemented. There is no clear-cut distinction made between the two here. In practice they overlap, with some gender critics using the work of feminist scholars, and gender functioning as an analytical category in feminist biblical scholarship. In my own work I still used the term "feminist scholarship" (Jacobs 2002b, 2005b; see also Nortjé-Meyer 2015).

2 For a recent collection of essays on feminist biblical studies in the $20^{\text {th }}$ century see Schüssler Fiorenza (2014). See also Castelli (1994) for an earlier comprehensive survey, and the essays in Vander Stichele and Penner (2005) for crucial questions posed by feminist biblical scholarship to historical-critical scholarship.
} 
some existing insights, many of which have not yet been commonly implemented, or not in the same combinations, and which have the potential of contributing to dealing with biblical texts in an ethical way. Although every utterance is already theory-laden, and some reading strategies will briefly come into play, the intention here is especially to focus on the concrete aspects that should flow from specific theoretical insights (see also Schüssler Fiorenza 2013b:92; Davaney 1997, 2000a).

Related to basic insights from feminist biblical scholarship, and from some other strands of biblical scholarship which also briefly operate here, a number of sentiments characteristic of my own work form part of this chapter. These include the importance, in my view, of "opening up" rather than "closing down", at our moment(s) in history, in this case specifically the Bible and the Christian tradition. This implies embracing plurality, with its accompanying complexity (see Jacobs 2010:107, 108; Meeks 2006:121; Davaney 1997, 2000a, 2006: 89-90, 148150; Kelber 1999:112, 113; ${ }^{3}$ Tarnas 1991:395-410, who relates plurality specifically to the postmodern mind). Related to this is the taking seriously of historicity, which calls for taking into account the nature of both the past and the present and the relation between the two. The long, earthly road of history is thus taken into account, although in practice only glimpses of this will come into the picture here. This includes the road of human involvement that lies behind the canon and its interpretations. And, since the Bible is for many still associated with "meaning", some kind of problem-informed and explicit creativity is opted for in dealing with parts of the Bible in order to attain this goal (see e.g. Byatt 1998). This takes into account that the Bible also lives on in non-authoritative genres such as poetry, literature and music, which may bring reception history into the picture (see Jacobs 2013). ${ }^{4}$ Although reception history does not receive explicit attention in this chapter, it is mentioned here as one way of "opening up", of keeping alive the Bible and the Christian tradition in a conscious, creative, informed and potentially nondomesticating way.

Important for the aim of this chapter is that in practice these sentiments entail the transgressing of different kinds of boundaries: that of the biblical canon to extra-canonical writingsby means of theorising on/historicising it, out of "traditional", non-engaged biblical scholarship into contemporary life, and of "traditional" biblical interpretation by opting for a dialogical approach (see Buell 2014:298-301). Together with prominent insights from feminist biblical scholarship, which will be identified and implemented in the sections below, these sentiments to some extent inform

3 In this regard Kelber (1999:75) quoted Martha Nussbaum's significant utterance: "The best ethical criticism, ancient and modern, has insisted on the complexity and variety revealed to us in literature, appealing to that complexity to cast doubt on reductive theories".

4 Focusing specifically on what he calls the poets' portrayals of Jesus of Nazareth, William Hamilton (1993:1) suggests the adding of "the non-traditional half-truths of the poets to the traditional half-truths we already think we know". The poets should be set "alongside, and not instead of, the historians and theologians" (1993:21). 
what follows. In methodological terms, the approach opted for here is not so much a neatly delineated methodology as a procedure consisting of a combination of (what I regard as) a number of crucial matters relevant to enhancing a dialogue with the Bible and our Christian past.

The basic structure of the chapter includes starting where "we" are with regard to how the Bible still commonly functions, especially outside of the academy, which is where in the South African context it still impacts on the lives of many people. This functioning is, of course, not uniform. It also entails looking backwards to detect which factors or developments have brought us where we are. Some of the insights to be discussed are then used to proceed more meaningfully and humanely than has often happened in the past, that is, with real human beings in sight and mind. Such a procedure will obviously have a critical slant to it ...

\section{Starting in the present: the often still authoritative functioning of the Bible as answer book}

Since the interest here is in concrete matters around the Bible and its interpretation, the obvious place to start is with how the Bible is still commonly used in church and society. In popular Christian religion the Bible functions in a variety of ways, often in combination with each other: selectively, ahistorically, amorphously, politically, anti-intellectually and with a dogmatic framework mostly still intact. ${ }^{5}$ Especially to the point is that the Bible often still functions as an authoritative, timeless answer book to contentious contemporary questions in both church and public discourses (Tolbert 1998; Jacobs 2005a:66-69). This authority, embedded as it was and often still is in power structures, partly explains how not only the good news in the Bible, but the bad news, for women and other "others", such as gay people, was able to travel - assisted as it was by restrictive and exclusionary interpretations - through time and space for almost two millennia. And why the Bible is even in our time still commonly used against women of different classes and races and other "others" (see e.g. Schüssler Fiorenza 2013b:92, 93).

In such authoritative kinds of reading, Tolbert (1998:176) reminds us, biblical texts are mostly read ahistorically, often "raised to the level of transcendence of its Divine Author". In the process culture-bound utterances are turned into timeless statements, prescriptions and prohibitions, as still commonly occurs in confessional contexts. In this way the worldview of an ancient era, in the case of the Bible, a patriarchal and hierarchical one, is idealised and imported into our time. This implies that the present situation has at best a secondary status $(1998: 177,178)$. By

5 In fairness it has to be said that, with abundant relevant information nowadays widely available, religion and spirituality are to some extent nowadays democratised (see Louw 2014:14), with dogma playing a less important role for some religious people. 
appealing to the divine origin of biblical texts, inspired in one way or another ${ }^{6}$ and to God for the justification of a specific view, the role of the reader or community of readers in reaching the interpreter's viewpoint is disguised $(1998: 169,180,182)$. In debating social, ethical and religious issues regarded as contentious, the bifurcation of those strands of biblical scholarship informed by historical consciousness and the way the Bible functions outside of the academy continues. ${ }^{7}$ For example, despite the abundance of information nowadays available on the different views on the status of women in biblical times and in our time, on the South African scene the synods of the Reformed Churches of South Africa are still debating the matter of women's admission to the ministry. In the process the struggle to unravel the meaning of a number of biblical passages regarded as providing answers to this question continues (Network24.com, 2015-01-10). Recently the Dutch Reformed Church back-pedalled on a previous (2015) more informed and humane decision on the position of gay people in the churches (Wagner and Hosken 2018). ${ }^{8}$

It has, of course, to be taken seriously that the Bible is a foundational religious text (Brenner 2016:17). That, in their fixed format into one volume, the biblical writings became so influential. And that this kind of functioning continued many positive things as well. This happened both by promoting the Bible's positive aspects and by means of various kinds of reinterpretation. Even some scholars who espouse a substantial historical orientation and who are fully aware of how complex it has become to bring the contexts/needs/questions of contemporary people and the Bible/Biblical Studies together, endorse the authority of the biblical canon. An informative example of this is provided by Loveday Alexander in her article "God's Frozen Word: Canonicity and the dilemmas of biblical studies today". ${ }^{9}$ While accepting the authoritative status of the canonical text -"if it wasn't authoritative, it wouldn't be worth preserving" (Alexander 2006:239) - for her this does not imply a one-way functioning into the present, and therefore not a rigid approach. She calls for a both/and approach, both "learning from the tradition" and "exercising a critical judgement on it" (2006:239). This implies a "complex interactive dialogue with the text", in which new discoveries should be incorporated into the text by the skilful interpreter (2006:239). As Buell (2014:300, footnote 23) rightly remarks, this proposed procedure has resemblances with the work of feminist biblical scholars.

6 In this regard Tolbert points out that, though "inspiration" is usually regarded as being unique to the Bible, many ancient authors believed that the texts they produced were inspired by divine guidance (Tolbert 1998:185, note 2).

7 For an illuminating brief discussion of the problems related to biblical interpretation in both popular Christianity and the academy, and meaningful suggestions in this regard, see Meeks (2006:101-121). Speaking from the context of the USA he points to pervasive anti-intellectualism in the churches along with a growing pervasive intellectual anti-religionism in the universities. This shows some resemblances with the contemporary situation in South Africa.

8 For an informative discussion of the "gay matter" with its different facets see Craffert (2007:191-193).

$9 \quad$ I am indebted to Buell (2014:300, footnote 23) for reference to and a brief discussion of Loveday Alexander's article, which shows clear echoes of the problems encountered by feminist biblical scholars with regard to the Bible, and with the interpretative options some of them take. 
As a result of its long and complex history of often authoritative interpretation, at least where it was most influential, and its diverse impact, the biblical canon will perhaps always be accompanied by ambiguity, even paradox, in reflections on it. And while some will continue to interpret within boxes of different kinds, sizes and shapes, others will at least attempt to interpret in a complex "open" arena. This is, of course, not a claim a disinterested position.

\section{Stepping back behind the canon and its origin}

For most New Testament scholars, as for Loveday Alexander, the biblical canon is still the obvious focus of their attention. Since there is an indissoluble relation between this final form and its authoritative functioning (see Vander Stichele 1986:253), a brief reflection on a number of views on canonicity and the history of the origin of the canon is provided here. In the process attention is also paid to the "what" of interpretation, not only the "how" (Buell 2014:303). Some of the relevant questions here are: How did the canon come to include some early Christian writings at the cost of others? How did it become such a fixed set of documents? These are not merely academic questions, since the way the canon is viewed and the resulting interpretations of it impact on the lives of human beings. Precisely the taking seriously of the human hand in this process makes a conversation with it possible, for those who are willing to do so.

\section{A contribution from media studies}

From the perspective of media studies (memory, orality, early scribal practices and print culture) - thus taking the long view of history - Kelber (2010) brought some significant insights to the matter of the biblical canon's origin, its ascribed authority and what would end up as its authoritative form and functioning. Using the work of well-known scholars on these matters, he pointed out that both the early Masoretic and Jesus traditions can appropriately be described as "mouvance". This implies that they should be viewed as "living tradition subject to reactivation and revisions" (2010:75). According to Kelber (2010:77), textual pluriformity also applied to the early scribal traditions, with scribes not merely interested in copying texts literally, but fulfilling the role of "creative traditionists" as well. "In the beginning" there was therefore plurality, not a fixed foundational text. While the codex, incorporating multiple writings into the same volume, to some extent paved the way for what would later become the biblical canon, it was print technology that made the crucial difference. In combination with some theological developments, the mode of print finalised the canonical authority of the Bible (2010:82): ${ }^{10}$ "Viewed against the

10 In this regard Kelber points out that the Jewish canon came into existence roughly between 200 B C E and 200 C.E. The Christian canon can be dated to the $4^{\text {th }}$ century C.E., but a "dogmatic articulation of canon and canonical authority did not occur until the Council of Trent (1546 C. E.)". See also Tolbert (1998:170) for dating the dogmas around the authority of the Bible mostly to the seventeenth and eighteenth centuries, after it became sola scriptura. 
mouvance of the Jewish and Christian textual tradition, the creation of the canon marks a principally authoritative and unmistakably reductive move" (2010:84). Furthermore, according to Kelber, "the elevation of the Bible to sola scriptura, a concept unthinkable prior to the invention of the printing press, conjured up the notion of the Bible as a free-standing monolithic artefact detached from tradition" (2010:93). It was thus deprived of "the oxygen of tradition" (2010:94). This development, clearly not positively evaluated by him, would have decisive implications for how the Bible would be dealt with during centuries to come. ${ }^{11}$

\section{The canon, feminist biblical scholarship and scholars of early Christianity}

The rise of feminist biblical scholarship marked a crucial moment in renewed reflection on the biblical canon. Since the end of the $19^{\text {th }}$ century there has been a growing awareness of the way the Bible had for centuries been used against women striving for emancipation. Together with increased information on gender construction in the ancient world, this not only required feminist biblical scholars to read differently; it also caused them to have another look at the composition of the canon. With early forerunners, and more extensively so since the 1960s, the Bible was consciously brought (down) to (patriarchal) earth - as did not happen in traditional historical-critical scholarship. In the process the eyes of those who were willing to see were acutely opened to one of the dark sides of the Bible and its impact. It was realised that canonisation not only entailed the exclusion of other early Christian writings on the basis of the dichotomy: orthodoxy versus heresy (see Schüssler Fiorenza 1994:5; Vorster 2003:122). From a gender perspective it was pointed out by some that biblical writings "infested with patriarchy and even with an outright hostile attitude towards women have been included and have been given supernatural status” (e.g. Vorster 2003:122). This “decisively contributed to the gender stereotypes which have structured our cultures” (2003:125). For nearly two millennia explicitly patriarchal passages such as 1 Corinthians 14:34-35 and 1 Timothy 2:9-15 were used against women, and are in some quarters still used in this way (Jacobs 2008b:148). This procedure not only kept women from leadership positions in the Christian churches - thus completely determining the face of these churches - but also impacted negatively on their position in society. ${ }^{12}$ This matter

11 It is not possible to do full justice to Werner Kelber's extremely thorough, detailed and nuanced chapter here, including his reflection on the printed biblical canon's complex aftermath. For some additional consequences of the printing revolution for the reading of the Bible see Craffert (2007:170-171). In a 1999 contribution Kelber "opened up" early Christianity, in this way demonstrating the sobering effect of taking the long road with its many twists and turns See also Castelli and Taussig (1996) and Davaney (2000b:39) for an emphasis on plurality in early Christianity.

12 Regarding the South African context, a recent article (2017) in the Afrikaans newspaper Beeld by Prof Christi Van der Westhuizen, which partly draws on the work of Prof Christina Landman, pointed out that, in a context in which Afrikaner nationalism prevailed, the well-known Afrikaner poet Totius expressed himself against suffrage for women. He was, in fact, the leader of a commission of the Reformed Churches of South Africa, which made a recommendation against this step in 1920. His sister, Marie, in her book Vrou en Feminist (1921), became a passionate advocate for the independence of women in all spheres of life, in the process also emphasising their own moral accountability. She, 
thus had to be urgently addressed, in a critical way. In the words of Bal, to discuss and problematise the canon "as a politically conservative force" has the function "to change its status - from self-evident power to a phenomenon to analyse, and thereby, by definition, to transform" (quoted in Buell 2014:293).

As time passed, the canon would be historicised, in various ways and from various perspectives, not only by feminist biblical scholars, but also by scholars of early Christianity (see Castelli \& Taussig 1996). The process-like character of its origin was pointed out by emphasising that the Bible was "the result of a process of centuries of use, interpretation, negotiation and debate" (Buell 2014:302). With what is now known about the patriarchal nature of the then world, the human, specifically the patriarchal male, hand in what happened first in and later to the biblical and other early Christian writings could be seen ever more clearly. With the greater variety of writings nowadays available, it is realised that writings in which women played a more substantial role (The Acts of Paul and Thecla ${ }^{13}$ and The Gospel of Mary ${ }^{14}$ ) were excluded, while writings which emphasised the subordination of women to men and excluded them from church offices were included and became extremely influential, as pointed out above. This does not imply that the excluded writings were completely free of ancient patriarchal cultural values, although one may assume "degrees of patriarchal intensity" (Vorster 2003:127). The hostile discourses against women, in some cases particularly Eve, would be continued, even radicalised, by the early revered Church Fathers (see Jacobs 2005b: 771-772).

In the light of the above it would not be too far-fetched to say that some biblical notions of women, which would for centuries form part of patriarchal cultures and power structures, contributed to the fact that "the history of the Western mind" with all its achievements, has been "an overwhelmingly masculine phenomenon" (Tarnas 1991:441). To recall these is not to rake up old grievances, but to participate in the much needed "ethics of remembering", a notion used by Kelber (1999:114) in a different context. It is about not continuing the harm done to women of the past into the present in often carefully veiled guises.

Countering the procedure of exclusion and its impact, the boundaries of the canon have been transgressed by some and its absolute authority relativised by introducing other early Christian writings in which women play a more substantial role. This transgressing happened, for example, in the two-volume commentary Searching

moreover, problematised the way the Bible was used against women. Unfortunately her story was more or less buried for a long time, while her brother's view was the one which counted.

13 With regard to the Acts of Paul and Thecla, and other apocryphal Acts, Castelli $(1994: 96,97)$ refers to important work done by Virginia Burrus. Typifying these Acts as folk stories which originated with female story-tellers, Burrus argues that they may possess "a historical kernel" and that they provide us with early documentation of the attraction which a life of chastity had for many early Christian women, over against the social conventions of the time. See also McGinn (1994) and Jacobs (2008b:149-151). 
the Scriptures (Schüssler Fiorenza 1993:10). The aim of this undertaking was not to include more writings into the existing canon, but to effect "an increase in historical-religious knowledge and imagination" (1994:9). The canon of the Bible was problematised by pointing to the interests at stake in its origination (1994:6). In Schüssler Fiorenza's commentary "scriptures" is preferred to Bible as the former emphasises the relations between people and their sacred texts and "the porousness and unsettledness of scriptural boundaries" (1993:10). This choice leads, for her, to the realisation that "new scriptural forms are created over and over again" and that scriptures are "contingent historical manifestations which must be reinterpreted in ever new situations” (1993:10). This “opening up” reminds one of Kelber's view of what happened to Christian and Jewish traditions in their pre-printed format, now during a different period in history and specifically informed by insights from feminist biblical scholarship.

\section{A dialogical approach to interpretation: setting the tone for suchan approach}

Opting - as an ethical position - for a dialogical approach (Buell 2014:298-301; see also Craffert 2007:196) as overarching framework for interpretation implies a clear movement away from the one-way discourse which for many centuries applied to the functioning of the Bible, especially but not only in confessional contexts. With patriarchal ideals nowadays regarded by many as ones to protest against rather than adhere to, a critical dialogue has become essential. Apart from the often still authoritative functioning of the Bible where it is most influential and the current realisation of historical-cultural differences between the biblical past(s) and our present(s) (Craffert 2007:181-183; Meeks 2006:11, 12), the need for a dialogue obviously presupposes that the Bible still lives on and impacts on the lives of many people in different ways.

Setting the tone for such a dialogue, I link up with Elizabeth Schüssler Fiorenza's 1988 presidential address to the Society of Biblical Literature, later elaborated on in her Rhetoric and ethic (1999). In these contributions, still extremely relevant, the focus is not merely on feminist matters, although they were substantially informed by these questions. Hers was a call for a transformation or decentring of biblical scholarship from what she called a scholarly in-house discourse of an antiquarian nature to an engaged one in which the interpreter's social location is taken as seriously as that of the biblical texts (Schüssler Fiorenza 1988:5; see also Castelli 1994:81; Stenström 2005:15). It thus entailed the transgressing of scholarly boundaries into real contemporary life. This would, in her case, be made possible by the rhetorical paradigm of interpretation for which she opted. Typifying this interpretative position as that of a connected critic, and in her own case as an “outsider's view”(1988:5), for Schüssler Fiorenza this stance implied that biblical scholarship had to be brought back to real life in an informed, problem-oriented and diverse way. The boundaries of the academy had thus to be transgressed and the safe, 
though complex haven of much of traditional scholarship left behind. Significant to note is that in this re-conceptualisation the "so what" questions posed in our time by biblical texts, which are left to biblical scholars to ponder individually in much of traditional biblical scholarship, become a crucial part of the discipline. The historical context of a text is still regarded by Schüssler Fiorenza as crucial for a number of reasons. A reading in historical context problematises an unlimited number of interpretations and "makes the assimilation of the text to our own experience and interests more difficult" (1988:14). Moreover, "By illuminating the ethical-political dimensions of the biblical text in its historical contexts, such an ethics of historical reading allows us not only to relativise through contextualisation the values and authority claims of the biblical text but also to critically evaluate them" (1988:14).

As the other, indispensable side of the interpretative coin, an ethics of accountability is needed (Schüssler Fiorenza 1988:15). For, if biblical texts have served not only noble causes, but contributed to the oppression of different groups of people, it is, according to Schüssler Fiorenza no longer sufficient to merely understand these texts in their contexts. The Bible's continuing and diverse impact calls for biblical scholarship as a public - political enterprise "that stands responsible not only for the choice of theoretical interpretive models but also for the ethical consequences of the biblical text and its subsequent interpretations" (Schüssler Fiorenza 1999:28).

This brings us to the important issue of the impact of biblical texts on the lives of real human beings, in this case especially women. As Schüssler Fiorenza puts it: "What does the language of a biblical text 'do' to a reader who submits to its world of vision?" Put even more concretely and extensively, the crucial questions, according to Davaney (1997:212, 2000a177, 178), become: What difference will it make if we live out of one imaginative rendering of life rather than another? What difference will it make to our bodies, to our communities, to those affected by our lives, to the larger web of human life and nature? Attention to impact clearly has public-political implications.

Despite attention to the effective history of the Bible in biblical scholarship, it has taken us a very long time to imagine these concrete questions with regard to the Bible, its interpretations and impact. Disregarding differences between gender construction in the $1^{\text {st }}$ century world and our own, and ignoring the wellbeing of contemporary human beings, some churches still need to convene special meetings to wring, at all costs, answers from the Bible about the position of women in the churches and on the fate of gay persons (see the specific examples above). And reflection on our responsibility to save the earth has only recently begun. 


\section{A brief introduction to the proposed dialogue ${ }^{15}$}

As an introduction to the proposed dialogue, and related to Schüssler Fiorenza's insights in the previous section, a brief summary is provided here of a number of crucial contemporary convictions of feminist biblical scholars regarding the Bible. In such a diverse field this would obviously not be representative of the whole picture. Having briefly reviewed a number of trends during the history of the discipline's existence, Davaney (2000a:174) points to the following common contemporary views of these scholars: that the Bible is often anti-female and has a long history of being utilised to oppress women, which calls for thorough criticism; that it is no longer regarded by feminist biblical scholars as "a repository of unquestioned divine revelation"; that "the Bible and the rest of our religious inheritance are not monolithic"; "they also contain intimations of more inclusive and just visions". According to these scholars, these visions can still function as "a set of resources" for persons within the biblical traditions and may even be seen as "resources for the creation of a new human society" (2000a:174). This clearly entails a movement away from absolutes and an explicit acknowledgement of the mixed nature of the content of the Bible and its impact, as has already become evident. Being of a both/and kind, this "summary" calls for a critical, multidimensional and nuanced dialogue with the Bible and our Christian past(s).

As a theologian in the fields of both feminist and historicist theology, and not a biblical scholar, Davaney claimed in various contributions that these contemporary emphases in feminist biblical scholarship call for a thorough reflection on the nature of religious traditions as well. In these she extended, from a historicist perspective, the nature of a religious tradition in the direction of greater plurality ${ }^{16}$ (see Davaney 2000a, 2000b, 2006; Jacobs 2008a, 2010). Important for a dialogue with the past is also how the relation between the past and present should be seen, something on which she has also reflected extensively. ${ }^{17}$

With the tone set by a number of Elizabeth Schüssler Fiorenza's insights, which are representative of those of many others, the brief introduction sketched above as context for reflection, and with the issue of "ethical interpretation" in mind, a

15 A dialogue in our time between ourselves and biblical texts/the Christian tradition calls for a more explicit reflection on our own/the modern/postmodern worldview. These are, of course, comprehensive topics in themselves, of which only glimpses will come into the picture here, some of which are merely presupposed. See in this regard Lategan (2010) and Davaney (2000b: 23, 64-67).

16 Since an "opening up" of the biblical canon and its long history of interpretation actually re-attaches it to tradition, renewed reflection on tradition/a religious tradition is required, something that cannot be undertaken here. Apart from Davaney's work see Bell (2001) and Hervieu-Léger (2000). In these contributions tradition is conceptualised from different perspectives and in different ways.

17 Reflecting from a historicist perspective on this matter, Davaney acknowledges that human beings are influenced by the past, and that they live out of what they inherit from their histories. Due to its contingent and mixed nature, however, the past cannot simply be appropriated into the present (1994:55). "To assert that something is biblical does not end debate about whether it should be espoused today ... We are still called upon to give reasons in our appropriate contexts and making our case for the validity of our positions" (2000b:150). 
few specific matters are given more detailed attention here: ethical interpretation as forcefully confronting the explicit patriarchy in some biblical texts; the acknowledgement of the active role of the interpreter in interpretation; ${ }^{18}$ and related to this, reflection on concepts crucial to feminist biblical scholarship/theology such as female subjectivity and the nature of being human.

\section{Exposing and confronting patriarchy in biblical texts}

Basic to a feminist dialogue with the past is the need for first exposing and confronting gender construction in the $1^{\text {st }}$ century world, and thus the nature of patriarchy prevalent in biblical texts, in some cases more explicitly so than in others. Nowadays still part of our religious and cultural heritage in different manifestations and to different extents, patriarchy is indeed a word/concept/discourse/system packed with significance. Its centuries-old consequences can hardly be overestimated. A few crucial components of this inherited patriarchal package which are all too often still underplayed in talk on the Bible are: hierarchy, which entails male domination and women functioning as objects of male discourses; a one-sex model with women not seen as persons in their own right, but defined in terms of the superior male gender; the public-private dichotomy which restricted women to the private sphere; the appeal to this “order” as natural and imbuing it with divine status (see Castelli 1999, especially 230-233 with regard to Paul on women and gender; Vorster 2003:55-119 for a comprehensive exposition of gender construction in the Graeco-Roman world, including its functioning in the Pauline letters). In the case of the Bible specifically, the implication is that patriarchal male voices and the voice of God were and are, even in the $21^{\text {st }}$ century, inextricably linked, at least in some church contexts. These views on gender could only become the building blocks of a sad story and have indeed kept women "in their place" for many centuries. Apart from addressing the patriarchy inherent in biblical texts, the patriarchy still prevalent in the South African society, fed from different cultural, social and religious sources, and its dire consequences should also be squarely faced. And, as is commonly emphasised in feminist biblical scholarship, questions of gender, race, class, etc. should not be dealt with as isolated cases of oppression, since they often function in combination (Schüssler Fiorenza 1992:114).

\section{The active role of the interpreter}

The active role of the interpreter in interpretation, and therefore of human agency, is nowadays acknowledged and highlighted in various strands of biblical scholarship (see Tolbert 1998:180-182; Martin 2006:1-5; Meeks 2006:64-67 specifically with regard to the interpretation of Jesus of Nazareth in the New Testament). Emphasising this role, Martin (2006:2), recently remarked: “As long as the text is regarded to

\footnotetext{
18 This is nowadays also emphasised by eminent mainstream New Testament scholars such as Dale Martin (2006) and Wayne Meeks (2006). Arguing this matter from a gender perspective, see Vorster (2003:88).
} 
provide its own interpretation, or to constrain or direct its own meaning, the ethical and political responsibility of interpreters can be masked, denied, or slighted". This active role applies to both the production of knowledge and of meaning, thus problematising an objectivistic approach an objectivistic approach. It also influences decisions on which aspects of a tradition should be continued or changed (Vorster 1994:473).

The active role of the interpreter, and the acknowledgement of the social location, presuppositions, interests, etc. from which interpretation takes place, has from early on been part and parcel of feminist biblical interpretation; the cards have from early on been on the table. In this regard Tolbert (1983:126) remarked that, by openly admitting not only that feminist biblical scholars interpret from a specific position, but that they are actively involved in what they do, they create the possibility of a truly humane discourse. This kind of discourse is, according to her, also needed in biblical scholarship in general and in the other contexts in which the Bible functions. ${ }^{19}$ Apart from the issue of integrity in interpretation, it is the acknowledged, informed and validly regarded involvement of the interpreter which makes meaningful dialogue with the past possible.

As is to be expected, there are differences in the way the role and status of the interpreter is seen in feminist biblical scholarship. For Schüssler Fiorenza the feminist biblical interpreter is a "feminist theological subject", in a broad sense (1992:160). Others problematise the "blending of theology and history" (for examples see Castelli 1999:223). Informed by historicist insights and reflecting on subjectivity in the wake of both "the postmodern disappearing self" and "the western fantasy of the autonomous self", Davaney (2000a:173) argues for an "embedded subjectivity" or what she calls "the historicised self". For her this implies that, while we are shaped by our past, we are at the same time beings who "continually recreate and transform our worlds and ourselves in novel ways" (2000a:173). She therefore makes a case for women as "historicised selves" as also being constructive historical agents (2000a:173). This kind of subjectivity will be addressed in the next section, in which snippets of a dialogue with the past will be provided. ${ }^{20}$

19 Interestingly, some of these sentiments are reminiscent of the idea of an "open conversation" ("oop gesprek") expressed by the well-known Afrikaans writer and poet N. P. Van Wyk Louw. His "open conversation" includes the following features: that no restrictions should be placed on the theme to be discussed; that, in such a conversation, one should carefully, courteously listen to another's views; that one should put one's cards on the table. This implies a comprehensive exposition and explanation of one's views (Burger 2006:iii). In a dialogue with someone from another era this would, of course, be a more complex endeavour.

20 Davaney's use of "women" does not imply adhering to essentialism, as nowadays also applies to most feminist scholars. She specifically argues against such a position or stance (2000a:170, 171). Relevant to the issue of subjectivity is also that, with the dawn of feminist scholarship, the issue of "being human" became the focus of attention once again, this time among feminist scholars from different disciplines. Moving away from centuries-old dualisms such as that between mind and body, between reason and emotion, and from the universal nature of the subject in some mainstream strands of thought, there has been a new emphasis on embodiment in feminist philosophy. The body is here not reduced to 


\section{A dialogue informed by different insights and involving different voices}

Using the above as a build-up to the matter of a dialogue with the Bible, what might a dialogue with biblical texts, and thus a dialogical interpretation, concretely entail? The intention here is not to provide a systematic exposition of such a dialogue. This may be unattainable, even undesirable, in what will inevitably not only be a multifaceted but also a somewhat fragmentary discourse. It will also be one that will have to be taken up again and again, since contexts continually change. A discussion of a proposed dialogue will in a sense merely be pointing out some trends, highlighting some elements that such a dialogue may include, giving voice to a number of views. Keeping this in mind, a few insights indispensable for such a dialogue are made explicit here.

In such a dialogue historical consciousness, ${ }^{21}$ and therefore the historical-cultural distance (specifically with regard to gender), between ourselves and the $1^{\text {st }}$ century will obviously have to play an important role (see Castelli 1999; Vorster 2003). A number of other decisive matters will also come into the picture. A meaningful, even indispensable, starting point for a dialogue/dialogical approach to biblical interpretation from a feminist perspective may be the fact that the sociallocation of the interpreter is taken as seriously as that of the biblical text (Schüssler Fiorenza 1988:5; Castelli 1994:81; Stenström 2005:15). This “move" implies that reciprocity, instead of one-way communication, is presupposed and positively evaluated. What is nowadays known about the origin and contexts of the biblical writings and the active role of the interpreter in interpretation, moreover, releases her from the supposed role of passive receiver of eternal truths (Fontaine 1997:111) and assigns her the freedom to use various strategies regarded as useful and meaningful in biblical interpretation in our time.

A well-known strategy specifically characteristic of feminist biblical scholarship is that of reading "against the grain" or "with suspicion", a reading which questions and does not merely affirm "what a text says". This procedure problematises not only the content of texts but also the long history of traditional, especially confessional-male interpretations (Schüssler Fiorenza 2013b:94). For an involved interpreter, informed on gender construction in the $1^{\text {st }}$ century Greco-Roman world and conversant with more liberating values available in own time, this

20 the biological or confined to social conditioning, but seen, at least by some, as "a field of intersection of material and symbolic forces ... it is one's primary location in the world, one's primary situation in reality" (Braidotti 1991:219). With some feminist scholars seeing rationality, specifically defined, as the instrument of masculine domination par excellence (Braidotti 1991:176, 177), there have also been attempts to think "thought" in a different way, thus integrating the unconscious, the subjective, the emotional with the structural, the rational and the intellectual (Rich in Braidotti 1991:212).

21 While historical consciousness functions prominently in feminist biblical scholarship, for many of these scholars this does not imply a complete break with the past and therefore does not exclude the possibility that aspects of the Bible and the Christian tradition may still be meaningful for the present, as pointed out above. This is not a return to simplistic interpretation. 
may imply breaking away "from what does not suit us ethically and existentially" (Brenner 1997:140), resisting what is not liberating (Fontaine 1997:112). It may entail challenging the content and interpretations of biblical texts regarded as androcentric (Buell 2014:301). It may lead to the realisation that serious attempts to understand biblical writings may in some instances entail leaving the views propagated by them behind (Jacobs 2002a:128). In the process both texts and readers are held ethically responsible (Milne 1997:55).

In a reading informed by these insights even the Bible partially acquires a different function. If in past societies it had mostly been used to socialise people into accepting a patriarchal worldview, for many it currently serves as the site of a critique of that system (Fontaine 1997:111). For as long as the Bible is used against women, gay persons, etc., it will be necessary to talk about its nature and the problems in its uncritical use (Fontaine 1997:112). Confronted with women-unfriendly texts from a different period in history, feminist biblical scholars cannot merely mine them for meaning, but are forced to negotiate meaning with the biblical texts as dialogue partners (Schüssler Fiorenza 1999:43).

Despite sometimes fierce, though mostly valid, criticism, many feminist critics also acknowledge and focus on positives in the Bible and early Christianity. There is, in Schüssler Fiorenza's feminist writing of women's history in early Christianity, her identification of liberatory, women-affirming moments behind biblical texts (Schüssler Fiorenza 1983:119, 134, 147-148). Well-known in this regard is her notion of the "discipleship of equals" (1983:35), which may, in her view, resonate with the ideals of contemporary women. This view has not gone unproblematised (e.g. Okland 2002:149-155).

There is also the acknowledgement, as pointed out above, that the Bible and the rest of our religious heritage are not monolithic (Davaney 2000:174), that not all biblical texts, traditions and stories "reflect the experience of men in power or were written in order to legitimate the patriarchal status quo" (Schüssler Fiorenza 2013b:94). This calls for a nuanced approach to the biblical writings. Having been critically evaluated with regard to their feminist liberating content and function in both their historical and contemporary contexts (2013b:94, 95), these texts may therefore still be useful as resources for today $(2013 \mathrm{~b}: 94,95)$. A dialogue may therefore end up in explicit dissent from some biblical passages and the embracing of others. Taking, in the case of biblical texts, both the positives and negatives seriously, according to Adam (quoted in Buell 2014:301), women should continue to wrestle with passages such as Ephesians 5:22 ("Wives, be subject to your husbands as you are to the Lord") "not simply to denounce, soften or explain it away, but to highlight its anomalousness and conflict with 'what we know about our story of God-with-us' and 'many other New Testament passages that recount the primacy of communal, grace-filled interaction over hierarchical social convention". This "continued wrestling" may also ensure that explicitly oppressive biblical texts will not silently vanish from the 
interpretative scene with their impact still firmly intact. And with biblical texts as dialogue partners with both positive and negative sides, informed choices in the light of our own context(s) will in the end be called for, rather than attempts to wring/produce at any cost life-giving meanings from texts not conducive to this.

In a discipline with real human beings at the centre of justice-enhancing attention - in this case women and other marginalised people - their diverse experiences should be taken seriously (Davaney 2000a:174). On the one hand, feminist biblical scholars emphasise that contemporary women's disparate struggles for liberation, both individually and collectively, should function as an authoritative counter-site for evaluating texts and interpretations as to their potential to contribute to the liberation of oppressed women (Buell 2014:294; see also Stenström 2005:15). On the other hand, it is acknowledged by some that, despite the use of the Bible against women struggling for liberation, it nevertheless "inspired countless women to speak out against injustice, exploitation, and stereotyping and energised them to struggle against poverty, unfreedom and vilification" (Schüssler Fiorenza 2013b:93). All of this boils down to the need for a critical, open dialogue which attempts to take both the positives and negatives seriously, while fully acknowledging the complexity of this endeavour.

Linking up with the emphasis on "openness" in this chapter, the last word in this section is given to a feminist poet, Alicia Ostriker, and the hermeneutics of indeterminacy she espouses. This kind of hermeneutics entails that there is never a final interpretation of a text (Ostriker 1993:122). With her work clearly informed by the problem of patriarchy in biblical texts, and speaking from "real life", she sides with consciously constructed plural interpretations as a solution to some of our problems. Not only are plural interpretations, according to her, inevitable; human civilization has a stake in these (1993:122): “This is an activity we' re undertaking on behalf of humanity, all of whom would be happier, I believe, were they to throw away their addiction to final solutions" (1993:123). In terms of dialogue one could translate her view into one with an "open ending". As all real dialogues, should, of course, be in some way. ${ }^{22}$

\section{Concluding remarks}

The starting point of this chapter is that the Bible has functioned for many centuries as an answer book, specifically when contentious issues have been at stake. In the process it has often been abused against those non-favoured of ancient patriarchal cultures and contemporary cultures influenced by them. Having devoted attention mainly but only to a number of matters crucial to feminist biblical scholarship, the chapter showed that these insights, when embraced and implemented meaningfully

22 In this regard N.P van Wyk Louw's view on an "open conversation" (Die (steeds) oopgelate kring) is again relevant. See Burger (2006:i-iii) 
and accountably, my contribute to a different kind of discourse, more specifically a critical dialogue with the Bible and our Christian past. In such a discourse, "devised" in the interest of greater justice and humaneness, and with real human beings in sight and mind, contemporary persons who are informed by both their complex past(s) and present(s) are enabled to transgress the limits of outdated discourses and claim the right to speak "in their own voices". This may at least have the potential to lead to a more humane dispensation, even if, in practice, the momentum of patriarchal texts and cultures are in many respects still with us.

\section{Bibliography}

Alexander, L. 2006. God's frozen Word: Canonicity and the dilemmas of biblical studies today, Expository Times, 117 (6): 237-242. https://doi. $\operatorname{org} / 10.1177 / 00145246063627$

Bell, C. 2001. Who owns tradition? Religion and the messiness of history. The Santa Clara Lectures, 7(2): 1-16.

Braidotti, R. 1991. Patterns of dissonance: A study of women in contemporary philosophy, Cambridge: Polity Press.

Brenner, A. 1997. Identifying the speaker-in-the-text and the reader's location in prophetic texts: The case of Isaiah 50, in A Brenner \& C Fontaine (eds.), A feminist companion to reading the Bible, Sheffield: Sheffield Academic Press, 136-153.

Brenner, A. 2016. On scholarship and related animals: A personal view from and for the here and now, Journal of Biblical Literature, 135 (1): 6-17. https://doi.org/10.1353/ jbl.2016.0009
Brümmer, W. 2016. 10 vrae vir professor Elna Mouton, Burger (By):2, 2 July 2016.

Buell, D K. 2014. Canons unbound, in E. Schüssler Fiorenza (ed.), Feminist Biblical Studies in the Twentieth Century: Scholarship and Movement, Atlanta: SBL, 293-306. https://doi.org/10.2307/j. ctt1287n2p.22

Burger, W. 2006 Voorwoord: Die steeds oopgelate kring, in W Burger (ed.), Die oop gesprek: N. P. Van Wyk Louw-Gedenklesings, Pretoria: LAPA Uitgewers, i-iii.

Byatt, A S. 1998. Christ in the house of Martha and Mary, in Elementals: Stories of fire and ice, London: Chatto \& Windus, 219-230.

Castelli, E A. 1994. Heteroglossia, hermeneutics and history: A review essay of recent feminist studies of early Christianity, Journal for the Feminist Study of Religion, 10:73-98. 
Castelli, E A. 1999. Paul on women and gender, in R S Kraemer \& M R D'Angelo (eds.), Women and Christian Origins, Oxford: Oxford University Press. 221-235.

Castelli, E A \& Taussig, H. 1996. Drawing large and startling figures: Reimagining Christian origins by painting like Picasso, in E A Castelli \& H Taussig (eds.), Reimagining Christian Origins, Valley Forge: Trinity Press International, 3-20.

Craffert, F. 2007. New Testament Studies - Preventing or promoting a humane society? Religion \& Theology, 14:161-205. https://doi.org/10.1163/1023080 12X13397496507144

Davaney, S G. 1994. A historicist model for theology, in J D Carlson \& R A Ludwig (eds.), Jesus and Faith: A Conversation on the Work of J. D. Crossan, Maryknoll: Orbis Books, 44-56.

Davaney, S G. 1997. Continuing the story, but departing the text: A historicist interpretation of feminist norms in theology, in R S Chopp \& S G Davaney (eds.) Horizons in Feminist Theology: Identity, Tradition and Norms, Minneapolis: Fortress Press, 198-214.

Davaney, S G. 2000a. Historicist interpretations of subjectivity, tradition and norms in feminist theology, Svensk Teologisk Kvartalskrift. Arg., 76:170-178.
Davaney, S G. 2000b. Pragmatic Historicism: A Theology for the Twenty-First Century, New York: State University of New York Press.

Davaney, S G. 2006. Historicism: The Once and Future Challenge for Theology, Minneapolis: Augsburg Fortress.

Du Toit, M. 1921. Vrou en feminist, Bloemfontein: Nasionale Pers.

Fontaine, C. 1997. The abusive Bible: On the use of feminist method in pastoral contexts, in A. Brenner \& C. Fontaine (eds.), A Feminist Companion to Reading the Bible: Approaches, Methods and Strategies, Sheffield: Sheffield Academic Press, 84-113.

Hamilton, W. 1993. A Quest for the Post-Historical Jesus, London: SCM.

Hervieu-Léger, D. 2000. Religion as a Chain of Memory, Trans. S Lee, New Brunswick: Rutgers University.

Jacobs, M M. 2001. Feminist scholarship, biblical scholarship and the Bible, Neotestamentica, 35 (1-2): 81-94.

Jacobs, M M. 2002a. Afskeid van die Pastor, in P Müller (ed.), Die Nuwe Hervorming, Pretoria: Protea Boekhuis, 112-133. 
Jacobs, M M. 2002b. The 'sense' of feminist biblical scholarship for church and society, Scriptura, 80:173-185.

https://doi.org/10.7833/800-754

Jacobs, M M. 2005a. In dialoog met die Bybel, in A Ferreira (ed.), Paaie: Verkenning van 'n geestelike landskap, Pretoria: Griffel Uitgewers, 66-69.

Jacobs, M M. 2005b. Eve: Influential glimpses from her story, Scriptura, 90:765-778. https://doi.org/10.7833/900-1065

Jacobs, M M. 2008a. On the relation between past and present: Two proposals from feminist biblical scholarship and theology, Theologia Viatorum, 32(2): 163-192.

Jacobs, M M. 2008b. Anderkant die Pastor, in L Nortjé-Meyer (ed.), Kykweer: Gender-kritiese kommentaar op geselekteerde bybelse tekste, Singapore: Tien Wah Press, 138-154.

Jacobs, M M. 2010. Theology in a historicist mode: The work of Sheila Davaney, Acta Patristica et Byzantina, 21 (1):102-120. https://doi.org/10.1080/1022648 6.2010.11879154

Jacobs, M M. 2013. Riders in the Chariot: Die resepsie van 'n ou simbool in 'n moderne letterkundige werk, Litnet Akademies, 10(3):800-823.
Kelber, W. 1999. The quest for the historical Jesus: From the perspectives of medieval, modern and post-enlightenment readings, and in view of ancient, oral aesthetics, in J D Crossan, L T Johnson \& W Kelber (eds.), The Jesus Controversy. Harrisburg: Trinity Press International, 75-115.

Kelber, W. 2010. The history of the closure of biblical texts, in A Weissenrieder \& R B Coote (eds.), The Interface of Orality and Writing: Speaking, Seeing, Writing in the Shaping of New Ground, Tübingen: Mohr Siebeck, 71-98.

King, K L. 1994. The Gospel of Mary Magdalene, in E Schüssler Fiorenza (ed.), Searching the Scriptures, Vol. 2. New York: Crossroad, 601-634.

Lategan, B. 2010. 'n 'Nuwe humanisme', Beeld (By): 6-7, 20 February.

Louw, D J. 2014. ICONS: Imaging the Unseen, Stellenbosch: AFRICAN SUN MeDIA.

Martin, D. 2006. Sex and the Single Saviour: Gender and Sexuality in Biblical Interpretation, Louisvillle: Westminster John Knox Press.

McFague, S. 1993. An earthly theological agenda, in C J Adams (ed.), Ecofeminism and the Sacred, New York: Crossroad. 
McGinn, S M. 1994. The Acts of Thecla, in E Schüssler Fiorenza (ed.), Searching the Scriptures, New York: Crossroad, 800-828.

Meeks, W A. 2005. Why study the New Testament? New Testament Studies, 51:155-170. https://doi.org/10.1017/ S0028688505000093

Meeks, W A. 2006. Christ is the Question, Louisville: Westminster John Knox Press.

Milne, P. 1997. Toward feminist companionship: The future of feminist biblical studies and feminism, in A Brenner \& C Fontaine (eds.), A Feminist Companion to Reading the Bible, Sheffield: Sheffield Academic Press, 39-60.

Mouton, E. 2003. (Re)Describing reality: The transformative potential of Ephesians across times and cultures, in A-J Levine \& M Blickenstaff, A Feminist Companion to the Deutero-Pauline Epistles, Cleveland: Pilgrim, 59-87.

Mouton, E. 2006. Interpreting the New Testament in Africa: Bernard Lategan on the threshold of diverse theological discourses, in C Breytenbach, J C Thom \& J Punt, The New Testament Interpreted: Essays in Honour of Bernard C. Lategan, Leiden: Brill, 177-198.
Mouton, E. 2011. Human dignity as expression of God images? Perspectives from/on 1 Corinthians 14 and Ephesians 5. Neotestamentica, 45(2): 275-292.

Mouton, E. 2014. Reimagining ancient household ethos? On the implied rhetorical effect of Ephesians 5:21-33, Neotestamentica, 48(1):163-185.

Network 24.com. Special Synod debates women in Reformed Church, available at: https://www. africanews.com/.../2499154news24.com-special-synoddebates-women-in-Reformed Church/2015-01-10 (Retrieved 10 September 2018).

Nortjé-Meyer, L. 2015. Feminist New Testament scholarship in South Africa, Nedotestamentica, 49 (1): 1-19. https://doi.org/10.1353/ neo.2015.0000

Okland, J. 2002. Feminist reception of the New Testament: A critical reception, in M Müller \& H Tronier (eds.), The New Testament as Reception, Sheffield: Sheffield Academic Press, 131-156.

Ostriker, A S. 1993. Feminist Revision of the Bible, Oxford: Blackwell.

Reinhartz, A. 1997. Feminist criticism and biblical studies of the verge of the twenty-first century, in A Brenner \& C Fontaine (eds.), A Feminist Companion to Reading the Bible, Sheffield: Sheffield Academic Press, 30-38. 
Schneiders, S. 2000. With Oil in their Lamps: Faith, Feminism and the Future, New York: Paulist Press.

Schüssler Fiorenza, E. 1984. In Memory of Her: A Feminist Theological Reconstruction of Christian Origins, New York: Crossroad.

Schüssler Fiorenza, E. 1988. The ethics of biblical interpretation: Decentering biblical scholarship. Journal of Biblical Literature, 107(1): 3-17. https://doi.org/10.2307/3267820

Schüssler Fiorenza, E. 1992. But SHE said: Feminist Practices of Biblical Interpretation, Boston: Beacon Press.

Schüssler Fiorenza, E (ed.). 1993. Searching the Scriptures, Vol 1, New York: Crossroad.

Schüssler Fiorenza, E (ed.). 1994. Searching the Scriptures, Vol. 2, New York: Crossroad.

Schüssler Fiorenza, E. 1999. Rhetoric and Ethic: The Politics of Biblical Studies, Minneapolis: Fortress Press.

Schüssler Fiorenza, E. 2013a. For the sake of the truth dwelling among us: Emerging issues in feminist biblical interpretation, in Changing Horizons: Explorations in Feminist Interpretation, Minneapolis: Fortress Press, 71-87.

https://doi.org/10.2307/j. ctt22nm7t3.9
Schüssler Fiorenza, E. 2013b. The will to choose or to reject, in Changing Horizons: Explorations in Feminist Interpretation, Minneapolis: Fortress Press, 89-100. https://doi.org/10.2307/j. ctt22nm7t3.10

Schüssler Fiorenza, E. 2014 (ed.). 2104. Feminist Biblical Studies in the Twentieth Century: Scholarship and Movement, Atlanta: SBL.

Stenström, H. 2005. Historical-critical approaches and the emancipation of women: Unfulfilled promises and remaining possibilities, in C Vander Stichele \& T Penner (eds.), Her Master's Tools? Feminist and Postcolonial Engagements of Historical-Critical Discourse, Atlanta: SBL, 31-45.

Tarnas, R. 1991. The Passion of the Western Mind: Understanding the Ideas That Have Shaped Our World View, London: Pimlico.

Tolbert, M A. 1983. Defining the problem: The Bible and feminist hermeneutics, Semeia 29: 113-126.

Tolbert, M A. 1998. A new teaching with authority: A re-evaluation of the authority of the Bible, in F F Segovia \& M A Tolbert (eds.), Teaching the Bible: The Discourses and Politics of Biblical Pedagogy, Maryknoll: Orbis Books, 168-189. 
Vander Stichele, C. 1986. Is

Silence Golden? Paul and

Women's Speech in Corinth,

New Testament Studies, 32:

225-246.

Van der Westhuizen, C. 2017. Totius se meestal vergete feminis-sus, Beeld, 11, 24 August.

Vorster, J N. 1994. The epistemic status of rhetoric, Neotestamentica, 28: 469-493.
Vorster, J N. 2003. Engendered strategies of reading, in Study Guide for SCR 309-E/501/2003, Pretoria: UNISA, 50-139.

Wagner, L \& Hosken, G. 2018. Church at odds with itself over allowing pastors to marry homosexuals, available at: https://www. businesslive.co.za/.../churchat-odds-with-itself-overallowing-pastors-to-marryhomosexuals/2018-07-17. (Retrieved 10 September 2018) 


\title{
Chapter 4
}

\section{Further Interrogation of the Comparative Paradigm in African Biblical Scholarship}

\author{
Towards an analogical hermeneutics for \\ interpreting the Old Testament in Africa
}

\section{Louis C Jonker}

\section{Introduction}

After a thorough analysis of dissertations on the Old Testament completed by African scholars in the period 1967 to 2000, ${ }^{1}$ Knut Holter came to the conclusion that a comparative paradigm dominates the majority of these studies. He describes this paradigm as follows: "[it] facilitates a parallel interpretation of certain Old Testament [and New Testament] texts or motifs and supposed African parallels, letting the two illuminate one another. Traditional exegetical methodology is of course found here, too; however, the Old Testament [and/or New Testament] is approached from a perspective where African comparative material is the major dialogue partner and traditional exegetical methodology is subordinated to this

\footnotetext{
Holter included dissertations by African scholars in the region between the Sahara desert and the Limpopo River, thus excluding South African students. He motivates this choice as follows: "Generally speaking, I very much subscribe to a geographical and not to a racial or cultural definition of 'Africa'. In other words, I generally use the word 'Africa' to refer to the African continent, and I use the adjective 'African' to relate to someone of something from the African continent. From this follows that the Arab north and the white south, in my view, are just as much 'African' as anything else on the continent. Nevertheless, when it comes to the practical work of this particular bibliography I will, for two pragmatic reasons, exclude dissertations that are written by South African scholars. One reason is that South African Old Testament scholarship already is well documented and, to some extent, analysed in international scholarly literature. The other reason is that an inclusion of dissertations written by South Africa scholars would have dominated the presentation. I find that dissertations written by scholars from the rest of the continent, north of the Limpopo River deserve to be presented without being overshaddowed (sic) by those of their numerous South African colleagues" (Holter 2002:15-16). He also included dissertations of African scholars that were done at non-African, Western institutions, including South African institutions. For further analyses of and contributions on African biblical scholarship, see (Holter 1996, 2000, 2006, 2008).
} 
perspective" (Holter 2002:88). Although it has been debated in further discussions what "comparative paradigm" means and how it should be evaluated, the analysis itself has been generally accepted in African biblical scholarship and beyond. Gerald West, for example, remarks: "Knut Holter's description is instructive and takes us to the heart of the exegesis/actualisation or interpretation/application debate" (West 2008:37). However, in his further remarks West indicates that there is a need to interrogate the comparative paradigm somewhat further in order to provide more nuanced descriptions. He says "Holter is careful to state that 'of course' African biblical scholarship is exegetical, thereby deflecting any potential charge that African biblical scholarship is 'merely' contextual.” However, Holter does go on to say that 'traditional exegetical methodology is subordinated to this [contextual comparative] perspective', pointing, perhaps to a significant difference between African biblical scholarship and Euro-American forms of biblical scholarship" (West 2008:37). West therefore indicates that his paper wants to interrogate the comparative paradigm "in an attempt both to understand what we as African biblical scholars are up to and to understand the similarities and differences between what we do and what our Euro-American colleagues do" (West 2008:37).

\section{State of the discussion}

Gerald West has given very good overviews of African biblical scholarship in various publications. ${ }^{2}$ However, the essay in which he interrogates the comparative paradigm in African biblical studies is probably the most illuminating. ${ }^{3}$ After giving the insightful analysis that biblical scholarship in Africa should not be seen as a full-blown colonialist project, but that one should rather "pause and cast our gaze further back if we are to understand African biblical interpretation more fully", ${ }_{4}$ West continues to ask what the dimensions are of African biblical scholarship's dialogue with the Bible. He states: "African biblical scholarship has a predilection for socio-historical textual analysis in dialogue with the socio-economic and religio-cultural realities of African contexts" (2008:47). ${ }^{5}$ However, this predilection

2 Among West's numerous publications, the following stand out in this regard: West $(1995,2002 a, b)$ West \& Dube Shomanah (2000).

3 This essay was derived from a paper Gerald West delivered at a conference held in Stellenbosch in January 2006 in which participants from Europe and Africa were brought into conversation with one another. The results of this conference, as well as responses to the various papers, were published in De Wit and West (2008). See also the earlier publication (West 2005).

4 Rather, West indicates that "a great deal of biblical interpretation was taking place before the emergence of African biblical scholarship. ... The long period of African sovereignty prior to any colonial presence laid the hermeneutical foundations for all subsequent interpretive activity. This period was followed by a period of limited colonial presence and African control in which a 'neo-indigenous' hermeneutic evolved, forged in the interface between indigenous and missionary interpretive practices. And finally, the long period of colonial control and African resistance has played a massive part in constructing African forms of interpretation, not least African biblical scholarship" (West 2008:45).

5 West indicates further that there is a distinction between biblical scholarship north and south of the Limpopo respectively. Whereas the majority of scholarship north of the Limpopo (thus, excluding 
which resonates with the life interests of African scholars is not merely an attempt to validate everything in the African socio-cultural world that is similar to the socio-historical world of the world behind the text. The dialogue rather proceeds in two directions, being evaluative and critical of African phenomena as well. ${ }^{6}$ The conclusion is then often drawn that the comparative approach, with its various evaluative thrusts, is not primarily interested in doing exegesis on biblical texts, but wants to apply the results of exegesis to the life interests of the African context.

Gerald West rightly problematises this understanding of African biblical scholarship within the dichotomy of exegesis and application. Taking his point of departure in Hans-Georg Gadamer's work, West emphasises: “Hans-Georg Gadamer has attempted to show that all understanding is necessarily perspectival, influenced by the assumptions, needs, and interest of the interpreter ... Gadamer has attempted to show that all understanding takes place in and through dialogue. The interpreter brings to a text a certain pre-understanding and through a to-and-fro engagement with the subject matter attempts to develop an appropriate interpretation. Understanding is a 'fusion of horizons' which is not merely a re-production of the text but a new historical appropriation of the text, a new perspective on the text. Just as understanding and interpretation cannot be separated into sequential moments, Gadamer insists that application is not a secondary practical concern but an intrinsic component of the one hermeneutic act of understanding/interpretation/ application" (West 2008). This insight of Gadamer's of course does not only apply to African biblical interpretation, but to (biblical) interpretation in general. Gerald West indicates, however, that not all other contexts are honest about (or even aware of) the life interests that drive them in their interpretations of the Bible. In contrast, he says "What characterises African biblical scholarship is that we are overt about why we come to the bible and what life interests drive our dialogue with it. In other words, we acknowledge the contexts out of which we interpret and for which we interpret. This does not make African biblical scholarship uncritical or un-exegetical ..." (West 2008:54).

South African scholarship) focuses mainly on religious and cultural contexts, African biblical scholarship in South Africa emphasises more the cultural and political contexts. See West (2008:39).

6 Justin Ukpong provides a useful analysis (with examples) in this regard. See Ukpong (2000). In this respect, it is interesting to note how this trend of using the Old Testament socio-historical world to critique certain contemporary phenomena on the African continent is still continuing in the master's or doctoral topics chosen by African students. From my (limited) experience at Stellenbosch University, it is interesting to see how issues such as political leadership, gender justice, corruption and environmental care are tackled in recent Old Testament studies. The following references show a fraction of work completed on these topics at Stellenbosch University in theses and dissertations since 2001: Cezula (2006, 2013), Mngqibisa (2006), Ahiamadu (2007), Olojede (2011), Juma (2014), Nkhonjera (2015), Audu Makama (2016). 
West furthermore shows that:

African biblical scholarship is critical, not only in how it interrogates the text , but ... also in how it interrogates the African context and the comparative relationship between text and context. Indeed, a key characteristic of African biblical scholarship is the critical interrogation of the whole interpretive process (West 2008:55). ${ }^{7}$

West also indicates that African biblical scholarship is thoroughly exegetical: "African biblical scholarship is also exegetical, even if we adopt the most orthodox, historical, sense of the term ..., for ... the predominant interpretive interests of African biblical scholars are socio-historical. We simply acknowledge why we ask socio-historical questions of the text; indeed, we even acknowledge why we ask the particular socio-historical questions we do and what relationship these questions have for our contexts" (West 2008:55 - his emphasis). West rightly indicates that the term 'biblical exegesis' no longer embraces the historical-critical subset of structured and systematic questions exclusively, but also incorporates other subsets of questions such as the literary, semiotic and others. 'Biblical exegesis' is therefore no longer exclusively focused on historical interpretive interests, but rather embraces a plurality of interpretive interests as well. Within this broader understanding of exegesis, African biblical scholarship is thoroughly exegetical.

Gerald West's interrogation of the predominant comparative paradigm in African biblical scholarship brought valuable nuance to the term, showing that this paradigm cannot be swiftly dismissed as uncritical or un-exegetical, and therefore not belonging to the domain of biblical scholarship. He should also be credited (certainly together with others, but with a unique input) for the positive developments in recent years within the largest guild of biblical scholarship, the Society of Biblical Literature (SBL), of giving African biblical scholarship its rightful and deserved place within the global landscape of biblical interpretation.

\section{The present quest}

It is within this context that the present contribution should be understood. My contribution fully acknowledges the rightful place of African biblical scholarship in the hugely varied landscape of global biblical interpretation. It does not merely acknowledge this kind of scholarship as another 'variation' that has to be 'tolerated' due to the commitment to variety, but is deeply convinced that African biblical scholarship makes (and should make) a valuable contribution in a discursive hermeneutical model (such as propagated by West via Gadamer). As will be shown in the next subsection, the value of African biblical scholarship should be appreciated within the communality and contextual integrity of our endeavours. 
However, exactly because of my commitment to a discursive development of our interpretive models, and because it is imperative that "the whole interpretive process" should be interrogated in African biblical scholarship (as indicated by West - see quotation on the previous page), I would like to further interrogate the modes through which the comparative paradigm often operates in African biblical scholarship. I will argue that the comparative paradigm often establishes a direct relationship between biblical texts and African contexts, or to be more precise, between the worlds constructed in the biblical texts and different African contexts. Although Gerald West contends that "African biblical scholarship accepts that history is constructed rather than found, and so sees its task as constructing biblical history in ways that bring it into dialogue with African concerns" (West 2008:58), my observation is rather that often the opposite is true from what West indicates. Often African biblical scholars do not take into account the fact that the biblical texts are constructed realities that wanted to engage in dialogue with those socio-historical circumstances within which they were written. The constructions in the texts are often accepted at face value in African biblical scholarship, and the socio-cultural values of that constructed reality is taken as point of departure for the dialogue with different African contexts. Often, the socio-cultural values of the time of construction of those texts are totally neglected in the process. In short, the comparative paradigm in African biblical scholarship often falls prey - at least in my opinion - to a lack of historical consciousness. ${ }^{8}$ In my further interrogation of the comparative paradigm I will suggest that an analogical paradigm might be more adequate for biblical interpretation in Africa (or, for that matter, in any other context). I will explain that an analogical paradigm - that avoids establishing direct relationships between the world(s) constructed in the biblical texts and various African contexts - is not something new, but is rather a further qualification of the comparative paradigm. The comparative mode will not be questioned; however, an alternative basis on which the comparison rests will be suggested.

I will elaborate further on these initial remarks below. However, before I participate in this discussion, it is necessary to describe my social location. In order to understand the alternative suggestion that I will make in the body of this essay, it is important to know where I come from (not only geographically, but also conceptually).

\section{The present author's social and academic location}

It is never self-evident for me to write on African biblical interpretation. Being a white, male, South African scholar with a Western-oriented upbringing and academic education, I am very aware of the pertinent (and legitimate!) discussion on whether my voice could in any way contribute to discussions on African hermeneutics. ${ }^{9}$ In the introduction to my essay collection published in 2015 I made the following

I will explain below how I use the term 'historical consciousness'.

See my participation in those discussions and engagement with other scholars in Jonker (2005). 
remarks: "I am in complete agreement with various contextual hermeneutical approaches that insist that one should begin reading the Bible by contextualising oneself" (Jonker 2015a:3). I also indicated in a further section that "the biography (social location) of a biblical scholar always influences the interpretations she/he makes" (Jonker 2015a:109). It has therefore become customary for me to situate myself socially and academically when writing about biblical hermeneutics. ${ }^{10}$ On several occasions I have used the term "hybridity" (which is well known from postcolonial theory) to characterise my social location. ${ }^{11}$ I have done so, because "I am actually a patchwork quilt of experiences, social locations, and identities. ... I know how each of these contexts, within which I have spent periods of my life thus far, has left indelible marks on me. I am also aware of the fact that these marks are not always complementary to one another, not always in harmony with one another. I know also of the conflicting experiences that have become part of who I am ... Am I a hermeneutical schizophrenic? ... I have come to realise that I live in different worlds simultaneously. The relatively short journey that I have travelled in my life has exposed me to contexts where I have come to appreciate thorough exegesis and rigorous scholarship. And it has also exposed me to contexts where I was touched by the naive interpretations of ordinary readers of the Bible - from traditional African communities to traditional Afrikaner Protestants - as well as the scholarship of many of my African colleagues ... I resist being described monolithically, because I live in different worlds simultaneously. My identity as a biblical scholar and reader of the Bible is a quilt of different - sometimes harmonious and sometimes conflicting - dimensions” (Jonker 2015a:77-78).

By emphasising my hybrid identity I also attempt to break through some of the simplistic dichotomies that are constructed by some theorists in our field. These dichotomies are often used in the service of underlying power games to control 'the game of interpretation', and my attempts to situate myself is a deliberate attempt to deconstruct some of these power hierarchies. I am fully aware that my own deconstruction in its part reflects my own 'power game' (which is inevitable for any interpreter), but it is at least an attempt to be overt about it.

Elsewhere I have summarised the dichotomies that I would like to break through in the following way:

The first is the dichotomy between academic and lay interpretations of the Bible ... Sometimes 'lay' readings are over-romanticised vis-à-vis 'informed' readings. And sometimes lay readings are belittled as if they cannot contribute anything to our reflection on biblical interpretation. A second dichotomy that surfaces is between African and European (or Western) readings of the Bible. This dichotomy is often described in terms of

\footnotetext{
10 See, for example, Jonker (1997, 2005, 2007, 2008, 2010).

11 See particularly Jonker (2008:77-79).
} 
opposition between exegesis ... and actualisation ... The third dichotomy is the opposition between historical and contextual readings of the Bible. Historical readings are often associated with Western-style exegesis, while contextual readings are found in grassroots life contexts. These descriptions of binary oppositions are too simplistic and untenable (Jonker 2015a:109-110).

These aspects are important to mention, because they reflect the hermeneutical model that I am working with, as well as the ethics of reading that I would like to foster. Flowing from my dissertation in which I argued against exclusivity in exegesis and in favour of multidimensional exegesis, I have indicated in various publications that communality forms the basis of the hermeneutical model I propose (Jonker 2001, 2005).

I have motivated it in the following way:

There are two reasons why I am suggesting a communal approach when we are doing biblical interpretation in (South) Africa. First, the sense of community belongs to the root paradigm of African cultures ... It is in the spirit of this sense of community that I am suggesting that a communal approach be considered in (South) African biblical interpretation, to preclude our developing tendencies towards exclusivism. Another reason for a communal approach relates to the view expressed ... on what community is ... [C]ultures do not interact with one another; only people from different cultural backgrounds interact. Interculturality thus has an interpersonal dimension: the place where people of different cultural backgrounds meet is the space of community. According to this understanding of community, a liminal space is created where different cultural backgrounds interact with one another, overlap with one another, and even influence one another in some cases... What applies to the interaction of cultures certainly also applies to contextuality in biblical interpretation ... [A] communal approach is the endeavour to open up liminal space in our (South) African biblical interpretation to facilitate interactions among the different kinds of contextuality (Jonker 2015a:51).

It is therefore important for me to foster an ethics of biblical interpretation which is characterised by contextual integrity. ${ }^{12}$ I have defined this as follows:

Contextual integrity can be achieved where justice is done to each of the contextualities involved in the process of biblical interpretation. Or, to put it in the inverse, contextual integrity cannot be achieved where one type of contextuality is overemphasised to the detriment of other types of contextuality. The communality of the approach suggested here opens up liminal space where scholars with different life interests can start sharing their scholarship on the different interpretative interests involved. Or to put it in yet another way, a communal approach moves away from binary oppositions that the quest for contextual authenticity would necessitate ... A communal approach would instead invite the diversity of (South) African scholars to come to the liminal space of community to share, to contradict, to influence, to change one another's interests in terms of the whole

12 My call for 'contextual integrity' stands in contrast to the insistence of some African biblical scholars (such as Jesse Mugambi - see Mugambi, (2003)) on 'contextual authenticity.' See my engagement with this debate in Jonker $(2005,2008)$. 
spectrum of contextualities involved in biblical interpretation. Within such a community of biblical scholarship, the individual interpreters (of African origin or otherwise) could interact with one another on the basis of the intercontextuality involved in our common pursuit of biblical interpretation (Jonker 2015a:52).

I am aware of the fact that I have been suspected of being naïve - unconsciously, or deliberately, in order to obscure my own power games that I am playing. By arguing in favour of a liminal space of communality and contextual integrity some would think that I am ignorant of the power I am exercising in my formulation of a hermeneutical model. This is now the time to confess that this accusation surely holds true for the earlier (post-dissertation and early-New-South-Africa) phase in my career when I was still very idealistic in formulating a communal approach in which I hoped everybody would participate joyfully and enthusiastically! However, through my own further reflection, but also through the very rigorous debates on the topic in South Africa, I came to realise that I am surely not 'neutral' when I want to advocate a communal approach of contextual integrity. This position surely expresses my resolution not to give up on my hybrid identity. If I would do so, I would not be able to achieve contextual authenticity anywhere (not in Europe and America, where I am a foreigner from another continent, but also not in my local (South) African context, where I am a white Westerner). ${ }^{13}$

The power I would like to exercise is to break through unwarranted dichotomies and to deconstruct power hierarchies. Elsewhere I have made this point as follows:

I am fairly convinced that I am not the only one with a patchwork quilt, or hybrid, identity. I believe, rather, that this is a strong characteristic of our postmodern era in which we do our interpretations of the Bible and our reflections on intercultural biblical hermeneutics ... I have tried to challenge our discussions to go another mile and not settle for simplistic explanations or conclusions. This is probably still the voice of protest against exclusivism that sounded already in my dissertation. Claiming exclusivity (and thereby, also scientific or moral high ground) for any social location leaves me feeling uncomfortable (Jonker 2015a:110).

These remarks about my social and academic location form the background of my further argument in the present study and the kind of hermeneutic I would like to advocate here. My proposal of an analogical hermeneutic is not new, but is rather another attempt to explain what I mean when calling for a communal approach and for an ethics of contextual integrity.

13 See again Jonker $(2005,2008)$ 


\section{Historical consciousness and the comparative paradigm in African biblical scholarship}

The term 'historical consciousness' is often misunderstood when used in African biblical scholarship. ${ }^{14}$ Because of the strong protest in this scholarship against the domination of the traditional historical-critical paradigms of interpretation, African scholars often respond negatively to any attempt at retaining 'historical consciousness' as part of our African hermeneutical framework..$^{15}$ Although Gerald West is right that there is great sensitivity in African biblical scholarship for the socio-cultural world(s) represented in the biblical texts, ${ }^{16}$ this sensitivity often does not translate into cognisance of, and appreciation for, the socio-cultural world(s) within which those texts originated and communicated. Dealing with the world(s) behind the biblical texts and taking into account the gradual growth of the biblical texts are normally associated in African biblical scholarship with traditional historical-critical enquiries, and are therefore often neglected. ${ }^{17}$ This neglect often stems from scepticism about whether those worlds behind the texts can be recovered or known at all. The fact that traditional (Western-oriented) historical-critical scholars often offer diverging - even contrasting - theories about the original contexts of the biblical texts deepens this scepticism. Admittedly, it is simply not possible to identify with absolute certainty those specific circumstances within which each and every biblical text originated and was edited or reformulated. However, biblical scholarship has advanced greatly in studying the broad historical periods and socio-historical circumstances which contributed to textual formation and reformulation. Differences of scholarly opinion about more specific historical indications should therefore not prevent African biblical scholarship from engaging with the world(s) behind the texts. ${ }^{18}$

\footnotetext{
14 See my further elaboration on this point in Jonker (2013).

15 See, for example, Masenya (ngwan'a Mphahlele) and Ramantswana (2012, 2015).

16 See again his statement in West (2008:47): "African biblical scholarship has a predilection for socio-historical textual analysis in dialogue with the socio-economic and religio-cultural realities of African contexts."

17 See also Meyer (2015).

18 Elsewhere I have made this point in the following way: "Although it often is not possible to know exactly the historical circumstances of every single text in the Bible, decades of historical scholarship have informed us about the broader dynamics of different historical periods in the history of ancient Israel and early Christianity. The kind of historical information needed for our task of seeing the analogies referred to above is not the meticulous historical constructions of past events that are often done in ancient historiography but rather the broader epochs as well as the dominating discourses of those epochs during which the literature of the Bible originated. It is, for example, important to take note of the discourses during and after the exilic period (the main period during which Hebrew Bible literature originated and was edited and redacted) as well as the discourses prompted by the Jesus event and the fall of Jerusalem in CE 70. The influence of empires; processes of identity negotiation; responses to changed sociocultural, sociopolitical, and socioreligious circumstances - all these formed the environments within which the biblical literature communicated. These are the circumstances within which biblical writers-as readers of their authoritative and transmitted traditions - engaged in acts of reinterpretation and reappropriation" (Jonker 2015a:299-300).
} 
My call for 'historical consciousness' is based in the belief that communication - in oral or written form - never takes place in a vacuum. Texts, therefore also biblical texts, are never written without having the commitment to communicate in very specific socio-historical circumstances. Texts, therefore also biblical texts, are never context-less (in the historical sense of the word). There is always a world-behind-a-text, whether the interpreter acknowledges it or not. Sometimes the socio-historical circumstances within which texts originate coincide with the socio-historical construction in the texts. However, this is rarely the case in textual communication. It is completely possible to construct a totally different socio-historical world in a text, with only traces (or even without any traces) of the socio-historical world within which the text originates and wants to communicate. But in order to get behind the rhetorical thrust (or, theological thrust, in the case of biblical interpretation) of ancient texts one cannot avoid relating the textual communication to its socio-historical setting of communication. ${ }^{19}$

In a previous contribution on why history matters in biblical interpretation (African, or otherwise), ${ }^{20}$ I came to the following conclusion:

The 'historical consciousness' that is implied here should ... not be confused with a longing for a past which is forever lost, or with an optimism that the intentions of the original authors can be reconstructed. Historical consciousness is rather the reader- or contextoriented appreciation of the contexts of textual production and of textual reception (from ancient times, throughout the ages, up to modern-day receptions in various and differing circumstances) (Jonker 2013:6).

My plea for 'historical consciousness' therefore has nothing to do with a positivistic understanding of 'history' or 'authorial intention', but is rather an attempt to show the analogies between ancient processes of reception, and modern-day processes of reception. In the contribution referred to here, ${ }^{21}$ I have tried to explain that textual production in ancient times was the resultant product of processes of contextual

19 See the following publication which explicates the role of 'historical consciousness' in Hans-Georg Gadamer's hermeneutics: Van Niekerk (2002). Van Niekerk concludes about Gadamer: "Gadamer's main contribution is to interpret historical consciousness in such a way that it does not yield to relativism and historicism, and that shows that, on the basis of our historical situatedness, we are beings that find meaning in the perpetual and progressive search for freedom and rationality" (2002: 240). Van Niekerk himself explains the concept 'historical consciousness' as follows: "By the term 'historical consciousness' I mean that which came to pass in the aftermath of Hegel's contribution to Western philosophy: a revolutionary understanding of the influence of time and history on our self-understanding and our understanding of the world, the realization that all knowledge is incomplete because it is situated in, is a function of, and is therefore made possible by a horizon of historically mediated meanings which constitutes the unavoidable platform from which we, via our interpretative existence, make our way through the world and history" (2002:235).

20 My call for historical consciousness in biblical interpretation is not only directed to African biblical hermeneutics, but to all reception-oriented interpretation that establishes a direct connection between the world(s) constructed in the biblical texts, and the contemporary context for which the interpretation is done. In earlier publications I have, for example, also directed this call to certain forms of intercultural biblical hermeneutics and feminist interpretations. See e.g. Jonker (2015b). 
reception of (oral or written) traditions of the past. Biblical texts bear witness to the processes of new appropriation of older traditions in ever-changing socio-historical circumstances over time.

Within the framework of such an understanding, I have concluded as follows:

I conclude that history matters in our interpretations because contextual reception is all that we have available! Interpretation without a historical dimension cannot be contextual; and interpretation without sensitivity to context cannot be historical. Contexts of reception of biblical literature span over many centuries. Some may prefer to explore the traces of the past in the biblical texts in order to relive and re-enact the past, and to figure out which questions stood behind the answers provided in the texts, knowing that they are doing these investigations from their own (post)modern contexts which influence their interpretations thoroughly. ${ }^{22}$ This mode of biblical interpretation will be highly beneficial to articulate the continuities and discontinuities with the biblical past in order to determine how they impact on their present and future. Others may prefer to explore the contextual contours of contemporary society and contemporary reading communities in order to help articulate with those communities their deepest needs and convictions. ${ }^{23}$ That mode of biblical interpretation will also be highly beneficial to articulating their continuities and discontinuities with the biblical past in order to determine how they impact on their present and future. History (whether ancient or contemporary) matters in order to grasp the full implications of context in biblical interpretation (Jonker 2013:6).

At this point I want to return to the preliminary assessment of the comparative paradigm in African biblical scholarship which I have made above. I have argued above that the comparative paradigm - as illustrated in a variety of African biblical interpretations - often establishes a direct relationship between the worlds constructed in the biblical texts, and the different African contexts for which the interpretations are made. Often, African biblical scholars do not take into account that the biblical texts are constructed realities that wanted to be in dialogue with those socio-historical circumstances within which they were written; that is, the historical context of communication is ignored or neglected. The constructed realities in the texts are taken as point of departure for the dialogue with different African contexts, rather than the contextual engagement of those constructed realities with the socio-historical circumstances of the time of textual formation. In short, the comparative paradigm in African biblical scholarship often falls prey to a lack of historical consciousness. Although there is an appreciation in the comparative paradigm for socio-historical constructions in the biblical texts that might resonate with the interpreters' own socio-historical circumstances, that appreciation still boils down to a treatment of the biblical texts as if they were context-less.

22 Gerald West would relate this to the interpretive interests of biblical scholarship.

23 Gerald West would relate this to the life interest of interpreters. 
When making this assessment of African biblical scholarship, one is of course always in danger of unjustified over-generalisation. ${ }^{24}$ African biblical scholarship is nowadays simply too diverse to make any generalisations. However, in the next section I will illustrate my point by referring to a few recent studies by African scholars which I consider representative of the direct comparative approach which I have identified above. The chosen studies are mere illustrations and are being discussed here for that exclusive purpose..$^{25}$ My using them as examples of the direct comparative approach does not suggest that their analyses are flawed, or that they do not make valuable contributions to biblical scholarship. All examples are studies on narrative texts from the Deuteronomistic History.

\section{Some African examples of the application of the comparative paradigm}

The first example is an African interpretation of the Solomon narrative. In a recent article Eraste Nyirimana from Rwanda (based as post-doctoral fellow at the University of KwaZulu-Natal) interpreted the Solomon narrative in 1 Kings 5:1-18 from a Rwandan perspective (Nyirimana, 2013). ${ }^{26}$ He summarises his argument as follows in the abstract of his article:

In a world that has become a global village some countries are seeing their sovereignty significantly curtailed because of the interest they represent for external powers. Small countries often see their stability jeopardised by interference of external powers interested in conflict. The present essay argues that external interests are part of the factors that jeopardised national unity in monarchic Israel. The article proposes a dialogical discussion

24 There are surely also many examples of African scholars who do not use a direct comparative approach, but who take the contexts of origin of the biblical texts as point of comparison. A very good example of this direction in African biblical scholarship is the response of Elelwani Farisani to the use of Ezra-Nehemiah in African theologies of reconstruction. Farisani criticised scholars such as Jesse Mugambi for not taking into account the ideological struggles behind the book Ezra-Nehemiah adequately. He therefore argued that one cannot directly link to the world constructed in the narrative of this book, but should first investigate which ideological and power struggles in the postexilic era formed the background to this narrative. Farisani articulated this best in his doctoral dissertation, but also took this line in some further publications. See Farisani (2002b, 2002a). Esias Meyer finds it surprising, however, that Farisani did not continue along this line of interpretation in subsequent studies, such as on 1 Kings 21 (see Farisani and Farisani (2004); Farisani (2005)). Meyer says: "I wonder why the same degree of criticism is not applied to the text of 1 Kings 21 . Why do we not hear anything about the political agenda of the authors of 1 Kings 21 ? It is no secret that the authors of these narratives were mostly pro-Judah and that, whoever the authors were, they clearly liked Southern kings most, especially reformers such as Hezekiah and Josiah ... I wonder whether we could really trust the authors of this text to provide us with a fair picture of the rule of the Omrides, or for that matter of any Northern king" (2015:6). See also Mtshiselwa's (2014) insightful response to Farisani's (and Nzimande's) studies on this text.

25 In his analysis of African biblical scholarship, Knut Holter has concentrated on completed dissertations by African scholars (see again Holter (2002)). One of the reasons for his choice was that African biblical scholarship was not well represented in scholarly journals during the period of his overview. However, my examples will come from recent articles published in Old Testament Essays, the journal of the Old Testament Society of South Africa (OTSSA), which has become a prominent vehicle for African biblical scholarship in recent years. 
between the socio-political context of Israel's monarchical period and the contemporary context in African countries. It contends that in Israel, like in many African countries, external interference has often been the factor determining the outcome of internal conflicts. Such interference aims more at promoting the interests of the intervening powers than it is rooted in a genuine concern for the powerless countries and their people. The discussion of the socio-political effects of foreign intervention in African countries, using the case of Rwanda as an example, is followed by an examination of foreign intervention in monarchical Israel which focuses on Hiram's involvement in Solomon's empire (Nyirimana 2013:172).

In the introduction to the article, the author further explains:

The present essay deliberately starts, not with the analysis of the selected text, but with the condition and experience of African people, who were subjected to domination and oppression by the colonial powers and continue to suffer marginalisation imposed by neocolonialism. The relation between Hiram and Solomon described in 1 Kings 5:1-18 is then scrutinised in the light of social, economic and political realities wrought by imperialistic domination, exploitation and oppression. The experience of colonialism and neocolonialism in Rwanda and in Africa in general guides the reading of the selected text with the aim of retrieving the silenced voice of the exploited people in Israel (Nyirimana 2013:173).

Nyirimana concludes the following from his analysis of the Solomon narrative:

This article has argued that Hiram of Tyre provided to Solomon's regime the kind of diplomatic and economic support that new colonial and imperialistic regimes continue to provide to some African unpopular regimes and for the same purpose. By doing so Hiram contributed to the social conflicts that culminated in the division of the Kingdom of Israel. The endemic problems of poverty, conflicts, and instability in Africa are not totally African, they have an international dimension. Any lasting solution to the complex African problems must consider this dimension" (Nyirimana 2013:193).

My problem with this approach is not that the analysis starts "with the condition and experience of African people, who were subjected to domination and oppression by the colonial powers and continue to suffer marginalisation imposed by neocolonialism", or that it ends by relating the text to a present-day reality on the African continent. My criticism is rather directed against the fact that the socio-political reality as constructed in narrative form in the text (namely, Hiram's relationship with Solomon) forms the point of comparison, and not the socio-political reality of Israel during the exile under imperial domination. In my opinion, there is great potential in this text for addressing the life interests of people in present-day Africa. However, this potential should be unlocked analogically, that is, via the socio-political context within which it was originally communicated, before relating it to present-day African realities. To realise that the story of Hiram's relationship with Solomon was (re-)told in a context of imperial oppression under the Babylonians would bring another dynamic to the interpretive potential of this narrative. The relationship of the exiled Israel with the 
Babylonian imperial master is addressed only indirectly. The narrative world of the relationship between Solomon and Hiram served the purpose of engaging in the discourses of the day in the real world of exile.

The second example is Yaw Adu-Gyamfi's analysis of Joshua 22 (Adu-Gyamfi 2013). The author starts his article with the following comments:

Africa has experienced civil wars and continues to experience them. Unfortunately, to stop them, we have spent resources that otherwise could have been used to improve the lives of the people. There is less talk about the prevention of future civil wars. The aim of this article is to show that civil wars can be prevented if careful steps are taken. The article uses Joshua 22:9-34 to investigate the process by which a potential civil war was averted to show that Africa can prevent civil war on the continent in a similar way (Adu-Gyamfi 2013:247).

Adu-Gyamfi indicates that there are mainly two reasons why the ancient text of the Bible is used in his enquiry:

First, the text deals with ethnic groups that misunderstood the attitude of the other, which generated an attempt to fight against brother ethnic groups ... Ethnicity is central to Africans and many of the civil wars on the continent are fought along ethnic lines. Secondly, Africans cherish the Bible as God's word, not only for Israel but also for them. For this reason, the Bible is the best book to use in appealing to Africans about any aspect of their beliefs and practices (Adu-Gyamfi 2013:247).

It is thus clear that the socio-political aspects of the narrative in Joshua 22 resonate with the author's own experiences on the African continent. Furthermore, the high view of the Bible held in many African contexts makes this the "best book" to appeal to.

In a first move in his article Adu-Gyamf then tries to establish "whether Joshua 22:9-34 describes actual events" (Adu-Gyamfi 2013:248). In doing so, the author takes studies into account that refer to the growth of the text, as well as to the differences in the Deuteronomistic and Priestly strands. However, after the discussion of those studies, he comes to the conclusion that "this essay is based on the understanding that Joshua 22:9-34 describes an actual traditional event in the history of ancient Israel. Thus it rejects the notion that Joshua 22:9-34 is a literary construct" (Adu-Gyamfi 2013:250). It seems that the author is of the opinion that the text can only be used for the benefit of his own African context if the historicity of the text can be established without doubt. It is explicitly denied that it is merely a literary construct. From this point of departure for the author's argument, it seems that there is no awareness of the fact that the historical reality reflected in the text is a constructed reality and does not necessarily coincide with a historical reality.

The further exegesis of the text consists of a verse-by-verse, or section-by-section discussion of textual features. The emphasis is on establishing the contents of the 
text as clearly as possible. In this way the narrative dynamic of the text is expounded very clearly and it leads to the application of the text in African contexts by means of the formulation of "Guidelines for African Ethnic Groups” (Adu-Gyamfi 2013:259). Three main guidelines are established from the exegetical process:

1. Understanding allegations: Uninvestigated allegations can lead to civil wars. To avoid conflict we need to understand what an allegation is ... When the Cisjordanian tribes heard the news, their first reaction was to go to war. But on second thought, they treated the news as an allegation that necessitates investigation. African ethnic groups should learn to take hearsay as allegation. Jumping to uninvestigated conclusions leads to unwarranted war.

2. The use of delegation: To find the truth of an allegation, a delegation is needed. A delegate is an elected or appointed group of people who serve as representatives with the task of finding the truth or falsity of an allegation. In our context, these people serve to mediate between factions. In Joshua 22, the task of the delegation was to inquire into the truth of what they heard, and the reason for it. A proper delegation is important if Africans want to avoid civil conflicts.

3. Dialogue: the means of conflict prevention: Most conflicts arise and escalate because of the unwillingness to engage into dialogue. Africans must resort to dialogue to avert conflicts. The western tribes resorted to dialogue based on communality. They saw the eastern tribes as brothers whose actions would affect them. Similarly, the western tribes saw that their action against the eastern tribes will affect them. They were even willing to compromise for the sake of peace; they were willing to share their land with their eastern brothers rather than allow a schism to take place (Adu-Gyamfi 2013:259-260).

The comparative paradigm is therefore established between the world constructed in the biblical text of Joshua 22 (which is accepted to reflect "an actual traditional event in the history of ancient Israel") and the socio-political reality on the African continent of ethnic tensions and civil wars.

The last example is the study of Alexander Abasili on Hannah's childlessness as narrated in 1 Samuel 1 (Abasili 2015). The author takes as his point of departure the realities on the African continent:"Polygyny (polygamy) is practiced in many parts of Africa. The emphasis placed on married men having [male] progeny, along with the presence and the deep rootedness of the Islamic religion in many parts of Africa are among the reasons that have consolidated polygyny in Africa ... Among African Christians and non-Muslims, one of the important roles of polygyny today is the provision of a way-out of childlessness (barrenness) and/or 'sonlessness' to a man when his wife is childless. In such a situation, the husband of the childless woman marries another 'fruitful' wife and guarantees the continuity of his lineage. But what becomes of the childless wife in such a polygamous marriage? What is the implication and consequence of polygyny for their ordeal of childlessness?" (Abasili 2015:581-582). The author then employs a contextual reading of 1 Samuel 1 and "uses the childless ordeal of Hannah (in both descriptive and prescriptive ways) 
to mirror the plight of childless women in some polygamous African families" (Abasili 2015:582).

The author explains his methodological choice as follows:

Although one acknowledges the importance of diachronic readings focusing on these broader significance of the 1 Sam 1 in the $\mathrm{HB}$, this article has opted for synchronic literary reading of the text (1 Sam 1 ) with emphasis on the silent ordeal of Hannah caused by her childlessness and its significance for women in similar predicament and contexts. In this connection, this article uses narrative criticism as its exegetical method, with particular focus on the point-of-view of Hannah in 1 Sam 1 (Abasili 2015:583).

However, the paragraph preceding this explanation indicates that the author most probably has a limited understanding of what diachronic analysis entails. He explains the "broader significance" of 1 Samuel 1 in the following way: "One is aware that the pericope of 1 Sam 1, in the larger biblical context, is not just the story of the devout barren woman - Hannah - whose prayer for a son is heard by YHWH. The pericope has a deeper significance. For instance, it inaugurates a decisive era in the history of Israel - the era of Monarchy. Thus, Samuel eventually became the 'king maker' by anointing both Saul and David - the first kings of Israel. In addition, 1 Sam 1 serves as a transition from judgeship to the new era of kingship in Israel" (Abasili 2015:583). The aspects referred to in this paragraph are actually also synchronic features of the text. They rather indicate that 1 Samuel 1 is embedded in a wider literary context, instead of referring to diachronic aspects of the text's growth or socio-historical context.

Abasili's study concludes after the analysis by highlighting certain "contextual implications of Hannah's ordeal of childlessness" (Abasili 2015:600). Three main themes are mentioned:

1. Silent Suffering of Childless (or Barren) Women in Patriarchal Polygynous Families ... Hannah's agony of childlessness in patriarchal Hebrew society resonates with the agony of women in similar predicaments in some African cultures. The agony of such women questions the fairness of defining a woman's marital success by her fecundity ... In the same vein, child bearing should not be used as a yardstick for defining a successful marriage in patriarchal African societies. It is reductionist, unfair and unacceptable.

2. Polygyny as a Solution to Childlessness or Barrenness is Questionable: ... Clearly, from a childless woman's perspective, polygyny as a solution to childlessness is questionable and unacceptable. It provides a lopsided cultural solution to childlessness in patriarchal societies. Polygyny solves the childless problem of the male gender but only aggravates the childless woman's suffering and agony. Since the husband of such a woman is not childless, he naturally cannot fully understand the deep agony of his wife's childlessness and thus cannot adequately empathise with her. Thus, men like Elkanah who resolve their childlessness through polygamy are prevented from grasping the depth of their wife's agony of childlessness. Against this backdrop, it is not unreasonable to say that Hannah's situation would have been slightly better in a monogamous family because the burden of childlessness will be carried equally by the 'childless couple' and she may not feel as lonely and isolated ... 
3. The Preference for Male Children is Questionable: For those childless African women living in contexts where 'sonlessness' is almost treated as childlessness, Hannah's request for a son is understandable. In Igbo land, for instance, only a male child has the right to inherit the parents' assets. Moreover, the patriarchal Igbo culture permits that only the male child is capable of perpetuating his father's lineage. For these reasons having a male child is a sine qua non. It is also the duty of a male child, among the traditionalists, to ensure a fitting burial for his father and pave the way for his reception into the prestigious group of 'family ancestors.' It is, therefore, not surprising that having a male child has a social prestige attached to it. Despite the value of these explanations in clarifying the role of a male child in such a patriarchal society, they cannot excuse the unjust treatment of female child in those contexts. Certainly such a lop-sided preference for a male child or children and discrimination against a girl child or children is unfair and unacceptable (Abasili 2015:600-602).

This interpretation never considers what this narrative could have meant in the exilic context within which the Samuel narrative most probably was finalised as part of the Deuteronomistic History. The original context of reception of this text therefore played no role in the modern-day appropriation of the narrative dynamics.

In all three examples discussed in this section a comparative approach is used to relate the socio-cultural or socio-political conditions constructed in narrative form in the biblical texts to contemporary African socio-cultural and socio-political conditions, without considering the socio-political conditions behind the biblical texts. They all illustrate what I have called a direct comparative strategy. In the following section I will propose that an analogical basis for the comparative paradigm in African biblical hermeneutics will be a more responsible and accountable way of giving expression to the ethics of contextual integrity (as set out above).

\section{Towards an analogical hermeneutics}

Within the context of discussions about intercultural biblical hermeneutics I have advanced the following: "I am proposing an analogical mode for facilitating the interculturality between ancient writer(s) and contemporary reader(s). The analogy proposed here is not an analogy between the historical circumstances and contemporary circumstances but rather between the dynamics of appropriation of the text in ancient versus contemporary contexts" (Jonker 2015a:299). This analogical mode holds - at least in my opinion - great potential for deepening our discussions on the comparative paradigm in African biblical hermeneutics as well.

Analogies are constituted on the basis of continuities and discontinuities. In my previous contribution on analogical hermeneutics I have explained this as follows:

There is great discontinuity between the historical and cultural environments in which the biblical texts originated and the environments in which contemporary readers appropriate these texts ... But there is also continuity between then and now. Continuity exists between the dynamics of engaging with a contemporary cultural environment in light of transmitted (oral or written) traditions-then and now. Contemporary readers of the Bible have a good 
understanding of the necessity of appropriating the authoritative texts of the Bible for contemporary problematic societal issues. In this respect, they are performing the same act of reinterpretation as their ancient counterparts who brought about the biblical texts. Those authors, editors and redactors behind the texts felt the need to respond to their contemporary life contexts through engagement with authoritative transmitted traditions. Their production of biblical texts is the result of processes of appropriation that are analogical to contemporary interpretations of those texts (Jonker 2015a:299).

Although the introduction of the concept 'analogy' into biblical hermeneutics, and particularly into African biblical hermeneutics, may seem to be novel, the issue of analogical thinking/talking is of course very old in philosophical and theological hermeneutics respectively. In theology the issue at stake is: "How is it possible to use human language to talk about God?” (White 2010:xi). It is acknowledged that our human talking about God can only be analogical; that is, the mindset of the human environment is used to talk about God who is the Infinite and Un-describable. ${ }^{27}$ The basic structure of analogical thinking, namely 'a is to b as c is to d' ( $a: b: c: d)$, already stems from Classical Greek mathematics. The analogy is established between two relationships. In the case of theological hermeneutics it is imagined that human beings stand in relationship to reality analogically to how God stands in relationship to reality.

My suggestion of analogical thinking in African biblical hermeneutics works somewhat differently from the above (simplified) description of theological hermeneutics, but still proceeds from the understanding of analogy as the relationship between relationships. As explained above already, I see an analogical relationship between the reception of authoritative traditions in past historical circumstances and the reception of authoritative traditions in modern-day historical circumstances. Or, to put it differently: the dynamic of appropriation of authoritative traditions in biblical times (as witnessed in biblical writings) is analogical to the dynamic of appropriation of authoritative traditions in our own contexts (as witnessed in our interpretations of biblical writings).

This implies the following:

Information on the world behind the text is therefore needed in order to understand something of the dynamic reception and reinterpretation that brought about these biblical discourses. The retrieval of historical information is therefore not an aim in itself but rather an attempt to grasp something of the dynamic of appropriation that lies behind the text (Jonker 2015a: 299).

Analogical biblical hermeneutics surely functions within the comparative paradigm which has been identified as the most prominent framework of understanding in

The often-quoted authority in theological hermeneutics is David Tracy. See Tracy (1981). See the following publication which represents a reception of Tracy's views in the South African context: Conradie (1992). See also Van Niekerk (1983). 
African biblical scholarship. Analogical interpretation departs from the conviction that biblical texts were intended to be appropriated by their immediate readership. It therefore accepts that biblical interpretation can never be detached scholarship, and can never be done merely as 'context-less' exercise. African biblical hermeneutics is therefore right in its overt insistence that life interests, and not only interpretive interests, drive our biblical interpretation. Analogical biblical interpretation admits that the act of appropriation of biblical texts of necessity involves the acknowledgement that the realities and experiences of the biblical writers can be compared to our modern-day realities and experiences.

However, I have indicated above that it would be problematic to draw a direct relationship between biblical texts and modern-day realities, without taking the original acts of appropriation into account. The analogy of relationships is therefore constituted between the life interests of the faith communities of biblical times and their appropriations of earlier authoritative traditions (as witnessed in the resultant biblical texts), on the one hand, and the life interests of modern-day faith communities (in Africa, or elsewhere) and our appropriations of earlier authoritative traditions (such as embodied in the biblical texts), on the other.

Gerald West has rightly indicated that an interest in socio-cultural aspects often creates the connecting point between biblical texts and modern-day contexts in African biblical scholarship. This is surely true. However, as I have indicated above, this strategy often works directly, relating the socio-cultural world constructed in the text to the socio-cultural environments in the contemporary African context. An analogical hermeneutic is therefore not established. Rather, the text with the socio-cultural values reflected in it, is taken out of its original socio-historical setting and transplanted into the contemporary African setting (where those socio-cultural values find resonance). With this direct strategy the dynamic of the original acts of appropriation in biblical times is lost.

With reference again to some of the example interpretations that were discussed in the previous section: If I were to select a text from the Solomon narrative in the biblical book of Kings for interpretation in an African context, I would be confronted with a narrative about political power and international relations in the early monarchy of Ancient Israel. Some of the events or values from this narrative might appeal to me in my context, where political power and international relations are also undeniable realities, and it might be a natural interpretive step to take to relate the political values from the Bible to my own reality. However, such a direct interpretive strategy will neglect one very important issue, namely that the political world constructed in the narrative is not the political world of the time of origin and finalisation of the Deuteronomistic History of which the book of Kings forms part. Although Old Testament scholars have moved away from Martin Noth's original theory of the Deuteronomistic History, there is still wide consensus among scholars that the majority of the literature in Samuel-Kings was merged into a literary 
work during the time of the Babylonian exile. The life struggle of the time was the disillusionment caused by losing all political, social and cultic power to an imperial master. The time within which the Solomon narrative is told was therefore not a time of successful kingship, but rather a time when the exiles did not have their own king and were subjugated to imperial master's. The Deuteronomistic literature wanted to engage theologically in a discourse on what went wrong in ancient Israel that resulted in them losing their land. The construction of the history of ancient Israel in the Deuteronomistic corpus served the purpose of explaining that they had lost the land because everybody did what was right in his own eyes and because their kings did not do what was right in the eyes of Yahweh.

An analogical hermeneutic will take this dynamic seriously. The Solomon narrative forms part of a constructed biblical narrative which did not want to portray successful kingship, but rather reflect on the failure of kingship. An analogical hermeneutic will therefore be interested in how the Solomon narrative, with all the constructed narrative details of his political endeavours and relationships with other international powers, formed part of the theological reflection during the exilic period on the catastrophe of losing their land to imperial forces. The dynamics of that ancient engagement with the life interests of the exilic period will then form the point of comparison with present-day African realities. The dynamic of interpretation of the Solomon narrative in this present-day context will be analogically shaped by its engagement in the ancient context of the exile.

\section{Conclusion}

In this contribution, I have continued the process of interrogating the comparative paradigm in African biblical scholarship. I have argued that many African scholars utilise a direct comparative paradigm in their interpretations of the Old Testament for and within the African context. Although one will never be able to generalise, this is (still) a strong predilection in African biblical scholarship. I have proposed that an analogical comparative paradigm might do greater justice to our interpretive interests, while not neglecting the life interests that drive our interpretations. 


\section{Bibliography}

Abasili, A I. 2015. Hannah’s Ordeal of Childlessness: Interpreting 1 Samuel 1 through the Prism of a Childless African Woman in a Polygynous Family, Old Testament Essays, 28(3), 581-605. https://doi.org/10.17159/23123621/2015/v28n3a3

Adu-Gyamfi, Y. 2013. Prevention of civil war in Joshua 22: Guidelines for African ethnic groups, Old Testament Essays, 26(2), 247-262.

Ahiamadu, A. 2007. Re-defining stewardship: a Nigerian perspective on accountable and responsible land ownership according to the Old Testament. Thesis, Stellenbosch: Stellenbosch University, available at: http://scholar.sun.ac.za/ handle/10019.1/1251 (Retrieved 19 May 2016).

Audu Makama, B. 2016. The abuse of power and sexual violence: a close reading of 2 Samuel 11 against the background of Boko Haram Atrocities in Nigeria, Thesis, Stellenbosch: Stellenbosch University, available at: http://scholar.sun.ac.za/ handle/10019.1/98513 (Retrieved 19 May 2016).
Cezula, N S. 2006. Theocracy: reflections of the relationship between God and King in Samuel-Kings and Chronicles, Thesis, Stellenbosch: Stellenbosch University, available at: http://scholar.sun.ac.za/ handle/10019.1/3479 (Retrieved 19 May 2016).

Cezula, N S. 2013. Identity formation and community solidarity: second temple historiographies in discourse with (South) African theologies of reconstruction, Thesis, Stellenbosch: Stellenbosch University, available at: http://scholar.sun.ac.za/ handle/10019.1/80038 (Retrieved 14 April 2015).

Conradie, E M. 1992. Teologie en pluralisme: 'n Kritiese analise van David Tracy se voorstel van 'n 'analogiese verbeelding', doctoral dissertation, Stellenbosch: Universiteit Stellenbosch.

De Wit, H and West, G O (eds.). 2008. African and European Readers of the Bible in Dialogue, in Quest Of a Shared Meaning, Leiden: Brill.

Farisani, E B. 2002a. The ideologically biased use of Ezra-Nehemiah in a quest for an African theology of reconstruction, Old Testament Essays, 15(3), 628-646. 
Farisani, E B. 2002b. The use of Ezra-Nehemiah in a quest for a theology of renewal, transformation and reconstruction, doctoral dissertation Pietermaritzburg: University of Natal.

Farisani, E B. 2005. A sociological reading of the confrontation between Ahab and Elijah in 1 Kings 21:1-29, Old Testament Essays, 18(1), 47-60.

Farisani, E B and Farisani, D. 2004. The abuse of the administration of justice in 1 Kings 21:1-29 and its significance for our South African context, Old Testament Essays, 17(3), 389-403.

Holter, K. 1996. Tropical Africa and the Old Testament: a select and annotated bibliography, Oslo, Norway: University of Oslo, Faculty of Theology (Bibliography Series, 6).

Holter, K. 2000. Yahweh in Africa: essays on Africa and the Old Testament, New York: Peter Lang (Bible and Theology in Africa, 1).

Holter, K. 2002. Old Testament research for Africa: A critical analysis and annotated bibliography of African Old Testament dissertations, 1967-2000, New York: Peter Lang (Bible and Theology in Africa, 3).

Holter, K (ed.). 2006. Let my people stay! Researching the Old Testament in Africa, Nairobi: Acton.
Holter, K. 2008. Contextualised Old Testament scholarship in Africa, Nairobi: Acton Publishers.

Jonker, L C. 1997. Bridging the gap between Bible readers and 'professional' exegetes, Old Testament Essays, 10(1), 69-83.

Jonker, L C. 1999. 'Communities of faith as texts in the process of biblical interpretation, Skrif en kerk, 20(1), 79-92.

Jonker, L C. 2001. Towards a Communal Approach for Reading the Bible in Africa, in M N Getui, K Holter and $\mathrm{V}$ Zinkuratire (eds.), Interpreting the Old Testament in Africa : papers from the International Symposium on Africa and the Old Testament in Nairobi, October 1999, New York: Peter Lang, 77-88.

Jonker, L C. 2005. 'Contextuality' in (South) African exegesis: Reflections on the communality of our exegetical methodologies, Old Testament Essays, 18(3), 637-650.

Jonker, L C. 2007. Reading the Pentateuch with both eyes open: on reading biblical texts multidimensionally, in J Le Roux and E Otto (eds.), South African perspectives on the Pentateuch between Synchrony and Diachrony, London: T \& T Clark, 90-107. 
Jonker, L C. 2008. Living in different worlds simultaneously or: a plea for contextual integrity, in $\mathrm{H}$ de Wit and G OWest (eds.), African and European readers of the Bible in dialogue, Leiden: Brill, 107-119. https://doi.org/10.1163/ ej.9789004166561.i-434.44

Jonker, L C. 2010. The Global Context and its Consequences for Old Testament Interpretation, in K Holter and L C Jonker (eds.), Global Hermeneutics? Reflections and Consequences, Atlanta: Society of Biblical Literature (International Voices in Biblical Studies, 1), 47-56. Available at: http://ivbs.sbl-site. org/ uploads/JONKER 1.PDF.

Jonker, L C. 2015a. From Adequate Biblical Interpretation to Transformative Intercultural Hermeneutics, Chronicling a Personal Journey, Elkhart: Institute of Mennonite Studies (Intercultural Biblical Hermeneutics Series, 3).

Jonker, L C. 2015b. Of Writers and Readers: Facilitating the Intercultural Encounter between (Ancient) Texts and (Contemporary) Readers, in D S Schipani, M Brinkman and H Snoek (eds.), New Perspectives on Intercultural Bible Reading: Hermeneutical Explorations in Honor of Hans de Wit, Elkhart/Amsterdam: Institute of Mennonite Studies/Vrije Universiteit Amsterdam, 239-256.
Juma, D C. 2014. Encountering the female voice in the Song of Songs: reading the Song of Songs for the dignity of Kenyan women, Thesis, Stellenbosch: Stellenbosch University, available at: http://scholar.sun.ac.za/ handle/10019.1/95821 (Retrieved 19 May 2016).

Masenya (ngwan'a Mphahlele), M and Ramantswana, H. 2012. Anything new under the sun of South African Old Testament scholarship? African Qoheleths' review of OTE 1994 - 2010, Old Testament Essays, 25(3), 598-637.

Masenya (ngwan'a Mphahlele), M \& Ramantswana, H. 2015. Anything new under the sun of African Biblical Hermeneutics in South African Old Testament Scholarship? Incarnation, death and resurrection of the Word in Africa, Verbum et Ecclesia, 36(1), 1-12.

Meyer, E E. 2015. South African Old Testament criticism: Squeezed between an ancient text and contemporary contexts, HTS Theological Studies, 71(3), 1-7.

Mngqibisa, O T. 2006. The relationship of humankind and nature according to Psalm 8, Thesis. Stellenbosch: Stellenbosch University, available at: http://scholar.sun.ac.za/ handle/10019.1/1279 (Retrieved 19 May 2016). 
Mtshiselwa, N. 2014. A Re-Reading of 1 Kings 21:1-29 and Jehu's Revolution in Dialogue with Farisani and Nzimande:

Negotiating Socio-economic Redress in South Africa, Old Testament Essays, 27(1), 205-230.

Mugambi, J N K. 2003. 'African and Africanist scholarship', Bulletin of Old Testament Studies in Africa, 14, 9-12.

Nkhonjera, L L S 2015. Esther as the new Moses: deliverance motifs in the Book of Esther, Thesis, Stellenbosch: Stellenbosch University, available at: http://scholar.sun.ac.za/ handle/10019.1/98067 (Retrieved 19 May 2016).

Nyirimana, E. 2010 The tribal dimension in the division of the kingdom of Israel: a contextual study of 1 Kings 12: 1-24 from the perspective of the struggle for national unity in Rwanda, doctoral dissertation, Pietermaritzburg: University of KwaZulu-Natal.

Nyirimana, E. 2011. Patrimonialism in the causes of the division of the kingdom in Israel: A reading of the division narrative from the perspective of the Rwandan context of social conflict, Old Testament Essays, 24(3), 708-730.
Nyirimana, E. 2013. Hiram's relations with Solomon viewed from the perspective of the relation between Africa and foreign powers: a postcolonial reading of 1 Kings 5:1-18, Old Testament Essays, 26(1), 172-195.

Nyirimana, E. 2015. Land Rights, Landlessness and Political Unrest in the United Monarchy of Israel: Reading 1 Samuel 22:1-8 from the perspective of struggle for land ownership in South Africa, Scriptura, 113, 1-16. https://doi.org/10.7833/113-0-912

Olojede, F O. 2011. Unsung heroines of the Hebrew Bible: a contextual theological reading from the perspective of woman wisdom, Thesis, Stellenbosch: Stellenbosch University, Available at: http://scholar. sun.ac.za/handle/10019.1/6493 (Retrieved 19 May 2016).

Tracy, D. 1981. The Analogical Imagination: Christian Theology and the Culture of Pluralism, New York: Crossroads.

Ukpong, J S. 2000. Developments in Biblical Interpretation in Africa: Historical and Hermeneutical Directions, in G O West and M W Dube Shomanah (eds.), The Bible in Africa: Transactions, Trajectories, and Trends, Leiden: Brill, 11-28. 
Van Niekerk, A A. 1983. Analogie en teologie: 'n Krities-wysgerige ondersoek van die funksie van analogie-teorieë omtrent teologiese taalgebruik, doctoral dissertation, Stellenbosch: Stellenbosch University.

Van Niekerk, A A. 2002. Hermeneutics and historical consciousness: An appraisal of the contribution of Hans-Georg Gadamer, South African Journal of Philosophy, 21(4), 228-241. https://doi.org/10.4314/sajpem. v21i4.31349

West, G O. 1995. Biblical hermeneutics of liberation: modes of reading the Bible in the South African context. 2nd Edition, Pietermaritzburg; Maryknoll, N.Y.: Cluster Publications; Orbis Books.

West, G O. 2002a. Indigenous exegesis: exploring the interface between missionary methods and the rhetorical rhythms of Africa - locating local reading resources in the academy', Neotestamentica, 36(1-2), 147-162.
West, G O. 2002b. Unpacking the Package that is the Bible in African Biblical Scholarship, in J S Ukpong (ed.), Reading the Bible in the Global Village: Cape Town, Atlanta: Society of Biblical Literature (Global Perspectives on Biblical Scholarship, 3), 65-94.

West, G O. 2005. Shifting perspectives on the comparative paradigm in (South) African biblical scholarship, Religion and Theology, 12(1), 48-72. https: / / doi. org $/ 10.1163 / 157430105$ X00121

West, G O. 2008. Interrogating the comparative paradigm in African biblical scholarship, in $\mathrm{H}$ de Wit and G O West (eds.), African and European readers of the Bible in dialogue, Leiden: Brill, 37-64. https://doi.org/10.1163/ ej.9789004166561.i-434.22

West, G O \& Dube Shomanah, M W (eds.). 2000. The Bible in Africa: Transactions, Trajectories, and Trends, Leiden: Brill.

White, R M. 2010. Talking about God: the concept of analogy and the problem of religious language, Farnham: Ashgate. 


\section{Chapter 5 \\ Experiencing the Fourth Gospel}

\section{Towards a methodology of biblical drama criticism}

\section{Cornelia van Deventer}

\section{"The whole drama of God's relationship with humanity is played out in the FG, with Jesus as the central character". \\ (Johnson 1999:53)}

\section{John as drama?}

This chapter begins with the assumption that the Fourth Gospel can be approached as a drama and wishes to briefly unpack the experimental methodology with which to analyse it accordingly. Various scholars have remarked that the Fourth Gospel contains in itself a variety of genre possibilities. ${ }^{2}$ Although categorised as gospel, the form in which the Gospel is presented seems to borrow from a variety of literary types and genres such as ancient histories, biographies, epics and dramas (Brant 2011:12). ${ }^{3}$ The possibility of reading, or experiencing ${ }^{4}$ John as a drama has already been explored by some scholars, but the development of an appropriate exegetical methodology still remains to be undertaken.

\footnotetext{
1 This chapter is a condensed version of Chapter 3 (John as Drama) of my unpublished doctoral dissertation, "Embracing Vulnerability: A Drama Analysis of the Johannine Prologue and Crucifixion Scenes", in which I appropriate biblical drama criticism for an analysis of the Johannine prologue (1:1-18) and two scenes around Jesus' crucifixion (18:28-19:16; 19:17-30).

2 Larsen (2015a:17) refers to the Gospel of John as a "genre mosaic", whereas Tovey (1997:209) speaks of a "spectrum of genres".

$3 \quad$ Windisch (1923:61) argues that the Fourth Gospel lies somewhere between a gospel of the synoptic type, a drama and a tragedy.

$4 \quad$ I will be using the word 'experience', since it encapsulates more than the mere act of reading
} 
Sommerstein (2002:1) defines a drama as "an enactment of a story ... in which each performer, or group of performers, represents ... a person or persons in the framework of the story, speaking or singing the words of a more or less fixed text". ${ }^{5}$ In the light of the layout of ancient public buildings, it is apparent that the most important public activities in the Greco-Roman world would have been sports events, theatre and musical performance (Barr 2002:37). Drama, therefore, had a significant role to play in the ancient Greco-Roman culture and lifestyle. Moreover, the ancient drama served as far more than mere entertainment, ${ }^{6}$ but acted as a reminder of the heritage of the past (Sommerstein 2002:3), aided in honouring the gods (Green 1994:170), provided commentary on social, religious and political life and circumstances (Barr 2002:37), and portrayed patterns in the god-human relationship (Mastronarde 2005:321).

The possibility of reading the Fourth Gospel as a drama is not a new one. ${ }^{7}$ Probably the biggest contribution to this reading methodology comes from Jo-Ann Brant in her book Dialogue and Drama. Elements of Greek Tragedy in the Fourth Gospel (2004). ${ }^{8}$ Moreover, many other scholars use the description 'dramatic' when referring to the content and style of the Fourth Gospel (Attridge 2015:34; Smalley 1978:192). ${ }^{9}$ Dramatic force is created by conflict which arises in the prologue and develops, especially through the dialogue, towards the ultimate climax. Moreover, the action-focused nature (Single Redman 2013:61), vivid use of (especially dramatic) irony (Attridge 2015:36), detailed characterisation (Hitchcock 1993 [1923]:24), and the inclusion of the prologue, which resembles the hypothesis of the ancient Greek drama (Attridge 2015:35), add dramatic force to the Fourth Gospel. ${ }^{10}$

5 The drama, as we have it today, probably has its origins in the $6^{\text {th }}$ century BC in Ancient Greece (Carver 2009:3; Sommerstein 2002:2). The first dramas were mostly categorised as tragedy, but the art of comedy also developed and became increasingly nuanced in the course of time (Sommerstein 2002:3). Throughout the Middle Ages there was the liturgical drama, which consisted of performances from the Christian Bible, followed by the development of dramatic performances based on historical events and later mysteries (Carver 2009:8). The Renaissance saw the move from outside venues to constructed theatre buildings as well as fictional and secular stories, especially tragedy and love stories, which became increasingly popular (2009:9).

6 Littlewood (1952:9) refers to the ancient Greek theatre as a "temple of dramatic art".

7 One of the first scholars to explore this art was Hitchcock with his exploratory article "Is the Fourth Gospel a Drama?" (1923), in which he argued that the Gospel adheres to the standard "canons of the drama" (1923:15). Other scholars who have explored the Fourth Gospel as a drama include Smalley (1978:192-203), Attridge (2015) and Conway (2015).

8 Brant (2004:4) confidently uses the word "drama" for the Gospel since it portrays "a story fraught with tension between characters with a conflict that arises at its beginning and builds to a crisis", and therefore approaches the text with a lens of ancient Greek tragedy (2004:3)

9 According to Smalley (1978:192-203), the author of John appears like "an artist with a strong feeling for drama". Among the four Gospel accounts, that of John can be regarded as having the closest to a dramatic structure (Brant 2011:13) and character (Windisch 1923:62).

10 Other dramatic elements include the 'delayed exit', where an announced action would be interrupted by dialogue, often occurring when a character is awaiting death (Attridge 2015:37), and the element of recognition (anagnorisis) and misrecognition of the identity of the hero or protagonist (2015:38). 
Some scholars, such as Hitchcock (1993 [1923]:15), even attribute the author's natural dramatic sense to possible experiences and interactions with individuals who had an awareness of the aesthetic practices of the time. Brant (2004:256) argues along the same lines by speculating that the author of the Fourth Gospel possibly drew upon many established methods and elements of ancient Greek drama. However, whether it was the intention of the author to incorporate elements of drama into the Fourth Gospel, or whether the resemblances are purely coincidental, the aim in this chapter of approaching the Fourth Gospel as a drama is to facilitate an imaginative and creative reliving of the text, in which the reader becomes an audience member, experiencing the happenings of the Johannine drama as if it were happening in front of them (Brant 2004:3).

\section{Drama criticism in the hermeneutical discourse}

As the study of the Fourth Gospel as drama is becoming increasingly popular among scholars (Cummins 2008:65), it is imperative to attempt to identify and define the parameters for a methodology with which to approach it. Scholars such as Tom Boomershine, Joanna Dewey, David Rhoads and Holly Hearon have addressed the general lack of attention to the oral/aural nature of biblical texts through the experimental avenue referred to as biblical performance criticism, which approaches biblical texts as witnesses which were composed to be read out loud and even performed in front of faith communities (Maxey 2012:1). ${ }^{11}$ Biblical performance criticism is described by Rhoads (2012:26) as "an effort to recover the oral performative nature of biblical materials". Rather than being a methodology, such criticism essentially represents a "paradigm shift from print medium to oral medium”. This paradigm shift paves the way for a new type of criticism in which the Gospel accounts are not simply regarded as narratives to be read, but dramas to be experienced.

Although such a methodological approach allows for the actual performance of a text (Rhoads 2009:89), it can also be appropriated to provide an imaginative reconstruction of a hypothetical dramatic performance of the text (2009:94). Such a reconstruction would include various dimensions such as probable sights, sounds, smells and feelings encapsulated in the text and probable historical settings. Moreover, an exploration of the possible reactions of the hypothetical audience to the drama is essential throughout the analysis. With this in mind, it is clear that drama criticism functions as a hybrid methodology, drawing from socio-scientific as well as reader-response criticism and reception theory. ${ }^{12}$ Moreover, since drama is one of many expressions of narrative (Thatcher 2008:22), the existing exegetical

\footnotetext{
11 Rhoads (2009:88) laments that there is a gap in NT studies, namely addressing "the oral/aural events in which early Christian writings were performed before a communal audience".

12 Reception theory seeks to explore the possible ways in which ancient audiences could have responded to a text (Rhoads 1999:273).
} 
methodology of narrative criticism serves as a foundation for drama analysis, enriched by the art of theatre criticism. ${ }^{13}$

In the field of theatre or drama, the date of composition of a text does not determine or limit the date of its performance and ancient texts are regularly performed in the $21^{\text {st }}$ century and evaluated through the lens of modern theatre criticism. Although the ancient audiences of the Johannine drama found themselves in a context of performances of ancient Greek drama, elements from modern drama can be used to imagine the text acted out. ${ }^{14}$ However, Bradby, Thomas and Pickering (1983:224) emphasise that, even though an older drama can be performed in modern theatre, theatre criticism at least has to take note of the social conditions and contexts within which the drama was composed..$^{15}$ Theatre criticism seeks to explore all things on stage, including settings and stage layout, atmosphere and lighting, sound, wardrobe, characterisation, text and dialogue, and the socio-historical world implicit in the dialogue (White 2001:13-24).

\section{Towards a methodology}

\section{Classifying the drama: genre}

To help clarify the imaginative response, the type of drama or genre needs to be identified. The genre of a drama can be defined as the "category of artistic composition characterised by similarities in form, style, or subject matter” (Carver 2009:444). The mood and message of the play will be influenced by its genre. ${ }^{16}$ Although the Fourth Gospel, when considered as biblical material, does fall within the genre of gospel, the art of drama also contains within itself various genre possibilities. ${ }^{17}$

13 Even though a drama and a narrative differ in technical terms, narrative is an overarching term which describes any literary work that tells a story (Powell 1990:23). Narrative criticism as methodology approaches the text with insights from the field of modern literary criticism (Powell 2010:240) and explores texts in view of their poetic function (Powell 1990:8). Theatre criticism, in contrast to narrative criticism, does not simply consider the text, but considers the text acted out. This means that, while the literary features within the text are important, non-literary features beyond the text are also essential in performance.

14 Carver (2009:4) argues that "much of what we still do today is based on the Greek theatre" and that the difference between ancient and modern drama is not that great. The use of modern criteria applied to ancient texts is not new to biblical studies (cf. Powell 2010:240). Moreover, in the art of drama, any text, regardless how old, can be performed in a modern theatre (Carver 2009:26).

15 This knowledge is of great help, especially when elements such as settings and characterisation are considered.

16 According to Rhoads (1999:275), the identification of the genre "helps to identify ... the social ethos, the issues being dealt with, and the expectations that an audience brings to a story"

17 Carver (2009:20) identifies seven main genres in theatre. The first is comedy, which refers to a drama containing light themes, humour and a happy ending. Building on that, the romantic comedy, which portrays a romantic affiliation between characters using the features of comedy, is a second option. The third option is that of fantasy, which refers to plays set "in another realm". A fourth option is the farce, which can be defined as extreme comedy, often over-animated and stereotypical. Another option is the melodrama, which is a "sentimental drama similar in themes to daytime soap operas". 
Moreover, types of literature within the drama, such as the use of prose or poetry, also need to be identified and discussed. This will aid the interpreter to anticipate the mood that the director of the drama wishes to create among its audience.

\section{Director (implied author)}

Since an audience of a drama does not necessarily have access to information regarding the historical author (Powell 1990:19; Tovey 1997:46), the hypothetical author known as the implied author or director will be used in drama analysis. This director provides the perspective from which the drama seems to be portrayed (Powell 2010:241) and serves as the party establishing the norms of the performance (Tovey 1997:46). In the art of drama the author in effect hands over the script to the director, who will interpret it by making choices in terms of what will be portrayed, as well as how it will be portrayed (Kreitzer 1993:16). ${ }^{18}$ The choices of the director determine the specific rhetorical effect on the audience of the drama.

\section{The audience}

In any drama or play the two-way communication between the characters and the audience runs throughout the performance. Both audience and actors feed off one another for energy, and respond to one another in various ways (Shiner 2009:60). The audience is a key element in the exploration of the possible rhetorical effect of the drama, since their (probable) reactions underline elements of shock, relief, humour, etc. Ancient performers were often evaluated by the effect (or lack of effect) that they had on their audience members, which would have included the stirring of compassion and affection for protagonists, and ill will towards antagonists (Shiner 2009:58). The audience would respond to the drama by cheering and jeering, clapping, weeping, gasping, leaping up from their seats, and even rushing to the stage in pure excitement (2009:60). Moreover, audiences were constantly looking for connections between the drama and their own situations (2009:61).

In order to explore the possible rhetorical effects of the drama on its audience, the probable reactions of the hypothetical audience need to be imagined on the basis of the socio-historical information that we have to our disposal (Rhoads 2009:90). ${ }^{19}$ In

\footnotetext{
17 The sixth genre identified by Carver is theatre for social change, which refers to a genre of drama which addresses social issues. Finally, the seventh possible dramatic genre is that of tragedy, which Carver (2009:20) defines as "a drama that deals in a serious and dignified way about sorrowful or terrible events".

18 This interaction between author and director is not a given, as directors often work with dramas written by deceased playwrights.

19 Where narrative criticism hypothesises about the reaction of the ideal or implied audience (Lategan 2009:88; Powell 2010:242; Tolmie 1999:8; Vorster 1989:27), drama criticism evaluates the possible reactions of a hypothetical ancient audience to the drama - whether they line up with the
} 
order to explore these possible reactions, it is important for the interpreter to align her/himself, as far possible, with the context of the probable ancient audience, as well as the language, perspectives and allusions in the text. For this to happen, the critic or audience will have to pick up on various cues within the text or performance.

These cues are provided by various strategies, including that of the voice telling the story, known as the narrator or storyteller, who functions as the voice that carries the message of the director (Powell 1990:25). In the art of drama the voice of a narrator or storyteller is always optional, since the plot can also be driven by dialogue between characters (Brant 2004:7, 202; Stibbe 1992:130). ${ }^{20}$ Often a narrator will tell the story to a specific character or person, known as the narratee (Powell 1990:27).

The director can also make use of various dramatic strategies such as dramatic irony, where the audience is aware of something that the character(s) on stage do(es) not know (Barr 2002:389). This knowing creates a tension in the audience and usually predicts an event that will be shocking, surprising, or devastating to the characters. Similarly, repetition functions as a key method to direct the attention of the audience and can be used for the sake of humour, tension or shock, or function as a way of binding different events together. ${ }^{21}$

Another strategy used by the director (in partnership with the writer) is creating a certain perspective or perception referred to as the point of view. The point of view refers to the world view presented in the drama. This includes the perspective from which the drama is performed (Tolmie 1999:29), as well as how it is performed (Resseguie 2013:3). Through the point of view, the director also makes value judgements on all events and characters, and encourages the audience to evaluate these events and characters accordingly. In order to ensure the success of the drama, the audience will need to accept the point of view of the director (Powell 1990:24). However, this is not always a simplistic process, and drama analysis wishes to explore the often-complex struggle of the hypothetical audience with the director's point of view throughout the events, or plot, of the drama.

\section{Plot}

The plot can be defined as the sequence of events that carries the drama. It mainly consists of a linear sequence, which includes a beginning, middle and conclusion (Van Aarde 2009:386)..$^{22}$ In order to explore the plot of a drama, it is often demarcated

director's point of view or not. The audience can, for instance, even find themselves at odds with the director and react negatively toward the drama.

20 Moreover, the narrator can either be present on stage (in the form of a character or a third-person teller) or simply function as a voice.

21 Repetition can also be used in an inclusion, which is when something which is mentioned at the beginning of a drama/scene is repeated at its end (Powell 1990:33).

22 A successful ending or conclusion doesn't necessarily imply the resolution of all tension in the drama (Van Aarde 2009:387). 
into scenes. In drama different scenes are usually marked by entrances and exits (Taplin 1978:31). Scenes build towards a climax (the most heightened place of conflict (Powell 2010:246)) through the increase of conflict, which can simply be defined as "a clash of actions, ideas, desires, or wills" (Perrine 1974:44). ${ }^{23}$ Examining the ways in which conflicts are portrayed and resolved, as well as their probable effect on the hypothetical audience, is essential in a drama analysis (Powell 1990:42). When considering the plot, the choice, order, frequency and duration of events all become important vehicles for the director's message. This message, however, needs to be conveyed in a context, which is found in the setting(s) of the drama (Powell 1990:69).

\section{Setting(s) and stage design}

The settings in which the director chooses to portray the characters and action add a crucial dimension to the drama as it places the events within a certain frame of time, space and mood. ${ }^{24}$ When considering a drama, it is important to realise that settings are more than locations and backdrops: they are usually "saturated with meaning” (Resseguie 2013:9). These settings are portrayed with the use of costumes, décor, sound, lighting and properties (Carver 2009:438). However, the starting point would be the backdrop, a painted back wall, which aids the audience in situating the drama (Carver 2009:438). The backdrop will then be complemented by a certain choice of décor (stationary elements on stage) and properties (more personal elements which are used by actors and moved around on stage). ${ }^{25}$ After the setting has been laid out on the stage, it will have to be brought to life through lighting, sound and special effects. ${ }^{26}$

Lighting is a very important tool within the drama (White 2001:90), and can be used for various purposes, including creating an atmosphere (for example, warm or cold), drawing attention to something (by the use of a spotlight), or simply indicating a time of day (light or dark). Sound also adds a dimension to the settings

23 Conflict can be external, as in the case of a physical disaster or where two characters oppose one another, or internal, which is usually portrayed by personal or psychological struggles such as fear, anxieties, despair, etc. Internal conflict can also play itself out in the conflict that a character experiences with abstract notions such as their fate, and characters can even be said to be in conflict with themselves (Powell 1990:42-43).

24 A drama consists of various types of settings. Firstly, the spatial setting describes the physical place or environment in which the story takes place (Powell 1990:70). This setting can be geographical (Galilee), topographical (mountain), architectural (temple), or religious (Passover) (Resseguie 2013:9). Secondly, the temporal setting refers to the time and era in which the events play out as well as the time frame in which the drama is placed (Powell 1990:72). Thirdly, the social or cultural setting refers to the socio-symbolic world operating within the drama, including "political institutions, class structures, economic systems, social customs, and general cultural context" (1990:74).

25 A property, or prop in short, is any item used in the drama that is not built into the set (White 2001:14).

26 While the ancients did not make use of special effects as we would, ancient comedy used the ekkyklema (a wheeled device on which characters would be rolled out) and the mechane (a pulley system used to present actors as flying; Storey \& Allan, 2005:44-45). 
as well as the events in the drama (White 2001:23). Sound serves to "reinforce the spoken word", or to "add direction and effects" (Carver 2009:363), which enhances the experience and pulls the audience into the world presented on stage. The sound plot is especially helpful to bring the often-neglected sense of hearing to life in the exegetical experience. Similar to lighting and sound, special effects serve to support the imagination and add a dimension to the settings and events in the drama (Carver 2009:379-380). These settings are filled with characters portraying the happenings in the drama.

\section{Characterisation}

Within a drama, characters are used by the director as the main means through which the plot is embodied (Powell 1990:51). They are known through their speech, actions, gestures and clothing, as well as the speech of others and the settings in which they appear and function (Resseguie 2013:11). ${ }^{27}$ The way in which characters relate to one another also portrays something of the perspective and point of view of the director (Van Aarde 2009:404). Character development, or lack thereof, is also important in a drama. ${ }^{28}$ Dramas, and specifically ancient dramas, utilise individual characters to portray certain sets of values and behaviours which the audience will then recognise in themselves or in others (Neyrey 2007:5). In this way, characterisation becomes a powerful tool to pull the audience into the drama. The audience can identify (or choose not to) with characters in various ways. ${ }^{29}$

Actors make use of various means in order to embody their characters more effectively. Rhoads (2012:29) emphasises that, although the Gospels were not

27 Scholars distinguish between round and flat characters (Tolmie 1999:54). Round characters are those who are portrayed as being more multi-dimensional and the most life-like, often creating tension and even surprising the audience (Bennema 2013:46; Van Aarde 2009:404), whereas flat characters are one-dimensional, often portraying one ideological perspective throughout the drama (Bennema 2013:46; Blomberg \& Markley 2010:114). Some scholars, like Blomberg and Markley (2010:114), will refer to a third type of character, namely the stark character, who is often exaggerated, stereotyped, or caricatured.

28 Characters can be static (those who are the same in the end of the drama as they were in the beginning), or dynamic (those who have shown development from the beginning to the end of the drama). Dynamic characters can also show negative development and regress throughout the drama (Resseguie 2013:11). Characters also fulfil various functions within a drama. The protagonists are the main characters, on whose side the director would try to get the audience (Van Aarde 2009:405). Other characters function as persons towards whom the values of the protagonists would be directed. The third function is that of the antagonists. An antagonist is a character whose efforts are aimed at causing the protagonist to fail. Another function would be that of the helper, who comes alongside the protagonist in order to ensure his/her success (2009:405).

29 Powell (1990:56) refers to empathy, sympathy and antipathy as reactions from the audience toward different characters. Empathy is the act of living oneself into the drama by "feeling into" characters, because they are similar to the audience or experiencing something that the audience can identify with (1990:57). The second way of associating with a character is that of sympathy, where the audience feels "alongside" the character (1990:57), being able to understand what the character is feeling or experiencing, but not able to feel it with them, since they cannot necessarily relate. Finally, the third way of associating with a character is that of antipathy, which implies feelings of alienation or disdain (1990:57) 
necessarily composed as scripts, they contain an ample amount of stage directions for "voice inflection and volume, gestures, movement, body language, and emotions". Directions for the performance of the drama are therefore included in the text and should be picked up by the imagination of both actors and audience. ${ }^{30}$ Moreover, characters' physical representations, which are brought alive by the use of costume, properties, accessories, and make up, serve to stimulate the imagination of the audience and give insight into the settings of the drama (White 2001:31). ${ }^{31}$

\section{Possible contributions of drama criticism}

Powell (1990:90) refers to the fact that the creative methodology of narrative criticism has already done so much to stimulate the interpretation of biblical texts. This paper wishes to this paper wishes to latch on to performance criticism and build this creative route where a diversity of individuals are able to experience the drama of the Fourth Gospel as an audience and reflect upon that experience. This adds a dimension of transformative power to the biblical text: both personally and socially.

Not only can drama criticism serve to bring biblical texts closer to our own experiences, but it also brings it closer to familiar means of entertainment, expression and learning by using the "moving picture", which has become all the more prominent since the early 90s (Kreitzer 1993:14-15). This means that the values of biblical texts have the opportunity to infiltrate (and transform) modern culture in ways that go beyond the scholarly realm. ${ }^{32}$ This acknowledges the mobility of a biblical text, as it allows texts to be read beyond their specific historical contexts (Lategan 2009:96). The experience of a drama is also a communal exercise, as it has the potential to speak to faith communities who experience the drama of the Word becoming in their own flesh and bodies. As different audience members experience the Johannine drama, its meaning potential widens and it is given the opportunity to minister life into a diversity of existential situations (cf. Rhoads 1999:270). Additionally, the communal nature of this methodology wishes to highlight that biblical texts are not read and interpreted in isolation, but that every believer functions as a story within a bigger narrative. Experiencing the Fourth Gospel as a drama, opens up the exegetic process to anyone who has access to the text, or even just the story of Jesus. ${ }^{33}$ This

\footnotetext{
30 Rhoads (2012:29) argues that these stage or performance directions occur in "virtually every episode of the gospel stories".

31 Carver (2009:332) refers to a "period feel" which is created by the selection of certain costumes or makeup.

32 This does not imply that any and every popular interpretation or portrayal of biblical texts is uplifting or helpful, or that exegesis can be reduced to a casual exercise. Biblical exegesis still ought to be an exercise undertaken with caution while remaining accountable to the nature and purpose of these texts and to biblical scholarship, as well as to the needs of faith communities. Rather, it provides a more accessible means through which people of faith can understand the findings of more rigorous biblical hermeneutics.

33 Ray (2002:17) affirms this characteristic of scripture by using the metaphor of mining. He argues that the mining tools in the interpretation of Scripture ought to be inexpensive and that all miners
} 
methodology also allows the biblical text to convey a coherent message, in spite of gaps and indeterminacies (Tovey 1997:260).

Drama criticism also allows the audience to recognise certain elements which might have been glossed over by the simple reading of the text. Ridderbos (1997:573) refers to the Fourth Gospel as being "extremely concise", often paying little attention to events or actions with great gravitas. Therefore, audience members need to take care to read beyond what language means and explore what language does (Brant 2011:13) by experiencing the words come to life. When the text comes alive, the exegetical process comes alive. The objective of drama criticism is therefore to stimulate the audience to have an experience that is enjoyable. Kreitzer (1993:20), who explored the New Testament through the lens of film, shares this sentiment: "The first conviction is that theological writing should be something that is enjoyable, entertaining, even fun, for the interested reader".

\section{Possible limitations of drama criticism}

Since drama criticism is relatively foreign to the field of biblical exegesis, there is not much criticism against it. However, many of the limitations of narrative criticism and the field of performance criticism are also applicable to this methodology. These objections include the so-called uncritical assumptions of literary unity, which "smooth over inconsistencies" within the text (Merenlahti \& Hakola 1999:24), ${ }^{34}$ failure to engage the social world that the narrative is addressing and representing (Stibbe 1992:51), ${ }^{35}$ and the use of modern tools and approaches to explore ancient texts (Powell 1990:93).$^{36}$ This also links with the objection to applying methods to biblical texts which were devised for the study of fiction or entertainment, ${ }^{37}$ and

(interpreters) ought to be encouraged to participate in the wonderful experience of interpreting texts. However, Powell (1990:86) does remind us that a basic knowledge of the world assumed by the narrative or drama is still important.

34 De Boer was one of the scholars who was of the opinion that narrative criticism be regarded as a step backward for critical exegesis. De Boer (1992:43) exclaimed: "Can any avowedly critical method really presuppose coherence, whether thematic or literary, as an unquestionable principle?" However, Rhoads (1999:267) remarks that such methodologies are aimed at the final form of the text as it was created for its audience. Rhoads motivates his statement by asserting that "a $1^{\text {st }}$ century audience hearing a Gospel would have experienced it as a whole and not as pieces of earlier tradition". social world more than narrative criticism would. Elements such as costumes, stage design and props are useful for adding various socio-historical elements that seem hidden in the text. essential to realise that the ancient text was not written with the intent of being interpreted, performed, or experienced in the modern context. Moreover, many hurdles arise in the attempt to read an ancient text as a drama. Barr (2002:17-18) refers to, among others, barriers of language and culture, which make it impossible for the modern audience to experience the text in the exact manner that the ancient audience did.

37 Even though this might be a valid concern, it needs to be kept in mind that drama criticism intends to analyse the biblical text according to its form and poetic function (Powell 1990:94). 
the critique of genre confusion, in which narrative criticism has been accused of over-complicating the Gospels (Ashton 1994:141-165). Moreover, the supposed lack of objective criteria that narrative analysis was criticised for will also be an issue in drama criticism (Powell 1990:95). ${ }^{38}$

\section{Conclusion}

It is clear that biblical drama criticism is anything but a clear-cut and unproblematic tool with which to experience texts, but the promises and possibilities that this methodology holds make it worthwhile to take the creative risk and test it on the Fourth Gospel in a further study. The process of drama criticism is one that will hopefully stimulate the imagination (Bradby, Thomas \& Pickering 1983:7; Powell 2010:245), allowing the Gospel of John to function poetically as a drama that "fire[s] the imagination, provoke[s] repentance, inspire[s] worship" (Powell 2010:241). ${ }^{39}$ A drama has the power to unify an audience, to pull them from their world, time and space, and place them in the events, time and space of what they are experiencing in front of them. "The audience becomes a witness to what it otherwise cannot see or, in some cases, cannot normally bear to look at ... What one sees - the diversity and conflict that are characteristic of the world out of which the audience comes - is enacted in the theatrical space, and the audience comes together and for a time becomes a united witness to an event” (Brant 2004:71).

38 This can be seen in the fact that narrative critics arrive at a wide array of interpretations for the same text. The same is true for the experience of a drama. No two individuals will walk out of a theatre performance having come to exactly the same conclusions. Moreover, in the field of drama, even the director could interpret and portray the drama in ways which are inconsistent with the author's intent. However, Powell (1990:96) seeks to remind us that any interpretative methodology runs this risk.

39 The idea is that the audience becomes part of the drama, and that the drama is again used to view and shape the audience's own context and circumstances (Powell 2010:241). 


\section{Bibliography}

Ashton, J. 1994. Studying John:

Approaches to the Fourth Gospel, New York: Clarendon.

Attridge, H W. 2015. The Gospel of John: Genre Matters, in K B Larsen (ed.), The Gospel of John as Genre Mosaic. Göttingen: Vandenhoeck \& Ruprecht, 27-46. https://doi.org/10.13109/978366 6536199.27

Barr, D L. 2002. New Testament Story. An Introduction (Third Edition), United States: Wadsworth.

Bennema, C. 2013. A Comprehensive Approach to Understanding Character in the Gospel of John, in C W Skinner (ed.), Characters and Characterization in the Gospel of John, London: Bloomsbury T\&T Clark, 36-58.

Blomberg, C \& Markley, J M. 2010. Handbook of New Testament Exegesis, Grand Rapids: Baker Academic.

Bradby, D; Thomas, P \& Pickering, K. 1983. Studying Drama, London: Croom Helm.

Brant, J A. 2004. Dialogue and Drama. Elements of Greek Tragedy in the Fourth Gospel, Massachusetts: Hendrickson Publishers.

Brant, J A. 2011. John. Grand Rapids: Baker Academic.

Carver, R K. 2009. Stagecraft Fundamentals, A Guide and Reference for Theatrical Production, Oxford: Elsevier.
Conway, C M. 2015. John, Gender and Genre, in K B Larsen (ed.), The Gospel of John as Genre Mosaic, Göttingen: Vandenhoeck \& Ruprecht, 69-84. https://doi. org/10.13109/9783666536199.69

Cummins, S A. 2008. John, in K.J. Vanhoozer (ed.), Theological Interpretation of the New Testament: A Book-by-Book Survey, Grand Rapids: Baker Academic, 60-73.

Davidson, J. 2005. Theatrical Production, in J Gregory (ed.), A Companion to Greek Tragedy, Oxford: Blackwell, 194-211. https://doi.org/10.1002/9780470 996676.ch13

De Boer, M C. 1992. Narrative criticism, historical criticism, and the Gospel of John. Journal for the Study of the New Testament, 15(47):35-48. https://doi.org/10.1177/0142064X 9201504703

Du Toit, A B (ed.). 1993. Guide to the New Testament, VI, The Gospel of John, Hebrews to Revelation: Introduction and Theology, Pretoria: NG Boekhandel.

Green, J R. 1994. Theatre in Ancient Greek Society, London: Routledge.

Green, J B (ed.). 2010. Hearing the New Testament, Strategies for Interpretation. Grand Rapids: William B. Eerdmans. 
Hearon, H E \& Ruge-Jones, P (eds.). 2009. The Bible in Ancient and Modern Media. Story and Performance, Eugene: Cascade Books.

Hitchcock, F R M. 1993 [1923]. Is the Fourth Gospel a Drama? in M W G Stibbe (ed.), The Gospel of John as Literature. An Anthology of Twentieth-Century Perspectives, New York: Brill, 15-25.

Johnson, L T. 1999. The Writings of the New Testament. An Interpretation, Minneapolis: Fortress Press.

Kreitzer, L J. 1993. The New Testament in Fiction and Film. On Reversing the Hermeneutical Flow, Sheffield: JSOT Press.

Larsen, K B. 2015a. Introduction: The Gospel of John as Genre Mosaic, in K B Larsen (ed.), The Gospel of John as Genre Mosaic, Göttingen: Vandenhoeck \& Ruprecht, 13-24. https://doi.org/10.13109/ 9783666536199

Larsen, K B. (ed.). 2015b. The Gospel of John as Genre Mosaic, Göttingen: Vandenhoeck \& Ruprecht.

Lategan, B. 2009. New Testament hermeneutics (Part II): Mapping the hermeneutical process, in A. du Toit (ed.), Focusing on the Message. New Testament Hermeneutics, Exegesis and Methods, Pretoria: Protea. 65-105.
Littlewood, S R. 1952. The Art of Dramatic Criticism, London: Sir Isaac Pitman \& Sons.

Mastronarde, D. 2005. The Gods, in J Gregory (ed.), A Companion to Greek Tragedy, Oxford: Blackwell, 321-332. https://doi.org/10.1002/ 9780470996676.ch20

Maxey, J A \& Wendland, E R (eds.). 2012. Translating Scripture for Sound and Performance, Eugene: Cascade Books.

Merenlahti, P \& Hakola, R. 1999. Reconceiving Narrative Criticism, in D Rhoads \& K Syreeni (eds.), Characterization in the Gospels. Reconceiving Narrative Criticism, Sheffield: Sheffield Academic Press, 13-48.

Neyrey, J H. 2009. The Gospel of John in Cultural and Rhetorical Perspective, Grand Rapids: William B Eerdmans.

Perrine, L. 1974. Story and Structure (4th Ed.), New York: Harcourt.

Powell, M A. 2010. Narrative Criticism, in J B Green (ed.), Hearing the New Testament: Strategies for interpretation (Second edition), Grand Rapids: William B Eerdmans, 240-258.

Ray, S K. 1990. What is Narrative Criticism? Minneapolis: Fortress Press.

Ray, S K. 2002. St. John's Gospel. San Francisco: Ignatius Press. 
Rhoads, D. 1999. Narrative Criticism: Practices and Prospects, in D Rhoads \& K Syreeni (eds.), Characterization in the Gospels. Reconceiving Narrative Criticism, Sheffield: Sheffield Academic Press, 264-285.

Rhoads, D. 2009. What is Performance Criticism? in H E Hearon \& P Ruge-Jones (eds.), The Bible in Ancient and Modern Media. Story and Performance, Eugene: Cascade Books, 83-100.

Rhoads, D. 2012. The Art of Translating for Oral Performance, in J A Maxey \& E R Wendland (eds.), Translating Scripture for Sound and Performance, Eugene:

Cascade Books, 22-48.

Rhoads, D \& Syreeni, K (eds.). 1999. Characterization in the Gospels, Reconceiving Narrative Criticism. Sheffield: Sheffield Academic Press.

Ridderbos, H. 1997. The Gospel of John. A Theological Commentary, Grand Rapids: William B. Eerdmans.

Resseguie, J L. 2013.

A Narrative-Critical Approach to the Fourth Gospel, in C W Skinner (ed.), Characters and Characterization in the Gospel of John, London: Bloomsbury T \& T Clark, 3-17.
Single Redman, J C. 2013. Eyewitness Testimony and the Characters in the Fourth Gospel, in C W Skinner (ed.), Characters and Characterization in the Gospel of John, London: Bloomsbury T \& T Clark, 59-78.

Skinner, C W (ed.). 2013. Characters and Characterization in the Gospel of John, London: Bloomsbury T \& T Clark.

Smalley, S S. 1978. John: Evangelist and Interpreter, Exeter: Paternoster Press.

Sommerstein, A H. 2002. Greek Drama and Dramatists, London: Routledge.

Stibbe, M W G (ed.).1992. John as Storyteller, Narrative criticism and the Fourth Gospel, Cambridge: Cambridge University Press.

Stibbe, M W G (ed.). 1993. The Gospel of John as Literature. An Anthology of Twentieth-Century Perspectives, New York: Brill.

Storey, I C \& Allan, A. 2005. A Guide to Ancient Greek Drama, Oxford: Blackwell. https://doi.org/10.1002/ 9780470776209

Taplin, O. 1978. Greek Tragedy in Action, Berkeley: University of California Press. https://doi.org/10.4324/ 9780203324301 
Thatcher, T. 2008a. Anatomies of the Fourth Gospel: Past, Present, and Future Probes, in T Thatcher \& $S$ D Moore (eds.), Anatomies of Narrative Criticism. The Past, Present, and Futures of the Fourth Gospel as Literature, Atlanta: Society of Biblical Literature, 1-38.

Thatcher, T \& Moore, S D (eds.). 2008b. Anatomies of Narrative Criticism. The Past, Present, and Futures of the Fourth Gospel as Literature, Atlanta: Society of Biblical Literature.

Tolmie, D F. 1999. Narratology and Biblical Narratives: A Practical Guide, London: International Scholars Publications.

Tovey, D. 1997. Narrative Art and Act in the Fourth Gospel, Sheffield: Sheffield Academic Press.
Van Aarde, A G. 2009. Narrative Criticism, in A du Toit (ed.), Focusing on the Message. New Testament Hermeneutics, Exegesis and Methods, Pretoria: Protea, 381-418.

Vanhoozer, K J (ed.). 2008

Theological Interpretation of the New Testament: A Book-by-Book Survey, Grand Rapids: Baker Academic.

Vorster, W S. 1989. The Reader in the Text: Narrative Material, Semeia, 48: 21-39.

White, C A. 2001. Technical Theatre, A Practical Introduction, London: Arnold.

Windisch, H. 1993 [1923]. John's Narrative Style, in M W G Stibbe (ed.), The Gospel of John as Literature. An Anthology of Twentieth-Century Perspectives, New York: Brill, 25-64. 


\title{
Chapter 6
}

\section{Tobit through the Lens of Trauma}

\author{
Helen Efthimiadis-Keith ${ }^{1}$
}

\section{Introduction}

Trauma can have a profoundly negative effect on one's life. It can lead to anxiety, hyper-vigilance, depression, anger, withdrawal, dissociation, regression, lack of trust, broken relationships, as well as feelings of powerlessness and of having been singled out, made special or set apart. ${ }^{2}$ It can also lead to the fragmentation of memories and their intrusion at inopportune times, sleep disturbances, behavioural addictions, self-injurious behaviours, and even the loss of the ability to speak about the event, which is the necessary precondition of healing. ${ }^{3}$ In other words, trauma shakes all one's unconscious assumptions about one's self, dignity, agency, safety and solidarity with trustworthy others, and impacts negatively on one's functionality (Frechette \& Boase 2016:5, 8). In literature, according to Granofsky (1995:16, 107-149), trauma effects and recovery may be expressed through fragmentation, regression, and (re)unification.

\footnotetext{
$1 \quad$ Also known as Helen Keith-van Wyk. Elna Mouton and I have known each other as friends and colleagues for approximately thirty years, starting in the days when we were both at the then University of Port Elizabeth (now the Nelson Mandela University). In all this time, I have found Elna to be a meticulous scholar, a deep thinker and an exceptional human being, who has remained full of love and compassion despite the traumas that she has been through. We have often shared thoughts on our respective traumas, and it is in the spirit of this sharing that I dedicate this trauma reading of Tobit to her on the occasion of her well-deserved Festschrift.

2 Please see references for this sentence and the next in footnote 3.

$3 \quad$ Krystal 1995:81; Frechette \& Boase 2016:5, 11-12; Poser 2016:29, 31, 32, 34, 39; Erikson 1995:186; Carruth 2011:18-20, 184; Granofsky 1995:8.
} 
In this paper, I would like to read Tobit ${ }^{4}$ through the lens of trauma, ${ }^{5}$ focusing particularly on Tobit's dysfunctional relationships with others and his subsequent recovery. In order to do so, I will use a Jungian psychoanalytic hermeneutic that regards all aspects of the text as manifestations of Tobit's psyche. I argue that the pervasive 'otherings' dominating the first section of the book (1:1-7:9a) function as representations of Tobit's psychic fragmentation, regression and ailing relationships, while the effects of his psychic integration and recovery, spurred on by Tobias' marriage to Sarah (7:9b-10:13) and evident in transformed relationships, are illustrated in the last section of the book (11:1-14:15).

\section{Tobit in trauma, transformation and recovery}

\section{Fragmentation, regression and dissolution in 1:1-3:6}

Tobit's opening verse (1:1) refers to the Assyrian exile, a source of severe traumatic othering for the Israelites who were forcefully deported from their land and resettled elsewhere, suffering multiple losses and experiencing a rupture in their national identity. ${ }^{6}$ For Tobit, however, the exile is preceded by at least two other traumatic events: the North-South split $(1: 4-5)$ and the death of his parents $(1: 8)$. While he glosses over the latter, the split had obviously caused Tobit a fair amount of consternation as he goes over it numerous times in chapter 1 (1:4-5). He depicts himself as the only one of his tribe who continued to worship 'correctly' in Jerusalem (1:6), thereby othering his fellow Israelites as apostates and othering himself from

4 Tobit (italicised) refers to the book of Tobit, while Tobit (normal font) refers to the character with this name. I use Di Lella's (2007) verse numbering and translation unless otherwise indicated. However, I retain the more conventional rendition of characters' names, except when quoting directly from his text.

5 As I do so, I am cognizant of a number of facts: 1) Most trauma theory is founded in Western culture(s) and ideology(ies); 2) reactions to trauma are significantly culturally cued; and 3) it may be considered anachronistic to apply modern trauma theory to ancient texts. However, I am also intensely aware of the fact that I cannot read the text from any perspective other than that of my own mind at this point in time. Moreover, as Egger-Wentzel (2015:193-198) states, "The expression of emotions is dependent on one's present culture and, therefore, subject to change. The feelings themselves, however, are constant throughout the millennia and within various cultures. They are, for example, similar in the cases of great misfortune or outstanding happiness". Similarly, Frechette and Boase (2016:7) note that, while "culturally specific factors" significantly determine what might be perceived as a threat/s to "safety, dignity, agency, and solidarity," "[a]ll mammals have a tendency to withdraw in the face of a threat ... [and] [c]ertain responses to stress are common among all mammals as a result of their social nature". Therefore, one could expect that immediate responses to threat might be largely similar across time and culture, even though what is regarded as a threat and how it is resolved may be socially and culturally cued.

6 Poser's words (2016:28-29) reflect the multiple traumas inherent in the Babylonian exile and, in my opinion, accurately reflect the traumas of the Assyrian exile: "Those affected by the siege experienced 'famine, pestilence, and the sword' (see Ezek. 5:12; 7:15), atrocities, torture, forms of sexual or sexualised violence, pillaging, and arson. Deportees had to endure a gruelling forced march over hundreds of miles. They witnessed the weakening and death of fellow captives. Families were torn apart, and most exiles had no hope of ever returning home." 
them through his religio-political allegiance to the South. ${ }^{7}$ This double othering continues in exile as he 'alone' upholds ceremonial food laws (1:10-11).

His double othering also manifests with his immediate family: in chapter 1 he merely mentions Anna and Tobias in passing (1:9), focusing instead on himself and his good works (cf. 1:6-8 and 1:3,16-20). His self-focus attests to his psychic fragmentation and produces relational dissociations in exile: seemingly oblivious to his family's needs, Tobit continues to other them by maintaining his focus on the poor, naked, hungry and dead of his people to his own detriment and that of his family. ${ }^{8}$

The ubiquitous uninterred Israelite dead become the symbol of Tobit's psychic fragmentation and withdrawal, while his burial activities $(1: 16-20)^{9}$ signify his suppression of traumatic memories and so his inability to process them at this point. While suppressing such memories is a form of dissociation and survival (Carruth 2011:76), the emotional burden of such memories ${ }^{10}$ only leads to further psychic and relational fragmentation, as depicted through the losses that Tobit endures because of his illegal activities: he loses all his worldly goods and has to flee from Nineveh with a price on his head (1:19-20). He is left 'only' with his wife and son $(1: 20)$, signifying the important role that they will play in his future recovery. ${ }^{11}$

7 Weeks (2011:393) refers to Tobit's "isolated righteousness" with regard to his constant statements and intimations that he alone maintained righteous behaviour.

8 While the text presents Tobit's tenacious do-goodery, particularly his burial of the dead, as a sign of his righteousness, I have always seen his activities as instances of compulsive, obsessive behaviour, as "something dis-eased" (Efthimiadis-Keith 2015:107). Similarly, Weeks (2011:393): "Tobit is a pious man, to be sure, but his piety comes close to the point of being obsessive and self-destructive, while his sense of isolated righteousness neglects the price paid by others for his behaviour". Tobit seems to choose the hungry, naked, poor and dead of his people over his family: the text shows no indication that he ever considers the effect of his deeds on his family. "Did they live in terror while he was out stealing the bodies of the slain and burying them (1.17-18)? How did they experience his fleeing for his life and their subsequent loss of all worldly goods (1.19-20)? Did they panic when Tobit left during 'his' Shavuot meal to tend to the dead yet again (2.1-4)?" (Efthimiadis-Keith 2015:107). For a contrary reading, one that flows with the surface level of the text, see Andersen (2011).

9 Regarding the cultural-religious significance of Tobit's burial activities, see Ego (2009), Bolyki (2005), MacDonald (2006) and Abrahams 1893:349-350. Regarding the relation between food and death in Tobit, see Efthimiadis-Keith (2013a) and MacDonald (2006).

10 "Severe or prolonged stress can suppress hippocampal functioning, creating context-free fearful associations, which are hard to locate in space and time. This results in amnesia for the specifics of traumatic experiences but not the feelings associated with them" (Van der Kolk \& Van der Hart 1995:172)

11 In my first reading of Tobit (Efthimiadis-Keith 2013b) I slated Tobit for what I saw as his addictionbased (addiction to good works) disregard for his family. However, in a subsequent publication I saw that the many losses that Tobit had experienced "could well have triggered Tobit's focus on his wider family, his compatriots and the poor, and his seeming neglect of his own family members" (Efthimiadis-Keith 2017:109). I also saw that 1:20-22 underscored "[t]he importance of family in Tobit's ultimate recovery" (Efthimiadis-Keith 2017:112). 
Be that as it may, any attempted memory integration - "the central goal in a recovery process" (Poser 2016:32) - is thwarted from this point on until his encounter with the angel. For example, the integrative potential of celebrating Shavuot with his family $(2: 1-2)$ is shattered twice. First, Tobit disrupts the meal by dispatching Tobias to find one less fortunate with whom to share it $(2: 2)$. Even so, he promises that he will not taste his meal until his son has returned, again highlighting the healing role that his family, particularly his son, will play in his recovery. Second, when Tobias returns, Tobit immediately disrupts the meal by going out to prepare an Israelite corpse that his son had found in the marketplace (2:3-4). Tobit's knee-jerk reaction signifies the disruptive potential of intrusive thoughts ${ }^{12}$ on one's psyche and relationships. Instead of eating his meal with Tobias, as he had intended, Tobit earns the scorn of his neighbours and returns to eat his meal in sorrow, ostensibly alone and in silence (2:5-8). His neighbours' derision points to the self-injurious and obsessive nature of some post-traumatic behaviours (Carruth 2011:220, 293; Van der Kolk \& Van der Hart 1995:167), while abandoning his meal - twice - signifies his increasing withdrawal from society. The fragmentation of his memory and his inability to articulate his trauma ${ }^{13}$ become evident as he quotes the book of Amos out of context $(2: 6)$.

Tobit buries the corpse and sleeps outside his house in fulfilment of ritual purity laws (2:9). Unfortunately, he does not cover his eyes, and they become partially blinded by the excrement of two sparrows (2:10). The integrative potential of ritual (Frechette \& Boase 2016:9-10) and of the spirit, symbolised by the birds, is disrupted as white films form on Tobit's eyes, physically encoding his traumatisation and withdrawal. Further attempts at integration are thwarted once again as doctors' medications leave Tobit completely blind, and thus physically othered (2:10). ${ }^{14}$ His loss of physical functionality ${ }^{15}$ aptly depicts the negative physical symptoms that one can develop as a result of unprocessed traumatic memories (Strawn 2016:145; Metzger 2014:47).

\footnotetext{
12 "One of the hallmarks of Post-Traumatic Stress Disorder is the intrusive reexperiencing of elements of the trauma in nightmares, flashbacks, or somatic reactions" (Van der Kolk \& Van Der Hart 1995:173). Intrusive thoughts are referred to as "intrusion symptoms", while "constriction symptoms" include "psychological numbing, rigidity, and social withdrawal" (Poser 2016:29). These symptoms typically occur simultaneously, causing problems in functioning, relationships and personal stability, among others.

13 Trauma survivors often find it difficult to articulate their experience(s) in words, while verbal articulation is key to the construction of a coherent narrative of the traumatic experience(s) and so to recovery (Poser 2016:34; Frechette \& Boase 2016:5-6). The inability to express the traumatic event(s) is part of dissociation (Frechette \& Boase 2016:6).

14 For Kiel (2011:288), Tobit's blindness reflects his faulty, strictly retributionally-based theology, a perspective which seems to shift once he is healed. This shift culminates in the last two chapters in which Tobit seems to abandon a strict correlation between human righteousness and God's action (Kiel 2011:294-295). While I agree with Kiel's interpretation of Tobit's blindness, I believe it may also be interpreted according to a related concern: his blindness towards his own family in his pursuit of righteousness.

15 Functional loss is one of the six principal loss types identified by Mitchell and Anderson (1983:36-46), the others being material, relationship, intrapsychichic, role and systemic loss.
} 
Tobit's functional loss impacts negatively on his family yet again: Anna, being a woman of good standing, has to other herself by doing 'women's work' to keep her family afloat (2:11). Instead of rewarding her, Tobit others her even further through his unfounded claim that she has stolen a goat and his insistence that she must return it (2:12-14). Tobit's pedantic attitude shows the kind of black or white, 'stuck' thinking (Granofsky 1995:108-109) that trauma can elicit: things are assumed and believed to be wrong, and attempted rectification occurs along rigid lines. While such thinking signifies an attempt to bring order to the survivor's life (Granofsky 1995:121), it does not bode well for either the sufferer or her/his loved ones as is tersely expressed through Anna's exasperated response: "Now where are your acts of charity? Where are your righteous deeds? See, these things are known about you!" (2:10).

Feeling misunderstood and helpless, Tobit succumbs to grief $(3: 1)^{16}$. His suicidal prayer (3:2-6) highlights a number of factors related to trauma response.

a. Regression - Tobit wishes to die, a symbolic representation of regressing into the safety of the mother's womb (Granofsky 1995:109).

b. Self-blame and untoward guilt ${ }^{17}$ - Tobit assumes that God is punishing him because of his own unwitting sins and the sins of his people. Tobit's irrational self-blame represents the toxic assumptions that can take the place of shattered core beliefs about oneself, one's relationship to others, and the world. ${ }^{18}$ While self-blame is a "survival mechanism to regain control, it leads to harmful consequences if left unchecked" (Frechette \& Boase 2016:5-6), as can be seen in Tobit's complete desperation by the time that Azariah, the angel in disguise, enters his abode $(5: 10)$.

c. Ascribing one's suffering to God is also a survival mechanism (Poser 2016:36-37). It assumes that the God who was able and willing to inflict just chastisement through the traumatic event is the same God who is powerful enough to restore his repentant people out of love and mercy. Such retributional, punitive

16 "This is the most emotion that Tobit has shown throughout this narrative and signifies the proverbial breaking of the dam wall ... It is as though the grief of all the years, from his childhood until now, becomes fully externalised for the first time" (Efthimiadis-Keith 2017:114-115).

17 Self-blame and untoward guilt are survival strategies in that they are an attempt to make sense of/ create meaning from the traumatic experience. Trauma survivors "often can tell the story of their traumatization with a mixture of past and present, but their current life is characterised by doubt and humiliation, by feelings of guilt and shame: past meaning schemes determine the interpretation of the present" (Van Der Kolk \& Van Der Hart 1995:178). Interestingly, trauma survivors may "inappropriately blame themselves for their trauma, and yet cannot take appropriate responsibility for their current actions and feelings" (Carruth 2011:106). "Past meaning schemes" may also be referred to as core beliefs/core schemas/core assumptions (Frechette \& Boase 2016:5). I have chosen to use the more familiar terms core assumptions/core beliefs.

18 When such a core assumption is shattered, it leaves a "toxic assumption" and a feeling of violation, which can cause negative emotions and moods as well as the reduction of positive ones, negatively affect one's sense of self, agency and safety, and relation to the world (and God, if one is religiously inclined) (Frechette \& Boase 2016:5; Erikson 2011:189-190). 
thinking arguably causes further fragmentation, ${ }^{19}$ but also allows the sufferer to maintain the concept of a just, holy, yet merciful God, and so allows 'God' to survive (Poser 2016:36-37). It prevents the dissolution of the sufferer's identity based on religious beliefs. The eschatological hopes reflected in chapter 14 are the ultimate manifestation of such thinking. ${ }^{20}$

\section{Suppression of the relational principle: 2:11-14 and Sarah's demonic lover}

As we have seen, Tobit's relationship with his immediate family is negatively affected by his psychic fragmentation. On a surface level, the text depicts this phenomenon through Tobit's altercation with Anna. However, the full extent of his psychic and relational fragmentation is poignantly captured through Sarah's plight. Sarah, the only child of Tobit's relative, Raguel, is beset by Asmodeus, a demon lover that has killed seven of her husbands in succession before the marriage could be consummated (3:7-9). The demon showcases Tobit's poisonous reasoning, ${ }^{21}$ his obsessive, controlling and self-injurious behaviour, as well as the resultant relational disintegration at a personal and communal level: Sarah's maid accuses her of killing her own husbands (3:8) and Sarah tries to commit suicide (3:10), while the knock-on effect of seven men dying without progeny potentially destabilises the exilic community for generations to come.

\section{Hope and the beginnings of transformation and recovery}

Despite this dire picture and the advanced state of Tobit's psychic and relational fragmentation, glimmers of hope for recovery may be found throughout the first section of Tobit.

a. Tobit's nephew, Ahikar, intercedes for him and he is reinstated in his former position (1:22).

b. All of Tobit's family mourn his blindness (2:10).

c. Ahikar takes care of him for two years after he is blinded (2:10).

d. Tobit acknowledges that he falsely accused his wife (2:14).

e. His wife and son remain with him and presumably care for him.

f. Sarah puts off her intended suicide out of concern for her father $(3: 10)$.

g. God dispatches the angel Raphael to heal Tobit and Sarah at the very moment that their prayers are heard (3:16-17).

\footnotetext{
19 Seeing suffering as a punishment from God plays a maladaptive role in the sufferer's life. For example, it increases dysfunctional moods and leads to greater levels of grief and grief intensity (Matthews \& Marwit 2006:96; Yeo 2011:5-6, 39; Lee, Roberts \& Gibbons 2013:293).

20 On the eschaton in Tobit, see the excellent work by Hicks-Keaton (2013) and (Baker 2014:236-252).

21 From a Jungian perspective, Asmodeus represents animus-Logos/rational function, while Sarah represents the anima-Eros/relational function (Efthimiadis-Keith 2016b:4).
} 
h. Tobit remembers the money that he had left in trust with Gabael (4:1-2). He sends his son to recover it, presumably to provide for his family once he is dead (4:20-21).

i. In his address to Tobias, Tobit shows tremendous care for his wife, and tries to tighten the bond between mother and son by reminding Tobias of the sufferings that she had endured for him (4:3-4) (Efthimiadis-Keith 2017:116).

j. Tobias eagerly agrees to retrieve the money (5:1-2).

k. Azariah/Raphael elicits positive memories from Tobit's past, namely that he was not alone in continuing to worship in Jerusalem (5:11-14), and assures him of his healing (5:10) (Efthimiadis-Keith 2017:118).

1. The angel accompanies Tobias on his journey (6:2) and takes him to Ecbatana to marry Sarah, having convinced him that it is God's will for them to be wed $(6: 10-7: 1)$.

These factors infuse hope into the narrative as they involve human and divine connections, pointing to the well-known fact that recovery can only happen in community, within caring relationships (Poser 2016:34). The first evidence of their restorative potential is found in the positive change that occurs in Tobit during Raphael's visit: he perks up and successfully comforts his wife concerning Tobias' departure (5:11-22). Subsequent evidence includes Azariah saving Tobias from the fish (6:3-4) and giving him healing aids for his father and Sarah (6:5-9), as well as Tobias falling in love with Sarah sight unseen (6:18), and becoming far more assertive $(7: 1,9 ; 10: 7-9) .^{22}$

\section{Transformation, recovery and (re)unification}

While significant changes occur gradually throughout the first section of Tobit, the middle section becomes the catalyst for the rapid changes that occur in the last section of the book. This is not surprising, as Sarah's deliverance from her demon-lover symbolises the restoration of Tobit's relational function, à la Jung. ${ }^{23}$ The result is a psychic, relational and communal (re)unification as symbolised by Tobias' marriage to Sarah ${ }^{24}$ and the joy that it brings $(8: 14-17 ; 11: 16-18)$. Significantly, the 'end' of Tobit's traumatic suffering is symbolised by Raguel filling in the grave that he had intended for Tobias $(8: 9-11,18)$.

\footnotetext{
22 On Tobias' increasing assertiveness, see Efthimiadis-Keith (2016:156).

23 See footnote 21 on Sarah as the relational, anima-Eros function.

24 From a Jungian viewpoint, Tobias and Sarah's wedding symbolises the hieros gamos, the reunification of masculine and feminine properties, at the acme of the individuation/maturation cycle (Efthimiadis-Keith 2016a:153).
} 
Consonant with the book's chiastic structure (Engel in Otzen 2002:4), ${ }^{25}$ most events portrayed in the last section reverse the negative ones portrayed in its first section and/or build upon them.

a. When Tobias' return is delayed, Tobit once again attempts to comfort his wife despitehisownanticipatorygrieffor hisson(10:1-7) (Efthimiadis-Keith2017:119).

b. When Anna excitedly announces Tobias' return (11:5-6), Tobit immediately exits the courtyard of his ruin and stumbles out to meet his son (11:10). As a result, his eyesight is restored by the application of the medicine Tobias had brought (11:11-15).

c. With his eyesight restored, Tobit's first action is to embrace Tobias and praise God because he can see his son once again (11:11-15) (Miller 2012:506).

d. Tobit testifies to God's good deeds to his neighbours, who are delighted at his healing (11:16-17).

e. When he hears of Sarah's approach, Tobit immediately runs out to welcome her (11:17).

f. He shows no interest in holding onto his newfound fortune and eagerly embraces Tobias’ suggestion to share it with Azariah (12:1-5) (Miller 2012:506-507).

g. His spiritual eyes are opened and he can see the angel whom God has sent to heal $\operatorname{him}(12: 11-22)$.

h. He no longer seems to do good works out of compulsion, even though he advocates them (14:8-11).

i. While he maintains a retributional approach to life, it does not seem to be as pronounced as before (see 3:2-6 versus 14:8-11). ${ }^{26}$

j. He is able to confirm Nahum's prophesy regarding the destruction of Nineveh and guide his son's family accordingly (14:9-10).

Tobit's exuberant praise to God is palpable. "Significantly, there is not a dead body in sight until Tobit dies 'in peace at one hundred and twelve years' ... and is 'buried with honour' in Nineveh (14:2)" (Efthimiadis-Keith 2013a:568). Equally significantly, he clearly envisions the eschaton (14:3-7) - that ultimate symbol of reversal and transformation, and Tobias and Sarah become the progenitors of the eschatological

\footnotetext{
25 Regrettably, I have been unable to obtain Engel's text and have to rely on Otzen here. Engel depicts Tobit's structure as follows:

26 For a careful analysis of the shift in Tobit's retributional beliefs, see Kiel (2011). See further his far more exhaustive work on retribution in Tobit (Kiel 2012), especially, 59-78.
} 
community (Miller 2009:130). Death has become life, darkness has become light, and joy and praise have replaced lament in the here and now as it will be in the eschaton. Tobit is no longer derided by his neighbours and there is no hint of bitterness in his family relationships. Rather, he and his family are (re)united, transformed and restored. The tyranny of trauma has been healed and Tobit has recovered.

\section{Conclusion}

In this paper I have read Tobit through the lens of trauma using a Jungian hermeneutic. My current reading is very different from the highly negative one which I first put forward in 2013 (Efthimiadis-Keith 2013b). In that reading I slated Tobit for being a good-deeds-obsessed man, a negligent father, and one who was more interested in his extended family than he was in Anna and Tobias. Reading Tobit through the lens of grief in 2017 began to soften me towards Tobit as I saw that he had suffered all six principal loss types identified by Anderson and Mitchell (1983:36-46). This softening has turned into compassion as I have applied trauma theory to the text through a Jungian lens. My trauma reading has also given me greater understanding of various aspects of the text, such as its structure. I have seen that Tobit's chiastic structure accurately reflects the aspects of fragmentation, regression and (re)unification identified by Granofsky (1995:16, 107-149). Fragmentation and regression dominate the first 'arm' of the chiasm (1:1-7:9a), while (re)unification/transformation dominates in the second (11:1-14:15), with Tobias and Sarah's wedding (7:9b-10:13) acting as the catalyst for that incredible reversal. In subsequent papers, given the essential unity of Tobit and his community, I hope to investigate the rhetorical effect of this structure on the reader with a view to discerning how the text may have functioned as a healing aid for communal trauma in the time of its final composition.

\section{Bibliography}

Abrahams, I. 1893. Tobit and Genesis, The Jewish Quarterly Review, 5(2): 348-350. https: / / doi.org/10.2307/1449875

Anderson, G A. 2011. Tobit as righteous sufferer, in E F Mason (ed.), A Teacher for all Generations: Essays in Honor of James $C$ VanderKam, Supplements to the Journal for the Study of Judaism 153, Leiden: Brill, 493-507. https://doi.org/10.1163/ 9789004224087_028
Baker, E W. 2014. The eschatological role of the Jerusalem temple: An examination of Jewish writings dating from 586 $B C E$ to 70 CE, doctoral dissertation, Berrien Springs, Michigan. Andrews University, Seventh-day Adventist Theological Seminary.

Bolyki, J. 2005. Burial as an ethical task in the book of Tobit, in the Bible and in the Greek tragedies, in G G Xeravits \& J Zsengellér (eds.), The Book of Tobit: Text, tradition, theology. Supplements to the Journal for the Study of Judaism, 98, Leiden: Brill, 89-101. 
Carruth, B (ed.). 2011. Psychological Trauma and Addiction Treatment, New York, NY: Routledge.

Di Lella, A A. 2007. Tobit, in A Pietersma \& B G Wright (eds.), A New English Translation of the Septuagint, Oxford: Oxford University Press, 456-77.

Ego, B. 2009. Death and burial in the Tobit narration in the context of the Old Testament tradition, in T Nicklas, F V Reiterer \& J Veheyden (eds.), The Human Body in Death and Resurrection. Deuterocanonical and Cognate Literature Yearbook 2009, Berlin: De Gruyter, 87-103.

Efthimiadis-Keith, H. 2013a. The significance of food, eating, death and burial in the book of Tobit, Journal for Semitics, 22(2): 553-578.

Efthimiadis-Keith, H. 2013b. Fish, food and death: An autobiographical perspective on Tobit according to one woman's binge-eating disorder, Keynote address, The International Conference: Body, Psyche and Space in Old Testament Apocryphal Literature', North-West University, Potchefstroom, South Africa, 13-17 July 2013.

Efthimiadis-Keith, H. 2015a. Food and death: An autobiographic perspective on Tobit according to one woman's binge-eating disorder" in A Brenner-Idan \& H Efthimiadis-Keith (eds.), A Feminist Companion to Tobit and Judith. A Feminist companion to the Bible, vol. 20; London: Bloomsbury T \& T Clark, 98-113.

Efthimiadis-Keith, H. 2016a. Structural and psychological coherence in the book of Tobit, in P J Jordaan \& N Allen (eds.), Construction, coherence and connotation: Studies on the Septuagint, apocryphal and cognate Literature, Deuterocanonical and Cognate Literature Studies, 34. Berlin: Walter de Gruyter, 149-164. https://doi. org/10.1515/9783110466942-009

Efthimiadis-Keith, H. 2016b. Loving the 'other' in the book of Tobit: An investigation into the interrelationships of the main characters in Tobit, Paper presented at the Bible and Psychology Programme Unit of the Society of Biblical Literature during the annual general conference in San Antonio, Texas, 19-22 November 2016.

Efthimiadis-Keith, H. 2017. Tobit transformed: Re-reading Tobit through the lens of grief and loss, Journal for Semitics, 26(1):101-122. https://doi. org $/ 10.25159 / 1013-8471 / 3110$

Egger-Wentzel, R. 2011. Sarah's grief to death (Tob 3:7-17), in S C Reif \& R Egger-Wentzel (eds.), Ancient Jewish prayers and emotions: Emotions associated with Jewish prayer in and around the second temple period, Deuterocanonical and Cognate Literature, 26. Berlin: Walter DeGruyter, 193-219. 
Erikson, K. 2011. Notes on trauma and community, in C Caruth (ed.), Trauma: Explorations in memory, Baltimore, Maryland: Johns Hopkins University Press, 83-199.

Frechette, C G \& Boase, E. 2016. Defining 'trauma' as a useful lens for Biblical interpretation, in E Boase \& C G Frechette (eds.), Bible through the Lens of Trauma. Semeia Studies, 86, Atlanta: SBL Press, 1-23. https://doi.org/10.2307/j. ctt1h1htfd.4

Granofsky, R. 1995. The Trauma Novel: Contemporary Symbolic Depictions of Collective Disaster, American University Studies, Series III, Vol. 55, New York: Peter Lang.

Hicks-Keeton, J. 2013. Already/not yet: Eschatological tension in the book of Tobit, Journal of Biblical Literature, 132(1):97-117. https: / / doi.org/10.2307/23488239

Kiel, M D. 2011. Tobit's theological blindness, Catholic Biblical Quarterly, 73(2):281-298.

Kiel, M D. 2012. The 'whole truth' rethinking retribution in the book of Tobit, Library of Second Temple Studies, 82, London: T \& T Clark.

Krystal, H. 2011. Trauma and aging: a thirty-year follow-up, in C Caruth (ed.), Trauma: Explorations in Memory, Baltimore, Maryland: Johns Hopkins University Press, 76-99.
Lee, S A; Roberts, L B \& Gibbons, J A. 2013. When religion makes things worse: Negative religious coping as associated with maladaptive emotional responding patterns, Mental Health, Religion and Culture, 16/3:291-305. https://doi.org/10.1080/1367467 6.2012 .659242

MacDonald, N. 2006. 'Bread on the grave of the righteous' (Tob 4:17), in M Bredin (ed.), Studies in the book of Tobit. A Multidisciplinary Approach. Library of Second Temple Studies, 55, London: T \& T Clark, 99-103.

Matthews, L T \& Marwit, S J. 2006. Meaning reconstruction in the context of religious coping: rebuilding the shattered assumptive world, Omega, 53(1-2):87-104. https://doi.org/10.2190/DKMMB7KQ-6MPD-LJNA

Metzger, N. 2014. Railway spine, shell shock and psychological trauma: The limits of retrospective diagnosis, in E-M Becker, J Dochhorn \& E K Holt (eds.), Trauma and Traumatization in Individual and Collective Dimensions: Insights from Biblical Studies and Beyond. Studia Aarhusiana Neotestamentica Vol. 2, Gottingen: Vandenhoeck \& Ruprecht, 42-61. https://doi.org/10.13109/ 9783666536168.43 
Miller, G D 2009. A match made in heaven? God's role in marriage according to the book of Tobit, Rivista Biblica, 57, 129-153.

Miller, G. 2012. Raphael the liar: Angelic deceit and testing in the book of Tobit, Catholic Biblical Quarterly, 74(3):492-508.

Mitchell, K R \& Anderson, H. 1983. All our losses, all our griefs: Resources for Pastoral Care, Philadelphia: Westminster Press.

Otzen, B. 2002. Tobit and Judith. Guides to Apocrypha and Pseudepigrapha, London: Sheffield Academic Press.

Poser, R. 2016. No Words: The book of Ezekiel as trauma literature and response to exile, in $\mathrm{E}$ Boase \& C G Frechette (eds.), Bible through the Lens of Trauma. Semeia Studies, 86, Atlanta: SBL Press, 27-48. https://doi.org/10.2307/j. ctt1h1htfd.5

Strawn, B A. 2016. Trauma, psalmic disclosure and authentic happiness, in E Boase \& C G Frechette (eds.), Bible through the Lens of Trauma. Semeia Studies 86, Atlanta: SBL Press, 143-160. https://doi.org/10.2307/j. ctt1h1htfd.11
Van der Kolk, B E \& Van der Hart, O. 1995. The intrusive past: The flexibility of memory and the engraving of trauma, in C Caruth (ed.), Trauma: Explorations in Memory, Baltimore, Maryland: Johns Hopkins University Press, 158-182.

Weeks, S. 2011. A Deuteronomic heritage in Tobit? in H Von Weissenberg, J Pakkala \& M Marttila (eds.), Changes in scripture: Rewriting and Interpreting Authoritative Traditions in the Second Temple Period, Berlin: De Gruyter, 389-404. https://doi.org/10.1515/ 9783110240498.389

Yeo, J C. 2011. The psychometric study of the attachment to god inventory and the brief religious coping scale in a Taiwanese Christian sample, A proposal presented in partial fulfillment of the requirements for the degree Doctor of Philosophy, Lynchburg, Virginia: Liberty University. 


\section{Chapter 7}

\section{Questioning the "Natural Given"}

\section{Reading John 12:1-8 with a gender-critical lens}

\section{Nina Müller van Velden ${ }^{1}$}

\section{Merely a matter of unlocking divinely ordained, gendered natures?}

The landscape of gender and sexuality discourses set in the context of the contemporary Christian faith is characterised by plurality and complexity. This landscape is characterised by a number of interrelated views, two of which continue to receive a lot of attention (for a variety of reasons!), namely essentialism and complementarianism.

From a theological perspective, gender essentialism is the view that the whole of humanity has been created by God in two distinct sexes, each with its own "essence" or set of characteristics, strengths and weaknesses, namely male and female (Thatcher 2011:20). ${ }^{2}$ From this point of view, it follows that one's sex naturally leads and equates to a corresponding gender, i.e. male-man and female-woman. ${ }^{3}$

1 Doctor Nina Müller van Velden completed her PhD in 2018 at the Faculty of Theology, Stellenbosch University. With specialization in New Testament studies, her current research primarily focuses on gender-critical readings of biblical narratives with the aim of promoting responsible and life-giving hermeneutical tools for contemporary discourses on gender, sexuality and the Bible. This chapter is based on the research and findings of Chapters 1 and 4 of her unpublished doctoral dissertation of 2018.

2 Generally speaking, sex refers to the biological categories of male and female, ascribed to a person at birth and based on their external genitalia (Lemmer 2005:122). A person born with a penis and testes is classified as "male", while a person born with labia and a vagina is classified as "female". Increasingly the social constructions pertaining to physiological aspects imply that sex cannot simplistically be read off genitalia.

3 Generally speaking, gender refers to the social expression, interaction and demonstration of that which is deemed as either masculine or feminine by a specific social context or environment. Whereas sex indicates biological difference, gender identity is socially defined (Nolan Fewell 1993:242). 
Socialisation processes are said to simply "unlock" the foundational gendered potential of a person present since before their birth, with only one of two options available to them, corresponding to their God-given sex. ${ }^{4}$

Complementarianism follows on such gender essentialist views and is the theological perspective that considers male and female natures as well as their desires to be fixed and directed towards the opposite sex (Thatcher 2011:20). Furthermore, these opposites are deemed to need each other and cannot fully reach their potential on their own accord. Accordingly, in the context of the Christian faith, essentialism and complementarianism uphold heterosexual marriage as the ideal relationship status for all people, as this is presented as the God-given space within which male and female can flourish in their respective ways.

Within the theological framework of essentialism and complementarianism, Godself is represented as a male God of gendered order, both the figurehead and main representative of the order, as well as the gatekeeper of this order. The divisions and distinctions between male/man and female/woman are posited as necessary for all of creation to fulfil its God-given purpose in a harmonious manner. These opposites are marked by very distinct corresponding masculine or feminine traits, which are to clearly indicate the differences between the two opposites. However, this is seldom a case of simply celebrating difference of equals; a prominent dominant/ subordinate motif is cast and remains prevalent between male/female, man/ woman and masculine/feminine. ${ }^{5}$ Furthermore, heteronormative ${ }^{6}$ and (white) privileged generalisations and stereotypes usually create the impression that such fixed categories and traits of sexual and gender identity are universally applicable to all persons in any given context, irrespective of physiology, anatomy, class, age,

However, the strong distinction made between the categories of sex versus gender has been contested in the light of the complexity and reflexivity of biological and cultural processes (West \& Zimmermann 1987:126). The socially constructed nature of both sex and gender is increasingly gaining recognition. See, for example, Johnson (2006:91).

4 In her book Gender Trouble. Feminism and the Subversion of Gender Identity (1990) and subsequent volumes feminist and queer criticist Judith Butler contends that gender is something that is performed or done, rather than something essential, natural or innate. However, this gender performativity is not boundless or automatic. Rather it is "a practice of improvisation within a scene of constraint" (Butler 2004:1).

5 Often the phrase "different, yet equal" is used in this regard. History has shown, however, that this difference very seldom implies actual equality for all involved in any sphere of society. On the contrary, male/man is even today still viewed as the ideal, whilst female/woman is the less desired. According to Woodward and Woodward (2009:103-105), feminists have made considerable progress in deconstructing the so-called equality/difference binary in very productive ways. One alternative to having to choose between difference and equality has been the deconstruction of the division and exploration of the cost of the maintenance of such a binary in society.

6 "Heteronormativity refers to the ideological presupposition that heterosexuality serves as what can be labelled as the 'normal' or ideal sexuality and sexual behaviour, at the expense of alternative sexualities or sexual behaviours" (Müller van Velden 2014:13). 
ethnicity, race, family, location, or any of the multiple other factors which create variety and differentiation between individuals. ${ }^{7}$

In short, the development and ongoing sustenance of a binary gender system assumes clearly distinguishable twin tracks, along similar lines and with equality - the latter feature, however, is not the case. So too the notion that the one needs the other, complements the other, depends on the other is, like the division itself, biased towards masculinity, and implicitly serves the prevailing patriarchal agenda of contemporary societies. A blurring of these fixed categories and stereotypically ascribed gender traits by, for example, the presence of $\mathrm{LGBT}^{*}$ persons, ${ }^{8}$ working women, single mothers, unmarried persons, heterosexual couples who choose not to have biological children, and gender-fluid or gender non-conformative behaviour of individuals or couples is often viewed as, at the very least, a nuisance to be tolerated, but in extreme cases even cited as the cause of the moral and ethical instability prevalent in societies. ${ }^{9}$

\section{(Even more) alternatives are needed}

On the opposite end of a continuum to essentialism there is gender constructionism. This view acknowledges the complex and different ways in which men and women relate to each other, in the light of the influence of social and cultural conditions and contexts. Constructionism contends that no aspect of gender is fixed - rather everything about it is constructed. Such theories assume that relations of gender are neither revealed by God nor read off nature, but are rather historical constructions which are produced by societies and social groups (Thatcher 2011:20). ${ }^{10}$

7 Van Leeuwen (1993:230-231) discusses the isolation of gender as a category from others such as race, class, ethnicity and religion, and rightly poses the critical question as to why the category of gender as a social category necessarily needs to be given such a high priority.

$8 \mathrm{LGBT}^{\star}$ refers collectively to those persons who identify themselves as belonging to sexual minority groups such as lesbian, gay, bisexual, transgender, intersex and queer. In recent years even more categories have been added to this abbreviation (e.g. asexual and pansexual), indicating a growing awareness of the spectrum of sexual identities in societies. The term "queer persons" is often used collectively, not in a derogatory sense, but rather to refer to those persons who do not identify with a heterosexual identity and/or heteronormative social prescriptions.

9 The North American conservative environment is saturated with so-called "family movements," promoting traditional and patriarchal family values (amongst which traditional gender roles). The motivation for these movements is often stated as attempts to "regain" stability and moral order in society, thereby implying that persons who do not conform are, indeed, the cause of unethical behaviour and immorality in society. South African bookstores stocking popular Christian literature typically have a variety of imported and local publications reflecting similar values and attempts.

10 The challenge that can rightly be posed to proponents of gender constructionism is the way in which sex and gender are often presented as such completely different categories, that yet another binary opposition of either/or in the form of nature versus nurture is created - as if there is no link between these two at all. In my opinion, however, it is important that the link acknowledged should be one of reciprocal influence (i.e. sex influences gender and gender influences sex), rather than giving hierarchical preference to the influence of sex on gender (as has generally been the case) (Woodward \& Woodward 2009:143). 
A large number of scholars across the globe, especially within the sphere of feminist theology, womanist theology, queer theology, and/or biblical scholarship have to this day made attempts to challenge essentialist and complementarian theological discourses, the universalistic generalisations they impose on men and women across the globe, as well as the dominant/subordinate motif which mostly accompanies the male/female, man/woman and masculine/feminine categories. ${ }^{11}$

However, there still remains a lot to be done, especially within the context of South Africa and the influence of essentialist and complementarian theological views in local Christian faith communities, and the interpretation of the Bible in particular. ${ }^{12}$ What is needed is perhaps an even more purposeful attempt within biblical hermeneutics to highlight the socially constructed nature of gender, both past and present, thereby questioning the popular "natural given" binary system of male/man/masculine and female/woman/feminine. As such, contemporary readers and audiences might have greater awareness of the fallacy of an ahistorical, timeless gendered system that seemingly had divine origins in antiquity, with the purpose of directing human relations throughout all ages - and the harm such a fallacy has and still does cause. A first step may be the unmasking and acknowledgement of the fallacy, including an investigation and tracing of its origins, but my focus now rather turns to the investigation of a gender-critical hermeneutics and the consequent reading of one particular narrative biblical text.

\section{Why a focus on a narrative biblical text?}

According to Van Leeuwen (1993:188), the sharing of sacred stories (i.e. those narratives which are viewed by a particular group or community as containing faith-based norms and values) is one of the ways in which a community develops its identity symbolically. The major source of sacred stories in the Christian faith is the Bible. The sacred stories contained in it are ascribed normative principles and moral imperatives. These principles and imperatives should be embodied in action by those who hold the narratives as sacred. The relations of story to imperative are diverse and numerous. These stories are shared within the context of a societal institution, the church, which has been characterised as playing an immense role in the process of gendering throughout the ages. The patriarchal context of the origin of biblical narratives and their subsequent repetitions has generated a very particular understanding of sexuality and gender.

11 According to Schüssler Fiorenza (2000:98), gender is one of several systems of domination in society. Therefore, she is of the opinion that it is necessary to conceptualise the formation of gender in terms of power relations. Tolbert (2000:104) is of the opinion that sex and sexuality should not be seen as eternal products of nature or God's decree, but rather as historically specific, politically informed discursive representations of the material body.

12 The patriarchal and heterosexist structure of South African society finds expression in extremely violent ways directed especially towards women and members of the queer community - both in word and deed. The official statistics available on instances of sexual abuse, domestic violence, rape and so-called "corrective rape" (already shockingly high) are but the tip of the iceberg, as most victims and survivors are unwilling to report out of fear of further abuse and victimization. 
From a biblical hermeneutical perspective, the essentialist and complementarian position on sex and gender is often based on a literal and fundamentalist interpretation of the sacred stories contained in the creation narratives of Genesis 1 and 2, and subsequent references to them in the New Testament. ${ }^{13}$ However, such limited and ahistorical interpretations of two versions of one narrative fail to take into account the immense gap between the context of the origin of the biblical narratives and contemporary contexts, especially with regard to matters pertaining to sexuality and gender. This narrative is conveniently made to serve the ideology of unequal power relations created and sustained by heteronormative, patriarchal and essentialist discourses in the Christian tradition, leading to the marginalisation, exclusion and abuse of persons who do not fit this narrow (and unrealistic) dichotomous mould of sexuality and gender.

By giving such prominence to only one biblical narrative for the sake of theological discourses on gender and sexuality, the potential depth and range of insights from other biblical narratives are inhibited. What is needed are not merely more possible interpretations of the creation narratives (of which a range of options already exist), but rather a wider scope of narratives to be considered in such discourses. Such a wider scope might shed light on the complexity of sexuality and gender, as already evident in biblical narratives themselves, and offer a broader range of perspectives to inform discourses, teachings and practices relating to gender and sexuality within the Christian faith tradition. In this regard numerous New Testament narratives contained in the Gospels could become valuable conversation partners.

\section{Reading biblical narratives with a gender-critical lens}

Gender-critical readings of biblical narratives offer the opportunity to engage critically with sacred stories and the way in which gender is embodied and expressed in social settings, within the boundaries of that narrative. Here the critical questions do not necessarily probe the presence and performance of only women in a $1^{\text {st }}$ century patriarchal setting (e.g. feminist-critical readings), or the way in which heteronormative biases are challenged (e.g. queer-critical readings), but rather the way in which gender prescriptions, expectations and standards within the given social setting of the narrative and against the socio-cultural background within which they originated, are conformed to, challenged, actively opposed and even transgressed. In short, the focus is on the literary construction of gender in the narratives under consideration.

Although related to feminist- and queer-critical reading strategies, a gender-critical reading has a specific focus on the backdrop of notions such as essentialism, constructionism and complementarianism, as well as being an enquiry into the

\footnotetext{
13 Gen. 1:27-28; Gen. 2:15-25; Matt. 19:4-6; Mark 10:6-9; 1 Cor. 6:16b; 1 Cor. 11:8-12; Eph. 5:31, 1 Tim. 2:11-15.
} 
sex-gender relationship, and the discourses of power involved in sex-gender relations; it is thus an ideological-critical reading strategy focused on the way in which gender and sexuality have been constructed and are expressed in a specific biblical narrative or set of narratives.

According to Kitzberger (2003:180), gender is an important aspect of characterisation in biblical narratives. As a social construct and as related to literary characters, it is established by the roles attributed to a character within the narrative, as well as by the context within which a character is portrayed. Furthermore, gender is constructed by means of the relation of a character to other characters, male and female, in the same text (configuration) and in other texts (interfigurality). ${ }^{14}$ Gender in biblical narratives takes shape in two processes: first, the construction of the text by its author; second, by its reconstruction on the part of the reader. This is no different to any other aspect of characterisation. In this sense, gendered characterisation is also a very individual issue, dependent on the readers and their own social location. Readings that concentrate on gender as constructed in the text and as reconstructed by the reader emphasise gender as a category of analysis (Kitzberger 2003:206).

Gender-critical readings ask: In what ways are the categories of male/man/ masculine and female/woman/feminine, as measured against the social setting serving as its background, affirmed and/or confused? What does the narrative offer readers, especially then in contemporary settings, for reflecting on gender relations and processes of gendering? Thus, both ancient as well as contemporary contexts of gender and sexuality inform such readings and need to be taken seriously, in attempting to question so-called "timeless truths" which operate in isolation from historical contexts - of the past and the present.

\section{$(\mathrm{Re})$ reading John 12:1-8 with a gender-critical lens}

The Gospel of John offers an interesting array of narratives for the purposes of discourses on gender, sexuality and theology. This has been explored by numerous biblical scholars, especially from feminist ${ }^{15}$ and, more recently, also from queer ${ }^{16}$ perspectives.

For gender-critical readings the Johannine Gospel also offers a number of options. One such option is the "meal and feet" story of John 12:1-8, i.e. Mary of Bethany anointing Jesus' feet. The narrative is positioned right before Jesus' entry of Jerusalem (John 12:9-19) and has the striking characteristic of giving much prominence to less

\footnotetext{
14 'Interfigurality' is a term coined by Wolfgang G. Müller and refers to the interrelations that exist between characters of different texts. It is considered one of the most important dimensions of intertextuality (Kitzberger 2003:179).

15 See, for example, Brown (1975:688-699), Schüssler Fiorenza (1984:323-333), Schneiders (1999:93-114), D'Angelo (1999:129-149), Reinhartz (2003:14-33) and Conway (2003:79-103).

16 See, for example, Thatcher (2011:169-170).
} 
attractive or appealing body parts, namely feet, in the intimate and personal space of meal-sharing with Jesus as protagonist. ${ }^{17}$ This takes place, furthermore, amidst prominent symbolic actions ${ }^{18}$ bearing much weight in the run-up to the crucifixion of Jesus as set out in the Gospel of John.

John 12:1-8 narrates the events of the anointing and drying of Jesus' feet as performed by Mary, in the presence of (at least) her recently resurrected brother, Lazarus, her serving sister, Martha, and the disciples of Jesus - and the subsequent reaction from Judas. Set against the background of a socio-cultural context in which male honour and female shame directed all private and public social acts, with an elaborate understanding that male and female be kept apart, ${ }^{19}$ one has here a narrative which, at least on one level, challenges gendered expectations in a number of ways. ${ }^{20}$

The narrative is set in Bethany, where Jesus arrived six days before Passover (12:1). Jesus and his disciples are underway to Jerusalem to participate in the celebration of this important Jewish festival. Shortly before (11:53), the narrator stated the intent of the chief priests and the Pharisees to kill Jesus. ${ }^{21}$ The event of Jesus' death is getting closer and closer. Brant (2011:179) considers the setting a ritual space in which rites of hospitality become funeral rites.

Initially (12:2), it would appear as if a "resurrection party" is being celebrated, in honour of Jesus and the miraculous deed he has performed in bringing Lazarus back to life (cf. Ridderbos 1997:414). Martha is serving ${ }^{22}$ the meal - a typically female gendered role. It is noteworthy that Lazarus, as the male family member, ${ }^{23}$ is not taking on the explicit role of a host - as might be expected given the reason

17 In the biblical tradition feet sometimes have broader connections, amongst which serving as euphemism for the genitals, or sometimes considered to have erotic connotations, as well.

18 According to Du Toit (1990:10), one of the key characteristics of the Gospel of John is its use of symbols "to bridge the gulf of understanding between spiritual truths and the everyday world." Smalley (1978:192) states that the narrative of the Fourth Gospel always operates on two levels at once, a deliberate ambivalence between earthly and heavenly, in time and in eternity. Movement between the two takes place easily and at times even seamlessly.

19 Bartchy (2008:163) states that the world of and around the New Testament was no different from ours in terms of the existence of distinct ideas of what sorts of behaviour should be expressed by males and females. Ancient sources offer many such examples and it can rightly be stated that, within the ancient worldview, everything was gender-divided.

20 The themes of honour and shame, their relation to gender and sexuality, and gender performativity as required within the $1^{\text {st }}$ century Mediterranean context, receive attention from scholars such as Malina (2001:27-56), Malina \& Neyrey (1991:25-66), Plevnik (1993:106-115) and Moxnes (2007:155-170).

21 The tipping point for their decision was the miracle that took place shortly beforehand, when Jesus resurrected Lazarus from the dead.

22 Martha's action is suggestive, since by the time the Fourth Gospel was written, there was apparently in some Christian communities an office of "deacon", who had the task of waiting on tables as a specific function (Thurston 1998:88; Brown 1979:187; Scott 2003:1191).

23 Women lived under the headship of a male, be it their father, uncle or brother (if they were unmarried or widowed), or her lawful husband. Thereby the man fulfilled the role of the pater familias. Lazarus, being the brother and male relative of the unmarried Mary and Martha, therefore fulfils this role in this narrative - however, not necessarily portrayed actively in the narrative as would be expected. 
for the occasion (Scott 2003:1191). Rather, he is reclining at the table with Jesus, i.e. fulfilling the role of a guest (Harris 2015:224). As in the case of John 11:1-44, Lazarus takes on a much less prominent role in this narrative than do Martha and Mary (cf. Talbert 1992:184). Although Martha and Mary do not speak in 12:1-8, they take on active roles of serving and anointing. Given the social rules of verbal and physical participation for women in social settings - even then in settings where the boundaries between male and female spaces were slightly blurred (such as funerals or feasts) - this is an interesting feature of narrative within a $1^{\text {st }}$ century (Jewish) setting.

What follows is the main scene of this narrative: Mary anointing the feet of Jesus with a large amount of expensive oil, after which she dries them with her hair. In case anyone missed seeing what had just happened, their nostrils would soon give them a hint; the whole house was filled with the fragrance of the oil (12:3).

Culturally, the act of washing and anointing feet was not strange in antiquity. However, this was usually done by oneself. Guests who arrived at someone's house after a long journey would typically be offered a basin and water by the host to wash their own feet before sharing the meal. This was mainly for hygienic reasons, given the dirt and dust of roads in the ancient Mediterranean world (Malina \& Rohrbaugh 1998:205). In some cases a host would also provide oil for his guests, although they would usually rub it onto their feet themselves (Koester 2003:127-128). Virtually the only person who would have been expected to wash and anoint the feet of another person would be a slave. ${ }^{24}$

Here it is a woman who is not simply washing, but anointing the feet of Jesus, a male guest of prominent status - during a meal. This was uncommon in all possible ways (Malina \& Rohrbaugh 1998:205; Kanagaraj 2013:123; Ridderbos 1997:414). It is a scene of extravagance and excess (Scott 2003:1191); Mary has come prepared with a litra of perfume, described as pure and expensive nard oil - the oil extracted from the roots and spike of the exotic nard plant (Ridderbos 1997:414; Beasley-Murray 1987:204; Carson 1991:428). This is an extravagant act: it is such a large amount of oil that its scent filled the whole house; an act which is therefore undeniably public and involves all present (O’Day 2012:524). Women were expected to know their place and be as 'invisible' as possible, especially in the presence of men. Mary not only spatially transgresses the boundaries of private (female) and public (male); as a female she also takes on a public (male) role that invites public (and male) participation. After anointing Jesus' feet, Mary wipes off the perfume with her hair. This was also not a normal Jewish custom (Kanagaraj 2013:123).

24 Rabbinic rulings did allow children to perform these tasks for their parents; however, on the whole the washing or anointing of the feet of another person remained identified with slavery (Koester 2003:128). 
Scott (2003:1191) is of the opinion that Mary loosening her hair to wipe the ointment is not only a unconventional picture, "but also one with a quasi-erotic tone." Ilan (1995:122-134) notes the necessity of head-covering in public settings and in the presence of strangers, with a view to the preservation of Jewish women's chastity within the setting of Greco-Roman Palestine. Morris (1971:576-577) comments on the fact that such an act - of a Jewish woman with unbound hair in public - went against the prescriptions for Jewish women as it "marked loose morals." Men, on the other hand, were to avoid head-coverings so as not to be marked as effeminate - a classification with implications linked not only to gender performance but also to one's sexuality. Mary is blurring gender lines and also finding herself in the grey area of sexually dubious behaviour.

Not only is Mary disregarding the familiar and clear-cut gendered boundaries of the time, Jesus - the male protagonist of this narrative - appears fully accepting of her behaviour. The expectation would be that Jesus would reprimand or even punish her, and yet there appears to be no sign of discomfort or judgment of the action on his part. Mary's act elicits two reactions: one by Judas (12:4-6) and the other by Jesus (12:7-8) (Talbert 1992:184).

Juxtaposed to the depiction of Mary's selfless devotion in 12:3 (De Jonge 1996:162; Koester 2003:128-129; Morris 1971:576) is the description of Judas in 12:4 (cf. Conway 2003:91-92). The contrast between these two characters - the female disciple, Mary, versus the traditional male disciple, Judas - could not be more evident (Scott 2003:1191), depicted at the meal "in all its radical and deadly seriousness" (Ridderbos 1997:415). ${ }^{25}$ Judas is the one who speaks, whilst others present most likely had the same thought, even amongst the disciples (Carson 1991:428; Harris 2015:225). Not only has Mary performed a seemingly reckless and extravagant act - Jesus also accepts it (Harris 2015:225); “Judas receives a harsh rebuke, 'Leave her alone!' while Mary earns a defence in the form of interpretation" (Conway 2003:92).

By now the reader is familiar with Judas. It is the second time he is mentioned in the Gospel of John and he is known as the disciple who will betray Jesus $(6: 60,71)$ (Moloney 1995:181). In both cases he is characterised as a thief whose greed is masked with a false concern for the poor. Here (12:5) he suggests that the cost of the perfume - the equivalent of a year's wages for a fully employed man (Adeyemo 2006:1277; Beasley-Murray 1987:208; Carson 1991:429; Harris 2015:225) - could have much rather been used to serve those in need. However, his intentions are not quite as pure as they may sound: the narrator makes it clear that Judas was lying for his own gain (12:6). He would much rather have that sum of money in the

Feminist scholars such as Schüssler Fiorenza are of the opinion that this is an intentional portrayal of a true female disciple, Mary of Bethany, as an alternative to the unfaithful male disciple, Judas (Conway 2003:91-92). 
common purse that he administered and from which he enriched (literally!) himself (Ridderbos 1997:415; Moloney 1995:181-182). ${ }^{26}$

Jesus' response to Judas (12:7-8) portrays Mary as the one who is in tune with his coming hour. ${ }^{27}$ It is the first time in the narrative that Jesus' proximate death is recognised: the action of Mary is preparation for the death of Jesus. She has symbolised the significance of that death by anointing the body of Jesus and wiping it with her hair (Moloney 1995:182). From Mary's perspective, her act was simply a way of telling her Lord how much she appreciated him; from God's perspective, however, her act marked the start of Jesus' passion (Adeyemo 2006:1277). Not only did Jesus give life to Lazarus; he will soon give his own life as gift. Mary is not simply expressing thanks for her brother's life (Koester 2003:127); she is prophetically (yet most likely unknowingly) offering a proleptic response to the consummate gift Jesus was about to give (Koester 2003:129-130; Carson 1991:430).

Jesus' reference to the poor in 12:8 is an attempt to give perspective on his own earthly presence (limited and only for a brief time), compared to the presence of the poor (an eternal presence in human history) (Moloney 1995:182; Carson 1991:430; Malina \& Rohrbaugh 1998:206). It should be understood as a response to Judas' apparent concern uttered in 12:5 in relation to the events that lie ahead. For Jesus, the priority at this point in time is to acknowledge him as the messianic King and to spend anything expensive for his sake, rather than to give money to the poor without real concern for them (Kanagaraj 2013:124).

\section{Creative possibilities in the "both/and"}

Read through a gender-critical lens, the narrative of John 12:1-8 presents two elements: first, a transgression of gendered boundaries (and the approval of this); second, a reversal of traditional gender roles. This in turn affects the identity of the characters represented in the narrative. Such transgression and reversal of gender cultural norms are highlighted in contrast to the depiction of traditional gendered frameworks that are simultaneously present in the narrative. Paradoxically, also, such transgression and reversal of gender cultural norms are performed precisely from the position of authority and status awarded within such a traditional framework - by the male protagonist, Jesus.

\footnotetext{
26 This is the only place in the New Testament where Judas is called a thief, or where any charge other than his role as ultimate betrayer is levelled against him (Carson 1991:429).

27 The burial saying (12:7) is presented in a particularly difficult form, which leads to ambiguity (Beasley-Murray 1987:205) and numerous translation options by commentators. For the purpose of this chapter it suffices to contend that Mary's anointing can be considered as an act that anticipates Jesus' burial, but does not imply that by the act the day of his burial had already commenced (Ridderbos 1997:417). Furthermore, an anointing at the burial of Jesus is also narrated in the Fourth Gospel (19:39-40) (in which Mary seems to play no part) (Scott 2003:1191); thus this anointment is not a replacement of any sorts.
} 
Transgression of gendered boundaries takes place primarily in the role that Mary fulfils in this narrative. Harris (2015:224) summarises the surprising irregularities of Mary's actions as follows: the feet were anointed; the anointing took place during a meal; hair rather than a towel was used for wiping Jesus' feet; Mary, a woman, let her hair down in public; and the oil was wiped off with her hair. Measured against the cultural expectations of women at the time, she is acting shamelessly and thereby bringing negative shame (instead of the expected positive shame) to herself and her household. Rather than serving the meal, as Martha was doing, Mary is at the feet of Jesus.

And yet, the extravagant hospitality and extraordinary gesture of letting down her hair in public, and touching Jesus, does not seem to offend or repel Jesus (Thurston 1998:88). Thereby Jesus also transgresses gendered boundaries. By not reprimanding Mary for such an excessive, yet intimate act, he condones her transgressive behaviour. Moreover, he actively defends her behaviour when Judas, a male disciple, raises his objection. Jesus is siding with a shameless woman and thereby makes the most significant possible move from one end of the bipolar male-female relation to the other: from male honour to female shamelessness.

At the same time Jesus is acting in a typically male fashion in terms of the script for defence of honour in a challenge and riposte situation between two males in a public setting. Judas' objection to Mary's behaviour is perhaps in the first instance a challenge to Jesus, as a man who has accepted such transgressive behaviour from a woman. Jesus' response to the challenge is to expose Judas' ignorance, thereby shaming Judas publicly and "winning" the challenge. One might argue that Jesus is thus not acting as transgressive in terms of traditional gendered roles as would have perhaps been hoped for. This would raise the critical question: is Jesus merely defending Mary for the sake of defending his own male honour?

The narrator is also offering a portrayal of a reversal of traditional gender roles. Lazarus, through his passivity in this public event, is not fulfilling the expected active role of a male host in a social setting. Public passiveness and subordination belong to the sphere of women, whereas public activeness and prominence belong to the sphere of men. One would have expected Lazarus to at least offer a word of thanksgiving to Jesus; after all, he is alive! The character in this narrative who fulfils a public active male role is Mary. This role is highlighted all the more by means of the contrast of female Mary with male Judas. She is portrayed as a true disciple, devoting herself completely to Jesus and humbling herself at his feet. At the same time, through the words of Jesus directed at Judas, the narrator sets Mary up as a prophet who unknowingly conveys the unavoidable ending to Jesus's life - at the very least to all the guests present, but perhaps even also to Jesus himself. In this narrative there is no other male disciple who takes up any similar role as true disciple or prophet. The only depiction of discipleship by a male person is the "anti-disciple example" set by Judas. Mary seems to be everything that Judas is not. 


\section{Conclusion}

The gender-critical reading of John 12:1-8 recognises, to a large extent, characterisation of male and female characters that do not comply with traditional gender expectations and prescriptions, as measured against the ancient setting of the $1^{\text {st }}$ century Mediterranean world. Yet there are moments in the narrative where the opposite is true, instances where the same character (in this case, Jesus) fulfils both the role of traditional and unconventional male in the same narrative. The judgment as to whether he is acting in Mary's defence by responding to Judas, or simply ensuring that his own male honour does not suffer harm in a challenge, is dependent on the position of the interpreter.

It might be that the tension of "both/and" rather than a forced choice for "either/ or" serves best the complexity of contemporary discourses on biblical narratives, gender and sexuality. Jesus defends and allows gender transgression and himself acts transgressively in terms of the prescribed and expected gendered norms and behaviour of his context. Simultaneously, Jesus can defend and allow such (gendered) behaviour precisely from his position of ascribed and acquired male honour and power. Yet the outcome of his use of power is surprising and unexpected for a strictly patriarchal setting: it is life-giving - it allows for Mary to act upon her convictions in that moment of devotion and thereby to fulfil a role of prophetic recognition of Jesus and his approaching crucifixion. Moreover, it would appear as if Mary's behaviour here is in some way pre-empting the footwashing of the disciples by Jesus that will take place shortly (O'Day 2012:525); a "shameless" woman setting the example for the honourable man, Jesus. ${ }^{28}$

Given how seamlessly Jesus appears to move between "proper" and "improper" contextual expectations of male behaviour in this narrative of John 12:1-8, it is much rather a gender-fluid than a one-dimensional, honourable male that is presented in the characterisation of Jesus. Such transgressive, unexpected behaviour in itself already affirms the sign-act of this narrative: the anointing of a respected, innocent man, recognised as leader and lord by his followers, who will lay down his life and power to be glorified and united with the Father through the crucifixion and resurrection.

As illustrated above with the (re)reading of the narrative of John 12:1-8, a gender-critical lens allows for more and different options to the phrase "the Bible says," as often heard from the perspective of essentialism and complementarianism in Christian theological discourses regarding gender and sexuality. The purpose of gender-critical readings of biblical narratives, as proposed in this paper, is not merely a knee-jerk reaction of prooftexting yet again, simply with a different outcome. Rather, it is an attempt to broaden the playing field; to undo oversimplifications,

28 Variations of the same verb, "wipe", is used both for Mary's action when wiping the oil off Jesus feet with her hair (12:3), and Jesus' action when drying the disciples feet with the towel (13:5) (Conway 2003:91). 
challenge binaries, and to bring to light the way in which socio-cultural contexts, past and present, had and indeed still have a profound impact on our understanding of gender and sexuality - specifically then also in religious contexts.

Perhaps such readings may pave the way for embracing the complexity of gender and sexuality as part of our personhood, opposing the need to oversimplify and typecast persons based on their sex and gender: not only in biblical hermeneutics, but within biblical scholarship, theology and faith communities in all their expressions across the globe. Such inclusive risk-taking, rooted in an ongoing and respectful dialogue between the interpretations of biblical texts and contemporary contexts, marks the faithful, enduring and hope-confessing endeavours of Prof Elna Mouton in a range of settings. May her example continue to encourage and inspire affirming, life-giving spaces.

\section{Bibliography}

Adeyemo, T (ed.). 2006. Africa Bible Commentary, Nairobi: Word Alive Publishers.

Bartchy, S S. 2008. Gender. Who Should Be Called 'Father'? Paul of Tarsus between the Jesus Tradition and Patria Potestas, in J H Neyrey \& E C Steward (eds.), The Social World of the New Testament. Insight and Models, Peabody: Hendrickson, 163-180.

Beasley-Murray, G R. 1987. Word Biblical Commentary Volume 36, John Waco: Word Books.

Brant, J A. 2011. John. Grand Rapids: Baker Academic.

Brown, R E. 1975. Roles of Women in the Gospel of John, TS, 36: 688-699.

Brown, R E. 1979. The Community of the Beloved Disciple, New York: Paulist Press.
Butler, J. 1990. Gender Trouble. Feminism and the Subversion of Gender Identity, New York, Oxfordshire: Routledge.

Butler, J. 2004. Undoing Gender, New York, Oxfordshire: Routledge.

Carson, D A. 1991. The Gospel According to John, Leicester Apollos, Grand Rapids: William B. Eerdmans.

Conway, C. 2003. Gender Matters in John, in A J Levine \& M Blickenstaff (eds.), A Feminist Companion to John, Volume II, London, New York: Sheffield Academic, 79-103.

D’Angelo, M R. 1999. (Re)Presentations of Women in the Gospels: John and Mark, in R S Kramer \& M R D’Angelo, (eds.), Women and Christian Origins, New York: Oxford University, 129-149. 
De Jonge, M. 1996. Johannes. Een praktische bijbelverklaring. Tekst en Toelichting, Kampen: Uitgeverij Kok.

Du Toit, A B (ed.). 1990. Guide to the New Testament, VI, in The Gospel of John, Hebrews to Revelation: Introduction and Theology, Pretoria: NG Kerkboekhandel.

Harris, M J. 2015. Exegetical Guide to the Greek New Testament: John, Nashville: B\&H Publishing Group.

Ilan, T. 1995. Jewish Women in Greco-Roman Palestine, Peabody: Hendrickson.

Johnson, L T. 1999. The Writings of the New Testament. An Interpretation. Revised Edition, Minneapolis: Fortress.

Johnson, W S. 2006. A Time to Embrace. Same-Gender Relationships in Religion, Law, and Politics, Grand Rapids, William B. Eerdmans.

Kanagaraj, J J. 2013. John. A New Covenant Commentary, Eugene: Cascade Books.

Kitzberger, I R. 2003. Transcending Gender Boundaries, in A-J Levine \& M Blickenstaff (eds.), A Feminist Companion to John. Volume II, London, New York: Sheffield Academic Press, 173-207.
Koester, C R. 2003. Symbolism in the Fourth Gospel, Meaning, Mystery, Community, Second Edition, Minneapolis: Fortress.

Lemmer, J. 2005. Identity \& Sexual Identity, Pretoria: Sexology SA.

Malina, B J. 2001. The New Testament World. Insights from Cultural Anthropology, Third Edition, Revised and Expanded, Louisville: WJK.

Malina, B J \& Neyrey, J H. 1991. Honor and Shame in Luke-Acts: Pivotal Values of the Mediterranean World, in J N Neyrey (ed.), The Social World of Luke-Acts. Models for Interpretation, Peabody: Hendrickson, 25-66.

Malina, B J \& Rohrbaugh, R L. 1998. Social-Science Commentary on the Gospel of John, Minneapolis: Fortress Press.

Moloney, F J. 1995. Signs and Shadows. Reading John 5-12, Minneapolis: Fortress Press.

Morris, L. 1971. The Gospel According to John. The New International Commentary on the New Testament, Michigan: Eerdmans. 
Moxnes, H. 2007. Where is 'Following Jesus'? Masculinity and Place in Luke's Gospel, in A C Hagedorn, Z A Crook \& E Steward (eds.), In Other Words. Essays on Social Science Methods and the New Testament in Honor of Jerome H. Neyrey, Sheffield: Sheffield Phoenix, 155-170.

Müller van Velden, N E. 2014. Crucifixion of masculinity: A gender critical (re)reading of the narrative of the cross as portrayed in the Gospel of Luke, Unpublished master's thesis, Stellenbosch: Stellenbosch University [Online].

Nolan Fewell, D. 1993. Feminist Criticism, in S L McKenzie \& S R Hanes (eds.), To Each its Own Meaning. An Introduction to Biblical Criticisms and their Application, Louisville: WJK, 237-251.

O’Day, G R. 2012. Gospel of John, in C A Newsom, S H Ringe \& J E Lapsley (eds.), Women's Bible Commentary. Revised and Updated, Louisville: Westminster John Knox, 517-530.

Plevnik, J. 1993. Honor/Shame, in J J Pilch \& B J Malina (eds.), Handbook of Biblical Social Values, Peabody: Hendrickson, 106-115.
Reinhartz, A. 2003. Women in the Johannine Community: An Exercise in Historical Imagination, in A J Levine \& M Blickenstaff, M (eds.), A Feminist Companion to John, Volume II, London, New York: Sheffield Academic, 14-33.

Ridderbos, H N. 1997. The Gospel according to John. A Theological Commentary, Translated by J Vriend, Grand Rapids: William B. Eerdmans.

Schneiders, S M. 1999. Written That You May Believe: Encountering Jesus in the Fourth Gospel, New York: Crossroad.

Schüssler Fiorenza, E. 1984. In Memory of Her: A Feminist-Theological Reconstruction of Christian Origins, London: SCM.

Schüssler Fiorenza, E. 2000, Jesus and the Politics of Interpretation, New York, London: Continuum.

Scott, J M C. 2003. John, in J D G Dunn \& J W Rogerson (eds.), Eerdmans Commentary on the Bible, Cambridge: William B. Eerdmans, 1161-1212.

Smalley, S. 1978. John: Evangelist and Interpreter, Exeter: Paternoster.

Talbert, C H. 1992. Reading John. A Literary and Theological Commentary on the Fourth Gospel and the Johannine Epistles, New York: Crossroad. 
Thatcher, A. 2011. God, Sex, and Gender. An Introduction, Chichester; Malden:

Wiley-Blackwell.

Thurston, B. 1998. Women in the New Testament. Questions and Commentary, New York: The Crossroad Publishing Company.

Tolbert, M A. 2000. Gender, in A K M Adam (ed.), Handbook of Postmodern Biblical Interpretation, St. Louis: Chalice, 99-105.
Van Leeuwen, M S (ed.). 1993. After Eden. Facing the Challenge of Gender Reconciliation, Grand Rapids: William B. Eerdmans.

West, C \& Zimmerman, D H. 1987. Doing Gender, Gender and Society, 1(2): 125-151.

Woodward, K \& Woodward, S. 2009. Why Feminism Matters. Feminism Lost and Found. London: Palgrave Macmillan. 
Section B | READING WRITINGS 


\title{
Chapter 8
}

In Search of the Female Sage

\author{
A decolonial reading of the story of the \\ Samaritan woman (John 4)
}

Lilly (SJ) Nortjé-Meyer

\section{Setting the scenario}

A decolonial reading of the story of the Samaritan woman in John 4 is partly based on a commentary by Charles Erdman of the Gospel of John, freely translated into Afrikaans by D R Snyman and will serve as intertexture that correlates with its social-cultural context (Weren 2014:298). The date of Erdman's original publication as well as Snyman's translation are not indicated in the book. An inscription by the previous owner of the book is dated 1943. I found the original date of Erdman's book on the internet as 1916.

The agenda for the translation into Afrikaans is stated in an Announcement by the Afrikaans publishers, Suid-Afrikaanse Bybelvereniging (The Bible Society of South Africa), namely that the purpose of this Afrikaans series is that the "publishers hope that our people (ons volk) will find these manuals or textbooks (handleidings) useful, especially during family prayers (huisgodsdiens); and they also kept the price low to enable the poorer segment of our people to be able to afford the book". Furthermore, in the Preface, the Bible Society says that due to the lack of space they have omitted all the illustrations and references from relevant literature. Although a translation, the choice of Afrikaans words and their context by the translator positions this commentary within the context and ideology of the coloniser.

The colonial ideology of the white Afrikaans male has clearly influenced his view of the person of the Samaritan woman and her conversation with Jesus. It serves as a cultural text that is central to the strategies of modern imperialism. The way in which Jesus and the Samaritan woman are interpreted by the Afrikaans translator demonstrates 
how these representations are governed by the politics of interpretation, theological persuasion and the ideological motives of the coloniser. From a decolonial feminist perspective this paper aims to reveal the colonial intended translation of Snyman and to reread the story of the Samaritan woman in searching for the female sage.

In this discussion I am taking into consideration the cultural expectations and gender divisions in the text of John (Neyrey 2009:147), but the focus is on the contemporary intertexture of the commentary of Snyman (n.y.).

\section{A decolonial reading}

Feminist biblical scholars focus on aspects of the biblical story with the potential for liberating Christian women; they also pay close attention to rhetorical criticism, by which they mean to unravel not only the ideological contexts of authors but also their intentions (Schneiders 1991:185). Decolonial reading focuses on texts that legitimate and authorise imperialism, including canonised and contemporary texts of different disciplines and genres. The use of the female gender to describe the colonised peoples serves the agendas of constructing hierarchical spaces, genders, races and cultures, but it also comes to legitimate the oppression of women in societies where these narratives are read and used (Dube 1996:42). This includes the perspective of stereotypical female behaviour and females as manageable cultural and ethnic objects in the contemporary cultural world.

Modern colonisers use different forms and methods from their ancient counterparts. Their strategies disguise military power and economic greed under the pretence of evangelical zeal and moral-rhetorical, technological, racial and cultural claims of superiority (Dube 1996:40).

Historically, missionaries were at the forefront of the colonisation process. Although the intention of the missionaries was to spread the good news of salvation, this resulted in the oppression and eventual destruction of the colonised people's culture, family life and their way of living. Missionaries did not act on their own or independently. They were sent and financed by their home churches to spread Christianity and had special protection from their home countries. Dube points out that:

1. missionaries alarmingly had no moral objection to the colonising of foreign lands;

2. missionaries acted as an important tool in the promotion of imperialism; and

3. missionaries cannot be separated from the conquering powers themselves (Dube 2000:58). 
Missionaries supported the spread of colonialism by doing the initial work of cultural imperialism for those in power by forcing colonised people to change their religion and social norms. Therefore, although missionaries built schools and hospitals for the colonised on the mission stations, they are indubitably connected to the colonising powers (Wood 2013:29).

Representation or stereotyping is a major rhetorical strategy by which colonial ideology exerts its power. Producing stereotypes is about the construction of the 'other' and how such constructions stereotype the identities of the colonised and the coloniser in terms of race, class and gender in religious and sexual categories. These images are based on the colonisers' perceptions of themselves and their cultures as the only true manifestations of what human beings should be or what informs and constitutes culture.

Colonial stereotypes produce two related types of representation: the misrepresentation of the colonised, and the affirmative presentation of the coloniser (Sugirtharajah 2012:161). According to Sugirtharajah, this misrepresentation of the colonised operates in dialectically opposite ways: the first in which the colonised 'other' is presented as impure, mute, inferior, unintelligent and incapable of any initiative; on the other hand, the coloniser is presented as having virtues, values and dignified traits such as piety, innocence, insight and true knowledge. These presentations of the colonisers sustain their virtues and values and assert their self-identity and self-importance, and emphasise their control and dominance of the colonised "other". What representation or stereotyping achieves is to categorise people and put them into manageable cultural and ethnic objects: "It divides the world into us and them, and creates an uneasy and complicated social hierarchy. Such binary thinking perpetuates certain myths such as the other as an undifferentiated category, and more permanently, it keeps alive the idea that there is a standard against which the 'other' can be assessed and absolved" (Sugirtharajah 2012:162).

\section{R Snyman's commentary “Die Evangelie van Johannes" (Gospel of John) as a colonial text: the Samaritan woman John 4}

The commentary on the Samaritan woman is a prime example of both categories of stereotyping - misrepresentation and affirmative presentation. It serves as a cultural text that is central to the strategies of modern imperialism (Dube 1996:41). The way in which Jesus and the Samaritan woman are interpreted demonstrates how these representations are governed by the politics of interpretation, theological persuasion and ideological motives of the coloniser (Sugirtharajah 2012:162). The ideology of the white Afrikaans male has clearly influenced his view of the person of the Samaritan woman and her conversation with Jesus. 
Dube says that "imperialism expounds an ideology of inferior knowledge and invalid religious faith for those who must be colonised" (Dube 2002:62). The people who need to be colonised must be seen as having an inferior and incorrect religion and inadequate knowledge of proper customs and cultural norms: "( $\mathrm{t}$ )hey are approached as people who are ignorant of the 'correct' way of life, culture, and religion” (Wood 2013:42).

It seems that the framework of the colonial worldview permeated the interpretation is John 4:9:

The Samaritan woman said to him, 'You are a Jew and I am a Samaritan woman. How can you ask me for a drink?' (For the Jews do not associate/share dishes/utensils with Samaritans).

This phrase sets the context for identifying the Samaritans with black people and therefore the colonised in South Africa; the imperial undertones are not directly addressed but rhetorically implied. Apartheid policy set black people 'apart' from the whites - no marriages were allowed between these groups; separate schools, hospitals, universities and churches - even separate entrances into buildings were provided. In the text the white coloniser identifies with Jesus by referring to him as "our Lord" ("onse Heer" Snyman n.y:43, 47) and sustains his superior insight, information and knowledge of who Jesus really is, namely Jesus is from the real people of God; he is knowledgeable (vv.10, 22), powerful (vv.14, 25, 42), knows everything about her private life (vv.17-18, 29), gives answers for her society (vv. 21-26), and teaches her and her people the truth (vv.21-23).

The white coloniser maintains his control and domination by describing the Samaritan woman as a member of a despised people ("versmade volk") doing the work of a "bediende - 'n maatskaplike verstoteling" - namely a domestic worker or, as they were called, a "maid" (Snyman n.y:45), because of her stereotypical inferior status as a Samaritan and a woman and because she fetches water from the well (John 4:7) as is the custom among black women in Africa. This coincides with the image of the colonised at the service of the master, as Jesus says: "Give me (something) to drink". These words spoken are clearly in the form of an imperative, implying an order or demand. However, this seems to be problematic because there is no greeting exchanged between Jesus and the woman prior to his words to inform us what the nature of the social interaction between Samaritans and Jews was. We also do not know what the social customs of the time were and "if Jesus is complying with the politeness principle”, to address a strange or foreign woman in public (Botha 191:115).

Snyman further describes the reaction of the woman to Jesus' request as sharp, offensive and frivolous (Snyman n.y. 45). He presents her as unintelligent and ignorant because the "poor woman" could not or was not able to understand everything Jesus said or promised (Snyman n.y:46). She is also categorised as a sinful woman with 
a dark secret (Snyman n.y:47) presenting himself as having dignified virtues and values. He makes no effort to find another explanation for the various husbands in her life. She has no name and no legitimate affiliation with a male, but with numerous unknown males and this positions the woman in a situation of exploitation and excommunication. Her sexuality jeopardises the cultural boundaries of male virtues and values. He rather interprets her question referring to the place of worship as steering the discussion away from the husband question and avoiding a response on her concealed personal life. Instead, Snyman says, the woman construes religion as an issue of forms and ceremonies, because she asks about the proper location of worship. The woman stereotyped as the "other" can be assessed and absolved because, despite her ignorance and sin, she keeps on hoping for deliverance (Snyman n.y:48), something the coloniser with his superior knowledge and power can provide.

Furthermore, the identity of the Samaritan woman is characterised as unintelligent and ignorant of proper social customs and conduct by addressing Jesus as "jy" (i.e. with the informal and inappropriately familiar "you"), when she first encounters Jesus seemingly not showing any form of respect (Botha 1991:124). Afrikaans and German make the difference between "jy" $(d u)$ and " $u$ " $($ Sie $)$ : a friend or peer will be addressed as "jy" $(d u)$ and a superior or elderly person as " $\mathrm{u}$ " (Sie). Groenewald (1980:101-102), another Afrikaans commentator on the Gospel of John, despite being aware that the Greek language makes no difference between formal and informal "speech", still puts forward this argument, interpreting the Samaritan woman's addressing of Jesus as "jy" as conveying disrespect in the same way as Jesus' opponents did, people who were contemptuous of the Jews, and vice versa. The commentary by Snyman echoes a particular perception of those who are on the margins of society, the poor, widows, women and the 'other'. There is a denial of the agency of the marginalis. On occasions when they speak, they are seen as uneducated (Sugirtharajah 2012:163). The story of the Samaritan woman reinforces the dependence of the woman - she is at the mercy of others and is entirely dependent on her benefactors (Jesus, the disciples, people of her home town Sychar) or on God for relief from her miserable status. Such a state of dependence is compensated for and rewarded generously when her testimony is accepted by Samaritans, namely the men from her home town (Sugirtharajah 2012:164).

\section{Retrieving the voice of the Samaritan woman as sage}

By removing the stereotypical prejudices of the coloniser by ignoring them, it is possible to retrieve the voice of this woman as a sage, a virtue seemingly impossible to associate with a "black" woman in apartheid South Africa. Therefore, the knowledge and attitude of the Samaritan woman echo a different situation to the one reflected in the commentary of the coloniser. 
Grabbe gives a definition of who the wise person or sage: this is a "generic term used of any intellectual ability or achievement, whether gained from learning or from native talent" (Grabbe 1995:175-176). Schüssler-Fiorenza is of the opinion that "(w) isdom is a state of the human mind and spirit characterised by deep understanding and profound insight". She maintains that wisdom is a perception of wholeness that does not lose sight of particularity, relativity and the intricacies of relationships. A wise person understands complexity and seeks integrity in relationships. Wisdom is usually seen as bringing together self-awareness and self-esteem with an awareness and appreciation of the world and the other (2009:3-4).

African ethics and wisdom have a strong communitarian character (Olojede 2014:3). Practical wisdom refers explicitly to traditional virtues, especially courtesy and natural dignity (Rosenbaum 2008:80). Life is seen as a journey from home where a person experiences her/his own security, to the community where her/his identity is formed through service to the community. It involves strong community interaction and a network of relationships focusing on issues of hospitality, sharing and social justice (Olojede 2014:5).

Folk wisdom is passed on in the context in which it is relevant (Whiting 1974:10). The wisdom of older African women is passed on during rites of passage such as circumcision, marriage and burials. During these events traditions, values and virtues are transmitted from generation to generation (Masango 2006:939). Masango (2006:937) says further that “(p)assing of knowledge or wisdom creates a world of humanness (Ubuntu) among other people.”

Therefore, wisdom in its wider context can be defined as the practical knowledge gained through experience and daily living as well as through the study of creation and human nature; all of this indicates capability. But capability should not just refer to skills; it is the ability to make good judgements based on one's insights, experiences and knowledge.

The Samaritan woman seems to be knowledgeable about public issues of concern and not shy to confront her Jewish interrogator with cultural, political and ethnic controversies (cf. John 4:9, 12, 19, 25). In this discussion Jesus is associated with Jewish imperialism and, therefore, he is the coloniser. Her knowledge of these traditions and religions is remarkable. She engages Jesus in a theological discussion about worship and the very important issue of the messiah. She is aware of the ethnic differences between the Jews and the Samaritans and therefore questions Jesus about breaking the ethnic and purity barriers by asking for water from a Samaritan and speaking to a woman in public (John 4:27).

She questions Jesus about the place of worship. Her knowledge must have come from listening to sermons and stories about legends and traditions of their religion. However, the Samaritans in general were probably well informed about the differences between 
themselves and the Jews, because the alienation between the Jews and Samaritans was a long-standing matter (Ashton 1991:294-299). She is well informed about her traditions, the history and symbolic importance of the well of Jacob (cf. Gen. 33:18; 48:22; Josh. 24:32) (Mullins 2003:155). Cleverly she takes the initiative and turns the conversation away from her personal circumstances to matters that are of collective and communal concern, namely religious, political and social issues, domains where women do not feature (Nortjé-Meyer 2001:8).

The woman was not led astray by Jesus' comments, but “clinging to her beliefs and traditions" (Botha 1991:119). She did not let him involve her in his argument and concerns. She constantly avoids referring to God as father. She deals with the traditions and religion the Samaritan way and not the Jewish way (cf. John 4:22-23). As a result, she introduces the issue of the messiah (cf. Nortjé-Meyer 2001:9). In this theological conversation with Jesus, the Samaritan woman wants Jesus to clarify the misunderstanding that the Samaritans and Jews have about the messiah and salvation. According to the Samaritans, the messiah would be a prophet like Moses (cf. Deut. 18:15,18-19), someone who would lead them out of oppression and domination to liberation. According to the Jews, the messiah would be a royal or imperial descendant of David, a warrior and invader (cf. Ashton 1991:255, 297-298; Geyser 1986:16). On two occasions the Samaritan woman demonstrates her resistance against religious and imperial domination, by not calling God father (like Jesus does in John 4:21 \& 23) and insisting that the Samaritan messiah is a prophet like Moses, the liberator.

As a woman with no name and no affiliation to legitimate males - neither a daughter, wife, widow nor a mother - she displays wisdom, knowledge and insight into male-dominated domains.

Schüssler-Fiorenza (2009:4) defines wisdom as follows:

Wisdom is the practical knowledge gained through experience and daily living as well as through the study of creation and human nature.

According to the ancient philosophical schools, the striving for wisdom constitutes a sage. But despite all the different definitions of wisdom, there is a pervasive emphasis among them, namely on the human attempt to understand the world and the self, using human reason. Decolonialising the stereotypical construction of the Samaritan woman as impure, inferior, unintelligent and incapable, similar to the representation of a black African woman, her stance and performance exhibit the attributes of a sage. Women were denied male virtues and values because they had another set of principles attributed to them: to be faithful and obedient wives and mothers; to appear shy and defensive of their virtues; to speak respectfully to men and to obey when commanded, especially by the coloniser; seeking the shelter of the "private" world as soon as possible and not lingering in public (Neyrey 2009:154). However, the Samaritan woman transforms her social role from being a female 
outcast shying away from social contact to a wise female who could go into the village marketplace where all the men of the village gather usually (Neyrey 2009:151) and tell them about her insights, knowledge and ability to unravel the mystery of the messiah, thus appropriating a quality possessed by the sages.

However, in antiquity women were not allowed to teach men. According to Trebilco (2004:513), it was not the teaching as such that was the problem, but that women might exercise authority over men when teaching or instructing them. Neyrey (1994:85) says “(s)he did not go from door to door, interrupting the private lives of her female neighbours; she did not go to her own house. She did not return to private space at all, but went into public space, to the one place where males would be expected to congregate". She challenges the men of the village who probably knew about her past. This must have disconcerted the men of the village, because her alleged husbands might have been among these men. Therefore they run to see the man for themselves and have to admit that the woman has spoken the truth. From a decolonial perspective, the Samaritan woman appears as a wise, just and saving woman whose autonomy is transparent both to Jesus and to the Samaritans. She shares her newly found knowledge and insight with her community in the hope that this will bring liberation for all the Samaritans.

I have to disagree with Schüssler-Fiorenza, who says: "If John 4:1-42 reworks a traditional mission legend about a woman's primary role in the beginnings of the Christian community in Samaria, then there is evidence from two different strata of the gospel tradition that women were determinative for the extension of the Jesus movement to non-Israelites" (Schüssler-Fiorenza 1983:138). Okure (1988) also emphasises the mission of Jesus and the disciples in the Gospel of John and specifically to the Samaritans. Okure is of the opinion that "(i)t is not simply the missionary dimension of the NT that needs to be reviewed, but the whole concept of mission today" (1988:294 ftn 8). Her view that Jesus and the disciples' mission to the Samaritans means rather an outreach to non-believers (1988:296) does not hold ground in light of the embodiment of the imperial power of Jesus and his disciples.

We have to move away from seeing the Samaritan woman as a missionary to non-Jews - occupying the role of a coloniser. We should rather see her as a prototype of "historical leadership" and woman wisdom in the early Jesus movement.

Contra to the interpretation of Snyman, who sees the Samaritan woman through his colonial ideological lenses as “'n bediende”, her stereotypical inferior status as a servant, unintelligent and ignorant of proper social customs, dependent, at the mercy of others, the decolonial rereading of the Samaritan woman as sage removes the control and domination of the white coloniser. A female sage or a wise woman is a woman who changes the course of history, because she understands individual facts, relates them to one another in a unified and structured way as the Samaritan woman did and more so, as so many black African women did to set themselves and the others free from colonial oppression and racism. 
Unfortunately, we are facing a new wave of brutal racism in South Africa. We need wisdom and sages to lead us through this dehumanising turmoil to real freedom - free from neo-stereotypes and neo-representations.

\section{Bibliography}

Ashton, J. 1991. Understanding the Fourth Gospel, Oxford: Clarendon Press.

Botha, J E. 1991. Jesus and the Samaritan Woman, A Speech Act Reading of John, 4:1-42, Leiden: Brill.

Danby, H. 1977 [1933]. The Mishna. Translated from the Hebrew with Introduction and Brief Explanatory Notes, Oxford: Oxford University Press.

Dube, M W. 1996. Reading for Decolonization (John 4:1-42), Semeia, 75: 37-59.

Dube, M W (ed.). 2000. Postcolonial Feminist Interpretation of the Bible, in Postcolonial Feminist Interpretations of the Bible 16, St. Louis, MO: Chalice Press.

Dube, M W. 2002. Reading for Decolonization, in John and Postcolonialism: Travel, Space, and Power, M W Dube and J L Staley (eds.), New York: Sheffield Academic Press.

Erdman, C R. n.y. Die Evangelie van Johannes: 'n Verklaring, Transl. D R Snyman, Cape Town: Afrikaanse Bybelvereniging.
Geyser, A S. 1986. Israel in the Fourth Gospel, Neotestamentica, 20: 13-20.

Grabbe, L L. 1995. Priests, Prophets, Diviners, Sages. A Socio-historical Study of Religious Specialists in Ancient Israel, Valley Forge: Trinity Press International.

Groenewald, E P. 1980. Die Evangelie van Johannes, Cape Town: NGKerk Uitgewers.

Masango, M J S. 2006. African spirituality that shapes the concept of Ubuntu, Verbum et Ecclesia, 27(3): 930-943. https://doi.org/10.4102/ ve.v27i3.195

Mullins, M. 2003. The Gospel of John. A Commentary, Dublin: Columba Press.

Neyrey, J H. 1994. What's Wrong With This Picture? John 4, Cultural Stereotypes of Women, and Public and Private Space, Biblical Theology Bulletin, 24: 77-91. https://doi.org/10.1177/ 014610799402400205

Neyrey, J H. 2009. The Gospel of John in Cultural and Rhetorical Perspective, Grand Rapids: William B. Eerdmans. 
Nortjé-Meyer, L. 2001. Is there any indication of female prophesies in Matthew's Gospel? The Spirit \& Church, 3(1): 129-145.

Nortjé-Meyer, S J \& Moruthane, S W. 2008. Family imagery in John 4:4-42, Ekklesiastikos Pharos, 90 (19): 81-97.

Okure, T. 1988. The Johannine Approach to Mission. A Contextual Study of John 4:1-42, Tübingen: JCB Mohr.

Olojede, F O. 2014. Woman Wisdom and the ethical vision of the book of Proverbs: An African reflection, HTS Teologiese Studies/Theological Studies, 71(3), Art. \#2846, 6 pages. http://dx.doi.org/10.4102/ hts. v71i3.2846.

Rosenbaum, S. 2008. The Wisdom of Mma Ramotswe, The Pluralist, 3 (3): 79-94.

Schneiders, S. 1991. The Revelatory Text. Interpreting the New Testament as Sacred Scripture, San Francisco: Harper.

Schüssler-Fiorenza, E. 1983. In Memory of Her. A Feminist Theological Reconstruction of Christian Origins, New York: Crossroad.
Schüssler-Fiorenza, E. 2009. Towards a Feminist Wisdom Spirituality of Justice and Wellbeing, Lieve Troch Felicitation Volume, São Bernardo do Campo: Nhanduti Editora.

Sugirtharajah, R S. 2012. Exploring Postcolonial Biblical Criticism, History, Method, Practice, Chichester: Wiley-Blackwell.

Trebilco, P. 2004. The Early Christians in Ephesus from Paul to Ignatius, Tübingen: Mohr Siebeck.

Venter, J G H. 1987. Jesus en die Samaritane, Unpublished $\mathrm{PhD}$ dissertation, University of Johannesburg, Johannesburg: RAU.

Weren, W J C. 2014. Studies in Matthew's Gospel: Literary Design, Intertextuality, and Social Setting, Leiden: Brill. https://doi.org/10.1163/ 9789004280519

Whiting, B B. 1974. Folk Wisdom and Child Rearing, Merrill-Palmer Quarterly of Behaviour and Development, 20 (1): 9-19.

Wood, M M. 2013. A Dialogue on Feminist Biblical Hermeneutics: Elisabeth Schüssler-Fiorenza, Musa Dube, and John Paul II on Mark 5 and John 4, master's thesis in Theological Studies; University of Dayton. Dayton: OH. [Retrieved 18 Jan 2018]. 


\title{
Chapter 9 \\ Living with Integrity and Wisdom?
}

\author{
The rhetorical situation of the letter \\ of James
}

Annemarie de Kock-Malan ${ }^{1}$

\section{Introduction}

In South Africa we are facing a complex, multifaceted moral and social crisis. The country has some of the highest numbers of rape instances and intimate partner violence in the world (Jewkes et al. 2009:5). Society is affected by social issues such as crime, poverty, gender-based violence, different forms of discrimination and HIV/AIDS. These events causes trauma to many citizens in the country and affect people's lives in intricate and manifold ways - personally and communally.

These moral and social issues that causes many dilemmas in South African society manifest at a deeper level where they become a theological crisis, especially for the church. When the church is not acting faithfully according to its identity and calling as the body of Christ in the world, it indeed faces a theological crisis. This theological crisis emerges because faith communities are not necessarily understanding the actual challenges behind it. What is needed is to have a different perspective

\footnotetext{
I am currently a PhD student at Stellenbosch University, South Africa. I first met Elna Mouton as a nervous first-year in 2009, when she as the Dean came to welcome students and parents to the 150-year-old Faculty of Theology in Stellenbosch. As an undergraduate student I had almost all my New Testament modules (except for the Synoptic Gospels and Acts) with Prof Elna as the lecturer. After every class one was inspired to dig deeper into the New Testament document we were busy with, marvelling at the many intriguing aspects of each one. Prof Elna's enthusiasm about the New Testament and its life-transforming potential for faith communities and society and her pastoral approach to us as her students motivated me to do my MTh (on James) with her as well as my PhD (on 1 Peter). Over the past eight years that I have come to know her, she has become a mentor and mother-figure in my life. Prof Elna, I hope you find this chapter to be demonstrative of what you have taught me and so many others over the years.
} 
on South Africa's moral crisis. In order to analyse and address this complex phenomenon, I wish to utilise the concept of "rhetorical situation". This may be helpful to understand the South African moral crisis and the underlying challenges.

Lloyd Bitzer (1968:6), who is the creator of this concept, defines "rhetorical situation" as follows:

Rhetorical situation may be defined as a complex of persons, events, objects, and relations presenting an actual or potential exigence which can be completely or partially removed if discourse, introduced into the situation, can so constrain human decision or action as to bring about the significant modification of the exigence ... Prior to the creation and presentation of discourse, there are three constituents of any rhetorical situation: the first is the exigence; the second and third are elements of the complex, namely the audience to be constrained in decision and action, and the constraints which influence the rhetor and can be brought to bear upon the audience.

Therefore it may be argued that a rhetorical situation originates from "an actual or potential exigence" - an urgent need or critical matter (as perceived by an author) that is present in the historical situation.

Bitzer further argues that any urgent matter is imperfect and derives from a stumbling block or a situation that anticipates immediate attention and action (Bitzer 1968:8). Furthermore, it is not just about identifying people, objects, events or relationships in concrete historical situations. The rhetorical situation is an invention of the author (in the case of the letter of James) or perceivers themselves. The author sees or anticipates a rhetorical situation that is happening or that could happen in the near future, of which the audience is not necessarily aware (yet). The urgent matter that is visible to an author or perceiver in its particular historical situation is not that explicit to others (or receivers of a document such as James' letter). This is probably because the author suspects that the audience could be aware of some of the factors causing an exigence. It is therefore impossible for later audiences to reconstruct the urgent matter that negated the rhetorical situation and the author's reaction to it. The best that can be done is to try to construct a probable picture of the historical situation and to read between the lines of the text to see what the rhetorical situation and potential exigence could have been (Mouton 2002:116-117). A rhetorical situation also implies a rhetorical audience or implied readers as well as some restrictions that could limit the change that the rhetorical situation implies.

Therefore, the rhetorical situation emerges from an actual or a fictitious observation of the historical situation in which the perceivers identify a concrete or an underlying problem.

In view of the above statement, what am I saying when I suggest that we have a "rhetorical situation of crisis" at hand in South Africa? I am suggesting that we only perceive the symptoms of our current reality. We are not challenging the problems behind these symptoms, such as people's understanding of gender and gender roles, 
what "real men" and "real women" ought to be, and how we relate to one another. The theological dilemma that we are facing is, generally speaking, because the churches are not always living their identity as alternative communities in Jesus Christ with integrity and wisdom. We are not speaking (enough) on behalf of the voiceless and marginalised, and we are not (necessarily) giving the marginalised a voice to tell of their experiences. This is one of the reasons why I perceive a "rhetorical situation" in South Africa - a situation which is in dire need of transformative, life-giving words and practices.

The author of the ancient canonised letter of James also perceived or anticipated a "rhetorical situation" in the historical circumstances of his audience. ${ }^{2}$ He reacts to this situation by arguing for radically alternative perspectives on the situation that his audience clearly did not see. He sees deeper. In this chapter the rhetorical situation addressed in the letter of James and the writer's reaction will be examined in order to devise a tool or a strategy that may help us, as current perceivers of a rhetorical situation of crisis in South Africa, to address our own situation. In this investigation, identifying the rhetorical strategies that are utilised by the author to present his argument is important. The rhetorical situation of this ancient text is not identical to our situation, but I believe that the process of (re)interpretation in this text holds a crucially important key that may help us to challenge our own situation.

\section{Rhetorical strategies in the Letter of James ${ }^{3}$}

In my first reading of the letter of James that I conducted for my master's thesis, I noticed various strategies in the text. Rhetorical strategies are important devices to persuade an audience of the alternative perspectives that an author wants them to accept - as his/her response to the perceived "rhetorical situation". The author of the letter of James utilises different rhetorical strategies, genres and themes to present his arguments. From the findings of the thesis it is evident that this letter does have an overall rhetorical structure and the above-mentioned strategies are used to support the bigger structure (De Kock 2014).

Luke Timothy Johnson suggests that James 1 could be seen as an index that introduces themes that are discussed later on in the other four chapters (Johnson 1999:510). This can also be seen as a rhetorical strategy in order to introduce the overall argument of the letter. In addition to this rhetorical strategy, the author makes use of strategies such as chiasms, repetition, inclusios, paranomasia, poliptotons, hyperboles, metaphors, hypothetical situations and quotations from the Hebrew

\footnotetext{
2 There is little consensus amongst scholars about the authorship of the letter of James. For this purposes of this paper I will refer to "the author".

3 For the purpose of analysing the rhetorical strategies, standard commentaries by the following authors were consulted: Martin Dibelius (1976), Ralph P. Martin (1988), Peter H. Davids (1992), Elsa Tamez, (1994:381-391), Luke T. Johnson (1995) and Robert W. Wall (1997).
} 
Bible to present his arguments (or alternative perspectives). The writer also introduces four characters from the Hebrew Bible (Abraham, Rahab, Job and Elijah) who lived with integrity and wisdom and in friendship with God. The way in which Jesus Christ and God are portrayed, as well as people in general, is used to present his alternative perspectives on the historical audience's world.

In addition to these strategies, the author also adopts different genres to get his argument across. It is an oversimplification to say that the letter of James has one overall genre. Duane Watson (2007:118-119), however, describes the core of what I understand to be the genre of James: "It is Jewish-Christian wisdom work influenced by Hellenistic rhetoric, but is arranged overall in the topic-to-topic fashion of Jewish wisdom texts." 4

This wisdom book or letter also makes use of other genres such as paranesis and diatribe as rhetorical strategies. It is already evident that the letter of James is not composed of loose statements, but that there is an overall structure that is kept intact by the use of different genres, characterisation and rhetorical strategies. After identifying these strategies, I asked myself what compelled the author to adopt these strategies. What lies behind it? With the use of these strategies, it is evident that the writer was responding to a specific situation (of crisis) that he observed in the audience of James' current situation, or that he anticipated to develop in the near future. It is clear from the text that the author saw this as a very serious situation. The letter of James is carefully crafted to speak to this situation. This phenomenon will be discussed accordingly.

\section{The rhetorical situation of James}

Identifying rhetorical strategies in an ancient canonised text is not that difficult. The challenge comes when one has to construct the "rhetorical situation". Then the text challenges the reader to read between the lines to see what the author was responding to. This section attempts to construct the rhetorical situation addressed in the letter of James.

The investigation of the rhetorical situation of the letter of James is important when considering rhetorical aspects of the text. Mouton (2002:114-115) suggests that the rhetorical situation is of importance in textual communication because the pragmatic function of the text is to convince the audience of a certain argument. In

\footnotetext{
In a recent work Margaret Aymer describes the genre of James as a "migrant document" that is structured according to an ancient speech. The author (whom she identifies as "James the Just") used the rules of ancient rhetoric, namely exordium, propositio, probatio, and peroratio, to structure this encyclical (Aymer 2017:19). James as a migrant writing is described as follows: "[We] should consider James as a piece of migrant writing: it proposes to a community a particular migrant strategy for dealing with a host community ... it functions as a kind of diaspora space, where cultures collide and commingle and where tradition is invented" (Aymer 2017:67).
} 
the case of New Testament documents, their authors were attempting to persuade their audiences to live according to their alternative perspectives on the world. These perspectives suggest a rhetorical situation which the author responds to. The rhetorical situation may be seen as the link between the textual aspects of the letter and the historical situation it addresses. There is, however, a difference between the historical and rhetorical situation of James.

Much effort can be put into an investigation of the social and moral world of the letter of James. It is evident, however, that it is not possible to (re)construct the whole picture of what the historical context of the historical audience was. This is a result of limited sources, and a text that implies certain knowledge about its original circumstances in its audience. This is regarded as a given in the letter, because the audience would have known their own circumstances. There may be elements of the historical situation present in the rhetorical situation. The "rhetorical situation" (representing the author's particular stance on the context), however, may differ from the historical situation.

Bitzer's perspective on the "rhetorical situation" was discussed in the introduction. The core of this concept is that it emerges from an actual or a fictitious observation of the historical situation in which the author identifies a concrete or an underlying problem. Furthermore, the author makes use of rhetorical discourse to address the rhetorical situation ${ }^{5}$. In the case of the letter of James, the author sees further than the probable historical context he recognises and implements the potential of rhetorical strategies and genres with the hope of changing the situation at hand.

Mouton (2002:118) suggests that the creation of the rhetorical situation implies that the author sees a stumbling block or a need in the historical situation. The nature of the letter of James could thus be seen as a prophetic reflection of the author on what he saw in the historical context. The author is therefore responsible for the rhetorical situation. This also indicates that the author's moral responsibility in terms of the ethical consequences of this text would increase.

The rhetorical situation of the letter of James could thus be outlined as follows. The writer of the letter of James was probably concerned about the total (especially social) wellbeing of his historical audience. He was also concerned about the fact that these believers did not live with integrity and wisdom and in accordance with their identity in Jesus Christ (James 2:1-13, 3:13-17, 5:7-11). This could be the major theme of the rhetorical situation. The letter opens with: "James, a servant of God and

Bitzer suggests the following: "a rhetorical situation must exist as a necessary condition of rhetorical discourse, just as a question must exist as a necessary condition of an answer." This statement implies that rhetorical discourse is an outcome of the rhetorical situation and it must be utilized to change the rhetorical situation. This is very important in the case of the letter of James and how the author's implements rhetorical discourse. See also below in this chapter which aspects must also be taken into account when it is implied that rhetoric is situational, in Bitzer (1968:6). 
of the Lord Jesus Christ, to the twelve tribes in the Dispersion (Diaspora): Greetings" (NRSV). Already in the opening, the use of the word "dispersion" or "diaspora" may indicate something of the situation the first audience found themselves in. ${ }^{6}$

After the greeting, the letter opens in James 1:2 with an exhortation on the trials that were present in the historical audience's situation. This could also be part of social aspects such as the rich that oppressed the poor in many ways, conflict because of class differences, and economic oppression by withholding pay. These trials may also refer to the writer's concern for some believers who were exploited and marginalised by the dominant culture of the time (De Kock 2014:94).

Furthermore, the author sees a lack of wisdom present in the historical audience. It seems as if they looked for it in other places than God. Doubt amongst believers was most probably also a challenge (the author refers to this phenomenon as "double-mindedness"). There could also have been people who believed that certain temptations were sent by God, but the author believes that they are misled in this view. The author is also concerned with the historical audience's inability to be "doers of the Word". Religiosity also seems to be a problem (De Kock 2014:95).

James 2 begins with the author exhorting the audience with regards to their identity in Jesus Christ. This exhortation introduces the theme of partiality. In the first place there is partiality in favour of certain people. It seems as if some people follow the dominant culture of the time that gave an advantage to the rich, mainly judging by outward appearance. It is furthermore possible that atrocities were committed against the poor and that the rich treated the poor unfairly. The writer is very concerned about this problem, especially in light of the audience's lack of integrity. This threatens the wellbeing of these early communities. In the second place, there seems to have been a challenge in terms of partiality of "the royal law found in Scripture" (James 2:8). These instances of partiality are related to the inconsistency of believers confessing their faith in Jesus Christ while not showing it in their deeds. The writer connects partiality and faith without works with the problem of the lack of integrity and living while ignoring their identity (De Kock 2014:95).

A shortcoming in integrity is connected in James 3 with the control over the tongue. Appropriate language is very important to the author. Control of the tongue also resonates with the problem of partiality in chapter 2 - with the same tongue God is praised and others are cursed. ${ }^{7}$ This is a big challenge. He refers further in chapter 3 to bitter envy and self-centredness. This is not heavenly wisdom. These personal struggles link with social influences and it could be that the audience was not aware of this.

\footnotetext{
6 Pedrito Maynard-Reid (1987:31) notes that the Jews (Jewish believers were probably part of James' audience) in the dispersion suffered in the $1^{\text {st }}$ century Roman Empire and that many of them were indeed very poor. This could have been part of the author's concern for his audience - especially because the author refers to the poor and economically oppressed in the letter.

7 This can relate to the South African context where people are marginalised by the stigma around HIV/ AIDS, also by faith communities, but at the same time people speak words of praise to God.
} 
These personal struggles caused conflict in these faith communities (as described in chapter 4). The author sees or anticipates people's individual desires translating into communal conflict. These are murder, jealousy, fighting, war, people who do not pray in the correct way, gossip, judgement of others, etc. There could also have been people who thought that they could live independently of God and their identity in Christ. The author regards this as signs of friendship with the world and manifestations of "earthly wisdom", endangering the wellbeing of faith communities on different levels.

Partiality according to social class and status in society features again in James 5. This description could be a reflection of the historical situation or something that the author anticipated. Examples of this are the rich who gathered treasures "in the last days", pay that was withhold from workers, the rich living in luxury and promiscuity, and the righteous who were murdered. The writer gives a warning to those who made themselves guilty of this. The author is also very serious about the fact that believers must not take an oath on their lives. This could be a reflection of a reality where people took an oath in a patron-client relationship in order to gain something from the patron. ${ }^{8}$ The writer relates this to judgement and to an absence of integrity, because people were buying into the dominant systems of the Roman Empire. The use of prayer is a fascinating part of this last chapter in James and the last verses speak about believers who deviate from “the truth” (De Kock 2014:96).

The rhetorical situation of the letter of James thus implies that the author was extremely concerned about the integrity of the historical audience, the (lack of) wisdom with which they lived out their identity in Jesus Christ and the (absence of) holistic wellbeing of these faith communities. It is evident that certain things had to be attended to. The rhetorical structure of the letter is important, because the author intended to persuade the audience of his argument and the alternative perspectives he proposed to deal with their situation. The next section will explore the intended rhetorical effect of the letter of James in order to see how the author wished to persuade the audience of his alternative perspectives, and how he anticipated them to respond (De Kock 2014:96).

8 Alicia Batten (2010:75) describes these relationships as arrangements that were made between people of different social classes for certain periods. They were thus hierarchical relationships. They consisted of a wealthy patron and a poor client. The client's responsibility was to honour and flatter the patron in public and to swear their loyalty to the patron in order to obtain food, clothes, work, land, protection etc. Sometimes it happened that the patron exploited the client, because he had all the power in this arrangement. Patron-client relations were not voluntary relationships. Clients were dependent on these relationships for their daily survival. 


\section{The author's reaction: alternative perspectives on the historical situation}

Given the situation outlined in the previous section, the following question is important: What effects were the alternative perspectives of James, in the light of the implementation of rhetorical strategies, expected to have on the historical audience? Wesley Wachob (2007:154) makes the following observation about the rhetoric used in this letter:

The instrumental aspect of the Epistle of James is one of the things that most intrigue us ...

From a rhetorical perspective, the Epistle of James has a message to convey and seeks to persuade an audience to believe it [the message] or to believe it more profoundly. ${ }^{9}$

Wachob thus suggests that the author does not only react to a specific situation, but responds by putting forward alternative perspectives for the audience to act upon. These alternative perspectives are briefly described below. ${ }^{10}$

The author makes it clear that the historical audience's identity lies in Jesus Christ, who is portrayed as "Lord". God is portrayed as the one with whom to have an ultimate, mutual friendship, and the audience is warned not to engage in exploitative relationships with the rich. God has chosen the poor and marginalised, and in the same way the audience must care for the sick, poor, widows and orphans. By analogy with what God does with the marginalised, the audience is encouraged to live a life of wisdom and integrity that exemplifies God's care, challenge the exploitative systems of the time, and bring faith into action. Integrity is seen in the judicious use of the tongue, prayer and caring for others, while wisdom is a virtue that is manifested by challenging the dominant ideologies. The author of James also exposes the dominant culture for what it was: exploitative, marginalising, dominant and self-centred. The audience is asked not to accommodate the dominant system, but to love God and to care for their neighbour. This care advances "the law of freedom" that stretches over boundaries and includes those whom others exclude. Ultimately, these alternative perspectives were intended to open the eyes of the audience to the needs of others, and to the systems that marginalised and exploited them (De Kock 2014:98-99).

These alternative perspectives are not as innocent as they may seem. They were to serve as opposition to the dominant ideologies of the time. Ideology, according to Alicia Batten, intends to unite social groups because of the tendency of people belonging to a group to have different opinions about particular issues

\footnotetext{
9 Wachob (2000:154) describe the rhetorical discourse of James in the following way: "rhetorical discourse is always situational and always functional. It is situational because it is a response to the particular rhetorical situation that elicits and determines it; it is functional because it exists to alter the rhetorical situation it addresses ... Consequently, rhetorical discourse is always pragmatic discourse. It does not exist for itself, nor is it an instrument of reflection. On the contrary, rhetorical discourse is generated to change reality and is fundamentally a socially motivated mode of action." 
(Batten 2007:9). This suggests that an ideology wants to pursue people to move from ideas to practice. Ideologies also advocate reasons for these actions and want to legitimise these actions in order to be perceived as the natural state of things. Batten furthermore suggests, with the help of some feminist scholars, that stereotyping is used frequently to caricature the opposition party.

The writer of the letter of James opposes ideological values and systems such as honour and shame, patronage and clientage, and Greco-Roman notions of identity. He also uses other ideologies such as the Jewish understanding of purity and the law to strengthen his own ideology with which he confronts the readers. He is thus utilising an alternative ideology. This can be seen, for example, in the way that he portrays the rich as acting against the poor. This is done to resist the threat of the dominant ideologies of the Roman Empire. ${ }^{11}$

The author of the letter of James thus proposes alternative perspectives as ideology on the world in which the historical audience lived. These perspectives served as a means to help the audience to accept the ideology of the writer, to make sense of their world and to act accordingly. The writer is concerned about the wellbeing of these faith communities, especially the way in which they lived with (a lack of) integrity and wisdom in their identity in Jesus Christ. ${ }^{2}$ The writer's concern is focused not only on individual behaviour, but particularly on the ethos of the community itself.

This focus suggests that these alternative perspectives were not only aimed at transforming individuals. According to the author, they were supposed to transform these communities in their living, worship of God and their concern for "the other". The author's intention was to move the historical audience from their previous position (which he identifies as problematic and even dangerous) to a position that bore witness to their integrity and wisdom. This implied that certain shifts in perspectives needed to be made in order to move to action in living with integrity and wisdom. Such dramatic changes would only be possible, according to the author, through the audience's acceptance of these alternative perspectives on God, the broader society and each other (De Kock 2014:98).

These changes would imply certain consequences, as Batten suggests, especially when God is portrayed as the primary benefactor in the ideology of the author, opposing the patron and client system of the Roman Empire (Batten 2010:178-180). ${ }^{13}$ The author opposed this dominant ideology where people, especially the poor, were exploited, by portraying God as the ultimate benefactor initiating mutual friendship

\footnotetext{
11 These ideologies include honour and shame, patronage and clientage, the notion of identity grounded in loyalty to the emperor and the empire, the exploitive economic system and so forth.

12 This can be understood from the content of the letter, even though James does not have a formal developed ecclesiology. The author's ethics are social and communal in nature (Chester \& Martin 1994: 35, 41).

13 For a discussion on what "friendship with the world" entails, see (Batten 2010:175-76).
} 
with the audience. This implies that the same values and vision attributed to God have to be cultivated, as well as trusting in God and seeing reality through the eyes of God (Batten 2010:175). On the basis of this friendship with God, the author suggests certain behaviour towards those who are marginalised in society, but are chosen by God (James 2:5). Through attaining friendship with God, the identity of these communities is described in terms of their ultimate loyalty to Jesus Christ and not to the Roman Empire (De Kock 2014:98).

The proposed alternative perspectives furthermore imply that commitment to and friendship with God are not only to be realised individually, but must be advocated in community life itself (Edgar 2001:231). It is clear that the author did not intend that the historical audience needed only to take cognisance of this, but he encouraged them to take action (as the definition of ideology suggests). This, moreover, implied that action against the dominant society and ideologies should have been taken. This is probably why there is such a strong emphasis on faith and works in the letter of James. Acting out their faith would entail that the audience take their identity in Jesus Christ seriously and not support the dominant structures and friendship with an "impure" world. This can be seen, as Darian Lockett suggests, in the way in which the author uses the language of purity to set boundaries for the audience in terms of their accommodation of the dominant structures and ideologies (Lockett 2007:51).

These boundaries must not be seen as restricting, but as ways in which lives could be lived in freedom. The writer intended the audience to realise that they had to live according to "the law of freedom" (James 2:12) in a new reality. This reality is not separate from the world, but the presence of God's alternative reality was supposed to help them to approach the world as "friends of God" in a new way (De Kock 2014:99).

God's reality is a reality where friendship with God together with perseverance, perfection, non-partiality in terms of people and the law, control of the tongue, justice, looking after the marginalised such as the poor, the widows and orphans, faith that is manifested in deeds, prayer that brings the community together, dependence on God, and where the wellbeing of the community as living with wisdom and integrity is seen as a priority. The author of the letter of James challenges the dominant ideologies of the time in order to propose his own ideology as the alternative reality of God. The author boldly and prophetically speaks on behalf of the voiceless and marginalised in order to open the eyes of the audience to the seriousness of their situation and to help them change it (De Kock 2014:99).

It is impossible to know whether the first audience responded to the appeals of the author of James. One can only speculate what they would have imagined when hearing or reading this letter. What is important, though, is how contemporary believers and faith communities respond to this letter (Niebuhr 2009:43). 


\section{Conclusion}

In conclusion, it is clear that the author of the (for the church) authoritative letter of James can help the church radically to challenge, and react to, our current situation of crisis in South Africa. It is not the same situation, but there are nonetheless similarities present. By analogy with the letter of James, it is important that believers and faith communities live the alternative reality of an impartial and just God in their daily existence characterised by moral and theological crisis. It is therefore crucial to recognise the underlying problems, to challenge oppressive structures and to give a voice to the marginalised. It is also important to tell the stories nobody wants to hear, to dig into our traumatic past and analyse our traumatised present.

It is of the utmost importance to live with integrity and wisdom derived from our identity in Jesus Christ. Friendship with the world should not be tolerated. Instead, the dominant ideologies of our time regarding gender stereotypes (and stigma) and discrimination that allow rape, domestic violence, HIV/AIDS infections, as well as other violations against people should be challenged. Biblical interpretations that oppress and spur on harmful ideologies should also be confronted. As Christians we are called to help people to see differently, to see our situation for what it is, and to use alternative perspectives on this, as the letter of James proposes, to counter and change it. It is necessary for the church in South Africa to practise our calling as described by the alternative perspectives in James. The wellbeing of our communities is at stake. Our identity in Jesus Christ compels us to move into action that speaks of integrity and wisdom, to practise "true religion" in caring for the vulnerable and voiceless.

\section{Bibliography}

Aymer, M. 2017. James: Diaspora Rhetoric of a Friend of God, An Introduction and Study Guide, New York: Bloomsbury T \& T Clark.

Batten, A. 2007. Ideological Strategies in the Letter of James, in Reading James with New Eyes: Methodological Reassessments of the Letter of James, R L Webb and J S Kloppenborg (eds.), New York: T \& T Clark Press, 6-26.
Batten, A. 2010. Friendship and Benefaction in James, Dorchester: Deo Publishing.

Bitzer, L. 1968. The Rhetorical Situation, Philosophy \& Rhetoric, 1 (1): 1-14.

Chester, A \& Martin, R P. 1994. The Theology of the Letters of James, Peter, and Jude, Cambridge: Cambridge University Press.

Davids, H. 1992. The Epistle of James: A Commentary on the Greek Text, The New International Greek Testament Commentary, Grand Rapids: William B. Eerdmans. 
De Kock, A S. 2014. 'Wie van julle is wys en leef verstandig?' ' $n$ Multidimensionele lees van die Jakobus-brief, op weg na ' $n$ etos van historiese lees en verantwoordbaarheid van die ekklēsia, master's thesis, Stellenbosch: Stellenbosch University.

Dibelius, M. 1976. James: A Commentary on the Epistle of James, Hermeneia, Grand Rapids: William B. Eerdmans.

Edgar, D H. 2001. Has God Not Chosen the Poor? The Social Setting of the Epistle of James, Sheffield: Sheffield Academic.

Jewkes, R; Sikweyiya, Y; Morrell R \& Dunkle, K. 2009. Understanding men's health and use of violence: Interface of Rape and HIV in South Africa, Pretoria: Gender and Health Research Unit, Medical Research Council.

Johnson, L T. 1995. The Letter of James: A New Translation with Introduction and Commentary, The Anchor Bible, New York: Doubleday.

Johnson, L T. 1999. The Writings of the New Testament: An Interpretation, Revised Edition, Minneapolis: Fortress.
Lockett, D. 2007. 'Unstained by the world': Purity and Pollution as an Indicator of Cultural Interaction in the Letter of James, in Reading James with New Eyes: Methodological Reassessments of the Letter of James, R L Webb and J S Kloppenborg (eds.), New York: T \& T Clark, 49-74.

Martin, R P. 1988. James. Word Biblical Commentary, 48, Waco: Word Books.

Maynard-Reid, U. 1987. Poverty and Wealth in James, Maryknoll: Orbis.

Mouton, E. 2002. Reading a New Testament Document Ethically, Leiden: Brill.

Niebuhr, K-W. 2009. James in the Minds of the Recipients: A Letter from Jerusalem, in K-W Niebuhr \& R W Wall (eds.), The Catholic Epistles \& Apostolic Tradition: A New Perspective on James to Jude, Waco: Baylor University, 43.

Nienhuis, D R. 2009. The Letter of James as a Canon-Conscious Pseudepigraph, in $\mathrm{K}-\mathrm{W}$ Niebuhr, \& R W Wall (eds.), The Catholic Epistles \& Apostolic Tradition: A New Perspective on James to Jude, Waco: Baylor University, 189-194. 
Tamez, E. 1997. James, in Searching the Scriptures: A Feminist Commentary, in Elisabeth Schüssler Fiorenza (ed.), New York: Crossroad, 381-391.

Wachob, W H. 2000. The Voice of Jesus in the Social Rhetoric of James, Cambridge: Cambridge University. https://doi. org/10.1017/CBO9780511488184

Wachob, W H. 2007. The Languages of 'Household' and 'Kingdom' in the Letter of James:

A Socio-Rhetorical study, in Reading James with New Eyes: Methodological Reassessments of the Letter of James, R L Webb and J S Kloppenborg (eds.), New York: T \& T Clark, 151-168.
Wall, R W. 1997. Community of the Wise: The Letter of James, The New Testament in Context, Valley Forge: Trinity.

Watson, D F. 2007. An Assessment of the Rhetoric and Rhetorical Analysis of the Letter of James, in Reading James with New Eyes: Methodological Reassessments of the Letter of James, R L Webb and J S Kloppenborg (eds.), New York: T \& T Clark. 


\title{
Chapter 10
}

\section{Reading the Tamar Story through a Postcolonial Lens}

\author{
Reflections from Zulu women's perspective
}

\section{Slindile Thabede}

\section{Introduction}

The inability to bear male children has resulted in the victimisation of Zulu wives, which subsequently diminishes their worth as human beings and also has implications for their religious life. In this investigation, the story of Tamar as told in Genesis 38 is read in the context of the ostracism and oppression that many Zulu women continue to experience in marriage. Reading the story of Tamar, who can be described as a victim of levirate marriage gone wrong, by way of a postcolonial feminist exegetical approach, this study proposes that the story of Tamar may offer Zulu women an alternative way of understanding their own situation, not just as victims, but as survivors as well. This chapter originates from a master's thesis "Tamar as Victim of Levirate Marriage? Reading Genesis 38 within a Zulu Cultural Context of Marriage". The thesis sought to prove that for many women in Zulu society, marriage is a power struggle in the sense that their bodies become the "sites of their oppression" (Isherwood 1998:15) due to the pressures of having to produce a son. Zulu culture, like many other African cultures, is mostly patriarchal in nature, socialising people to the extent that not only are men regarded as superior to women, but women are viewed as the possessions of men.

My earlier work on Genesis 38 adopted a micro-level perspective, while my investigation here views the story of Tamar through the lens of nationality. This is a helpful tool for reflecting on gender at the macro level of Zulu life, given past experiences of colonialism and apartheid, and their repercussions on the colonised, turning the latter into individual colonisers who continue the oppression in their marital spaces as a form of claiming the power that the apartheid regime denied 
them. Therefore, the focus on the macro level offers a glimpse into the elements that affect gender and consequently women's individual behaviour. A postcolonial feminist approach helps us to consider ways in which African communities (and the Zulu community in particular) deal with their colonial past and how postcolonial concepts such as multiculturalism and hybridity may be helpful in thinking of gender dynamics in an African setting.

\section{Tamar, Zulu women and hegemony}

Moolman (2013:94) asserts that one cannot define a black South African man without taking into consideration the repercussions of imperial rule on the black nation, for the apartheid system left a definite mark on the identity of both black men and women in South Africa. Colonised men and women assume the same status of equality because they share a common oppression, which is subjugation by the coloniser (Dube 2006:150). However, usually when the colonial threat has been terminated, men assume a superior position of privilege and hold women to be inferior in the society. The reality is that Zulu ${ }^{1}$ society prides itself in regarding men as superior to women, given masculine cultural, social, political and economic prowess. However in the neoliberal world women are offered social, economic and political autonomy, which places the patriarchal system under great pressure as Zulu men seek new ways to reassert their power; therefore they use childbirth specifically a boy child - as a form of control (Punt 2003:282-283).

The fluid Zulu identity and its counter effects on individuals who can never claim to be pure Zulus, but rather exhibit a hybrid identity due to many cultural influences around them (Laband et al. 2008:23). This also implies complications in carrying out their cultural traditions through marital relations. While ancient cultural practices demand that women be submissive to their husbands as a form of honour and respect, modern practices insist on women's autonomy (Yafeh Deigh 2012:431). Hence Zulu women are influenced by both modernity and traditional culture and often find themselves at the margins of a welcoming space. The renegotiation of their identities shows that they belong to and at the same time are excluded from their culture.

This paper engages the Tamar story from a postcolonial methodological perspectives. It envisages that the approach might foreground some important elements of $21^{\text {st }}$ century Zulu identity. Postcolonial theory with its emphasis on the experience of the colonised could help Zulu women find new modes of survival. The postcolonial reading of the story of Tamar, I argue, has significant implications for understanding the Zulu marital context. It has the potential to help women who are married to Zulu men in their struggle for resistance against subjugation by Zulu men in contemporary

Apartheid was a system that affected all black South African cultures; however, the point of departure of my study is that Zulu men and women specifically are going to be my focus. 
South African society. Zulu society for the most part is deeply patriarchal in nature and rooted in male dominance, which is supported by androcentric cultural beliefs and practices that have led to the oppression of women. Because of patriarchy, Zulu marriage for many women implies victimisation and objectification. In particular, the inability to bear male children has resulted in the victimisation of the wives, which subsequently diminishes their worth as human beings and also has implications for their religious life (Ngubane 2010:1).

The approach followed in this chapter employs hybridity as a lens to explore the imperial elements in Genesis 38, while doing a close reading of the text along narrative critical lines. The paper first seeks to understand the position of Zulu women, who have been colonised historically. Second, it offers suggestions on how these women, given their hybrid position, can continue to strive under new forms of oppressions. Therefore, Tamar's story read through a postcolonial feminist lens might affirm subalterns like Tamar as well as many Zulu women today in demonstrating that they have a voice after all. This study opens up the possibility for the voices of Zulu women to be heard regarding the oppression they experience in terms of marriage. Female survivors of such oppression are called to help liberate the women of our culture by teaching them how one subverts the oppressive patriarchal structures in order for every woman in Zulu culture to flourish.

This postcolonial African feminist hermeneutics reading of Genesis 38 furthermore focuses on the story of an individual as a cipher for the people of Israel as a whole. The idea of the coloniser and the colonised will be explored and the different modes of resistance used by the subjugated in a colonial context examined. Attention will be devoted to the two main characters in the story and the ways in which they relate to the power dynamics present in the story. The character of Judah will be viewed as a coloniser because of the dominant and subjugating role that he plays in the lives of people who are not of Israelite descent-the subjugated Canaanite 'Other' like Tamar.

Regarding the concepts of power and power structures, this chapter focuses on the two operational power structures that made life difficult for Tamar. First, there are signs of a colonial agenda that aimed to subjugate Tamar as the Canaanite Other. Secondly, Tamar became the victim of a patriarchal androcentric agenda that objectified her because of her gender. In this paper I am interested in exposing the power dynamics that take precedence in the relationship between the characters of Tamar and the Israelite man Judah. The analysis will reveal the creative methods that Tamar employed in her struggle to live with the powerful men around her, which included dealing with rejection, victimisation and oppression. 


\section{Postcolonialism, imperialism and biblical texts}

In order to understand postcolonialism one first needs to address the nature of colonialism. ${ }^{2}$ Colonialism is an ancient phenomenon whose roots extend beyond the European colonial age. According to Loomba (1998:20), colonialism can be defined as the conquest and the control of other people's land and goods with the purpose of settling in the land and exploiting it. Colonialism involves political, religious, cultural and economic conquests. Dube (2006:187) shows that the forms of colonialism may vary with spatial settings, but power remains the common thread. She further states that the power is used for ruling, for trading and to promote the colonisers' culture and ideology. Berquist (2006:79) argues that when an empire defeats the people of a region and takes a bounty of food, products or humans, it performs an essential task of imperialisation.

In postcolonial writing terms such as "imperialism" and "colonialism" are often lumped together and tend to be used interchangeably. In this usage the term imperialism means the practice, theory and attitudes of a dominating metropolitan centre ruling a distant territory, whereas colonialism, which is almost always a consequence of imperialism, is the implanting of settlements on distant territory (Said 1993:8). It is notable that throughout history colonialism has been characterised by genocidal practices, torture of prisoners, rape and enslavement of indigenous populations (Dube 2006:149).

This imperial paradigm is inspired by the history of Yehud. Yehud was captured by the Babylonian Empire, which was later defeated by the Persian Empire, resulting in the restoration of Judah as a colony (Berquist 2006:78). Berquist also traces ways in which Yehud's canon constitutes colonial and colonising literature and argues that the canon cannot be understood unless one takes into consideration the realities of empire that led Jerusalem into exile. Brett also remarks that the ancestral religion is not exempt from colonial regimes (2008:45). Furthermore, Berquist (2006:79) contends that both the Old and the New Testaments are not free from imperial ideologies. Thus one must be attentive to such ideological realities in the Israelite story when engaging with the canon, and the fact that Israel asserts itself as an empire in its scriptures because it had been under other empires.

2 Colonialism is a policy of acquiring political control over another country, occupying it with settlers and exploiting it politically, culturally and economically. Apartheid is a policy of segregation or discrimination on grounds of race. These two systems are different and yet related to one another in that one is the repercussion of the other: apartheid emerges from the system of colonialism (Patel 2011:72-73) 


\section{Genesis 38 as postcolonial text}

According to Tyagi (2014:23-74), postcolonialism is a term which suggests resistance to colonial power and its discourses, which continue to shape various cultures. Part of the task of postcolonial theory is taking a long historical look at both old and new forms of domination (Sugirtharajah 2006:6). This is not surprising as the vision of a postcolonial approach lies in using the past to understand the shape taken by the present. Edward Said also adds that it would be absolutely naïve to study the present without taking into consideration the way that the role played by the coloniser informs the present (Hamadi 2014:41).

Dube (2012:3) also rightly states that postcolonialism "describes the modern history of imperialism beginning with the process of colonialism through the struggles for political independence, the attainment of independence and to the contemporary neo-colonialist realities". She shows that postcolonial theory identifies how colonialism continues to assert itself in the new millennium. Postcolonial theory does not only recognise the repercussions of the colonial past, but it also critiques imperial oppressions which are disguised in new forms.

It therefore goes without saying that stories of many African countries are stories of colonisation. Dube links this to the popular African saying that "When the white man came to our country he had the Bible and we had the land. The white man said to us, let us pray. After the prayer the white man had the land and we had the Bible" (Mofokeng 1988:34). Dube (2012:3), in discussing the colonisation in Africa, asserts that each Western colonial power attributed to itself the right to grab what they regarded as available pieces of land in Africa. According to Dube, the idea of deciding to take other people's land, the enslavement of the people and claiming every resource of that colonised land were going to be used to empower and enlarge the Western empire, leaving the rightful owners of the lands with nothing to gain. South Africans experienced both colonialism and apartheid, which is a policy of segregation or discrimination on grounds of race. Colonialism and apartheid are two different systems yet are very closely related to one another in that one is the repercussion of the other: apartheid emerged from the system of colonialism (Patel 2011:72-73). My point of departure will be the South African context with a particular focus on Zulu women's marital discourse. ${ }^{3}$

In his determination to reveal the spirit of colonialism in biblical literature, Brett (2008:7) asserts that the biblical text is a colonising discourse whose construction was undertaken by individuals who emerged from imperial contexts. Berquist (2006:83) also asserts that the biblical text was a politically constructed

I will not be generalising here. I am aware that many Zulu women did not end up marrying Zulu men, and also that many Zulu men married women of other African nations, and therefore experiences may differ here. I will, however, be drawing upon the experience of the suffering undergone by some Zulu women who have married Zulu men. 
document for the purposes of advancing an imperial ideology. Therefore, it is conceivable that national power dynamics would be at play as authors composed the text. Barr (1980:268) confirms that the Bible contains multiple political images, whilst Ogden (cited in Brett 2008:179) points readers to the harsh reality that the biblical text is not fundamentally based on religion alone, but that it is also a discourse that involves cultural, political and economic matters within which religion is embedded. Many texts in the biblical corpus are found to be informed by an imperial paradigm, and in the story of Judah and Tamar as told in Genesis 38, one encounters similar political, cultural and economic powers at work, which we shall investigate briefly based on the historical background of the book of Genesis.

The Pentateuch is the work of various authors from different periods of history. In the Pentateuch, the nation of Israel commemorates its past through memory, using the stories in Genesis in a symbolic fashion, where the mythic past is utilised for understanding and legitimatising the present (Bailey 2013:42). Many of the authors who wrote the patriarchal records always inscribed them in such a way that their records portray Israel as the favoured nation (Marttila 2012:36). The ideology of Israel's chosen-ness is particularly clear in the way Israel interacts with other nations such as the Canaanites, Amalekites, Midianites (Marttila 2012:36). This sets the scene for xenophobia and violence. Marttila further contends that these nations are also intentionally portrayed in a negative light by biblical authors, asserting that within various biblical texts, it becomes "a customary command that Israelites annihilate them" (Marttila 2012:36). ${ }^{4}$

Such an ideology of exclusion and anti-foreignness by Israel is also observed in the Tamar and Judah narrative, although not many scholars devote attention to this dynamic. The fact that Judah was an Israelite and Tamar a Canaanite thus has significant implications for the direction the story takes. The story is told from the Judahite perspective and it forces Tamar to participate in the establishment of an empire. Even though Judah married a Canaanite woman, ${ }^{5}$ he operated with a colonial mentality that subjugated and violated the non-Israelite Tamar. Judah's marriage to a Canaanite woman is problematic in itself, since the foreign women have always been stereotyped as dangerous, seductive and promiscuous (Pui-lan 2005:110). It is thus a question if the Canaanite women, Tamar and Shua's daughter whom Judah and his sons married, are free from this negative stereotype?

$4 \quad$ Interesting about this division of nations, and oppressor versus oppressed ideologies, is what Brett attributes to European modernism and colonialism, namely that he asserts that these shaped the biblical canon (2008:42-43).

5 Up until that point marrying a Canaanite was prohibited by the patriarchs in (Gen. 24:3). Abraham forbade Isaac to marry a Canaanite (Gen. 27:46; 28:1), while Isaac and Rebecca regretted Esau's marriage to a Canaanite woman and prevented Jacob from suffering the same fate as Esau (Brett 2008:77). 


\section{Reading Genesis 38 through a postcolonial lens: A perspective of hegemony}

Works of intertextuality where a story from the past still relates to and even foregrounds newer retellings of the story have been employed in establishing the setting for Genesis 38. This is done to establish elements of imperial characteristics embedded in Israelite patriarchal society and culture.

As already mentioned, postcolonial criticism is a helpful tool in reading Genesis 38, as it helps to unveil the hidden ambiguities that are overlooked by patriarchal and colonising approaches to the text. Dube $(2006: 148)$ stresses that it is crucial not to blur the lines between patriarchy and colonialism/imperialism. Patriarchy should not be mistaken for empire, nor should empire be mistaken for patriarchy. The difference between the two is that imperialism oppresses both men and women, even those of prominent status, while patriarchy oppresses only women and some men from marginalised categories. Consequently, I shall attempt to show that the Tamar narrative as told in Genesis 38 contains both patriarchal and imperialistic elements.

Genesis 38 describes Judah's movement of settling in Canaan, an act of a coloniser, where he forms alliances with a man called Hirah. Shortly upon arrival, Judah is mentioned acquiring a Canaanite wife with words translated as "saw" "took" and "went into". Judah's actions are reminiscent of a colonial assertion of conquest. Firstly, Judah is witnessed as violating the family norms by marrying a Canaanite woman (Brett 2008:77). Furthermore there is no mention of Shua being "given" in marriage by her father as was the case of every respectable Israelite bride; rather Shua is "taken" by Judah as a form of capture. This diminishes the role of parents to negotiate on her behalf, specifically the father's role (Aschkenasy 1998:82). In the context of colonisation, colonised relations are played in terms of bodies, especially bodies of women that are vulnerable to be taken by foreign men (Pui-Lan 2006:82).

Judah was the product of a culture that was significantly grounded in patriarchal and imperial ideology. His marriage to Shua's daughter is informed by the need to obtain heirs and therefore his sons must follow suit. This is observed in the magnitude of Judah's authority and dominance over his household, where the members of his household do not oppose his commands; his wife and sons do not have a contending voice; rather what the narrator shows is Judah's aggressive stance about the way things should be. Judah, by making matrimonial decisions on behalf of his sons, reinforces his authority over even the grown men in his home (Aschkenasy 1998:82)!

In Genesis 37, which serves as part of the literary context of the story, it is established in the first verse that Jacob and his family had settled in Canaan. Hamilton (1995:405) notes that for Isaac, Canaan was a place of sojourning, a place of temporary stay, while for Jacob it was a place of settlement which connotes permanence. However Spina (2005:36) asserts that settlement in Canaan for Judah was not only because of economic and social interests, but that his intentions were highly personal. At 
play in the story is Israel's colonising ideology which involved taking possession of foreign geographical space, acquiring the women and oppressing the men in the land (Dube 2006:148). Thus, the plot of Genesis 37 is about Jacob's sons who engage in actions of deception that would cause division in the family (Bosworth 2008:37). Earlier in Genesis 34:13-17, Jacob's sons had also succeeded in deceiving the men of Shechem, which resulted in the annihilation of the men and the abduction of the women and children. The latter act of deception by Jacob's sons is seemingly balanced by the fact that their sister Dinah was violated (Jeansonne 1990:94). However, the retribution is portrayed in the text as an unjust crime. In as much as it is the honour of an Israelite family that had been violated, in this imperial context it is a case of the subjugated demeaning the coloniser.

Dube (2006:145) states that the "territory of a nation not only consists of a physical piece of land but also contains the economic and cultural resources of a people." The conquered subjects in this scenario are stripped of territory, as well as political, economic and cultural power (Dube 2006:146). This implies that, often, subjugated people do not wish to put up a fight; rather, they surrender willingly because they know that resistance might bring about a violent response.

In a similar fashion in Genesis 34:16, after agreeing to be assimilated into Israelite culture, the Hivite men were all killed, and their children and women captured (Jeansonne 1990:94). The subjugation of people in a region through violence and abduction can be described as an act of imperialism (Berquist 2006:79). As colonisers, the Israelite world is governed by specific relations of the powerful to the powerless (Kharbe 2009:426). Colonisation was achieved by instilling fear and by killing their victims randomly (Dube 2006:147).

Features of a coloniser in Judah can be traced in his character, which might have been evident in his involvement with his brothers in the Shechem episode, and later when they sold Joseph to slavery. In Genesis 38 Judah's individual tactics confirm the traits of the coloniser outlined above.

\section{The coloniser's wife}

Segregation is regarded as a common political strategy of the coloniser that is used to divide and rule (Chia 2006:175). In other words, the selection of the best candidates from the colonised nation serves the interest of the empire and it is evident in the idea of using certain people for certain tasks while designating others to perform tasks that are less pleasant. ${ }^{6}$

6 Divide and rule is used here to refer to a strategy that breaks up existing power structures, and especially prevents smaller power groups from linking up, causing rivalries and fomenting discord among the people. The prevention of the two Canaanite women to form alliances is what is at play in this story because of the fear that they may unite and will so sabotage the colonisers rule. 
Another interesting observation is that "the coloniser expects the colonised to become like them, implying that they must rid themselves of the inferior cultural habits, in order to be elevated to the culture of the coloniser" (Jonker 2016:31). In the Tamar narrative a distinction is made between the two Canaanite women. Shua's daughter assumed the position of a colonising woman because she was more favoured than Tamar. In a society where a woman was recognised only when she had a child, Judah's wife, unlike the childless Tamar, proved to be an ideal of procreation, as she fulfilled the cultural norms and expectations (Anderson 2009:36). In a sense therefore, Judah's wife was worthy because she had played a significant role in the consolidation of the empire (Pui-lan 2005:107). The empire was flourishing through her, while Tamar was unproductive. The female colonisers are usually protected and sheltered and they seem to share the glory of their men (Dube 2006:151). Judah's wife is portrayed in a good light by the narrator; her wellbeing is stable and protected. She is much like Ruth, who Donaldson (2006:168) says moved from savagery to civilisation as she abandoned her ethnic and cultural identity. Furthermore, Shua's daughter received the honour of naming her last two sons (Spina 2005:39), which is seen as a symbol of having power and authority (Thatcher 2011:24). The privilege of naming the babies confirms the level of power and prestige attributed to the wife of Judah by the narrator. Chia (2006:176) adds that the significance of naming is not necessarily in the name but in the authority of the powerful.

When Judah sent Tamar home to her father's house (v.11), he was stripping her of every right and opportunity to bear a son (Newsom \& Ringe 1998:26). Judah's wife remained silent through every ordeal experienced by Tamar. She must have seen Tamar oppressed, but she never spoke out against the oppression. Dube (2006:150) contends that the silence of the female colonisers is always recognisable and never hidden. In this narrative, the audience was not oblivious to the silence, and the text hardly mentions that Judah's wife showed any concern for Tamar. Be that as it may, one can also argue that the silence of Judah's wife as a coloniser's wife could also imply that she did not have a voice in the household, and she could have been held at a distance for being a Canaanite.

\section{The colonised Canaanite men}

A reading of Genesis 38 through an African postcolonial feminist lens enables one to view the two Canaanite men Hirah and Shua as colonised men (vv.1-2). Hirah and Shua had connections with Judah. Hirah was Judah's friend and he probably helped Judah to settle in Canaan (v.1), which recalls Dube's (2006:146) point that in colonised lands, the colonised men usually grant the coloniser access to the land and its resources, possibly for personal gain. Later in the story (v.20) Judah sent Hirah to find the prostitute he had slept with, which could mean that he sent one of his colonised men to help cover his shame. Chia (2006:174) notes that it is ironic that the narrator presents the coloniser as trustworthy and honourable. This means that Judah could not be degraded; he could not be seen delivering the promised goat 
to the prostitute because that would be demeaning to him. Interestingly, Tamar's father could also be counted amongst the colonised males in Canaan, since Judah had the audacity to send Tamar home after she had been married to his two sons without informing her father. There appears to be no mutual respect between Judah and Tamar's father.

The text does not show that the Canaanite men in Genesis 38 resisted the injustice that Judah imposed on the women of their community. Even when Judah commanded that Tamar be burnt, the community simply ignored such an atrocious request without any sign of protest. It is assumed that the role players in the burning of Tamar were mostly men. This implies that marginalised men are usually easily swayed to commit atrocious acts against their own kind in order to curry favour with the coloniser. However, Freire $(2005: 47)$ has argued that quite often the oppressed themselves tend to become oppressors, because they have lived under dehumanising conditions for so long that their thought patterns cannot but take the shape of that of the oppressor. Cooper (2003: 186) also observes such realities in her own African-American context, where men are denied social, economic and political power, and their women become the targets of violence in order for the men to gain the kind of masculinity that they are denied. Black South African men, especially Zulu men, ${ }^{7}$ are not exempt from such behaviour (Adams 1999:56-57).

\section{Tamar, a questionable female "other"}

By looking at Tamar through the eyes of the other, I wish to demonstrate that the urge to survive produced the trickster in her. Viewing Tamar as the subjugated colonised "other" exposes certain limitations she encountered and the psychological implications of the injustice that she suffered. Darden (2012:63) argues that the "imperialism-colonialism system is not only a system of economic and military control, but also of cultural penetration/domination that subjugates psychologically and intellectually." Freire (2005:44) explains that often, at a stage during the struggle, the oppressed, instead of striving for liberation, tend to become oppressors or sub-oppressors. The reason for this, according to Freire $(2005: 45)$, is that the contradictions involved in their structural realities are also salient in shaping their intricate thought patterns. In Tamar's case, being impregnated by her father-in-law was the "ammunition" that she needed to liberate herself. Having sex with her father-in-law was probably not the ideal thing to do; however, at that point it was crucial for her to do so. The restoration of her dignity and identity depended on her committing unethical actions to reclaim her identity.

This is not to generalise that Zulu men are the only black men caught in the neo-colonialism of postcolonial South Africa; the writer is aware that this phenomenon affects all black cultures in South Africa. This paper focuses specifically on the Zulu patriarchal nation. 
Thus, Tamar's action is comparable to Rahab's, who betrayed her own people for personal security under colonial rule; she denied her own people for her selfish gain (Josh. 2). Tamar figured out a way that could guarantee her restoration to Judah's house. One could imagine why, after facing humiliation in Judah's house, Tamar did not choose to find love somewhere else, for example, with a Canaanite man. Regarding Rahab, Mill (cited in West 2004:4), who writes about utilitarian moral ethics, asserts that utility is found in everything which contributes to the happiness of every national being. Actions are judged morally acceptable based on the happiness of the largest number of beneficiaries. One's search for happiness stops if the effect of that happiness decreases the happiness of another individual or of the community. It is in that context that Rahab's actions could be regarded as selfish, since her pursuit of happiness caused suffering to her nation. However, seen through the eyes of the excluded and subjugated “other”, Rahab's action appears justified. It was a struggle for survival, which defied all sense of ethics. Freire (2005:44) argues that the ideal for the oppressed is to be human; but then, to be human is often to act as an oppressor, which in many instances serves as their model of humanity.

It is noteworthy that the coloniser always guarantees life in exchange for something that affects the core of those foreign subjugated female characters. For instance, in the case of Rahab, she had to betray her own people and culture and assimilate into Israelite society. For Ruth, to finally find happiness and continuation of life, she had to renounce her own culture, gods and people to qualify as an Israelite. In that sense, Tamar also acted to regain access into the coloniser's family. As in the case of Rahab, she had become familiar with being in the middle and with living between continuity and discontinuity, acceptance and rejection, life and death, dream and nightmare (Dube cited in Darden 2012:69). Due to her suffering, Tamar became a different being. Freire (2005:49) asserts that liberation is thus a childbirth and a painful one the man or woman who emerges is a new person, produced from the struggle of the oppressed against the oppressor in a context of dehumanisation.

However, an examination of the measures of survival employed by foreign women in the biblical narratives would confirm Jackson's (2014:243) comment that non-Israelites indeed threatened the purity of Israel by their very presence. This is especially clear in Jezebel's case, for what distinguished her from the other women in her context, whether Israelite or foreign, is her rejection of Yahweh! However, Stanley Frost (1964:505) also points out that often Israelite women were pardoned when they committed crimes such as murder and seduction, as in the case of Judith (Dube 2006:142), who emerges a hero, whereas Jezebel, a foreign woman, met with condemnation. It is thus significant that Tamar the foreigner was almost burned for committing adultery, whereas Judah, who had committed an even graver crime of denying her the continuation of life, marginalising her, sending her back to her father's house, and stripping her of all economic rights, got off free. There seems to be a double standard at work if, in the eyes of the community, Tamar should be burned for having crossed the line based on unspecified criteria. 
Furthermore, Israelite women employed trickery to have their way like the matriarchs Rebecca (Gen. 24-27) and Rachel in (Gen. 31:19). However, none of them were condemned, perhaps because they were Israelite women. According to Jackson (2014:245), this contradiction implies that when the actions benefit Israel, they are considered right and acceptable, but when they affect Israel negatively, these actions are regarded as wrong. One could make a similar argument regarding Jezebel, who is portrayed as nothing less than an intransigent unapologetic enemy of Yahweh. She is never one of 'us', but remains one of 'them', hence, permanently and quintessentially 'the other'. Tamar also may be one of 'them', married to Judah's sons, but she is "othered" in many instances that serve as boundary markers and which clearly expose her foreignness. She belonged but did not quite belong to the family; she was therefore treated as one that disrupts the homogeneity of the family. However, by giving birth to sons, she regained access to the coloniser's family, and only then is she worthy enough to mingle with the Israelites.

\section{Tamar as a decolonising agent}

The narrator depicts the character of Tamar as a woman who found herself in a colonised environment. McKinlay (2004:47) asserts that Rahab was created as the 'Other' in order to provide the 'us' of Israel with an identity, and it seems that Tamar suffered the same fate. Tamar is in the same class as women such as Orpah (in Ruth 1) and Jezebel (1 Kings 16:31). The imperial setting requires the individuals to either surrender to the imperialist or suffer death (Dube 2006:149). Tamar was ushered onto the scene when Er needed a wife, and Judah took her as wife for Er. When Er died, Onan went into her, according to the levirate marriage custom.

However, Onan spilled his seed so that Tamar would be unable to conceive. Based on Deuteronomy 25:7-10, it is clear that Tamar had the power invested in her by law to expose Onan's action, but she chose not to. Rather, she remained silent and obedient perhaps due to the fear of being thrown out of Judah's family. Tamar kept quiet probably also because she realised that she had little power to resist all the suggested options regarding her future. Without any protest, Tamar then accepted Judah's orders (Spina 2005:43) to go and "remain a widow in your father's house" (Gen. 38:11). It is interesting to note that Tamar used her silence as a form of resistance. Silence, according to Yafeh-Deigh (2012:430), is a central aspect of resistance in the power dynamics involving gender relations. Therefore, Tamar's silent response can be understood as a symbol of her determination to undermine the imperial subject. In line with Scott's (1990:4) notion of hidden and public transcripts, one could argue that Tamar seemed to act out what the coloniser expected of her, but while allowing herself to be victimised by her subjugator, she secretly searched for her own source of strength. 
Moreover, Van der Walt (forthcoming) raises an important question, namely "How does one resist oppressive structures without assuming the oppressive identity in return, that is, without one also resorting to oppression?" Thinking back to the central concept of hybridity in postcolonial criticism, one is reminded of the point that the identity of the colonised is always in a hybrid form. On the one hand there is the identity by birth and on the other is the identity imposed by the colonising context (Chia 2006:181). Therefore, Tamar lived between her Canaanite culture and the Israelite culture, but she was committed to neither. Unlike other foreign women who pledge to follow the God of their coloniser (for example, Ruth), Tamar neither worshipped her Canaanite gods nor the God of Israel. According to Bhabha (2012:247), hybridity constantly causes people to negotiate the middle spaces. Tamar is seen moving in and out of both Israelite and Canaanite cultures as a form of survival. In the house of the coloniser, Tamar had to live like the coloniser, which recalls Bhabha's (2012:247) notion of mimicry, which she defines as a state of imitating the coloniser because the oppressors plot to assimilate the other into their culture. Although Tamar lived like the coloniser, she was not quite like the coloniser. She lived in a place of difference, because she could never be fully an Israelite (Jonker 2016:32). She acted according to a hidden transcript which implies that in public, the dominated seem to accept their inferior position, while in a subtle way, they question the hegemonic system that oppresses them (Scott 1990:4). Because of the victimisation she faced, Tamar learned to be a woman of many faces - her identity shifted from that of a daughter-in-law, childless widow, prostitute and seductress, to a mother of twin boys (Collins 2009:11).

Tamar recognised the graveness of her situation and the reality of its harshness provoked her to resort to deceptive measures (Krutschwitz 2012:398). Her resistance is carried out through an act of seduction through which she jeopardised not only her own fate but also the lives of her family members (Chia 2006:181). Because Judah disregarded Tamar's father by sending Tamar back to him without conferring with him, Judah probably believed that Tamar plotted the act of trickery with her family's knowledge. Moreover, Judah could have blamed Tamar's father for allowing her to leave the house and appear in public when she was still in mourning, and for that reason he could have called for the punishment of the entire family rather than for Tamar alone. However, Judah the coloniser played right into the hands of the colonised - Tamar (Chia 2006:173). Pedrotti and Edwards (2014:21) assert that while individuals draw upon their own sources of power, the environment may also provide sources of strength as well as resources from which individuals can draw. Therefore, it is safe to conclude that Tamar's hybrid identity enabled her to exercise power in an environment and family that were also noted for deception, that is, Judah's imperial family. 


\section{The significance of Genesis 38 for the postcolonial South African Zulu context}

As in many other African cultures, childlessness is considered a misfortune in Zulu culture (Akujobi 2011:3). This is because African societies place great emphasis on a woman's duty to procreate. In the same vein, Ikenga Metuh (1999:188) contends that motherhood is a much sought-after status in most African societies and it is the dream of many young African women. "A woman who has not given birth or is infertile is regarded a social misfit. If she has never conceived, she is openly ridiculed and told that she is not a woman." Only through motherhood is an African woman's worth established. Oduyoye (1995:142) further argues that "often procreation is described as if women are simply objects of genetic and social transmission." Punt (2003:282) confirms this dynamic by asserting that often gender theories tend to incite insider/outsider rhetoric. In such a culture women often find themselves as outsiders, they are both welcomed and at times rejected as their worth is determined by their ability to contribute to androcentric norms.

According to Turaki (1999:107), children are regarded as a source of power for women, that is, in relation to men. Therefore infertility poses a threat to both women's power and the social order in which it is exercised. However, the issue is further problematised by the fact that the significance of begetting a child depends solely on the gender of the child. It is expected to be a male child (Baloyi 2009:4). Abasili (2011:561) again points out that in such a patrilineal society, the fate that accompanies a childless or infertile woman is also shared by the woman who bears only girl children. Among typical African societies, for example, when a baby is born, the first question asked is about the gender. If the child is a girl, the mother would be judged harshly, and if a boy, praises will be showered on the mother. Zulu culture does not necessarily react with contempt towards the mother of a girl child; rather, the judgement is silent. Ngobese (2003:61) asserts that in African marriages, it is only in the birth of a son that the marriage process is completed. When a woman gives birth to a baby boy, her status is elevated; she is recognised within the family and society at large (Masenya 1998:121). At times a woman could be sent back to her parents if she is infertile, and the lobola is repaid because of the shame of infertility. Many Zulu people still believe that infertility implies that the ancestors are not happy with the marriage (Ngobese 2003:57).

Lastly, Oduyoye (1999:114) asserts that issues of infertility or failure to conceive a boy child can lead to infidelity in the community. At times, some men engage in sexual relationships outside marriage to acquire sons or children as a result of their wives' infertility. Thus, whether a woman is sent back to her natal family or remains in her matrimonial home, she continues to suffer different forms of injustice one way or another. Being childless or having only female children in this kind of context could drive any woman to take dangerous measures in order to prevent ostracism and stigma. Therefore it is against this background that Tamar's desperate move to disguise herself as a prostitute should be understood. 


\section{Genesis 38 and Zulu women's marital experiences}

Reading the story of Tamar through an African postcolonial feminist lens approach is particularly significant in the contemporary context as it reveals the unique situation of South African Zulu women. In this regard, Tamar serves as a model of those who identify with both their cultural as well as their neo-colonial context. Tamar, having been confronted by both worlds, offers possible ways of resisting the powers that are life-denying for Zulu women.

In the story of Tamar, the main character can be understood in terms of her hybrid identity, as she wears the masks of both a Canaanite and a faithful wife to Israelite men. She lives in the "betwixt," which gives her enough power to betray and the same time embrace a new culture that puts her at odds with normal existence. In the biblical text it seems that Israelite identity takes pride in "othering” non-Israelites. For example, Israel acknowledged that it is God's chosen nation consequently and its people maintained that mingling with other nations jeopardised their relationship with God. Tamar discovered the intensity of this exclusion through her marriage to an Israelite; and when she lost him to death, her outsider identity became most prominent. She chose when to belong and when to reject her adopted society's cultural demands. Her hybrid identity is evident when she played the harlot. Waiting for a long period for the cleansing ritual that would have signalled the end to her widowhood added to her pain and rejection. Therefore, she overturned all the rules that bound her to the Israelite code of law; she slipped out of the garment that identified her with Er and Onan's wife, and wore the mask of a prostitute.

Through this study I have come to realise the masculinity crisis that Zulu men in my context today face. In the postcolonial South African context in which Zulu men are situated, black masculinities are seen as masculinities in crisis or masculinities in transition (Morrell, cited in Moolman 2013:96). African men find that their masculine identities are in jeopardy because of their experiences during the apartheid period, and trying to reconstruct their identities in a neoliberal context comes with new challenges. However, this does not mean that the dilemma is unique to black African masculinities; Western (white) men who live on the African continent also have their own crisis, which has much to do with having to deal with the loss of power. Nonetheless in this study, the focus is on Zulu men in particular.

The transition and crisis in masculinity are said to spark "ambiguity, multiplicity and contradiction" in African men and specifically in Zulu men of my community. This implies that African masculinities continuously undergo a process of negotiation with everything else that intersects with them. Moolman (2013:96) stresses that the way in which masculinities are produced/reproduced is central to the perception of women as oppressed and objectified creatures. The history of apartheid in South Africa shows that colonisation denied Zulu men a healthy expression of masculinity and reduced men to the level of children (boys), which resulted in an African masculinity that is at odds with itself. The insights into the crisis in Zulu masculinities help set the tone for the reading of Genesis 38 with a postcolonial feminist lens. 
Matsakis (1998:29) stresses that a people who have gone through the history of colonisation often become dangerous to themselves and those around them in ways that the colonised internalised violence and therefore mimic the violent actions of the coloniser. This he elaborates by asserting that it is a given that the repercussions of colonisation will leave the subjugated with negative psychological effects. Amongst the traumatic events of the colonised is domestic violence and sexual abuse, which we have mentioned above regarding Zulu women's experience in the marital setting.

Therefore the reading of the biblical text with a postcolonial feminist approach is important, because it demonstrates that a singular approach may be inadequate for reading the biblical text. However, using multiple complementary lenses is helpful when reading a text such as Genesis 38 , as it helps to take seriously the Zulu community's experience of the past and helps people find new modes of survival in their new postcolonial context.

The reading of the Tamar narrative shows Tamar as a deserving model whom Zulu women can emulate. Tamar outsmarted the oppressive colonial powers of her context and hence offers tools of resistance that could help Zulu women to face their contextual realities with courage. Zulu women have also experienced colonialism in the form of apartheid in their South African context. Their experiences may differ from Tamar's in the sense that their oppression under colonisation comes from their own Zulu men rather from foreign colonisers. Due to their experiences in the past, the ramifications of colonialism have negatively affected the relational dynamics between men and women, especially in the marital setting, for apartheid deliberately institutionalised gender inequality (Baden 1998:11). Many women are caught between the cultural expectations that they must submit to their men, versus the political and economic power available to them in their contemporary world which greatly threatens the traditional patriarchal household. Thus, we can say that Zulu women find themselves in a liminal space, that is, like Tamar who was familiar with "being in the middle, living in between continuity and discontinuity, acceptance and rejection, life and death, dream and nightmare" (Dube cited in Darden 2012:69). However, it is at the margins of their oppression that the Zulu women could also "challenge and subvert the dominant ethos" (Darden 2012:69).

Reading Tamar's story that a postcolonial feminist lens affirms that the subalterns do have a voice after all. Zulu women have much to say about their marital oppression, and the possibility for these voices to emerge from the margins of oppression can be opened up in studies such as this one. Ironically, even though Zulu men prioritise sons over daughters, those sons will never be able to constitute tribes and clans without daughters. Zulu women's pain can become the new frontier for cultural reform, as it demands new cultural norms that consider the reality of women and recognise that both males and females are equally important to the family and the society at large. No one group will succeed without the other. Even though Judah needed sons to continue his tribe, he did not have a womb to help him achieve his 
wish; it took Tamar's subtle intervention for him to achieve that. The postcolonial feminist lens assists Zulu women as they seek new ways to resist not only their patriarchal culture, but also the oppressive powers of the colonial world in whose shadows they continue to live. Tamar's model of resistance may therefore be an important tool for empowering Zulu women to resist injustice.

\section{Conclusion}

Reading Tamar's story through a postcolonial feminist lens affirms that subalterns like Tamar, as also so many Zulu women today, do have a voice after all. Studies like this open up the possibility for the voices of Zulu women to address the oppression they experience in terms of marriage. Female survivors of such oppression are called to help liberate the women of our Zulu culture by teaching them how one subverts the oppressive structures in order for every woman in Zulu culture to flourish.

\section{Bibliography}

Abasili, A I. 2011a. Genesis 38: The Search for Progeny and Heir, Scandinavian Journal of the Old Testament, 25(2): 276-288. https: / /doi.org/10.1080/0901832 8.2011 .608545

Abasili, A I. 2011b. Seeing Tamar through the Prism of an African Woman: A Contextual Reading of Genesis 38, Old Testament Essays, 24(3): 555-573.

Adams, H. 1999. Tortured People: The Politics of Colonization, Penticton: Theytus Books.

Akujobi, R. 2011. Motherhood in African Literature and Culture, CLCWeb: Comparative Literature and Culture,13.1. http://dx.doi. org/10.7771/1481-4374.1706
Anderson, C B. 2009. Ancient Laws and Contemporary Controversies: The Need for Inclusive Biblical Interpretation, Oxford, New York: Oxford University Press. https:// doi.org/10.1093/acprof:oso/ 9780195305500.001.0001

Aschkenasy, N. 1998. Woman at the Window: Tales of Oppression and Escape, Detroit, MI: Wayne State University Press.

Baden, S; Hassim, S \& Meintjes, S. 1998. Country Gender Profile: South Africa Report Prepared for the Swedish International Development Co-operation Agency (SIDA), Pretoria, Republic of South Africa. Available: http://www.bridge. ids.ac.uk/sites/bridge.ids.ac.uk/ files/reports/re45c.pdf. Last retrieved 10 April 2015. See more at: http://www.sahistory.org.za 
Baloyi, M E. 2009. Critical Reflections on Infertility in Black African Christian Communities, Pretoria: University of South Africa.

Barr, J. 1980. The Bible as a Political Document, in J Barr (ed.), Explorations in Theology, London: SCM, 91-110.

Berquist L J. 2006. Postcolonial and Imperial Motives for Canonization, in R S Sugirtharajah (ed.), The Postcolonial Biblical Reader, Oxford: Blackwell Publishing, 186-192.https://doi. org/10.1002/9780470775080.ch5

Bhabha, H K. 1994. The Location of Culture, London, New York: Routledge.

Bhasin, K. 1993. What is Patriarchy? Kali for Women, New Dehli: Raj Press.

Bosworth, D A. 2008. The Story within a Story in Biblical Hebrew Narrative, Washington DC: Catholic Biblical Association of America.

Brett, M G. 2008. Decolonising God: The Bible in the Tides of Empire, Sheffield: Sheffield Phoenix Press.

Byrne, D. 1998. Social Exclusion, Second Edition, Maidenhead, Berkshire: Open University Press.
Chia, P. 2006. On Naming the Subject: Postcolonial Reading of Daniel 1, in R S Sugirtharajah (ed.), The Postcolonial Biblical Reader, Oxford, UK: Blackwell Publishing, 171-185. https://doi. org/10.1002/9780470775080.ch11

Collins, S. 2009. Weapons upon Her Body: The Female Heroic in the Hebrew Bible, London: Cambridge Scholars Publishing.

Cooper, V. 2003. Some Place to Cry: Jephta's Daughter and the Double Dilemma of Black Women in America, in C Kirk-Duggan (ed.), Pregnant Passion: Gender, Sex and Violence in the Bible, Atlanta, GA: Society of Biblical Literature.

Darden, L. 2012. Hanging out with Rahab: An Examination of Musa Dube's Hermeneutical Approach with a Postcolonial Touch, in M W Dube, A M Mbuvi \& D Mbuwayesango (eds.), Postcolonial Perspectives in African Biblical Interpretation, Atlanta, GA: Society of Biblical Literature.

Donaldson, E L. 2006. The Sign of Orpah: Reading Ruth through Native Eyes, in R S Sugirtharajah (ed.), The Postcolonial Biblical Reader, Oxford, UK: Blackwell Publishing, 159-170. https: / / doi. org/10.1002/9780470775080.ch10 
Dube, M W. 2006. Rahab Says Hello to Judith: A Decolonizing Feminist Reading, in The Postcolonial Biblical Reader, R S Sugirtharajah (ed.), Oxford, UK: Blackwell Publishing, 142-158. https://doi. org/10.1002/9780470775080.ch9

Dube, M W. 2012. Talitha Cum

Hermeneutics of Liberation: Some African Women's Ways of Reading the Bible, in Postcolonial Perspectives in African Biblical Interpretation, $\mathrm{M} \mathrm{W}$ Dube, A M Mbuvi \& D Mbuwayesango (eds.), Atlanta: SBL, 29-42.

Frost, S T. 1964, Judgement on Jezebel, or a woman wronged, Theology Today, 20: 503-517. https://doi.org/10.1177/ 004057366402000407

Freire, P. 2005. Pedagogy of the Oppressed, New York: The Continuum International Publishing Group Inc.

Hamadi, L. 2014. Edward Said: Postcolonial Theory and the Literature of Decolonization, European Scientific Journal, 2: 39-46.

Hamilton V P. 1995. The Book of Genesis: Chapters 18-50, Grand Rapids, MI: William B. Eerdmans.
Jackson, M. 2015. Reading Jezebel from the 'Other' Side: Feminist Critique, Postcolonialism and Comedy, Review \& Expositor, 112.2: 239-55. https://doi. org/10.1177/0034637315582469

Jeansonne, S P. 1990. The Women of Genesis: From Sarah to Potiphar's Wife, Minneapolis, $\mathrm{MN}$ : Fortress Press.

Jonker, L C. 2016. Defining All-Israel in Chronicles: Multi-levelled Identity Negotiation in Late Persian-Period Yehud, Tubingen: Mohr Siebeck.

Kharbe, A S. 2009. English Language and Literary Criticism, New Delhi: Discovery Publishing House PTV Ltd.

Krutschwitz, J. 2012. The Type Scene Connection between Genesis 38 and the Joseph Story, JSOT, 36: 383-410.

Laband, J \& Sithole J (eds.). 2008. Zulu Identities: Being Zulu, Past and Present, Scottsville: University of KwaZulu-Natal Press.

Loomba, A 2005. Colonialism/ Postcolonialism: The New Critical Idiom, New York: Routledge.

Matsakis, A. 1998. Trust After Trauma: A Guide to Relationships for Survivors and Those Who Love Them, Oakland: Ca, New Harbinger. 
Marttila, M. 2012. Foreign Nations in the Wisdom of Ben Sira: A Jewish Sage Between Opposition and Assimilation, 13, Berlin: De Gruyter. https: / / doi. org/10.1515/9783110270112

Masenya (Ngwan'a Mphahlele), M. 1998. A Bosadi Womanhood Reading of Genesis 16, Old Testament Essays, 11(2), 271-287.

McKinlay, J E, 2004. Reframing Her: Biblical Women in Postcolonial Focus, Sheffield: Sheffield Phoenix Press.

Metuh, E I. 1999. Comparative Studies of African Religions, Enugu: Snaap.

Mofokeng, T. 1988. Black Christians, the Bible and liberation, Journal of Black Theology in South Africa, 2(1): 34-42.

Moolman, B. 2013. Rethinking 'Masculinities in Transition' in South Africa, Considering the 'Intersectionality' of Race, Class, and Sexuality with Gender, African Identities, 11(1), 93-105. https: / / doi.org/10.1080/1472584 3.2013.775843

Newsome, C A \& Ringe S H. 1998. Introduction to the First Edition, Women's Bible Commentary, Expanded Edition, in C.A. Newsome and S.H. Ringe (eds.), Louisville, KY: Westminster John Knox Press.
Ngobese, W R M. 2003. The Continuity of Life in African Religion with Reference to Marriage and Death among the Zulu People, Pretoria: University of Pretoria.

Ngubane, S J. 2010. Gender Roles in African Culture: Implications for the Spread of HIV/AIDS, master's thesis, Stellenbosch: Stellenbosch University.

Oduyoye, M A. 1995. Daughters of Anowa: African Women and Patriarchy, Maryknoll, New York: Orbis Books.

Oduyoye, M A. 1999. A Coming Home to Myself, in L M Russel, M A Farley and S Jones (eds.), Liberating Eschatology: Essays in Honor of Letty M Russell, Louisville, KY: Westminster John Knox.

Patel, L. 2011. Race, Inequality and Social Welfare: South Africa's Imperial Legacy, Paper delivered at Colonialism and Welfare: Social Policy and the British Imperial Legacy, 15-19 March, London: London School of Economics.

Pedrotti, J T \& Edwards, L. 2014. Perspectives on the Intersection of Multiculturalism and Positive Psychology, London and New York: Springer. https://doi. org/10.1007/978-94-017-8654-6

Pui-lan, K. 2005. Postcolonial Imagination and Feminist Theology, Louisville, KY: Westminster John Knox Press. 
Punt, J. 2003. Postcolonial biblical criticism in South Africa: Some mind and road mapping, Neotestamentica, 37(1): 59-85.

Said, E W. 1993 Culture and Imperialism, London: Chatto \& Windus.

Scott, J C. 1990. Domination and the Arts of Resistance: Hidden Transcripts, New Haven, CT: Yale University Press.

Spina, F A. 2005. The Faith of the Outsider: Exclusion and Inclusion in the Biblical Story, Grand Rapids, MI: William B. Eerdmans.

Spivak, G C. 1993. Can the Subaltern Speak? in P Williams \& L Chrisman (eds.), Colonial Discourse and Postcolonial Theory, New York: Harvester Wheatsheaf, 66-111.

Sugirtharajah, R S. 2006a. Charting the Aftermath of Postcolonialism, in R S Sugirtharajah (ed.), The Postcolonial Biblical Reader, Malden, MA: Blackwell, 7-32. https: / doi. org $/ 10.1002 / 9780470775080$

Sugirtharajah, R S (ed.). 2006b. The Postcolonial Biblical Reader, Malden, MA: Blackwell. https:// doi.org/10.1002/9780470775080
Thatcher, A. 2011. God, Sex, and Gender: An Introduction, Oxford, UK: Blackwell Publishing. https://doi. org/10.1002/9781444396386

Turaki, Y. 1999. Christianity and African Gods: A Method in Theology, 75, Potchefstroom: Universiteit vir Christelike Hoër Onderwys.

Tyagi, R. 2014. Understanding Postcolonial Feminism in Relation with Postcolonial and Feminist Theories, International Journal of Language and Linguistics, 1 (2): 45-50.

Van der Walt, C (forthcoming). 'Is There a Man Here?' The Iron Fist in the Velvet Glove in Judges 4, in L J Claassens \& C Sharp (eds.), Feminist Frameworks: Power, Ambiguity and Intersectionality, London: T \& T Clark.

West, H R. 2004. An Introduction to Mill's Utilitarian Ethics, Cambridge: Cambridge University Press.

Yafeh-Deigh, A. 2012. The Liberative Power of Silent Agency: A Postcolonial AfroFeminist-Womanist Reading of Luke 10:38-42, in M W Dube, A M Mbuvi \& D Mbuwayesango (eds.), Postcolonial Perspectives in African Biblical Interpretation, Atlanta, GA: Society of Biblical Literature. 


\title{
Chapter 11 \\ The Perfect Believer in Manly Religion (James 1)
}

\section{Ancient notions and modern effects ${ }^{1}$}

\author{
Jacobie M Helena Visser
}

\section{Introduction}

The letter of James presents strong images of the ancient ideal of masculinity ${ }^{2}$. In the pericope of James 1 the masculine images that are constructed robustly echo the ideal masculine values of the $1^{\text {st }}$ century CE Mediterranean world. The Jesus followers are exhorted to live up to the ideal of $1^{\text {st }}$ century Greek and Roman images of manliness: ${ }^{3}$ being perfect $(1: 4$,$) complete (1: 4)$, lacking in nothing $(1: 4)$, being able to endure trials (1:12) and ready to be tested (1:12). The believers are considered blessed (112) and promised the crown of life (112) if they can adhere to these manly traits, but all in the name of being faithful to God.

1 Contribution prepared for the volume in honour of Prof Elna Mouton. I will be forever thankful for the life-giving classes on the Catholic Epistles given by Prof Mouton' (or as we call her "Prof Babe'"). Within those few weeks the New Testament academic in me was born; I rediscovered two texts I would devote my MTh (First Peter) and PhD (James) studies to, and most importantly she has shown me what it really

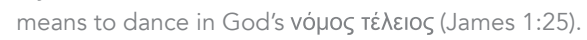

2 The term 'ideal masculinity' is used rather than 'hegemonic masculinity', which has negative connotations attached to it. By ideal masculinity is meant the predominant characteristics of the discourse of masculinity at a given time in a given context (Conway 2008:11).

3 Granted, different notions and versions of masculinity were around in the 1st century, but the focus here is on the dominant core that prevailed. This is, naturally, a somewhat artificial construction but helpful to frame this discussion below. What this dominant core consisted of is the view that the male body was considered the only perfect body and the female body was considered less masculine and hence less perfect. Masculinity constantly needed to be proved; the ideal man had to be the active agent rather than passive; the ideal masculinity was associated with certain virtues in order to be considered a "perfect man" and an ideal man had to prove he could control himself (Mayordomo Marín 2006:4-7). 
The focus here is on James' use of perfection and its connection with the ideal of masculinity in the $1^{\text {st }}$ century CE. Cheung (2003) and Lockett (2008) point out that

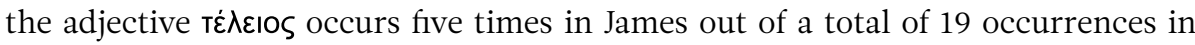
the New Testament, establishing it as an evidentially relevant concept in this letter. When the Jesus followers are exhorted towards a life of perfection, they are urged to live perfectly. ${ }^{4}$ The notion of perfection is used respectively in relation to work $(1: 4 ; 2: 22)$, wisdom $(1: 5 ; 17)$, faith $(2: 22 ;$ cf. $1: 6)$, law $(1: 25 ; 2: 8,10)$ and in connection to phrases, for example, the word of truth, the law of liberty and which is perfect $(1: 25)$. Wisdom is singled out once more as it is considered the perfect gift (1:17) given to those who God love fully (Cheung 2003:178; Lockett 2008:22). Such sentiments did not only resonate in ancient times.

On South African soil the Mighty Men Conferences (MMC) also construct a high ideal of masculinity, which strives towards these idealised masculine values. ${ }^{5}$ According to the MMC's website, the aim of the movement is "to inspire, to encourage men to be men, to be good fathers, good husbands, good leaders and good citizens (Mighty Men Conference Central South Africa [Online] 2017)“. "Good”, refers here to an idealised construction of masculinity "speaking from God's word" as "stout-hearted ambassadors" and thus men are naturally cast in the role of leaders, which probably qualifies the nature of fatherhood, husbandry and citizenship. In other words, men are encouraged to aspire to cultivate an idealised manner of being men in South Africa, according to the Bible. As presented in the work of, amongst others, Nadar (2009), Nortjé-Meyer (2011) and Dube (2015), Buchan's interpretation and construction of masculinity are highly problematic and even life-denying.

Both the MMC, as well as the letter of James, advocate a form of idealised masculinity in their particular socio-historical contexts. In both these movements, men are not just men, but they are advised and even urged to take up their superior role as men, who should lead by example.

This paper aims to contribute to current scholarship in two ways. Firstly, it wants to fill the current gap in scholarship regarding gender studies on James. Secondly, the advocacy of oppressive constructions of masculinity in the MMC, which adds to the public discourse of South African masculinities, suggests the need to explore the construction of masculinities in the New Testament and more specifically, in

4 The notion of $\ddot{\varepsilon}$ pyov $т \dot{\varepsilon} \lambda \varepsilon$ Iov (1:4, perfect work) is often a contested term and means, among other definitions, "endurance must attain its end". It relates to the "complete outcome of endurance" or the "full effect". It is also related to the fullest form of character or perfect character. In order to accomplish the goal of perfect work, one needs to be "completely complete" (Cheung 2003:178).

5 The Mighty Men Conference is considered a "major contemporary Evangelical Christian men's movement in South Africa (Dube 2015:1)this article ventures that the major contemporary Evangelical Christian movement in South Africa, the Mighty Men Conference (MMC)." 
the epistle of James. ${ }^{6}$ This paper, then, investigates the intersection of $1^{\text {st }}$ century masculinity and perfection as it is constructed in James 1, to expose some of the different elements of idealised masculinity involved, and their intersectionality. ${ }^{7}$ The effects of postulating religion and its vast impact on contemporary attempts to re-masculinise religion are also considered.

Although both the movements of MMC and the text of James are mentioned, I will limit my attention to the discussion of ideal masculinity in the epistle of James as religious and the highly ideal masculine constructed text in its $1^{\text {st }}$ century Greek and Roman world. References to the MMC underline the enduring relevance of the intersection between masculinity and perfection to this very day.

\section{Notion of perfection in the $1^{\text {st }}$ century Greek and Roman world}

\section{Ancient masculinity and perfection}

The general idea that the ideal of being a man was dominant, perfect $(1: 4)$ and complete (1:4) in the ancient Greek and Roman world is nothing new to gender theory scholars (Kuefler 2001:2). Laqueur's famous one-sex theory has been around since the early 1990s and claims that there existed not two binary conceptions of "male and female" but just one, namely male, according to Thatcher (2011:11). ${ }^{8}$ Laqueur argues that when there are not two sexes but one, the difference should be seen not in numerical terms but in "spectral terms" resulting in a single gender (male) spectrum, gradating from being "male to female". Thus, the difference between male and female is not based on sex (in the sense of biological features), but solely on the person's performativity (degrees of power, strength, excellence, virtue, status etc.) about gender. The gender gradient illustrates various binaries within

$6 \quad$ Hardly any studies examine the intersection of masculinity studies and the epistle of James in current scholarship. Even studies that investigate gender in James are rare. Aside from brief investigations by Tamez (1994), Johnson (2004) and Aymer (2017), hardly anyone has seriously investigated gender in the epistle of James.

7 Intersectionality is a concept developed by Kimberlé Crenshaw in 1989 to account for the multiple aspects impacting on each other in the formation of identity (Kartzow 2014:383). Intersectional studies aim to bridge and investigate notions across different categories of identity. Intersectional studies acknowledge that the social context of a particular time and place is a complex phenomenon and that issues of identity intersect and are intertwined with multiple categories of identity (Kartzow 2014:385).

8 In the modern framework of religious and secular references to sex and gender, the notion exists that there are two sexes (Thatcher 2011:7). These sexes are seen as counterparts within the post-enlightenment Western religious and secular mind-set. Conversely, Walter Laqueur (1990:8) argues that an one-sex model prevailed in ancient times, and in fact, until a century or three ago. He states that within the pre-enlightenment texts there exists the perception of not two sexes but one - the man (Thatcher 2011:7). Laqueur (1990:8) distinguishes between the notions of sex and gender saying that sex should be understood "epiphenomenonally", and gender as the "primary" or "real." He comments that gender, in terms of being either man or woman, played an important role relating to the "order of things within the pre-enlightenment conception". Thus, sex was conventional, "( $t$ )o be a man or a woman was to hold social rank, a place in society, to assume a cultural role, not to be organically one or the other of two incommensurable sexes". 
the ancient context relating to gender, namely masculine/feminine, honourable/ shameful, active/passive, free/slave and dominant/submissive. As a result, notions of masculinities and femininities shaped modalities related to men as superordinate, phallic and active, and women as subordinate, receptive and passive (Knust 2006).

Although the male body and performance of masculinity were the supposed standard and norm of perfection, only a few men met the cultural, religious and political standards of perfection (Wilson 2015:50). Men lived under the constant tension of having to "prove" themselves and aspired to perform the ideals of masculinity as they were mostly constructed and modelled by the gods, emperor and elite class. Men felt immense pressure "perform" their masculinity in both private and public spaces. Since a big part of defining ancient masculinity is related to the ancient notion of perfection, males in antiquity had to live up to this ideal of perfection. Of course, the expression of the ideal man differed from context to context and social level to social level, but the constant jostling to attain the ideal is what defined the lives of men. Studying the text's persuasive character with reference to $1^{\text {st }}$ century masculinities, this paper reads the text with an awareness of the values and ideals of $1^{\text {st }}$ century men in their $1^{\text {st }}$ century Greek and Roman context, and therefore masculinity will be investigated as a "cultural construct that centralises the roles, practices, and beliefs of men" (Roisman 2005:2). To study the text and investigate $1^{\text {st }}$ century masculinities in James, a close reading will be undertaken. A rhetorical close-reading, with the specific focus on $1^{\text {st }}$ century masculinities, encompasses three main objectives: firstly, to scrutinise James 1 for words and concepts where masculinity is constructed and expressed; secondly, to unpack and interpret the identified words and concepts with the specific focus on the rhetoric of $1^{\text {st }}$ century masculinities; and thirdly, to question, discuss and investigate the identified notions with reference to $1^{\text {st }}$ century masculinities (Kain 1998:1-3). For our purposes here, masculinity can be described as "a place in gender relations, the practices through which men and women engage that place in gender, and the effects of these practices in bodily experiences, personality and culture" (Connell 2005: 71). ${ }^{9}$ To further our discussion, Ivarsson's useful taxonomy of links between religious discourse and masculinity in 1 Corinthians can fruitfully be considered also in the broader $1^{\text {st }}$ century context and for James 1 in particular (Ivarsson 2007:165-166).

Ivarsson's taxonomy involves three "protocols" of ancient masculinity: masculinity as mastery, masculinity as competition and masculinity as moral values (Ivarsson 2007:165-166). These three recurring qualities of ancient masculine discourse are particularly helpful for investigating masculinity in James, as will become clear below.

9 Masculinity studies is the investigation of the way in which masculinity is expressed or performed in a given socio-historical context (Moore 2014:540). 


\section{Application to James 1}

\section{Mastering masculinity}

Firstly, Ivarsson (2007:165) mentions that to be a respected man and an "on top of the world" man, one's masculinity had to be mastered. The $1^{\text {st }}$ century men constantly had faced the tension of aspiring to and maintaining an idealist or perfect image of masculinity. In each sphere of life, these men had to be superior in relation to the inferior men, which included women, slaves, children, barbarians, and they also had to be able to be in control of themselves. They had the constant tension of mastering their own desires and needs (Ivarsson 2007:166). In the constructed rhetorical world of James, this was no exception.

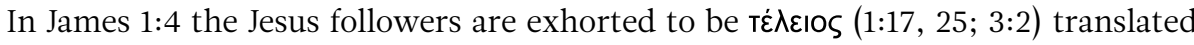
as "finished", "complete" or "mature". In ancient times the notion of perfection is connected to having the endurance to achieve or master a task or disposition (Johnson 2008:178). Theologically, the mastering of perfection is also related to the identity of the believer, and the action of perfection is intimately linked to the identity of the person. This also echoes the idea that masculinity is constructed by their behaviour and the way the believers act. If the Jesus followers are exhorted to a life of perfection, they had to master the act or acts of perfection.

The adjective ò The Jesus followers are exhorted to be complete. The striving for completion is also found in the broader literary context of the NT, such as in Matthew 5:48 (Johnson 2008:179). The Jesus followers had to be complete and whole by the idealised masculine values of the time. James uses the verb катєрүá孔દтаı ("to bring about/ produce”), grammatically connected to perfection and being complete, and غ̇ pyá̧દтa in 1:20 and 2:9 that is used to indicate something needed to be produced, performed and mastered. The term sets up the use of हैpyov (literally "work," but translated as "product") in the next line. More significantly, the construction shows from the start how the text rhetorically connects the perfection of "faith" and its "work/deed/ product," namely as the theologically effective development and expression of faith itself (Johnson 2008:178). It is significant that the notion of perfection is rhetorically linked to works $(1: 4 ; 2: 22)$, faith $(2: 22$; cf. $1: 6)$, law $(1: 25,2: 8,10)$ and wisdom $(1: 5,17)$. The exhortation to the Jesus followers to master perfection is deeply rooted in the letter of James.

Elliott (1993:73) links wholeness and holiness, connecting wholeness with the language of purity and perfection as key constructs in both the ancient Mediterranean world and the biblical texts. He indicates the overlapping nature and emphasis on perfection (Lockett 2008:25). The striving for perfection is connected to wisdom in James 1 . Wisdom is achieved when the perfect law is practised and studied (1:4-5). The Jesus followers strive towards achieving the final goal of a Christ-following

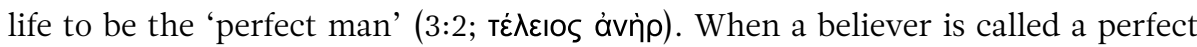


man, he has perfect control over his tongue and the full realisation of perfection and maturity at the end of days. The Jesus followers can only strive for complete perfection, because it cannot be wholly attained or achieved in this life (Cheung 2003:180).

The notion of mastering perfection and completeness, not only regarding perfection itself but also regarding the lack of perfection, is essential for James when the rhetoric is considered. Lockett notes the numerous adjectives that also point to the antithesis of perfection as a social value, for example, double-mindedness $(1: 8 ; 4: 8)$, being unstable $(1.8 ; 3.8$; cf. 3.16); the lack of wisdom (1:5-8) and control of the tongue (3.2, W2; 4.11; 5.12) (Lockett 2008:23). The text warns the Jesus followers against these notions of double-mindedness and division in opposition to perfection, and therefore also the need for mastering an ideal form of masculinity. On the one hand, they are urged to be complete and perfect; on the other hand, they are also not to doubt, boast (1:9), not be tempted when they are lured (1:14) and enticed by their desires (1:14). All these notions above could be related to unmanliness or effeminacy in the ideal masculine frame of reference in the $1^{\text {st }}$ century context.

In summary, in James the Jesus followers are strongly exhorted to master perfection, which was considered to be tantamount to this idealised masculinity, together with controlling their desires and emotions not to perform in effeminate ways, for example, being double-minded, boasting and being lured and enticed by desires. In the next section the perpetual jostling of and between men to establish their masculinity, and also the interrelationship between masculinity and morality in the ancient social and literary contexts, are pointed out as crucial for making sense of masculinity in James.

\section{Competing for masculinity}

The process of achieving and mastering one's masculinity, moreover, led to constant competition between men among themselves, their fellow Jesus followers and their contemporaries. As mentioned above, mastering masculinity was an on-going and continuously reconstructed phenomenon. When men competed with one another, they expressed how they understood themselves, but also how they made sense of others and more specifically, of other men (Ivarsson 2007:166).

The text calls the Jesus followers to compete with themselves, one another and their counterparts to achieve the masculine ideal of perfection. They would know that this striving towards perfection would make them face trials $(1: 2)$, test them $(1: 3 ; 1: 12)$ tempt them $(1: 13)$ and test their ability to endure $(1: 12)$. To achieve this masculine perfection is not something that they would master once and for all, but they would have to compete continuously and would constantly be asked to prove and redefine themselves - and constantly redefined other men, too. To some extent, the competition with self and others never ceased for $1^{\text {st }}$ century men. 
James uses the notion of "facing various trials" in the same way as the notion of "testing your faith". When one faces various trials, endurance is strengthened.

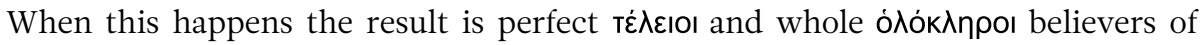
God (1:3-4) (Strange 2010:44). This idea is echoed by Batten (2010:106), who notes that the endurance that is achieved through the trials the believers face results in perfection that they should be "perfect and complete, lacking in nothing." But the ultimate aim of the testing of their faith is not endurance or steadfastness, but rather to be perfect and whole, a state which James encourages the believers to achieve.

James uses the example of continuously being on trial and competing against the desires of the world, which could be seen as a vice, and turns this into a virtue of self-control and self-accomplishment. By referring to trials and hardships to endure, even if it just regards morality and self-control, the text of James echoes moral philosophers of his time by seeing the confrontation with temptations and trials as a sign of virtue, or in the case of James as perfect faith (Conway 2008:75). By phrasing the idea of the trial as a masculinising phenomenon, the text is exhorting the Jesus followers to a life of endurance in striving for masculine perfection. The epistle is juxtaposing endurance in their life of faith to compete and being challenged by various trials in life. However, some ambiguity is introduced in that the author suggests that passive endurance can feed into an alternative way of participating in the wide-ranging social construction of ideal masculinity (Conway 2008:76).

The author puts the moral life of faith of the Jesus followers on display, in fact in the spotlight, for the Jesus followers to compete against themselves and one another for the masculine ideal of perfection (Conway 2008:76). They had to compete and prove that they will be able to endure in being steadfast (1:3-4), without doubt (1:6), not to be double-minded (1:7) or unstable (1:7). Brent Shaw in (Conway 2008) discusses endurance as an "explicit co-optation of passivity in resistance as a fully legitimised male quality - a choice that could be made by thinking, reasoning and logical men" (Conway 2008:76). Therefore, by comparing their life of faith to a trial or test where they needed to show endurance and compete with themselves and each other, the text is using a $1^{\text {st }}$ century ideal masculinity discourse. While Shaw points to a shift to passive endurance as a "moral revolution", in the light of the abundance of active and aggressive values associated with manliness, Conway stresses that under the influence of the Stoic philosophers "the virtue of endurance and self-control is used rather than of perseverance in action." Thus, when the text of James draws on the rhetoric of endurance and trials, it draws on an already deep-rooted masculine religious discourse that entered the culture through Stoic responses to tyrannical rule (Conway 2008:77). 


\section{Masculinity as moral quality}

In his book The Moral World of James Strange shows extensively how deeply intertwined the construction of morality in James was with moral codes of the ancient Greek and Roman world. In James there is another strong link between morality and religion. James' construction of morality is deeply connected to receiving life instead of death from God and therefore "values, modes of thought about the divine, and their implications for how people live are to be transformed within tightly defined groups" (Strange 2010:191) is James' main reason for his exhortation to a life of Godly-inspired perfection.

The notion of perfection points toward ideal notions of masculinity, which is also closely linked to divine status (Conway 2008:179). Although we would prefer not to speak about God in gendered terms in the modern world, the God of ancient times was undoubtedly be the "perfect" example of masculinity and would be associated with "perfection, unity, rationality, order and completeness and to lack in nothing" (Conway 2008:36).

But links between ancient conceptions of religion, morality and masculinity were not as clear-cut as they may have seemed. The way in which the Jesus followers served God maintained the social order of the day, and conducted or performed themselves in private and public spheres, were all interconnected to the way in which they identified themselves as gendered beings.

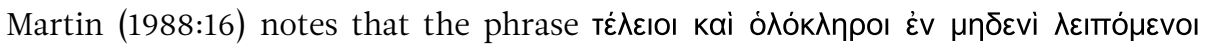
points to a life of "moral integrity", "full maturity" (cf. Eph. 4:13) and a life that is "morally blameless". This occurrence of what follows after the textual references in the same sentence, is also seen in 1 Thessalonians 5:23 (cf. Wis. 15:3;4 Macc. 15: 17; Philo, Abr., 34), where Noah is described in this instance as "perfect" in his pursuit of virtue. The action of acquiring perfect work is directly connected to having perfect moral character. The notion of perfect work is eschatological and will be achieved by God at the end of time when the world has reached its fullest maturity (Martin 1988:17).

The Jesus followers are urged to be nothing less than perfect believers in God and according to the moral ideals of the day; to be as perfect as the masculine God is perfect. The text makes clear that living a life of moral perfection implies that the Jesus followers ought to be steadfast (1:3-4), without doubt (1:6), and not double-minded (1:7) or unstable (1:7) since God is perfect and steadfast. The highest form of masculine authority, consistent with the gendered ideals of virtus, is the Jesus followers' notion of God, which is quoted numerous times in the letter of James. God personifies moral perfection for the Christ-believers (Kuefler 2001:139). 
The main image that is sketched in James is one that is the ideal masculine image of $1^{\text {st }}$ century Greek and Roman world. The text constructs God, as one would expect in the ancient world, as being perfect. This is nothing new for New Testament texts or their contemporaries to construct God as perfect. ${ }^{10}$ For example, in Matthew 5:48 Jesus urges the Jesus followers: "Be perfect, therefore, as your heavenly Father is perfect" (5:48). A direct exhortation is made for ideal masculinity in the New Testament by using God as the epitome of masculine perfection, an example to what the Jesus followers should strive for (Conway 2008:120).

If manliness is considered to be a moral quality in human behaviour, it is necessary to investigate the moral construction in James regarding the values and virtues that are advanced to see if the moral quality of James' exhortation are also those of the dominant masculine (Ivarsson 2007:166). Moral quality also defined masculinity. ${ }^{11}$

By referring to moral quality, Ivarsson points to the double meaning of masculinity in the Latin vir, which translates as both virtue and manliness. To become a vir in the Greek and Roman world, one was required to demonstrate manliness through the practice of particular virtues. Indeed, as Williams and others have pointed out, virtus, often translated as "virtue", is etymologically equivalent to vir or "manliness" in the Roman world (Conway 2008). McDonnell (2006:129) elaborates that in the process of the categorisation of virtues some authors claimed that virtus traditionally represented a single, wide-ranging ethical ideal that subsumed other cardinal Roman values, physical prowess and courage among them, and furthermore that this constituted a particular Roman ideal.

These linguistic claims confirm the apparent association between the so-called true man and virtue (Conway 2008:23). "Virtue was so intimately linked to maleness in the Roman universe that it is impossible to separate Roman definitions of masculinity from more general notions of ideal human behaviour” (Kuefler 2001:19).

The text of James can be regarded as a moral exhortation with regards to the way in which the Jesus followers identified themselves with God and with each other, exhorted themselves to maintain the social order and aspire to notions of moral perfection. The James text is an appropriate example of the way in which ideas of religion and morality are connected, with the important focus here on masculinity in conjunction with morality; the demonstration of self-discipline or self-control was a further fundamental key to ideal masculinity in the $1^{\text {st }}$ century.

10 The notion of perfection is not new to the idea of ideal masculine values. Ancient authors like Aristotle, Philo and Galen's writings corresponds with this fact. Aristotle wrote about the "superior perfection of the male embryos" (Gen. an. 775a), Philo indicates that "male is more perfect than female" (OE 1.7) and Galen assumes: "Now just as mankind is the most perfect of all animals, so within mankind the man is more perfect than the woman" (Usefulness of the Parts, 2.630) (Conway 2008:120).

11 Sexual penetration was not necessarily the primary way for members of the Greek and Roman elite to demonstrate manliness, nor was it in some instances the preferable way (Conway 2008). See also (Martin 2001:88-101). 
The Jesus followers are explicitly exhorted to practise masculine self-control, for example, by means of steadfastness (1:3-4), not doubting (1:6), not being double-minded (1:7), unstable and tempted by themselves or by anyone else, and not able to be lured and enticed by their desires.

\section{Conclusion}

To conclude, the modern-day Mighty Men movement in South Africa is keen to extol the virtues of manliness, relying on age-old notions of what constitutes not only manliness, but perfect manhood, men who have withstood adversity and stood the test of time - becoming typical, i.e. perfect, men and, in the religious context, perfect believers.

The Jesus followers in James 1 are urged to live up to recurrent $1^{\text {st }}$ century Greek and Roman ideal images of manliness: being perfect $(1: 4$,$) complete (1: 4)$, lacking in nothing (1:4), being able to endure trials (1:12) and ready to be tested (1:12). They are urged to master, compete for and live in a morally acceptable way to aspire to the perfect and complete masculine image modelled by their perfect God.

In the text of James the Jesus believers are encouraged to assume and model a life of flawless religious perfection and to strive towards a performance of hypermasculinity. Conway notes that such construction in the NT texts points to an alternative masculinity that is even more "perfect" than imperial masculinity performed by the Empire (Conway 2008:125).

Texts like James 1, which construct and advocate forms of hypermasculinity, run the risk of also promoting and affirming forms of oppressive and dangerous masculinity, modelled by the MMC movement, for our modern day. For this reason, there is a need for careful and contextual readings of texts such as James 1 also to let the constructive aspects that the text has to offer come to the fore. 


\section{Bibliography}

Aymer, M. 2017. James: An Introduction and Study Guide: Diaspora Rhetoric of a Friend of God, London: Bloomsbury.

Batten, A J. 2010. Friendship and Benefaction in James, Dorset: Deo.

Cheung, L L. 2003. The Genre, Composition and Hermeneutics of the Epistle of James, Carlisle: Paternoster.

Connell, R W. 2005. Masculinities, Cambridge: Polity.

Conway, C M. 2008. Behold the man: Jesus and Greco-Roman masculinity, Oxford: Oxford University Press. https: / / doi. org/10.1093/acprof:oso/ 9780195325324.001 .0001

Dube, S. 2015. Muscular Christianity in contemporary South Africa: The case of the Mighty Men Conference, HTS Teologiese Studies/Theological Studies, 71(3): 9 pages. Available: http:// hts.org.za/index.php/HTS/ article/view/2945 [Retreived 7 April 2017].

Elliott, J H. 1993. The Epistle of James in Rhetorical and Social Scientific Perspective Holiness-Wholeness and Patterns of Replication, Biblical Theology Bulletin: A Journal of Bible and Theology, 23:71-81.
Ivarsson, F. 2007. Vice Lists and Deviant Masculinity: The Rhetorical Function of 1 Corinthians 5:10-11 and 6:9-10, in T Penner \& C Vander Stichele (eds.), Mapping Gender in Ancient Religious Discourses, Leiden: Brill, 163-184.

Johnson, L T. 2004. Gender in the Letter of James: A Surprising Witness, in A-J Levine \& M M Robins (eds.), A Feminist Companion to the Catholic Epistles and Hebrews, London: T \& T Clark, 103-113.

Johnson, L T. 2008. Anchor Bible Dictionary: The Letter of James, New Haven: Yale University Press.

Kain, P. 1998. How to Do a Close Reading. Writing Centre at Harvard University [Online], available: http://writingcenter. fas.harvard.edu/pages/ how-do-close-reading [Retrieved 26 October 2015].

Kartzow, M B. 2014. Intersectional Studies, in J M O'Brien (ed.), The Oxford Encyclopedia of the Bible and Gender Studies, Oxford: Oxford University Press, 383-389.

Knust, J W. 2006. Abandoned to Lust: Sexual Slander and Ancient Christianity, New York: Columbia University Press. 
Kuefler, M. 2001. The Manly Eunuch: Masculinity, Gender Ambiguity and Christian Ideology in Late Antiquity, Chicago: University of Chicago Press.

Lockett, D R. 2008. Purity and Worldview in the Epistle of James, London: T \& T Clark.

Martin, R. 1988. Word Biblical Commentary: James, 48, Dallas: Word. https: / / doi. org/10.1215/9780822380276-004

Martin, D B. 2001. Contradictions of Masculinity: Ascetic Inseminators and Menstruating Men in Greco-Roman Culture, in V Finucci \& K Brownlee (eds.), Generation and Degeneration: Tropes of Reproduction in Literature and History from Antiquity through Early Modern Europe, Durham: Duke University Press, 81-108.

Mayordomo, M M. 2006. Construction of Masculinity in Antiquity and Early Christianity, Lectio Dificilior, 2: 1-33.

McDonnell, M. 2006. Roman Manliness: Virtus and the Roman Republic, Cambridge: Cambridge University Press.

Moore, S D. 2014. Masculinity Studies, in J M O'Brien (ed.), The Oxford Encyclopedia of the Bible and Gender Studies, Oxford: Oxford University Press, 540-547.
Mighty Men Conference Central South Africa [Online]. 2017. Mighty Men Conference Central South Africa, available: http:// www.mightymen.co.za/ [Retrieved 16 April 2017].

Nadar, S. 2009. Palatable Patriarchy and Violence against Wo/men in South Africa: Angus Buchan's Mighty Men's Conference as a Case Study of Masculinism, Scriptura, 102: 551-561. https:// doi.org/10.7833/102-0-614

Nortjé-Meyer, L. 2011. A critical analysis of Gretha Wiid's sex ideology and her biblical hermeneutics, Verbum et Ecclesia, 32(1): 7 pages, available: http://www.ve.org.za/index. $\mathrm{php} / \mathrm{VE} /$ article/view/472 [Retreived 7 April 2017].

Roisman, J. 2005. The Rhetoric of Manhood: Masculinity in the Attic Orators, Berkeley: University of California Press.

Strange, J R. 2010. The Moral World of James: Setting the Epistle in its Greco-Roman and Judaic Environments, New York: Peter Lang.

Tamez, E. 1994. James, in E Schüssler Fiorenza (ed.), Searching the Scriptures: A Feminist Commentary, 2, New York: SCM Press, 381-391.

Wilson, B E. 2015. Unmanly Men: Refigurations of Masculinity in Luke-Acts, Oxford: Oxford University Press. https: / / doi.org/10.1093/acprof:oso/ 9780199325009.001.0001 


\title{
Chapter 12
}

\section{Where Heaven and Earth Meet}

\author{
On reading the 'book of nature' right
}

Angelique Havenga

\begin{abstract}
We know God by two means:
First, by the creation, preservation, and government of the universe, since that universe is before our eyes like a beautiful book in which all creatures, great and small, are as letters to make us ponder|the invisible things of God ... (Belgic Confession, Article 2: The Means by Which We Know God)
\end{abstract}

Elna Mouton is well known as New Testament scholar and professor at the Faculty of Theology of the Stellenbosch University. Throughout the years she has done research, taught and published numerous articles on how to read (biblical) texts rightly by consistently emphasising that the way in which Scripture is read and understood deeply influences - and is meaningful for - the way in which the reader thinks and ultimately acts. Time and again Elna's research has urged readers of Scripture to engage with biblical passages responsibly with a sensitivity to the context in which these texts originated. Her work is a constant reminder that that way that texts are read matters, that reading is not an inconsequential act.

When Elna Mouton's name is mentioned - especially in an academic context - most people will probably immediately think of her above-mentioned research in New Testament and the many New Testament modules she has taught during her time at the Faculty of Theology at Stellenbosch. I, myself, attended Elna's classes throughout my undergraduate studies, and continue to consult her writings when dealing with scripture passages from the New Testament (whether I am preparing a sermon for a church service or working on my doctoral research in Practical Theology). What few people outside the Faculty of Theology are aware of - and students and colleagues inside the Faculty quite often forget - is the fact that, as professor at Stellenbosch, Elna was not only responsible for doing research in and lecturing on the books of the New Testament, but that once a year, as part of the 
Faculty's Master of Divinity programme (which is aimed at training students who will soon be entering full-time ministry), she also had the responsibility of leading a week-long module on spirituality (that has become known, among students, as the 'spirituality week'). Interestingly, this module, although very much part of the academic programme of the Master of Divinity course, does not take place in a formal classroom setting, but is presented as a retreat at the Volmoed Christian Conference and Retreat Centre situated near Hermanus in the Western Cape.

Now, 'spirituality', as most theologians and ministers in the church are fully aware of, is a rather contentious word, ${ }^{1}$ which could signify many different things, and it can easily be assumed that a course on this topic - especially at a retreat centre away from the Faculty of Theology and the hustle and bustle of everyday life - would focus purely on (what could be called) the 'life of the soul', on the world beyond this one, on the reality of the wholly transcendent God; and would thus, momentarily, ask of students to turn their attention away from material existence. For Elna Mouton, however, as students would quickly realise during this week, 'spirituality' is not something that can (or should) be detached from this world; it is not something that asks of one to leave this world behind, to turn one's eyes away from corporeal reality. For her, our spirituality is very much tied up with our embodied lives on earth; and, in fact, has to do with how we see, interpret and understand the world around us.

During this week Elna would thus repeatedly emphasise that it is not only important to read texts rightly (as her classes and research in New Testament teaches us), but also to read what has often been called 'the book of nature' 2 in a right manner. The focus of her spirituality course would indeed be to guide students to not only think about God, but to see God in the world around them; to develop what could be called a 'sacramental vision': a vision where all things are seen as gifts from God, speaking of his goodness and grace; a vision whereby this world, in its creatureliness, express something of God's beauty and glory. And therefore, for Elna, in order to develop a healthy spirituality, we need - and I quote Josef Pieper - to "learn how to see again" (Pieper 1990:29).

This essay will begin with a short description of the setting where this spirituality module is taught on a yearly basis, as it is no coincidence that this retreat takes place

Robert MacAfee Brown writes that it is a difficult task to pin down one definition for "spirituality", as it may vary in meaning depending on the individual defining it (MacAfee Brown 1988:112).

2 The reference to the 'book of nature' as seen in the epigraph, is found in the Belgic confession - the $16^{\text {th }}$ century confession written by Giudo de Brès in defence of the Reformed faith in the region known today as Belgium and the Netherlands. This phrase, however, has a rich history within the church and Christian Theology, and the first mention of it is already found with the Early Church Father, Tertullian in the $2^{\text {nd }}$ century - see Van Berkel and Vanderjagt (2006). Vanderjagt $2^{\text {nd }}$ century conclusion ... ways occupied by an ensemble of fellow actors; he is inserted into the ensemble. 
at Volmoed. Place is, after all, very important to Elna. ${ }^{3}$ Next, the question will be asked if the focus on the reading of the 'book of nature' (that forms an integral part of this 'spirituality week') can be justified in the Reformed tradition to which both Elna Mouton and I myself belong to - a tradition which is often characterised as being hostile towards the physical body and creaturely existence. Here the thinking of John Calvin - the 'father of the Reformed tradition' - will play an important role in my enquiry. This will then be followed by a reflection on the Lord's Supper, as the spirituality week - with its focus on 'reading' creation rightly - culminates in the celebration of this sacrament (in the Volmoed chapel). Calvin's thinking will again be consulted in this regard. This essay will then conclude with a short reflection on the way in which Elna, herself, embodies this understanding of spirituality (that is taught during the 'spirituality week').

\section{Volmoed}

When driving in the direction of the town Hermanus from Cape Town, one's first inclination is normally to turn to your right and look towards the beautiful Walker Bay - especially during the annual whale season (from June to October), as Hermanus has been recognised by the World Wildlife Fund as one of the twelve best whale-watching destinations in the world. But if you don't look only at the ocean and rather, just before entering Hermanus, turn onto the R320 towards the mountain range on your left, you drive into another majestic area which has been named the Hemel and Aarde Valley (in English, the 'Heaven and Earth Valley') - a name, one quickly realises, that perfectly describes this region, as the valley's hills stretch high into the sky, creating the impression that here heaven and earth meet. ${ }^{4}$

It is within the folds of the Hemel en Aarde Valley that Volmoed is situated, and from the moment one sets foot on the centre's grounds, one is struck by the beauty of the lush, fynbos-filled landscape. It is a scene of tranquillity and natural splendour - not in a romantic Alpine manner (as one finds, for example, in the Swiss countryside) - but in a truly African sense. Volmoed's beauty lies in its earthiness; in the rocky contours of the mountain peaks. The valley in which Volmoed is situated is of this land; it is of this country; its beauty is African. And like most places on this continent and in this country, it also has a complex history.

3 Throughout Elna's life place has always played a significant role. When she talks about her life and the places that influenced her, it is usually done in beautiful and expressive language such as her description of Ceres, her hometown, in a recent interview with Frits Gaum for the Kerkbode: "In my diepste wese is ek 'n aardse mens, lief vir eenvoud en stilte. Ek het op Ceres grootgeword met magtige bergspitse, vars vrugte en helder water ... " (e-Kerkbode, 26 May 2016).

4 Brother R. Schmidt of the Moravian Mission in Genadendal described the surroundings in an account written in 1889: "Rightly has it got its name because so high are the hills, which closely embraces the valley all round, that they seem to touch the sky and you cannot see anything but Heaven and Earth" (De Gruchy \& De Gruchy 2006:2). 
The first recorded description of this valley dates back to the year 1817 when the land was bought by the Cape government to establish a leper colony - a quarantine community of the physically sick who were forced to be there because of their illness. A Moravian missionary from the nearby Genadendal (in English, 'Grace Valley') became steward of and - with the help of fellow Genadendal missionaries - ministered to the lepers. Dr James Barry, ${ }^{5}$ army surgeon from the Cape, also played an important role in improving care for these patients and reforming the settlement to include a place of worship where Bishop Hallbeck, also from Genadendal, conducted services. In 1846 this leper community was moved to Robben Island - the place where Nelson Mandela and many other struggle leaders would later be imprisoned by the apartheid government - and the grounds were divided into two farms (Burman 1989:41). One of these farms would come to be known as Volmoed, meaning "full of courage", in recognition of those who ministered to the lepers (De Gruchy \& De Gruchy 2006:12).

During the next (politically tragic and tumultuous) century, Volmoed remained farming ground until 1983, when Bernard Turkstra and Harry Wood had a vision that South Africa, as a country caught in the grip of apartheid, was in dire need of a place for healing and wholeness. In what they describe as a miracle from the hand of God, it was possible for them to procure this farm, and they accordingly established what would become known as the 'Volmoed Community' - a place that would be "open to all" to "pursue reconciliation amongst people divided by race and class" (De Gruchy \& De Gruchy 2006:v). Over the next twenty years the grounds were developed into the retreat centre it is today, becoming a place where people from all walks of life could meet with God and with one another; where all people, regardless of who they are, or where they come from, could spend time in prayer and in fellowship with fellow brothers and sisters in Christ (De Gruchy \& De Gruchy 2006:4).

Besides the charmingly decorated living quarters (which have been named after the valley's fauna and flora), Volmoed has a number of purpose-built buildings, including a beautiful chapel (which is known as the Thanksgiving Chapel), where Sunday services, daily prayer meetings and, importantly, the weekly celebration of the Lord's Supper (of which more will be said in what follows) take place. Volmoed's main asset, however, remains its natural surroundings, and each of these buildings - the chapel in particular - has been designed so as to focus one's attention on what lies beyond their four walls; to draw one's gaze towards the mountains, trees, rolling grass fields, rivers, dams and starry skies that are to be found on the outside. When visiting Volmoed one is continually exposed to God's creation in all its splendour, and it is within this setting that people are encouraged to meet and spend time with God and one another (De Gruchy \& De Gruchy 2006:57-60).

5 Dr James Barry was an army surgeon employed by Lord Charles Somerset. He was passionate about caring for the lepers in the Hemel and Aarde Valley and applied principles of hygiene, nutrition and improved accommodation. When Dr Barry died in England, it was discovered that she was really a woman who kept this secret throughout her life. Women were still barred from studying medicine or entering the military in the Victorian era in Britain (Krüger 1966:283). 
Given its rich history, its vision to be a place of communion between fellow Christians and God, and also - as emphasised above - its awe-inspiring natural beauty, Volmoed would prove to be the perfect place to host the Master of Divinity 'spirituality week', and for many years Elna would indeed bring her students here.

\section{Spirituality, creation and (Reformed) theology?}

The way in which Elna would present the spirituality week on a yearly basis at Volmoed was to start off each day with morning prayers, followed by (somewhat formal) lectures on spirituality (it is after all an academic module!). Once this was done - usually by the end of the morning - Elna would give students the rest of the day off, encouraging them to spend time in the Volmoed surroundings in meditation and prayer - not primarily with their eyes closed (as is often assumed should be the case when conversing with God), but with their eyes open, so as to become aware of the way in which nature itself - as a gift from God's hands - speaks of His infinite beauty and glory. For Elna, as already said above, part of one's spiritual formation involves learning to recognise God's goodness and providential care in the physical world around one; learning to see how the created world, in its material existence, points to, and proclaims the majesty of the One who lovingly and joyously made (and sustains) heaven and earth.

A concern that could be raised, as alluded to in the introduction of this essay, is whether this approach to spirituality, wherein the material world around one is very much part of one's reflection on and encounter with the reality of the wholly other God, is ultimately justifiable within the broader parameters of Christian and particularly, Reformed thought. At first glance Elna's emphasis on the right reading of the 'book of nature' in this spirituality course seems completely appropriate (and even commendable), especially in the beautiful setting of Volmoed, but is this necessarily so? Christianity in general and specifically the Reformed tradition have, after all, often been held to be opponents of the physical world, which asks of its adherents to denounce their bodies and material existence, and focus their undivided attention solely on the God who is to be found beyond the realities of this life.

One of Christianity's most fervent critics in the last few centuries, Friedrich Nietzsche (who, himself, was initially enrolled as a theology student with the hope of becoming a minister in the Lutheran Church), for example, famously wrote that Christianity in most forms should be regarded as "Platonism for the masses" - as a belief system inherently built on, and promoting a dualistic understanding of reality, wherein the (good) realm of God is set against the (evil) realm of creaturely existence. In Nietzsche's estimation, Christianity was indeed, from the very beginning, marked by "nausea and disgust with life [itself] ... [a nausea and disgust] concealed behind, masked by, dressed up as, faith in 'another' or 'better' life”. For him, the Christian worldview constituted nothing other than a "hatred of "the world", a "fear of beauty 
and sensuality", "a beyond invented ... to slander this life" - essentially "a craving for the nothing" (Nietzsche 1967:22-24). The gist of this critique by Nietzsche (which sees Christianity as some sort of 'fable of the soul', which despises material reality) is, as most of us know all too well, regularly repeated in conversations on Christianit - also when people are discussing the Reformed tradition and the legacy of one of its founding figures, John Calvin. In a recent publication David Taylor, professor of Theology and Culture at Fuller Theological Seminary, writes that "both detractors and supporters of John Calvin have deemed him an enemy of the physical body (and) a pessimist towards creation" (Taylor 2017: 5) - a view of Calvin's thought that has in many ways come to define the Reformed tradition (where the primary focus is on the Word that is heard) over the centuries.

This perception of Christianity (and also of the Reformed tradition) - so strongly articulated by Nietzsche - is obviously not groundless. David Bentley Hart writes that, when looking back throughout history, it is clear that (what he calls) the Gnostic impulse (to see reality in a dualistic sense) has, to varying degrees, surfaced in Christian theology in almost every age (Hart 2003:22). Reformed theologian Edward Farley also contends that the Judeo-Christian tradition has regularly propagated that it is best to turn one's eyes away from the beauty and splendour of the material world, and rather focus on the immaterial - and invisible - reality of God (Farley 2001:9). According to him, there have essentially been three reasons behind this rejection of the physical realm (and its beauty) within Christianity. The first, he holds, has to do with Christianity's fear of idolatry (which is grounded in the warning in the Decalogue, not to equate the things of this world with the One True God; see Ex. 20:4-5a) (Farley 2009:10); the second, with Christianity's strong emphasis on asceticism, on the self-denial of earthly pleasure (which, he argues, has been the result of a deeply ingrained suspicion of humanity's bodily experiences and their connection to 'sin'); and the third with, what he calls, the futurism found in Christianity (where this world is seen as something that is passing away, as something that will be abolished at the end of time, and does not form part of the impending reality of God's reign) (Farley 2009:11). For Farley it is for these reasons, among others, that Christianity - including, importantly, the Reformed tradition to which he himself belongs - has upheld a dualistic worldview, where God and the world, the supernatural and the natural, grace and nature, are in stark contrast to one another.

Both Hart and Farley, while stressing the pervasiveness of this dualistic worldview within different Christian theological traditions, note that there is also another side to the story; that this is not all that one can say about the Christian faith (as Nietzsche and many others believed to be the case). For them - despite the many examples in history to the contrary - Christianity at its very heart could also be seen to be a faith system that affirms, and even celebrates, the reality of the physical world; a faith system which, in principle, does not ask of its adherents to turn away from their material existence, but to see and experience the goodness of the One True God in and through it. Christianity, they emphasise, is after all a religion of 
creation and incarnation; a religion which says that is was God who created this world ex nihilo, called it 'good', and sent his Son to become flesh, so as to redeem and renew creaturely reality (in all its components). And, fortunately, amidst the many voices who have propagated a staunch dualistic understanding of the world, there has also - they hold - been a host of voices, drawing on the biblical witness and the orthodox theological tradition who have advocated exactly the opposite.

When looking back in the history of Christian theological thought, one indeed comes across many Christian voices who have done exactly this: voices who have affirmed creation and our bodily existence. Important names in this regard include Early Church Fathers such as Irenaeus, Augustine and the Cappadocian Fathers; scholastic thinkers such as Bonaventure and Aquinas; and later also Protestant theologians such as the "father of the Reformed Tradition", John Calvin. Notwithstanding the many caricatures of this $16^{\text {th }}$ century Christian thinker, one surprisingly finds in Calvin a theologian with an immense appreciation of the beauty of the physical world. And given the fact that both Elna and myself (as well as most of the students who attend the spirituality week) belong to the Reformed tradition, it is quite interesting to see what he has to say in this regard.

\section{John Calvin and the Reformed tradition}

When examining the thinking of John Calvin - the $16^{\text {th }}$ century Reformer who spent most of his life working in a refugee community in Genève, Switzerland - the best place to start is undoubtedly his magnum opus, the Institutes of the Christian Religion, which is recognised to this day as one of the definitive works of Protestant (and indeed then Reformed) theology. Even though there is more to Calvin than his Institutes (and it is an absolute joy, for example, to read through his sermons or his commentaries on the books of the Bible), it is in this work that we find his theological ideas expressed in the most comprehensive and systematic way (Hesselink 2004:74).

Reading through the Institutes, it is very interesting to discover that, already in the very opening sections - dealing with the knowledge of God the Creator - Calvin has a lot to say about the way in which the physical world should be seen and understood, and that his views on this matter are indeed quite different from what most people would expect - given his reputation alluded to above. Calvin, writing in a beautiful poetic style filled with emotive language and imagery, declares, for example, that he is "completely overwhelmed by the boundless force of [creation's] brightness" (Inst. I.5.1); that the universe that God has made is nothing less than a "dazzling theatre" of His glory (Inst. I.5.8; I.6.2). According to him, "God has revealed himself in such beautiful and elegant construction of heaven and earth, showing and presenting himself there every day, that human beings cannot open their eyes without having to notice him" (I.5.1). Calvin acknowledges that creation bears witness to God's providential care and involvement in this world, and that by beholding the realm of nature, we can sense the way in which God "sustains the 
universe by his boundless might, regulates it by his wisdom (and) preserves it by his goodness" (Inst. I.2.1). For him, it is therefore not only permissible, but in fact desirable for the Christian to constantly look to creation, and to "find delight and enjoyment, in the grasses, trees and fruit, and the beauty and pleasant odors of the flowers, quite apart from their usefulness"; for it is in and through the splendours of the created world - splendours that fills us with awe and delight - that we encounter the good Creator God (Hesselink 2004:78).

In passages such as these it is clear how important the realm of creation is in Calvin's thinking. John Hesselink (2004:84) writes that Calvin evidently does not want his readers to ignore or denounce creaturely reality, but actively encourages them to see the world around them as a "mirror" showing us the face of God; as a "garment in which God makes himself known to us". Guenther Haas agrees that these words by Calvin - uttered in the opening pages of his Institutes -shows that for Calvin, the "Christian life of self-denial, bearing the cross, and hope, does not entail a withdrawal from earthly things" but asks for a "participation in the good gifts in (and of) creation" - gifts that God has given humanity not only "for their good", but also for "their delight, enjoyment, and comfort" (Haas 2004:96). Alister McGrath also writes about how important creation - including the enjoyment of nature - is for Calvin in this section (on the Knowledge of God the Creator). Although Calvin affirms, McGrath writes, that "God is invisible and incompressible (and that we should be wary of naively equating the things of the world with Him)", he is still adamant about the fact that God "makes himself known (for all to see) ${ }^{6}$ under the form of created and visible things", and that we, as human beings, should thus constantly turn our eyes to God's handiwork around us (McGrath 2007:153).

Given Calvin's strong affirmation of material reality, and the way in which he explicitly encourages his readers to look to, and revel in, the beautifully wrought world around them - a world that was created by, and thus points to and express something of the goodness of the One True God - it can indeed be said that Elna's focus on the reading of the 'book of nature' during the spirituality week, is very much in line with this Reformer's thought. What Elna asks of her students is indeed what Calvin asked of his readers: to learn to see how God reveals himself through creation.

Calvin's concern with - and affirmation of - the creaturely realm does not end with these opening remarks in (the first book of) his Institutes (focused on the knowledge of God the Creator), but runs like a golden thread throughout the rest of his work and can in many ways be said to culminate in his Christology - discussed in his section

6 McGrath (2007:153) writes that it is quite interesting to note that Calvin "makes no suggestion whatsoever that this knowledge of God from the created order is peculiar to, or restricted to, Christian believers". According to him, "Calvin is arguing that anyone, by intelligent and rational reflection upon the created order, should be able to arrive at the idea of God". 
on the knowledge of God the Redeemer (found in Books II and III of the Institutes). One of the central emphases of Calvin's Christology is the fact that Jesus - God's Word - truly becomes flesh; that in the incarnation God truly becomes one with creation (without ceasing to be God), so as to save and renew humanity and the world (see Hesselink 2004:81). Hesselink writes that while Calvin affirms the deity of Christ unequivocally (and adheres to Chalcedonian Orthodoxy), he nonetheless gives "a special place to the humanity of Christ in effecting our salvation" (2004:81). For Calvin, Christ is not some or other gnostic or docetist saviour who comes to 'spirit' us away from this world, but the One who really enters our earthly reality and brings about redemption as a result of his solidarity with this very creation that Calvin describes in the opening sections of his Institutes (2004:81).

This emphasis on the fact that Christ truly becomes flesh - "that God not only reveals Himself through creation, but in creation itself (in the incarnation)", to quote Helsinki (2004:79) - also then has a major influence on Calvin's understanding of, for example, the sacrament of the Lord's Supper (which he develops in Book IV of his Institutes) - a part of his theology which is of specific importance for my own doctoral research. ${ }^{7}$ And given the fact that the spirituality week culminates in the celebration of the Lord's Supper (in the Thanksgiving Chapel), it is perhaps also interesting - given all that has been said above - to briefly look at Calvin's understanding of this sacrament.

\section{The Lord's Supper}

When reading Calvin's section on the Lord Supper in his Institutes, it becomes clear that for him one of the most important aspects of this sacrament is that Christ (through the work of the Holy Spirit) is really present at the "holy banquet" (as he calls it); and that it is in and through the (physical) elements that we encounter the risen Christ. What is significant here is that this encounter with Christ does not involve turning away from this world - does not require of us to denounce creaturely existence or ignore the material reality around us - but asks of us to turn to some of the most everyday of items, bread and wine. In Calvin's theology of the Lord's Supper these tangible symbols, in their time- and space-bound state, should be understood as communicating the reality to which they refer, namely that of the risen Christ who redeems and transforms humanity and the world (De Gruchy 2013:121). "In this sacrament", he writes, "we have such a full witness of all these things, that we must certainly consider them as if Christ, here present, were himself set before our eyes and touched by our hands" (Inst. IV.7.3).

I am currently working on my PhD dissertation on the Lord's Supper and Human Dignity, focusing specifically on Calvin's writings about the Lord's Supper. 
In a telling passage Calvin continues to write the following about the way in which the bread and the wine at the Lord's Table, in their physical state, convey the real (spiritual) presence of Christ (through the work of the Holy Spirit), and draw us into the mystery of the Triune God:

And so as we previously stated, from the physical things set forth in the Sacrament we are led by a sort of analogy to spiritual things. Thus, when bread is given as a symbol of Christ's body, we must at once grasp this comparison: as bread nourishes, sustains, and keeps the life of our body, so Christ's body is the only food to invigorate and enliven our soul. When we see wine set forth as a symbol of blood, we must reflect on the benefits which wine imparts to the body, and so realise that the same are spiritually imparted to us by Christ's blood. These benefits are to nourish, refresh, strengthen, and gladden. For if we sufficiently consider what value we have received from the giving of that most holy body and the shedding of that blood, we shall clearly perceive that those qualities of bread and wine are, according to such an analogy, excellently adapted to express those things when they are communicated to us (Inst. IV.7.3).

Calvin's understanding of the Lord's Supper thus affirms, in a very definite manner, his view that God uses the things of the earth, uses his creation, to make himself present to us and to reveal his goodness, grace and love in the world. Just as the beauty of nature declares God's glory as Creator, in a general sense, the ordinary material elements of bread and wine unite us with Christ - the Word who became flesh - in a special manner. It can be said that all of our encounters with God through the beauty of creation culminate in this encounter with Christ in the celebration of the Lord's Supper, and that the encounter with Christ in the celebration of the Lord's Supper, in turn, imbues us with a new vision and encourages us to look differently at the world around us. ${ }^{8}$ And this is indeed what happens during the the spirituality module at Volmoed.

When I think back on my own attendance of the 'spirituality week' - a mere four years ago - I remember how everything Elna taught us during this week (about reading the 'book of creation' rightly), and, importantly, everything I experienced of God during my daily walks in the hiking trails in and around Volmoed, reached a climax in the moment that we, as a class, gathered around the Lord's Table (in the Thanksgiving Chapel's sanctuary). While looking out of the windows upon the beautiful mountains and fynbos outside, and receiving the bread and wine in my outstretched hands, I realised anew that this world, in its materiality, matters to

8 In this regard one can also expand this argument to include the ethical implications of this new vision that not only changes the way in which one views the created world and one another, but also inherently changes the way in which one acts; to see sacramentally has a significant influence on one's ethical life - optics is linked to ethics; how we see the world influences the way we act in the world. Brian Gerrish writes in his seminal work, Grace and Gratitude, The Eucharistic Theology of John Calvin, that the Lord's Supper was for Calvin a dramatic presentation of all the Gospel proclaims; that in the Sacrament God does still more clearly what he always does, providing his children with the bread of life; and they in turn enact the meaning of authentic human existence as continuous sacrifice of praise (Gerrish 1993:158). 
God; that this world is his good creation; that God sent his Son, in the incarnation, to become one with this world, so as to redeem and renew creaturely reality; that it is here, in this world, that heaven and earth meet. Our spiritual lives could thus not, as Elna continually emphasised, be about leaving this world behind, but had to be focused on learning to see the world around us - including ordinary items such as bread and wine - differently; about looking at the world in a sacramental manner. And what is important to note is that these ideas are not foreign to the theology of someone like John Calvin (the "father of the Reformed tradition") but in fact lie at the very heart of it.

\section{Conclusion}

For me, the spirituality week, hosted at Volmoed in the Hemel and Aarde Valley, was one of the defining moments of my theological training. Here, I realised - under Elna's guidance - that if Christianity is about creation and incarnation, our spiritual lives cannot be detached from our corporeal existence; that how we see and interact with the world around us forms an integral part of our spirituality. One of the reasons, I think, why these ideas as expressed by Elna (which, as I have hopefully shown convincingly above, stand in continuity with the thinking of someone like Calvin) made such a big impression on me has to do with the fact that Elna not only communicated them through her words, but also through the way she herself lives. Theology - one could argue - is not something that only needs to be taught, discussed and written down, but also to be lived, to be embodied, to be enacted (see Ward 2016:119,137). And this is what makes Elna Mouton such a wonderful theologian (and mentor for many individuals): her theology is not only something that finds expression in what she says and what she writes, but also in and through who she is, and through what she does, on a daily basis.

While spending time with Elna at a place such as Volmoed (as we did during the spirituality week), or anywhere else for that matter, one becomes deeply aware of the fact that for her (as for Calvin - as emphasised above), creation is indeed a wondrous gift out of God's hands; a place where we, together with others, encounter the living God. Yes, many Christian thinkers throughout the ages have propagated that the reality of God stands over against the reality of creaturely existence, but from the way Elna lives and looks at the world around her - it is clear that she thinks differently about creation; that she, and I think Calvin would concur, reads creation rightly - that is, as a beautifully written book, authored by God himself. 


\section{Bibliography}

Brown, M R. 1988. Spirituality and Liberation: Overcoming the Great Fallacy, Louisville: Westminster Press.

Burman, J. 1989. Hermanus, A Guide to the Riviera of the South, Cape Town: Human \& Rousseau.

Calvin, J. 1975. The Institutes of the Christian Religion, 1536 Edition, Trans. F L Battles, Grand Rapids: William B. Eerdmans.

De Gruchy, J. 2013. 'Real Presence' and Sacramental Praxis - Reformed Reflections on the Eucharist, NGTT, 54:5: 177-125.

De Gruchy, J \& De Gruchy, I. 2006. The Volmoed Journey, Hermanus: Self-Published.

e-Kerkbode, 2017. 10 Vrae aan Elna Mouton, Viewed 18 September 2017, http:// kerkbode.christians. co.za/2016/05/26/10-vrae-aanelna-mouton/

Farley, E. 2001. Faith and Beauty:

A Theological Aesthetic, Aldershot: Ashgate.

Gerrish, B A. 1993. Grace and Gratitude: The Eucharistic Theology of John Calvin, Minneapolis: Fortress Press.
Haas, G H. 2004. Calvin's Ethics, in D K McKim (ed.), The Cambridge Companion to John Calvin, Cambridge: Cambridge University Press. https://doi.org/10.1017/ CCOL0521816475.006

Hart, D B. 2003. The Beauty of the Infinite: The Aesthetics of Christian Truth, Grand Rapids: William B. Eerdmans.

Hesselink, J. 2004. Calvin's Theology, in D K McKim (ed.), The Cambridge Companion to John Calvin, Cambridge: Cambridge University Press. https://doi.org/10.1017/ CCOL0521816475.005

Krüger, B. 1966. The Pear Tree Blossoms. The History of the Moravian Church in South Africa 1737-1869, PhD dissertation, Grahamstown: Rhodes University.

McGrath, A E. 2007. A Life of John Calvin: A Study of the Shaping of Western Culture, Oxford: Blackwell Publishing.

McKim, D K. (ed.). 2004. The Cambridge Companion to John Calvin, Cambridge: Cambridge University Press. https://doi. org/10.1017/CCOL0521816475 
Nietzsche, F W. 1967. The Birth of Tragedy, Trans. W Kaufmann, New York: Vintage.

Pieper, J. 1990. Only the Lover Sings: Art and Contemplation, Trans. L Krauth, San Francisco: Ignatius Press.

Taylor, W D O. 2017. The Theatre of God's Glory: Calvin, Creation and Liturgical Arts, Grand Rapids: William B. Eerdmans.
Van Berkel, K \& Vanderjagt, A (eds.). 2006. The Book of Nature in Early Modern and Modern History, Leuven: Peeters.

Ward, G G. 2016. How the Light Gets in: Ethical Life I, Oxford: Oxford University Press. https:// doi.org/10.1093/acprof:oso/ 9780199297658.001.0001 


\title{
Chapter 13
}

\section{The Pathos of}

\section{New Testament Interpretation}

\author{
Reproof and reconciliation in \\ Matthew 18:15-20
}

Marius J Nel

\section{Introduction}

The topic of Elna Mouton's inaugural lecture as the first female professor in New Testament Studies at Stellenbosch University in 2005 was the pathos of New Testament Studies, pathos being the "persuasive power, reception and lasting effects in people's lives" of theinterpretation of New Testament texts (Mouton 2005:4). Acknowledging the pathos of New Testament Studies is important, according to Mouton, since it directly influences people's understanding of God and their own identities (Mouton 2005:5). In agreement with Mouton's important emphasis on the pathos of New Testament interpretation, ${ }^{1}$ this chapter will specifically focus on the possible life-affirming or life-threatening pathos of interpreting Matthew 18:15-20. ${ }^{2}$

Mouton's contributions to the feminist interpretation of the New Testament (Fiedler, Hofmeyr \& Fiedler 2016:17, 42, 57), hermeneutics (Runesson 2016:xxiv-xxv), the ethics of interpretation (Bockmuehl 2006:55; Hunsberger 2016:66), the study of Ephesians (Heil 2007:1; Hogan 2014:264; Tolmie 2016:113) and 1 Timothy (Theron 2015:70) have already been reflected on by other scholars. This chapter will therefore engage with Mouton's reflection on the pathos of New Testament Studies as a tribute to the life-affirming pathos of her career as New Testament scholar.

2 See the studies by Forster (2017a) for the pathos of Matthew 18:15-35 within an intercultural context in South Africa, and $\mathrm{Nel}$ (2015) for the understanding of interpersonal forgiveness in Matthew 18. 


\section{Matthew 18:15-20}

Matthew 18:15-17 is a community rule (Bornkamm 1970:94) ${ }^{3}$ comprised of five similarly constructed conditional sentences ${ }^{4}$ formulated as a casuistic law (Forkman 1972:124; Luz 2001:448). Its authority is based on the promise of Jesus in 18:18 that God, who is in heaven, will uphold the decisions taken by the earthly community gathered in his name. The nature of the decisions to be taken are disputed, since it is unclear if Matthew in 18:18, as in 16:19, uses the verbs "to bind" (סn்nऽ)

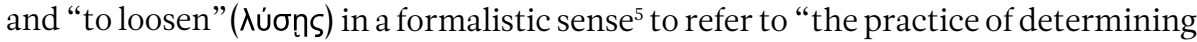
the application of scriptural commands to contemporary circumstances" (Powell 2003:439) or to the procedure for determining if a member should be forgiven their sins against a fellow community member (Luomanen 1998:244).

It can be argued that the binding and loosening formula does not refer to a decision to forgive a fellow disciple or not, since the Matthean Jesus is depicted as being against withholding forgiveness (the implication of the binding formula) in the following parable of the Unforgiving Servant (18:23-35). It is instead the Jewish practice of determining the correct interpretation of the law, and its applicability in a specific instance (i.e. was a sin committed for which forgiveness was needed?) at hand (Powell 2003:439). This interpretation of 18:18 is in line with the Matthean Jesus' stated aim of not abolishing the commandments of the law, but instead of determining their true intent by using life-affirming love as hermeneutical key (cf. 22:34-40). ${ }^{6}$ The brother in 18:15-20 is, according to this line of interpretation, not persisting in a mutually acknowledged sin. There is instead a disagreement over whether the law applies in his specific case and in order to decide if it does the

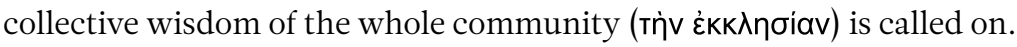

3 While 18:15-20 can be described as a community rule, the whole of chapter 18 is not formulated as such (France 2007:673; Hagner 1995:514).

4 The subjunctive ákoúon in the second and third sentences correspond to mapakoúøn in sentences four and five (Forkman 1972:124). The third sentence contains a quotation from Deuteronomy 19:15 which is applied in a novel way by Matthew. While Deuteronomy 19:15 refers to those who had witnessed a transgression in 18:16, they instead witness the reproof of the transgressor (Hagner 1995:532).

5 Other possible translations are "declare as forbidden," "declare as permitted," "burden with an obligation" and "lift an obligation" but not "lay a ban" or "raise a ban", which is found only once in rabbinic literature (Forkman 1972:130). The terms can also refer to the capturing and freeing of prisoners or of the binding and loosening of satanic forces and therefore a legal context cannot just be assumed (Luomanen 1998:249).

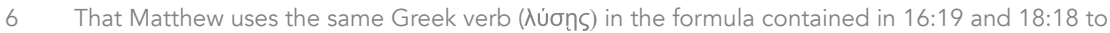
indicate that he had not come "to break" or "loosen" any of the commandments in 5:17-19 supports this interpretation. Jesus' repeated statement that "you have it heard said, but I say to you" is not meant to negate the authority of the law. It instead intends to bring out its true intent and to define its sphere of applicability. In this regard the Matthean Jesus criticises, through the use of cognates of $\delta \dot{\varepsilon} \omega$ to describe a legal judgment, the scribes and Pharisees who do not loosen the law where necessary,

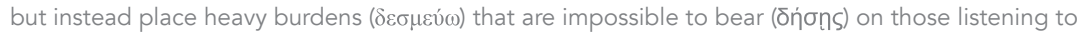
their teaching (23:4) (Powell 2003:440-441). While the Matthean Jesus claims to offer an "easy yoke" and a "light burden" (11:30; cf. 23:4), in practice, however, he more frequently binds laws than loosens them. 
Some scholars such as Forkman (1972:124, 130), however, see a difference between how the formula is used by Matthew in chapters 16 and 18 in that 16:19 focuses on the authority to make a decision on doctrine, while 18:18 refers to the endorsement of the expulsion of a member from the community. According to this view, references

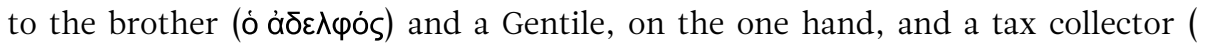

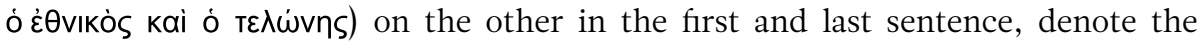
difference between inclusion and exclusion ${ }^{7}$ in terms of the Matthean community.

While these two interpretative positions are not logically exclusive, since the determination of whether the law applies in a particular case can result in the expulsion of the perpetrator ${ }^{8}$ their pathos can be radically different in that they may contribute to faith communities with an ethos emphasising either being inclusive or exclusive. Appropriated with an ethos of inclusivity 18:18 reminds faith communities of the need to continuously communally discern the meaning of biblical texts together, because of the inherent complexity of applying their meaning as ancient texts to the present context of the church (Mouton 2005:5). If 18:15-20 is, however, alternatively understood as primarily establishing ethical boundaries for the church, it can instead be used to sanction specific procedures which exclude some from the church..$^{9}$ The pathos of the interpretation of Matthew's community rule can thus have a life-giving focus on reconciliation, or a life-threatening emphasis on ostracism, in contemporary Christian communities.

The potential pathos of an interpretation can, however, not simply be used to choose between exegetical options, since an ethical reading of a text needs to be aligned with the direction of the text itself (Mouton 2002:252-253) and not just the sensibilities of the interpreter and his or her audience. It is, therefore, important to take note of the linguistic-literary pointers, or constraints, within a text to better understand the complex interaction between the implied author, the text and its readers, which should guide its interpretation and thereby also its pathos (Mouton 2002:124).

7 The scribes and Pharisees are accused in 23:13 of locking ( $k \lambda \varepsilon i \omega)$ people out of the kingdom of heaven (Luomanen 1998:245). They can thus also claim to possess the keys of the kingdom of heaven. This passage may be based on Isaiah 22:22 MT ("the keys of the house of David"), while 18:15 appears to be based on Leviticus 19:17 (LXX).

8 It is clear that the authority to bind and loose is directly linked to the authority of Jesus as the unique manifestation of God's presence in Matthew (1:23; 11:27). In 16:13-20 the focus is on how the community will exercise its authority to bind and loose in the presence of Jesus as the Christ and Son of the Living God. A similar link occurs in 28:20. The presence of Jesus is also in 18:20 the foundation of the authority of a process ultimately involving the whole community (described in 18:15-20), and not just a single leader (like Peter in Matthew 16). Jesus also has the authority to loosen the Sabbath law in 12:8(Powell 2003:443).

9 See Luz (2001:455) for a brief historical overview of the use of 18:15-18 for the justification of life-threatening ecclesial practices such as expulsion, excommunication and penance. While 18:15-18 has been used to justify the excommunication of believers in later ecclesiastical practice, it would be anachronistic to import this developed concept into Matthew (France 2007:691). 
In interpreting 18:15-20 in line with its argumentative thrust, it is crucial to consider if the overall structure of Matthew 18 determines its interpretive pathos. Or does 18:15-18, as Luz (2001:450) argues, instead fit awkwardly in the context of Matthew 18 and the rest of Matthew's Gospel, which understands that the church as corpus permixtum is a place where good and evil exist side by side until the judgment (13:37-43, 49-50; 22:11-14)? ${ }^{10}$

\section{The literary placement of Matthew 18:15-20}

Matthew 18:15-20 is part of a distinct literary unit ${ }^{11}$ for which the noun oúpavós , which occurs 11 times in combination with various key words, provides an important orientation point. References to heaven occurs in the introduction of the chapter (18:1-5), as well as the frame of the parable of the lost sheep (18:10-14), the key formula of binding and loosening (18:18), and the parable of the unforgiving servant (18:23-35). In view of these key occurrences of oủpavós, Matthew 18 can be divided into three main sections:

a. 18:1-5 - The fundamental order of the kingdom of heaven;

b. 18:6-14 - Caring for the disciples; and

c. 18:15-35 - The importance of communal forgiveness (Forkman 1972:118).

\section{Matthew 18:1-5 - The fundamental order of the kingdom of heaven}

Matthew 18 begins with a question by the disciples as to who is the greatest in the kingdom of heaven. ${ }^{12}$ The question, which comes from Mark 9:33-37, is modified by Matthew in order to emphasise its fundamental nature. Firstly, Matthew makes it a general question (tis) about status and authority instead of a specific question asked in the aftermath of a quarrel between the disciples over their relative status

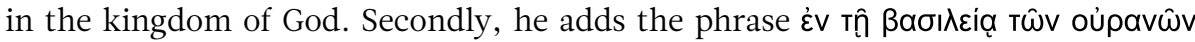
, which occurs three times in 18:1-5, to its first and last verse to form an inclusio indicating that for Matthew the ethos of the earthly community of those who follow Jesus should be analogous to that of the kingdom of heaven.

\footnotetext{
10 According to this view, Matthew is seen as a redactor of various traditions, which included his own church's rule of excommunication "in the least inhospitable context he could find." As redactor Matthew therefore made 18:15-17 an integral part of Matthew 18, since it is prepared for by 18:6-7, underscored by 18:18 and intensified by 18:19-20 (Luz 2001:451, 461).

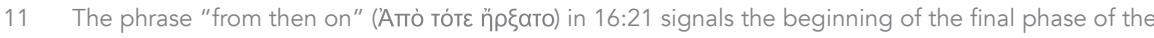
ministry of the Matthean Jesus, which culminates in his death and resurrection (Anderson 1994:168). It is during this phase that Matthew in his fourth large discourse (18:1-35) relates Jesus' instructions to his disciples on how to maintain the relationship between community members.

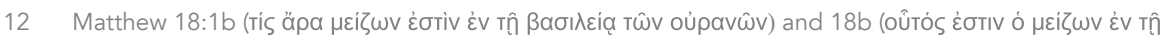

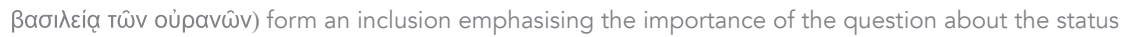
of the disciples (Luomanen 1998:233).
} 
The authority exercised within this kingdom community will therefore fundamentally differ from that enforced by earthly kings (17:25). This is made clear by 18:1 being linked to Jesus' second passion prediction $(17: 22-23)^{13}$ by an utterance on the payment of Temple Tax (17:24-27), which deliberately contrasts the ways of the "kings of

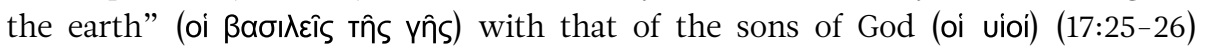
(Pennington 2007:319). ${ }^{14}$ The lifting up of a child by Jesus as an example of who is the greatest in the kingdom of heaven, combined with his warning that only those who are willing to become like a child with no status or authority (18:2-3), also rules out the imposition of a hierarchical communal structure ${ }^{15}$ (Forster 2017b:3).

The phrase "the kingdom of heaven" is an example of how Matthew, in the words of Mouton(2005:8), "reinterpreted, rearrangedand reappropriatedavailable traditional symbols from the symbolic world of Torah" in order to describe the radically new identity and ethos of the Matthean community. According to Pennington (2007:140), the phrase is neither a circumlocution for God, ${ }^{16}$ nor a mere Semitism. Furthermore, Matthew uses the 27 singular and 55 plural forms of oúpavó $\varsigma^{17}$ with different meanings. ${ }^{18}$ While the singular forms refer to the visible, created, world (often in heaven and earth combinations), the plura ${ }^{19}$ refer to the invisible realm that is usually either explicitly,

13 Matthew 18:1-5 is explicitly linked to Jesus' second passion prediction by the prepositional phrase "at

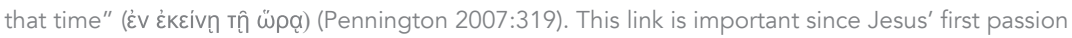
prediction in 16:21-23 follows directly after his statements about the post-Easter community along with his command that the disciples deny themselves by taking up their crosses and following him in 16:24-28 (Luomanen 1998:231). The example set by the Passion of Jesus thus determines the character of the Matthean community.

14 The reference to the kings of the earth possibly alludes to Psalm 2, which contrasts them with God in heaven (Pennington 2007:319).

15 In 23:1-12 the Matthean Jesus criticises the trappings (clothing, seating arrangements at meals and assemblies, and titles) which reflect a hierarchical understanding of God's community (Forkman 1972:121).

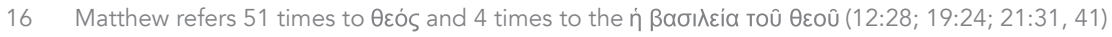
(Pennington 2007:35).

17 Matthew uses oúpavós 82 of the 274 times (30\%) it occurs in the New Testament (Schoenborn 1991:543). Of the 90 plural forms in the New Testament of oúpavós, 55 are in Matthew. The uniquely Matthean expression "the kingdom of heaven" accounts for the majority of the plurals (32 of 55). It is noteworthy that the phrase kingdom of heaven, which occurs 32 times, substitutes only in 12 instances for the phrase kingdom of God in the other Synoptics (Pennington 2007:2, 68-70).

18 While Schoenborn (1991:543) states that an unambiguous rule for the use of the plural and singular forms of oúpavós cannot be discerned, Betz (1995:379) like Pennington, has noted that in the Sermon on the Mount the singular heaven means "sky" when used in conjunction with earth, while the plural refers to God's realm.

19 Matthew $16: 19$ is an exception to the use of the singular and plural forms of oúpavó in that it twice

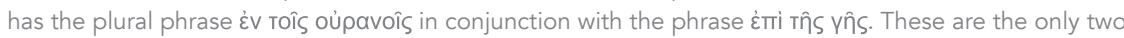
instances where Matthew uses the plural form in conjunction with earth (Pennington 2007:147). In the parallel passage in 18:18 the formula contains the singular forms of oúpavós. It could be that this serves to indicate that a distinction is being made by Matthew between teaching (16:19) and disciplinary (18:18) authority even though they are intertwined (Pennington 2007:148). A more plausible reason could be that the juxtaposition of kingdom of heaven with heaven and earth, which occurs here only in 16:19, necessitated Matthew to use the plural żv roîs oủpavoîs in respect to binding and loosening, 
or indirectly through metonymy, identified as God's realm (Pennington 2007:140)..$^{20}$ For Matthew heaven and earth ${ }^{21}$ are thus two different and distinct realms of reality (Schneider 1988:283-297). The first is the dwelling space of God and his angels and the other that of humans. This distinction between heaven and earth is important for two reasons. First, the phrase heaven and earth is for Matthew not a way of referring to the two parts of the whole universe, but rather a way of emphasising the innate dichotomy which exists between these two opposite poles of the universe (Syreeni 1990:3). This dichotomy between heaven where God's will is done, and earth where it not, creates a need for mediators between these two distinct realms. In 28:18 Christ is the one with full authority in both spheres as mediator, while in 16:19 it is Peter who receives the keys to the heavenly realm, whereas in 18:18 it is the whole community who must mediate between the two realms (Syreeni 1990:4). ${ }^{22}$

The dichotomy between heaven and earth is important, secondly, for understanding the clear differences between how authority is to be exercised in the two realms. Bauckham (1996:4-6) has in this regard remarked that the Gospels in the New Testament almost never depict God as King in order to avoid creating the false impression that God rules in the same way that earthly kings do. The Gospel writers instead underline how the teaching of Jesus reveals the way in which God's rule differs from earthly rulers and can therefore be described as being "status quo" - overturning. It is thus not just important to note who rules where, but also how they rule, since Matthew wants to highlight the difference between the ethos of God's kingdom, which is from heaven, and all earthly kingdoms (Pennington 2007:322).

Heaven and earth will, however, not always stand in contrast to each other in that they will be unified with the consummation (6:9-10). The present distinction between God's heavenly kingdom and the earthly kingdoms therefore, according to Matthew, creates an eschatological hope that in Jesus the kingdom of heaven will be extended to earth (cf. 6:9-10), the realm of humans (Pennington 2007:323). It is in evoking this hope that the metaphorical language in the New Testament, like

where he usually used the singular in order not to create the impression that there is a contrast

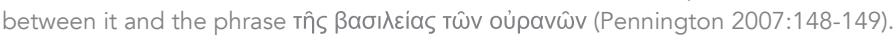

20 The plural forms serve a theological and literary function and do not indicate that Matthew believed in multiple heavens, according to Pennington (2007:148). Therefore, Matthew always refers to heaven in the plural when speaking of the Father or the kingdom (Pennington 2007:141). The plural is also used for invisible or divinely-related objects and beings (cf. 18:10; 24:29,36), unless - like the angel in 28:2 - they have descended into the visible world (Pennington 2007:141). The plural use was unknown to secular Greek writers (Schoenborn 1991:543).

21 The juxtaposition of heaven and earth occurs in $6: 10 ; 16: 19 ; 18: 18$ and 28:18.

22 According to Schneider (1988:283-297), there is therefore a Christological mediation "from above" and an ecclesiological mediation "from below" between these two realms. This division of how mediation should be done is, however, too neat, as Syreeni (1990:4) has argued that in the Lord's Prayer the mediation between heaven and earth is not the task of a person or a group, but rather a mysterious process that is to be prayed for $(6: 10)$. 
references to the kingdom of heaven, becomes transformative in that it allows readers to glimpse a new world which they might inhabit, or an alternative point of view with which they can identify, in the present. New Testament texts, such as Matthew 18, thus have a persuasive thrust towards the renewal of their readers by inviting them to re-imagine their life stories and to inhabit the world proposed by the text as the new world for them (Mouton 2005:9). The pathos of the interpretation of the New Testament should thus reflect this life-affirming vision and note the life-threatening consequences it warns of for those who do not align themselves with the ethos of the kingdom of heaven in the present (cf. 18:3, $6,8-9,34-35)$. It is, however, not just interpretations which warn of judgement which can be life-threatening. Even interpretations which emphasise forgiveness and reconciliation can have a life-threatening pathos for those who are struggling to overcome the effects of the violence as it can vilify them for not being ready to forgive the perpetrators of the violence

\section{Matthew 18:6-14 - Caring for the disciples}

Matthew 18:6-14 focuses on the care of the "little ones" as is indicated by the

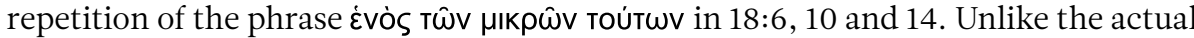

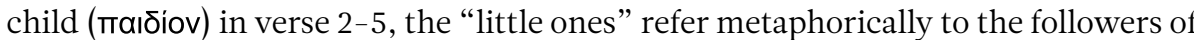
Jesus, ${ }^{23}$ since they are described as believing in Jesus (18:6) (Luomanen 1998:237). The issue, according to verse $7 \mathrm{a}$, that demands the attention of the Matthean community is that unidentified persons from outside Matthew's community (cf. the reference to "the world") has caused them to stumble.

Two lines of interpretation, each with a different possible pathos, have been followed in interpreting the warning in verse 8-9.

The first line of interpretation argues that the Matthean Jesus is referring to the conduct of a community member, referred to in a symbolic manner as being either a foot, eye or hand that have caused another member of the community to stumble (Kupp 1996:179; Osborne 2010:675). There is according to this interpretation, no shift in the addresses from those who cause others to stumble in 18:6-7 to individuals who themselves sin in verse 8-9. In support of this corporate interpretation it is argued that since the focus of Matthew 18 is on communal matters, the emphasis in 18:8-9 is on not allowing temptation to enter into the community to the detriment of vulnerable disciples by expelling those who tempt them (Luomanen 1998:239) and that the causative force of $\sigma \kappa a v \delta a \lambda i \zeta \omega$ and its cognates which occur throughout 18:6-9 indicates that it means "cause others to stumble" (Thompson 1970:112, 116-118). Furthermore, the metaphorical description of the amputation of a limb and that of

23 It could be a general title for the disciples taken over from Mark (Luomanen 1998:237) 
the expulsion of false prophets in 7:19 (to be cut down like a tree) uses the same verb (غ่кко́тт $\omega)$ to indicate the decisive action that needs to be taken against these individuals in order to safeguard the community. ${ }^{24}$

The second line of interpretation is that Matthew is referring to personal temptation since his formulation is similar to that of the second antithesis on adultery $(5: 27-32) .{ }^{25}$ The wording of the warning in 18:8-9 in the second-person singular thus indicates that the focus is on individual disciples addressing the causes of their own stumbling and not on how to expel others from their community, which would be a communal (indicated by a second-person plural) and not individualistic task (France 2007:683). ${ }^{26}$ Attempts to understand the body parts that must be cut off in 5:29-30 as referring to the expulsion of members of the church, in order to link it to the expulsion of member in 18:17, are unlikely since Matthew does not refer to the church as the body of Christ comprised of various members (Davies \& Allison 1991:765). The pathos of the interpretation of 18:6-14 should thus emphasise that individuals take responsibility for the life-threatening conduct of others (18:6-7) and themselves $(18: 8-9)$, which is in line with the warning of the Matthean Jesus in 7:1-5 against hypocrisy when judging others (Davies \& Allison 1991:765). ${ }^{27}$

The most problematic aspect of the interpretation of 18:15-20 from a pathos point of view is the question of whether the expulsion of members from the Matthean community is to be understood as being permanent, since this can lend support to contemporary life-threatening ecclesiological practices such as excommunication.

Key to determining if the possibility exists for those who have been expelled from

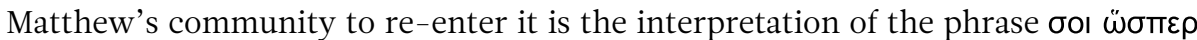

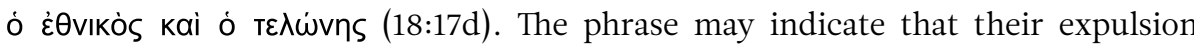
was permanent in line with the rules for the expelling of tax collectors from the Pharisaic fellowship that allowed no contact at all with them after their expulsion (Forkman 1972:126-127). In determining if this is the case, it is important to ascertain if reference to a Gentile and a tax collector in 18:17 and 5:46, which both have a pejorative tone, must be understood against the background of Matthew's negative view of both, or his other utterances of them being allowed into the kingdom of heaven.

\footnotetext{
24 If this line of interpretation is followed, 18:8-9 and 7:19 each provide a specified reason why a member of the community is to be expelled in that they have respectively caused another member of the community to sin or follow false teaching.

25 In terms of formulation Matthew uses $\varepsilon$ i with the present indicative $(5: 29 ; 18: 8)$ in both passages, while the verbs $\dot{\varepsilon}$ Kко́пт $\omega(5: 30 ; 18: 8)$ and $\dot{\varepsilon} \xi \alpha ı \dot{\varepsilon} \omega(5: 29 ; 18: 9)$, which express the remedial action, also occur in both passages.

26 Osborne (2010:675) sees them as collective singulars and therefore in line with the corporate nature of 18:6-7 and 18:10-14. The different formulation, however, seems more in line with an intertwined emphasis on corporate $(18: 6-7,10-14)$ and individual (18:8-9) ethical responsibility, especially since the formulation of 18:8-9 is similar to that of the second antithesis on adultery, which addresses an individual (5:27-32) 
Gentiles are derided in Matthew for their practice of only greeting their brothers (5:47) and their manner of praying (6:7), while toll collectors are placed on the same level as sinners (9:10-11) and prostitutes (21:31-32). In contrast to this negative view, both 9:10-11 and 21:31-32 indicate a preference for a tax collector over the Pharisees (Forkman 1972:129). It is also assumed by Matthew that the tax collector could repent (Luomanen 1998:251) and that the gospel must be proclaimed to the Gentiles $(4: 15 ; 12: 21 ; 28: 19)$. Jesus is even called a friend of tax collectors and sinners in 11:19. Despite these positive references the fact that the phrase in 18:17 referring to tax collectors and sinners indicates the result of a failed process which had made every attempt to reconcile with a brother, indicates that Matthew uses it here with its conventional, pejorative connotation (France 2007:694). The immediate outcome of the failed process to rebuke a brother who had transgressed is thus to shun them entirely. The brother who does not repent is not simply no longer part of the Matthean community, but is to be categorised as belonging to those who are despised by them (Hagner 1995:532).

There are, however, other indications in chapter 18 that point in the direction of a possible future reconciliation with the expelled brother. The inclusio formed by the reference to "the little ones" and "my Father in heaven" in 18:10 and 14, for example, indicates that the enclosed parable about the lost sheep is to be understood as a symbolic depiction of the treatment of errant disciples in view of God's heavenly rule as Father. ${ }^{28}$ The parable in Matthew three times (18:12 [x2], 13) describes the

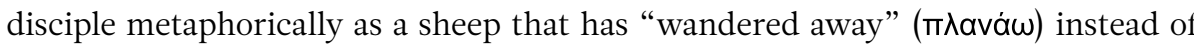
being "lost” (ámó $\lambda \lambda u \mu l)$ like in Luke 15:4 (France 2007:685). A clear distinction is thus made between going astray and being lost, with the latter referring to the ultimate loss of salvation and the first to behaviour that may result in the loss of salvation, but does not of necessity do so (Luz 2001:442). It is thus possible that Matthew intends that the parable of the lost sheep should function as an introduction to his instructions on how to deal with a brother who sins in 18:15-20 in order to emphasise the need for caring for them with the intent of reconciling them with the Matthean community, even if they are expelled from it for a period. Being expelled from the Matthean community thus does not necessarily imply they must remain permanently outside it (Nolland 2005:748; Turner 2008:445), since while they may have "wandered away" they are not "lost" (Davies \& Allison 1991:772). The intention of engaging with

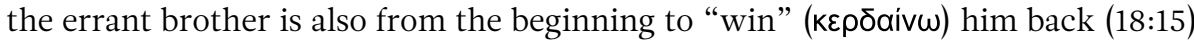
and not to expel him. The expulsion of a brother is thus an unintended outcome of the reproof process and not its intended goal.

\footnotetext{
28 The sheep metaphor, which emphasises the need of the disciples for care, is an important one in Matthew as is evident from its use in key parts of the Gospel. The disciples of Jesus are often symbolised as sheep (cf. 10:16; 25:32, 33; $26: 31$ and implicitly in 7:15). While Jesus is identified at the

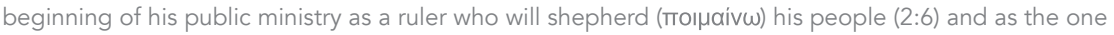
sent to the lost sheep of Israel (15:24), while he is also depicted by Matthew as having compassion for the crowds, who are described as being like sheep without a shepherd (9:36). Shepherding also forms part of the mission of the twelve (10:6) (Luomanen 1998:247).
} 
The possible reconciliation with an errant brother, however, is not for Matthew an automatic process, as his narration of both the parable of the lost sheep (18:10-14) and the question about the brother who sins (18:15-17) are similar in that in both instances the joyous outcome is not a forgone conclusion (Forkman 1972:130). ${ }^{29}$

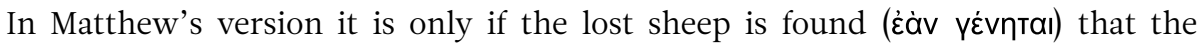
shepherd rejoices and in dealing with a brother who has sinned he is only won back

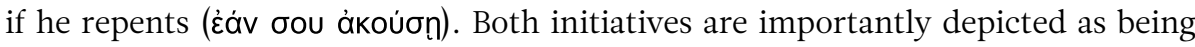
the will of God (Forkman 1972:130) and as a continuation of the ministry of Jesus (Luomanen 1998:248).

\section{Matthew 18:21-35 - The importance of communal forgiveness}

The section following 18:15-20 is comprised of a responsive chreia (18:21-22), which demands unlimited interpersonal forgiveness within the Matthean community, and a parable (18:23-34) which illustrates that community members should forgive each other since they had already been forgiven by God (Bailey \& Vander Broek 1992:112; Luz 2001:465; Neyrey 1998:50-51). ${ }^{30}$ In short, their willingness to forgive others will determine if they will be forgiven by God themselves $(18: 23-34,35)$. The parable, however, warns of the dire danger of not forgiving others and thus against the implementation of the community rule $(18: 15-17)$ with an unforgiving attitude to reprove, and even expel, community members. If the community rule is linked to 18:21-35, it is apparent that forgiveness should not be withheld even after repeated offences and that the expulsion of a member may thus only be temporary in instances where the offence is an unwillingness to ask for forgiveness ${ }^{31}$ (Luz 2001:461-462), or to forgive others, since the parable emphasises that the acts of forgiveness of God and men are interwoven. ${ }^{32}$ It could thus be that the refusal to engage in a process of forgiveness and reconciliation either as a victim (cf. 18:20-22, 23-35) or perpetrator of the transgression $(18: 15-17)$ is for Matthew the sole justification for expelling members from his community.

\footnotetext{
29 It should be noted that the forgiveness of the brother who had transgressed is not dependent on his contrition. It is instead because he had been forgiven that the process of reproof should be undertaken so that victim and transgressor may be reconciled with each other (Davies \& Allison 1991:791).

30 According to Watson (1992:105), 18:21-22 can be understood as a chreia with humour, while Berger (1984:81) takes 18:21-35 as a chreia. The latter can, however, best be described as a parable.

31 The brother's' refusal to ask for forgiveness that results in their expulsion from the Matthean community means that their excommunication is in essence a self-imposed sentence (Davies \& Allison 1991:804).

32 Neither the neglect of ritual purity nor the non-observance of the Sabbath resulted in expulsion in Matthew (9:10-13; 12:1-8) (Luomanen 1998:251).
} 


\section{Conclusion}

According to Mouton, the pathos of New Testament Studies can be either life-affirming or life-threatening. While interpreters should take responsibility for their interpretations of the New Testament, a possible life-threatening pathos of a specific interpretation cannot be used in a simplistic manner to negate the potential meaning of a text (i.e. by ignoring texts expressing judgement). It is instead for Mouton important to determine if the pathos of an interpretation of a specific text is in line with its grain or intention. In considering the pathos of the interpretation of Matthew 18:15-20 this chapter has therefore attempted to read it within its immediate literary context (Matthew 18).

An analysis of the literary structure of Matthew 18:15-20 indicates that while the emphasis in Matthew is on the innate dichotomy between the heavenly and earthly spheres (Syreeni 1990:202), the ethos of the earthly Matthean community must correspond to that of the kingdom of heaven where God the father is king (Forkman 1972:119). In line with the ethos of the kingdom of heaven, which discourages any attempt to become the greatest (18:1), the Matthean community was to have a non-hierarchical structure. Community members were to use their authority to mediate between heaven and earth (18:18), care for vulnerable disciples $(18: 6-10)^{33}$ and grant limitless forgiveness to those who had transgressed against them (18:21-22). Not only are they warned against not forgiving others (18:23-35), but is a clear procedure given in 18:15-20 that affords transgressors three chances to repent. The importance of seeking reconciliation with transgressors is furthermore indicated by the community rule being framed by two parables that emphasise the importance of seeking those who wander away from the community (18:12-14) and practising interpersonal forgiveness (18:23-35) (Davies \& Allison 1991:804).

The authority sanctioned by heaven in 18:18 is the determination of the applicability of the law, which establishes the ethical boundaries of the Matthean community. Exercising the authority is to be undertaken in conjunction with all members of the community and not just designated leaders like Peter. This may be due to Matthew's awareness of the limitation of leaders, who cannot consistently discern the will of God correctly on their own. Immediately after Peter had been identified as a key mediator between heaven and earth in 16:13-28 he, for example, fails in this role (18:23).

In interpreting the law thereare two dangers to avoid which result in a life-threatening pathos. The first is to loosen what should not be loosened because of the influence of human tradition (15:6). The second is to refrain from loosening the law when it should be loosened and thereby condemning the guiltless (12:7). To aid his hearers

33 The use of family and household imagery like "children" (18:2-5), "little ones" (18:6, 10, 14), "brothers" $(18: 15,21,35)$ and "fellow slaves" $(18: 29,31,33)$ for the disciples should be noted (Turner 2008:432). 
avoid both dangers the Matthean Jesus provides them with various examples and guidelines. Jesus, for example, interprets and applies (i.e. binds) the law prohibiting murder to include anger and insults (5:31-32), and expands the command to love your neighbour to incorporate enemies as well (5:43-48) (Powell 2003:441-443). Jesus also forbids the loosening of the command to honour your father and mother by some Pharisees (15:3-9), but loosens the prohibition against working on the Sabbath (12:9-14). In terms of guidelines, Matthew prioritises life-affirming scriptural mandates such as the Golden Rule (7:12), the preference for mercy over sacrifice $(9: 13 ; 12: 7)$, the priority of love for God and neighbour $(22: 34-40)$, and the "weightier matters of the law" like justice, mercy and faithfulness (23:23) (Powell 2003:443). These guidelines, which provide a clear indication of the pathos of interpreting the law intended by Matthew, can be extrapolated to determine the pathos that should characterise contemporary readings of the First Gospel.

It is possible to speculate that the pathos Matthew wanted to evoke from his initial readers was to mitigate an uncontrolled implementation of an ostracising procedure that was tearing his community apart (Syreeni 1990:5-6). If Matthew was writing for a community struggling with its Jewish heritage, amidst of an influx of Gentiles, that was meeting to settle a dispute about whether the law applied or not when a Jewish community member had accused another Gentile member of a transgression, the overzealous expulsion of the latter would have had catastrophic consequences for the unity of the community. Therefore, Matthew may have intended to remind his readers that they had a greater authority than to interpret the law or ostracise transgressors. They had the authority and responsibility to forgive each other. He,therefore, situates his community rule for dealing with errant members within an intricate theological frame which provides specific guidelines for its intended pathos.

While some brothers are thus to be expelled from the Matthean community as a result of their failure to respond to a process of reproof, their expulsion was not its goal. The reason for rebuking a brother who had transgressed against another is instead

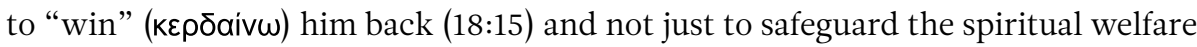
of the community by expelling him (France 2007:692). The reproof of a brother who has sinned against another (18:15-20) should therefore be done in humility ${ }^{34}$ (18:1-5), not give offence (18:6-9), imitate God's forgiveness (18:21-35) and focus on those who have strayed (18:10-14) (Davies \& Allison 1991:751). The meaning of the derogatory phrase "to treat someone as a heathen and Gentile" (18:17), when considered within the broader narrative of Matthew, does not preclude a future reconciliation with the expelled member. According to Matthew 18 it is the will of God that no disciple should be lost. Both the seeking of those who have strayed, and the expulsion of those who do not seek forgiveness, are part of the process of reproof that is intended to prevent them becoming lost.

\footnotetext{
34 Where reproof is exercised, the dignity of the person should be protected as far as possible by initially restricting the involvement of the community (Nolland 2005:746).
} 
It is in her sensitive and thorough engagement with the intricate theological frames of various biblical texts within their different settings that Elna Mouton has reshaped the pathos of New Testament Studies to be life-affirming for all, but especially for women, who often continue to be marginalised on the African continent. This chapter is therefore offered as a token of my heartfelt personal appreciation for the life-affirming pathos of Elna's work as a truly pioneering New Testament scholar.

\section{Bibliography}

Anderson, J C. 1994. Matthew's narrative web over, and over, and over again, Sheffield, England: JSOT Press.

Bailey, J L \& Vander Broek, L D. 1992. Literary forms in the New Testament: a Handbook, Louisville: John Knox Press.

Bauckham, R. 1996. Kingdom and Church According To Jesus and Paul, Horizons in Biblical Theology, 18(1):1-26. https: / / doi. org/10.1163/187122096X00013

Berger, K. 1984. Formgeschichte des Neuen Testaments, Heidelberg: Quelle \& Meyer.

Betz, H D. 1995. The Sermon on the Mount: a commentary on the Sermon on the Mount, including the Sermon on the Plain (Matthew 5:3-7:27 and Luke 6:20-49), Minneapolis: Fortress Press.

Bockmuehl, M N A. 2006. Seeing the Word: Refocusing New Testament Study, Grand Rapids: Baker Academic.
Bornkamm, G. 1970. Die Binde- und Lösegewalt in der Kirche des Matthäus, in Die Zeit Jesu: Festschrift für Heinrich Schlier, Freiburg: Herder, 93-107.

Davies, W D \& Allison, D C. 1991. A Critical and Exegetical Commentary on the Gospel according to Saint Matthew 8-18, Edinburgh: T \& T Clark.

Fiedler, R N; Hofmeyr, J W \& Fiedler, K. 2016. African Feminist Hermeneutics: An Evangelical Reflection, Luwinga: Mzuni Press.

Forkman, G. 1972. The Limits of the Religious Community. Expulsion from the religious community within the Qumran sect, within Rabbinic Judaism and within primitive Christianity, Lund: Gleerup.

Forster, D A. 2017a. The (Im)possibility of Forgiveness?: An Empirical Intercultural Bible Reading of Matthew 18:15-35, Stellenbosch: AFRICAN SUN MeDIA. 
Forster, D A. 2017b. A public theological approach to the (im)possibility of forgiveness in Matthew 18:15-35: Reading the text through the lens of integral theory, in Luce Verbi, 51(3):1-10.

France, R T. 2007. The Gospel of Matthew, Grand Rapids: William B. Eerdmans.

Hagner, D A. 1995. Matthew 14-28, Dallas: Word Books.

Heil, J P. 2007. Ephesians: Empowerment to Walk in Love for the Unity of All in Christ, Atlanta: Society of Biblical Literature.

Hogan, P N. 2014. Response to Choi and Huff: Paul and Women's Leadership in American Christianity in the Nineteenth Century, in N Calvert-Koyzis \& H Weir (eds.), Strangely Familiar: Protofeminist Interpretations of Patriarchal Biblical Texts, Atlanta: Society of Biblical Literature, 259-267.

Hunsberger, G R. 2016. Mapping the Missional Hermeneutics Conversation, in M Goheen (ed.), Reading the Bible Missionally, Grand Rapids: William B. Eerdmans, 45-67.

Kupp, D D. 1996. Matthew's Emmanuel: Divine Presence and God's People in the First Gospel, Cambridge: Cambridge University Press. https://doi. org/10.1017/CBO9780511627958
Luomanen, P. 1998. Entering the kingdom of heaven: a study on the structure of Matthew's view of salvation, Tübingen: Mohr Siebeck.

Luz, U. 2001. Matthew 8-20: A Commentary, Minneapolis: Fortress Press.

Mouton, A E J. 2002. Reading a New Testament Document Ethically, Atlanta: Society of Biblical Literature.

Mouton, A E J. 2005. The Pathos of New Testament Studies; of what use are we to the church? Stellenbosch: Stellenbosch University.

Nel, M J. 2015. Interpersoonlike vergifnis in Matteus 18:15-35, in Luce Verbi, 49(2):8.

Neyrey, J H. 1998. Honor and Shame in the Gospel of Matthew, Louisville: Westminster John Knox Press.

Nolland, J. 2005. The Gospel of Matthew: A Commentary on the Greek Text, Grand Rapids: William B. Eerdmans.

Osborne, G R. 2010. Matthew, (Zondervan Exegetical Commentary Series), Grand Rapids: Zondervan.

Pennington, J T. 2007. Heaven and Earth in the Gospel of Matthew, Leiden: Brill. https://doi.org/10.1163/ ej.9789004162051.i-399 
Powell, M A. 2003. Binding and loosing: a paradigm for ethical discernment from the Gospel of Matthew, Currents in Theology and Mission, 30(6): 438-445.

Runesson, A. 2016. Divine Wrath and Salvation in Matthew: The Narrative World of the First Gospel, Minneapolis: Fortress Press. https://doi.org/10.2307/j. ctt9m0ss8

Schneider, G. 1988. 'Im Himmel auf Erden', eine Perspektive matthäischer Theologie, in L. Schenke (ed.), Studien zum Mattausevangelium: Festschrifte fur Wilhelm Pesch, Stuttgart: Katholisches Bibelwerk, 285-297.

Schoenborn, U. 1991. oúpavós, in H Balz \& G Schneider (eds.), Exegetical Dictionary of the New Testament, 2, Grand Rapids: William B. Eerdmans, 543-547.

Syreeni, K. 1990. Between heaven and earth: on the structure of Matthew's symbolic universe, Journal for the Study of the New Testament, (40):3-13. https: / /doi.org/10.1177/ 0142064X9001304001
Theron, P. 2015. Cultural Perspectives on Gender Equality. Prominent indicators for Christian churches in Sub-Saharan Africa, in E Mouton, G Kapuma, L Hansen \& T Togom (eds.), Living with Dignity: African perspectives on gender equality, Stellenbosch: AFRICAN SUN MeDIA, 53-86.

Thompson, W G. 1970. Matthew's Advice to a Divided Community, Rome: Biblical Institute Press.

Tolmie, D F. 2016. Pauline Studies in South Africa: Did anything change in 50 years? in R. Venter (ed.), Theology and the (post)apartheid condition: Genealogies and future directions, Stellenbosch: AFRICAN SUN MeDIA, 107-121.

Turner, D L. 2008. Matthew, Grand Rapids: Baker Academic.

Watson, D F. 1992. Chreia/Aphorism, in Dictionary of Jesus and the Gospels, J B Green, S McKnight, I H Marshall (eds.), Downers Grove: InterVarsity Press, 104-106. 
Section C | READINGS AND WRITINGS 


\title{
Chapter 14
}

\section{An Enigmatic Longing}

\author{
Reflections on Christian spirituality
}

Denise M Ackermann

\section{Enigma as mystery}

The word 'enigmatic' means both 'puzzling' and 'mysterious'. I contend that longing for God is a hunger known by human beings, one we are free to explore or to ignore. Augustine (1991:39), who knew the cost of ignoring his longing, wrote: "My God, how I burned, how I burned with longing to leave earthly things and fly back to you". Is the psalmist filled with this same enigmatic longing when he cries out: "O God, you are my God, I seek you, my soul thirsts for you" (Ps. 63:1)? How our longing is manifested is often beyond rational thought; hence it can be both puzzling and mysterious. This essay is dedicated to Elna Mouton in profound appreciation for her work and in the belief that she too knows the enigma of longing.

Clearly these reflections are personal. Wrestling with enigma and mystery is a subjective exercise, one that can persist throughout the life of faith. I do not pretend to have neat templates for my reflections. Rather they are a series of markers that have been useful guides as I have grappled with the meaning of longing in a life of faith.

There are countless references to the experience of mystery in the writings of Christian luminaries over the centuries. Mystery is not the absence of meaning but rather the presence of what is beyond our understanding. Faith in a Triune God cannot be limited to neat theological statements. It is permeated with mystery. In our desire for relationship with God we encounter mystery because we cannot 'know' the totality of God's being. There are also elements of mystery in our relationships with one another and even with ourselves. 
Karl Rahner (1978:42) acknowledges the presence of mystery in the life of faith. He writes: "First of all being constituted as transcendental subject, he [sic] is in the presence of being as mystery, a mystery which constantly reveals itself and the same time conceals itself". Being in relationship with God is drenched with mystery. It is a paradoxical experience of 'knowing' through 'unknowing', a dawning of a transcendental truth beyond our 'knowing'. How can a living encounter with the Holy One be anything else?

The experience of mystery is undoubtedly subjective, another reason why both 'experience' and 'mystery' are often viewed with scepticism. I argue that God in Christ is the source of our subjective knowledge. And it is not without trial and suffering. Attempting to live with Christ entails both cross and resurrection. Jewish philosopher Martin Buber (1878-1965) (1958:99) wrote: "He who knows God knows also very well remoteness from God and the anguish of bareness in the tormented heart; but he does not know the absence of God; it is we only who are not always there". The $13^{\text {th }}$ century German mystic Meister Eckhart knows this truth when he says: "God is always at home. It is we who have gone out for a walk" (Ward \& Wild 2006:118). Paul confirms knowledge of God in Christ when he writes to the Colossians (2:2). "I want their hearts encouraged and united in love; so that they may have all the riches of assured understanding and have the knowledge of God's mystery, that is Christ himself in whom are hidden all the treasures of wisdom and knowledge".

\section{A personal note}

In 2000 when I retired from full-time academic life at the University of the Western Cape, the Faculty of Theology at Stellenbosch University invited me to teach a few courses. My interests were twofold - the role of gender and culture in the Christian tradition, and Christian spirituality. To my surprise the Dean at the time agreed to my request to fund the students for a week away from the Faculty at a place of quiet for the course on Christian spirituality. I spent the mornings discovering the different Christian traditions of spirituality from the time of the desert fathers and mothers to the present. In the afternoons the students were required to keep silence and to meditate on scripture and then pray. Between times of prayer they were encouraged to take exercise. After supper the silence was broken and we discussed their experiences. After ten years, I retired and was delighted when Elna Mouton agreed to continue with this course. Our common interest has given rise to these reflections. 


\section{Spirituality and the Academy}

The course described above raises the following question: Is such a course a legitimate academic exercise for theological students at university? The answer may well depend on how the word 'spirituality' is understood as there are a myriad of definitions and descriptions of its meaning.

At the outset it is necessary to clear up a common misunderstanding. Christian spirituality is not some elite set of Christian practices. It is not something to be relegated to monastic seclusion, or limited to certain denominational practices. It is more useful to view spirituality as fundamental to human experience, and as such, it can be studied. It is also important to note that contemporary use of the term 'spirituality' characterises not only Christian spirituality but other world religions as well. A cursory perusal of the poems of the Muslim mystic Rumi (1207-1273) (1985) bears this out, as do the writings of contemporary Buddhists such as Tich Nhat Hahn (1976). There is little doubt that since the end of the $19^{\text {th }}$ century there has been a widely growing interest in spirituality in the modern world. Publications have proliferated and reference works such as the 25-volume World Spirituality: An Encyclopaedic History of the Religious Quest and Bernard McGinn's series The Presence of God: A History of Western Christian Mysticism, are now found in academic libraries.

The historical development of Christian spirituality from the time of Paul, who used the Greek adjective pneumatikos when referring to God the Holy Spirit, to the deserts of Upper Egypt, through the Middle Ages to the present, use of the term merits an essay of its own. My reflections include insights from both contemporary and past practices in Christian spirituality.

Given modern interest in Christian spirituality, it has been studied as a legitimate academic discipline for the last seven to eight decades. Sandra Schneiders (1990:23), analysing the place of spirituality in the academy, describes it as "the experience of consciously striving to integrate one's life not in terms of isolation and self-absorption but of self-transcendence towards the ultimate value one perceives".

Succinctly put, Christian spirituality "is the field of study which attempts to investigate in an interdisciplinary way spiritual experience as such" (Schneiders 1990:31). This involves, among other things, the study of scripture, history, theology and psychology. Thus thestudy of spirituality is inter-disciplinary and descriptive-critical rather than prescriptive and normative. Ecumenical and cross-cultural realities all have a significant role to play in the study of spirituality. As experience is examined, participative methods are employed. Schneiders comments (1990:34): "Like psychology, spirituality deals with material that often cannot be understood except through analogy with personal experience". The students' experiences with silence and meditative prayer were clearly deeply subjective. Interdisciplinary insights, however, were helpful in furthering understanding. 
Finally, a word from Archbishop Emeritus Desmond Tutu (1999:26)

The Bible and our faith and its tradition declare unequivocally that for an authentic Christian existence the absolute priority must be spirituality. When we want to grow our intimacy with God, through prayer, Bible reading, meditation, retreats and regular use of the sacraments, then we must be growing in the contemplation of the God who has created us for the divine life.

\section{Relationship}

In my view, Christian spirituality arises from the human longing for greater intimacy in our relationship with God. Martin Buber based his well-known work I and Thou on the belief that in the beginning was the relationship, the relationship between God and the human being. "The Thou meets me. But I step into direct relation with it. Hence the relation means being chosen and choosing, suffering and action in one” (1958:11). For Buber relationship is by definition never one-sided.

The mystery-laden statement that we are made in the image and likeness of God affirms our human worth and dignity. In Tutu's (1999:8) words: "Each human being is of intrinsic worth because each human being is created in the image of God". Because we all share our godly image, we are in some mysterious way connected to each other. Our godly image lays the foundation for relationship - with God, with others, with oneself and with creation. Relationship, as Tutu (1999:5) points out, is "the first law of our being". We are all set "in an interdependent network with our fellow human beings and with the rest of God's creation”.

Furthermore, our scriptures and human experience throughout the ages affirm the truth that God desires to be in relationship with human beings. The Incarnation is a final affirmation of this desire. "The Word became flesh and lived among us" (John 1:14). Jesus was radical, not in his embrace of sacrifice, but in his power to engage people in mutuality. He paid the ultimate price because he refused to abandon the radical activity of love. His acts of love crossed all established barriers and expressed solidarity with those who were the least in his society.

Human relationships are not without risk. Lofty expectations can endanger relationship when we fail to live up to them. Relationships can also be unhealthy, exploitative and even abusive. Hence relationships should be mutual and reciprocal. "Let no attempt be made to sap the strength of the meaning of the relational: relational is mutual" (Buber 1958:8). All human beings - all of us created in relation to one another and to God - are called to the radical activity of love. It is precisely the possibility of mutual loving relationship that lies at the heart of Christian spirituality.

Without the goal of mutual relationships there is little hope for building community. Community does not just happen. Community is the result of mutual relationships as well as the place in which these relationships are put to the test. We are not made 
for self-constituted, self-directed and undisturbed existences. Being a community that can acknowledge our differences, yet is able to cross the barriers that separate people, is a hard-won achievement.

\section{Markers from the past}

Singling out certain markers from the traditions of Christian spirituality is, once again, a matter of personal choice. I have chosen those that have served as guides, at times as nudges and reminders when needed, for the lifelong task of living with faith.

The mothers (ammas) and fathers (abbas) of the deserts of Upper Egypt merit mentioning for their pithy wisdom that emerged from the deprivations of desert life, self-imposed solitude and their own personal struggles to live holiness (see Ackermann 2014:110-124). ) Their sayings were generally simple, down to earth, and undergirded by an abhorrence of pretence. One of the earliest and most influential of Christian desert fathers was Anthony the Great (c. 251-356). In a saying attributed to him, Anthony affirmed simplicity: "Those who aim to practise the life of virtue and holiness should not incur condemnation by pretending to a kind of piety which they do not possess. But like painters and sculptors they should manifest their virtue and holiness through their works" (Ward and Wild 2006:30). Despite the solitary existence of these people, relationship was often affirmed in their sayings. "Our life and our death is with our neighbour. If we win our brother, we win God. If we cause our brother to stumble we have sinned against Christ", said Anthony (Williams 2005:13).

Judging another was frowned on. "A brother who had sinned was turned out of the church. Abba Bessarion got up and followed him out; he said: 'I too am a sinner'" (Williams 2005:21). Often they advised the young novices to keep their prayers short. A monk asked Abba Macarius how to pray.

He answered:

It is not necessary to use many words. Only stretch out your arms and say: 'Lord, have pity on me as you desire, as you well know how!' And if the enemy presses you hard, say 'Lord, come to my aid!' (Ward and Wild 2006:81).

These early desert dwellers left a significant legacy that subsequently led to the establishment of monastic communities in Europe and certain Middle Eastern countries. They embraced silence and solitude, they lived simple and moderate lives away from worldly comforts and they prized humility and self-knowledge. These characteristics of desert living were embraced by monastic communities and embedded over centuries in traditions of Christian spirituality. 
Initially, before my encounter with the desert mothers and fathers, my interest in Christian spirituality was sparked by an encounter with Benedict of Nursia (c. 480-543 or 547) and the practice of lectio divina. Benedict established a number of monastic communities, but is best known for the community at Monte Casino in southern Italy founded in about 528. Many of the members of early monastic communities could not read. But six times a day they gathered to hear the Bible read to them. They listened as the passage was repeated until a word, a phrase, or an insight compelled them to leave the chapel silently and return to the privacy of their cells for prayer. Thus scripture became their daily bread. Lectio divina is prayerful reading. In essence lectio engages with the text in a meditative, life-transforming way under the guidance of the Holy Spirit.

Benedict's renowned Rule (see Fry 1981) was written as a guide for balanced and positive communal living. Esther de Waal, the renowned Benedictine scholar, writes about how skilfully Benedict drew on contemporary sources:

But this is not just the work of an intellectual, the cerebral achievement of a skilled codifier. It is the work of a man who lived what he has written (De Waal 1984:18).

The very first words of the Rule (1981:15) are "Listen carefully". De Waal (1986:42) writes that the word obsculta has a rich meaning; "it involves a reverent, ready and humble way of listening". Followers of Christ had to listen to and heed the word of God. Benedict knew full well that this was not easy. We are awfully good at speaking to God. We praise, confess, petition, intercede and give thanks. We seldom take time to listen. Conversation in relationships is a two-way affair. It is worth reminding ourselves that the word for 'obedience' is derived from the Latin oboedire that shares its root with audire, to hear. We listen in order to obey. We obey because we love.

Nowhere in the Rule does Benedict set out instructions for lectio. Method and technique were foreign to the monastics of those early days. De Waal (2009:66) recounts how the $12^{\text {th }}$ century Carthusian monk Guido (1140-1193) gave lectio its classical formulation in the following four steps: lection, mediation, oratio, contemplation (reading, meditation, prayer, contemplation). Today this is the commonly accepted formula for lectio divina. Thus lectio means reading scripture, giving each word and phrase equal attention, being receptive and listening carefully, followed by prayer. We ponder the words of the text allowing it to speak to us in the silence. Practice teaches us to trust the silence. Generations of Christians attest to the truth that the practice of lectio enriches and deepens their faith. For centuries Benedict's Rule was commonly used in the Latin church and it deeply shaped monastic and church life in Christendom.

My interest in Benedict was followed by the desire to read more of the old classics in the field of spirituality. Favourites were, among others, German Benedictine Hildegard of Bingen (1098-1179) (see Flanagan 1990); the anonymous English mystic's The Cloud of Unknowing (middle $14^{\text {th }}$ century) (see W. Johnston 1973); the mystic Julian of Norwich's Showings (1342-1416) (see Skinner 1986) and 
The Interior Castle of Carmelite nun Teresa of Avila (1515-1582) (see Williams1991). It was, however, a life-changing encounter with the Spiritual Exercises of Ignatius of Loyola (1491-1556) that is central to these reflections.

Ignatius's life and the creation of the Jesuit Order marks an important phase in the development of Christian spirituality. Born in the Basque district of Spain, Ignatius, then a soldier, was wounded in the defence of Pamplona. During his long and painful convalescence he read books on the lives the saints and was converted. He resolved to go on a pilgrimage to the Holy Land after his recovery and managed to reach Jerusalem in 1523. On his return he studied, was ordained a priest, and eventually founded the Society of Jesus, i.e. the Jesuits.

The Spiritual Exercises (Fleming 1996) is not a book simply to be read. It is rather a working manual that sets out a series of steps (exercises) to follow on a 30 -day silent retreat, accompanied by a spiritual director. The genius of the Exercises lies in its insight into and understanding of the human longing for a deeper relationship with God. Using scripture throughout, the Exercises begins with the affirmation that God loves us. Then we are able to plunge into a hard and bruising encounter with our sinfulness. After acknowledging our sinfulness and accepting forgiveness, we are invited to accompany Jesus all the way to Golgotha and beyond. Jesuits are required to do the Exercises, preferably twice in their lives.

Ignatius's awareness of the movements of the Holy Spirit led him to discern and to distinguish between those that enable consolation and those that cause desolation. These two concepts sound rather archaic, but they are intended to pinpoint inner movements of the Spirit that can then be incorporated into our prayers. We speak to God about experiences of gratitude and joy as well as of dryness and darkness. Ignatius also prized discernment. Kenneth Leech (1980:65) writes: "Discernment is one of the key ideas in spirituality ... Discernment essentially is an extreme sensitivity which comes from close listening to the voice of God". He continues: "Yet knowledge and discernment must be held together by love". Paul prays in the Epistle to the Philippians "that your love may overflow more and more with knowledge (epignosis) and full insight (aesthesis) (Philem. 1:9). Love needs knowledge and discernment (insight).

Participants in the Spiritual Exercises are given the following prayer by Ignatius, an all-encompassing submission to the will of God that becomes the lodestar for the life of faith. 


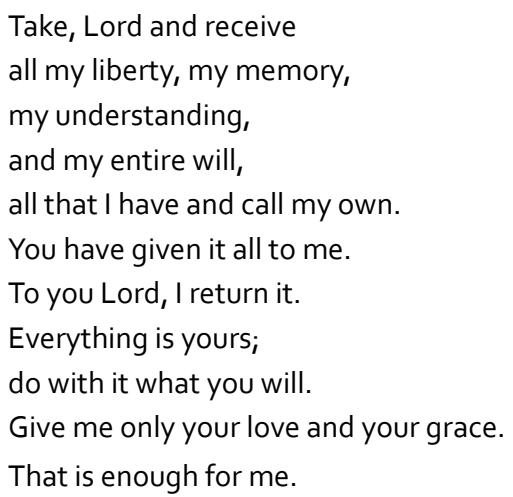

My last marker from works on Christian spirituality is the legacy of Thomas Merton (1915-1968). His writing is accessible, profoundly insightful and deeply related to the challenges of living with faith in our contemporary world. Commenting on his output, Raymond Bailey (1975:12) writes that Merton's “greatest contribution was the particularity of his person and the synthesising and contemporising of ancient and universal truths".

Merton was born in France to a New Zealand artist father and an American Quaker mother. He lived there, in England and eventually settled in the United States of America. Merton studied at Cambridge University and later graduated from Columbia University in New York in English literature. In 1938 he converted to Roman Catholicism and in 1941 he entered the Abbey of Gethsemani in Kentucky where he spent the rest of his life until his untimely death in Bangkok in 1968. Merton's autobiography The Seven Storey Mountain appeared in 1948 to much acclaim. Although he lived a monastic life, Merton was deeply in touch with the world outside the Abbey. He was a prolific writer, publishing some seventy books. His interests were wide-ranging, from social issues such as secularism, totalitarianism, 'ban the bomb' activism and civil rights in the USA to every conceivable topic under the rubric of Christian spirituality (see Furlong 1980).

One of the themes that permeated Merton's writing was love - our potential for love and God's love for humanity. He was deeply concerned that human beings had lost “Dante's vision of that 'love which moves the sun and the other stars', and in so doing he has lost the power to find meaning in his world" (Merton 1960:07). He writes: "Man's greatest dignity, his most essential and peculiar power, the most intimate secret of his humanity is his capacity to love. This power in the depths of man's soul stamps him in the image and likeness of God ... The vocation to be sons of God means that we must learn to love as God Himself loves" (1960:98). Merton's faith in love is vested in the person of Christ: "All true love is a death and a resurrection in Christ” (1960:100). In Merton's thinking, the theme of death is closely related to the willingness to embrace our poverty. This is our inability to 'know', unfettered 
by religious conventions, so that we may begin truly to 'know' anew, uncluttered by dogma, or captured in concerns of self.

In the silence and solitude of his hermitage, Merton wrestled with what it means to live the spiritual life. In the traditions of Christian spirituality, Merton's reflections on prayer, the discipline of silence, the need for solitude, the enigma of 'knowing in unknowing', are uniquely accessible to contemporary readers.

\section{Longing and prayer}

Prayer is central to Christian spirituality. Prayer is both intensely personal as well as communal and liturgical; it can be vocal or silent. The following reflections on prayer will be confined to personal prayer. Our relatedness to God, our longing for God, compels us to speak to the Beloved, to be heard, and in turn to listen. Prayer is our response to God's love. There is a fine line between being prescriptive about how to pray, on the one hand, and drawing on centuries of wisdom to inform our practices of prayer, on the other. I shall attempt to skirt this boundary with care while referring to a variety of views expressed over time.

Augustine (354-430) understood the source of our enigmatic longing for God when he famously said: Noverim te, noverim me (May I know you, may I know myself). God-knowledge and self-knowledge are inseparable. John Calvin $(37,39)$ echoed Augustine when he said: "Our wisdom in so far as it ought to be deemed true, and solid wisdom, consists almost entirely of two parts: the knowledge of God and of ourselves". He continues, "the knowledge of God and the knowledge of ourselves are bound together by a mutual tie”. Prayer is the means by which we seek greater God-knowledge and self-knowledge to assuage our longing.

In a mutual relationship we both speak and listen. Listening prayerfully requires faith that God speaks to us through the Spirit, and the willingness to be quiet and receptive. Listening (see Ackermann 2014:181-196) for the voice of God is not some new-fangled fashion. Throughout scripture God speaks and is heard. When the prophet Elijah (1 Kings 19:1-18) has to flee into the wilderness to escape Jezebel's threats, he is thoroughly miserable and alone. An angel sends him off to a cave on Mount Horeb to wait, "for the Lord is about to pass by" (v.111). He waits but God is not in the great wind, nor in the earthquake or the fire. After the fire there is "a voice of sheer silence" (v.12). Elijah 'hears' this voice, wraps his face in his cloak and goes to the mouth of the cave to receive God's commands for the people of Israel.

In prayerful silence we need to wait with patience and expectancy. In Merton's words: "My life is a listening, His is a speaking" (1956:74). What are we hoping for as we listen? We long for an encounter, a sense of Presence, and that "voice of sheer silence”. Richard Rohr (2009:35) says: “Presence' is my word for this encounter, a different way of knowing and touching the moment". However we describe our silent waiting, such waiting is an act of faith in the Holy Spirit for it is through the Spirit that we are transformed in Christ. 
Paul describes this role of the Spirit in his first letter to the Corinthians $(2: 9-10,12)$. "But, it is written, What no eye has seen, nor ear heard, nor the human heart conceived, what God has prepared for those that love him - those things that God has revealed to us through the Spirit; for the Spirit searches everything, even the depths of God ... Now we have received not the Spirit of the world, but the Spirit that is from God, so that we may understand the gifts bestowed on us by God".

Hearing requires silence. And a listening silence requires solitude, a time away from the din and demands of the day. In traditions of Christian spiritually guided retreats meet the need for solitude and quiet listening. Silent listening prayerfulness leads us to the deepest ground of our identity in God. It is an act of utter poverty - we stand naked before God. In Merton's words: "Let me seek then, the gift of silence, and poverty and solitude, where everything I touch is turned into prayer" (1956:94).

In summary, the wisdom of our traditions teaches us that intention is more important than attention when we pray; that prayer is not performance, but an opening of the heart; that brief but frequent prayer is advocated; that distractions are inevitable when we pray and should be acknowledged and then put aside. Merton (1969:82) says: "Prayer is yearning for the simple presence of God, for a personal understanding of his word, for knowledge of his will, and for the capacity hear and obey him”.

\section{Solitude and solidarity}

In the Judeo-Christian biblical tradition the manifestation of the divine is not primarily found in being solitary but rather in being in solidarity with the human community. There is a danger of spirituality becoming a disease of the infinite or what Pablo Neruda, the Chilean poet, calls a "fetish of the incomprehensible" (Gordon 2000:27). We can become inwardly dazzled by our piety. Jesus called himself the 'son of the human' (ben adam), the One who identifies fully with human beings and shows us the true meaning of relationship. He gives us the commandment to love God with heart, mind and strength and to love our neighbour as ourselves. Spirituality is an inextricable bond between our interiority and our external reality. We are communal not solitary beings who are called to live in love. But love is not only an experience. It is above all a doing. Love is to be enacted. God is not only committed to justice but defined by it. We are called to look away from self toward the other - the first step in the journey to solidarity. The God of love is also a God of justice. Love and justice are inseparable. Any attempt to promote spirituality as a way of avoiding or evading the demands of justice in our societies and the struggle for a more equitable world is to be deplored. To pray is to act, or as Francis of Assisi said: "One knows as much as one does" (from Gordon 2009:20). Gus Gordon (2009:20) continues: "Both solidarity and solitude ... are fundamental and integral movements of the spiritual life". 
Our painful history of racist oppression is a living reminder of what can happen when justice is ignored. Almost every chapter in the Gospels tells of Jesus' concern for the poor and the needy. When the lawyer, seeking to inherit eternal life, asks Jesus: "Who is my neighbour?" (Luke 10:29), the answer is the story of the Good Samaritan. Jesus is in fact asking this man to think about what it means to be human. According to Gordon (2000:113), "If God is not God of the oppressed, then the God of the Gospels is not the God of the Judeo-Christian scriptures". To be a disciple is to be drawn into acts of compassion and care for the oppressed, the poor and the needy. I am deeply indebted to Desmond Tutu. For three years during the turbulent 1980s I worked in close proximity to him at Bishop's Court. He marched, he demonstrated and he spoke out against apartheid, yet every month he took off time for prayer in solitude. He showed all who worked there how solitude and solidarity are at the core of living the Gospel of Christ.

\section{Finally}

The ways in which we experience the enigma of longing will differ, depending on varied contexts, personal histories and faith traditions. There are, however, certain threads that have been constant through time. To begin with, exploring the longing for the Holy One shapes the practice of prayer and increases the desire for silence and solitude. As we practise inner listening, a greater awareness of God at work in the world follows and our ability, in the words of Ignatius "to find God in all things", grows. Central to this awareness is the person of Jesus Christ, in whom the fullness of God is manifest. Following that enigmatic longing requires being rooted in the Word. The Word is the source in which food for prayer and nourishment for our faith is found.

Exploring our longing will not be without pain and times of darkness, for there are no short cuts in the desire to deepen relationship with God. There is mystery at the heart of God that human beings cannot plumb. Yet our longing does not allow us to turn away from mystery. We find that in the darkness of 'unknowing', truth about God is revealed. This is so because God, the Source of all Being, desires to be in relationship with us. Throughout, silence and solitude are inseparable. The cry for justice expressed through loving our neighbour is God's truth that we are summonsed to live by. We cannot, we dare not ignore that enigmatic longing, for it draws us ever deeper into life in Christ. 


\section{Bibliography}

Ackermann, D M. 2014. The Man on the Borrowed Donkey: Ordinary Blessings, Cape Town: Lux Verbi.

Augustine. 1991. Confessions, Trans. H Chadwick, Oxford: Oxford University Press.

Bailey, R. 1975. Thomas Merton on Mysticism, New York: Doubleday.

Buber, M. 1958. I and Thou, Trans G B Smith, New York: Macmillan.

Calvin, J. (n.y.). Institutes of the Christian Religion, Trans H Beveridge, Grand Rapids: William B. Eerdmans.

Cousins, E (ed.). 1985. World Spirituality: An Encyclopaedic History of the Religious Quest, New York: Crossroad.

De Waal, E. 1984. Seeking God: the Way of St. Benedict, Glasgow: Collins.

De Waal, E, 2009. Seeking God: the Baptismal Invitation of the Rule of St. Benedict, Collegeville: Liturgical Press.

Flanagan, S. 1990. Hildegard of Bingen: A Visionary Life, New York: Barnes \& Noble.
Fleming, D L (n.y.). (transl. \& com.). 1996. Draw me into your friendship: a literal transaction and a contemporary reading of the Spiritual Exercises, Saint Louis: The Institute of Jesuit Sources.

Fry, T \& Horner, T (eds.). 1981. The Rule of St. Benedict in English, Collegeville: The Liturgical Press.

Furlong, M. 1980. Merton:

A Biography, Glasgow: Collins.

Gordon, G. 2009. Solitude and Compassion, Maryknoll: Orbis Books.

Hanh, T N. 1976. The Miracle of Mindfulness: A Manual of Meditation, Boston: Beacon Press.

Jalal al-Din, R. 1985. The essential Rumi, Trans. C Barks, New York: HarperCollins.

Jones, C; Wainwright, G \& Yarnold, E (eds.). 1985. An Introduction to Christian Worship, New York: Oxford University.

Johnston, W (ed.). 1975. The Cloud of Unknowing and the Book of Privy Counselling, New York: Doubleday.

Leech, K. 1980. True Prayer: An Introduction to Christian Spirituality, London: Sheldon Press. 
Leech, K. 1992. The Eye of the Storm: Spiritual Resources for the Pursuit of Justice, London: Darton, Longman \& Todd.

McGinn, B. 1991. The Presence of God: A History of Western Christian Mysticism, 4, New York: Crossroad.

Merton, T. 1948. The Seven Storey Mountain, New York: Harcourt, Brace \& Co.

Merton, T. 1956. Thoughts on Solitude, New York: Farrar, Straus \& Giroux.

Merton, T 1960. Disputed Questions, New York: Harcourt Brace \& Co.

Merton, T. 1969. Contemplative Prayer, London: Darton, Longman \& Todd.

Merton, T. 2003. The Inner Experience: Notes on Contemplation, in W H Shannon, London: Society for Promoting Christian Knowledge.

Merton, T. 2005. Contemplative Prayer, London: Darton, Longman \& Todd.
Oxford Annotated Bible. 1991. Oxford: Oxford University Press.

Rahner, K. 1978. Foundations of Christian faith: An Introduction to the Idea of Christianity, Trans. W V Dych, New York: Crossroad.

Rohr, R. 2009. The Naked Now: Learning to See as the Mystics See, New York: Crossroad.

Schneiders, S. 1990. Spirituality in the Academy, in B C Hanson (ed.), Modern Christian Spirituality, Atlanta: Scholars Press.

Skinner, J (ed. \& Transl). 1985. Revelations of Love, New York: Doubleday.

Tutu, D M. 1999. The Essential Desmond Tutu, Compiled by J Allen, Cape Town: David Philip.

Ward, H \& Wild, J (eds.). 2006. The Monastic Way, Grand Rapids: William B. Eerdmans.

Williams, R. 1991. Teresa of Avila, London: Geoffrey Chapman.

Williams, R. 2005. When God Happens: Discovering God in One Another, Boston: New Seeds. 


\title{
Chapter 15
}

\section{On Leadership in Vulnerability}

\author{
Honouring Elna Mouton
}

Nico Koopman

The leadership of Elna Mouton is an example of vulnerable leadership, leadership in vulnerability, leadership that does not flee from vulnerability, leadership that does not view acknowledgement of vulnerability as something to be ashamed of, leadership that knows that where vulnerability is acknowledged, accepted and affirmed, the way is paved for leadership that serves with humble assertiveness and leadership that seeks justice for all.

This essay in her honour is structured as follows. In a first round some remarks are made about vulnerability. Vulnerability in terms of a Trinitarian anthropology of vulnerability is then discussed. In the two last sections of the essay humble assertiveness and the quest for justice for especially the most vulnerable are portrayed as two features of leadership in vulnerability.

This essay draws upon and freshly applies various earlier works of mine on the theme of vulnerability. ${ }^{1}$ In this essay vulnerability is specifically applied to leadership in various spheres of life.

\section{On vulnerability}

The notion of vulnerability is used in a variety of ways. Vulnerability firstly means that we are at risk and under the threat to suffer. We are predisposed towards various forms of suffering. We are frail and fragile and can easily be wronged and hurt. Theologian Thomas Reynolds (2008:108) refers to the root meaning of vulnerability

1 See, amongst others, Koopman (2003, 2008, 2009, 2013). 
to illustrate this point. Vulnerability derives from the Latin word vulnerare, to injure and harm, and to be open to be wounded - in my words, to be under the threat of, and to be susceptible to be, hurt and wounded. Secondly, vulnerability refers to our actual and concrete suffering in a variety of forms.

Vulnerable beings are always at risk and under the threat that our basic needs for dignified living might not be met. Three types of needs need to be addressed in order to avoid severe suffering and to experience a life of dignity.

Psychologist Abraham Maslow (1954), in line with Dutch social scientist Rob Buitenweg (2001:94-95), identifies three sets of basic human needs to be addressed in order for humans to flourish. The first set of needs pertains to our physical needs, namely the need for goods like housing, food, water, clothing, medical care and education. Our vulnerability with regard to the fulfilment of these needs might be called physical vulnerability.

The second set of needs refers to our need for safety and security, and also the need to participate in different spheres of life, including the political and economic domains. Living in communion with others and not being alienated and excluded is a central aspect of the fulfilment of this second set of needs. The susceptibility to the non-fulfilment of these needs might be phrased as social vulnerability

The third set of needs refers to our quest for the freedom to actualise our potentialities and to render meaningful service to others. The fragility that we experience with regard to the fulfilment of these needs can be termed teleological vulnerability, since it has to do with the meaning-giving telos, purpose and aim of our lives.

Where these sets of needs are not met, we experience suffering in a variety of forms. Famous Dutch theologian Bram van de Beek (1984:24-26) discusses the various facets of human suffering, i.e. physical, psychological, social, political and economic. Suffering takes on the form of homelessness, hunger and famine, dehydration, nakedness, illness, death, assault, violence, alienation, exclusion, political oppression, poverty. Suffering is intensified by the powerlessness to overcome forms of suffering such as severe poverty, illness and death. Van de Beek states that all forms of suffering, also the suffering of animals and plants, constitute a violation of wholeness and shalom.

Our vulnerability comes to expression in multiple ways. The various generic and specific disabilities with which human beings live may be one concrete expression of our vulnerability. Indeed, Alisdair MacIntyre (1999:1) explains that all humans face forms of disability and dependency throughout our lifespan.

This dependence on particular others for protection and sustenance is most obvious in early childhood and in old age. But between these first and last stages our lives are characteristically marked by longer or shorter periods of injury, illness or other disablement and some among us are disabled for their entire lives. 
MacIntyre (1999:1-3) is convinced that Western societies, and I would add African and other societies of the world, attend inadequately ${ }^{2}$ to the depth of the challenge of vulnerability, dependency and disability.

Dependence on others is, of course, often recognised in a general way, usually as something that we need in order to achieve our positive goals. But an acknowledgement of anything like the full extent of that dependence and of the ways it stems from our vulnerability and our afflictions is generally absent.

This illuminating description of the general vulnerability and general disability, and consequent dependency, of all human beings does not relativise or minimise the variety of specific vulnerabilities and specific disabilities, and the consequent distinctive challenges, that human beings with specific disabilities have to live with.

\section{On a vulnerable God}

Faith in the triune God is faith in the vulnerable God. Jaap Durand (1976:94-98) argues that the vulnerability of the triune God comes to clearest expression in the life of service, humility and self-sacrifice, and in the eventual death and resurrection of Jesus Christ. He appeals to Karl Barth, who states that in the death and suffering of Jesus Christ we see the Parental sympathy of the triune God, and to Jürgen Moltmann's emphasis of the pain of God when we have pain, and to GC Berkouwer's reference to God's compassion. In the suffering of Jesus, God identifies with suffering humans. He shows concern, sympathy and compassion for us. In the suffering of Jesus, the compassionate heart of God, which is described in passages such as Isaiah 63:9, Jeremiah 31:20, Hosea 11 and Hebrews 2:16, is seen in its clearest form. The suffering of Jesus Christ also reflects the vulnerability of the Spirit Who can be hurt, as is testified in passages such as Isaiah 63:10 and Ephesians 4:30. Dutch theologian Hans Reinders (1996:30-31, 60-61) also emphasises the focus on interdependence within the trinity. Reinders pleads for a revaluation of the trinitarian views of the three Byzantine church fathers of the $3^{\text {rd }}$ century CE, the Cappadocians, namely Gregory of Nyssa, Basil of Caesarea and Gregory of Nazianzus. Where the Western church fathers such as Augustine focused on the being and unity of the triune God, these Eastern theologians concentrated on the diversity and relationships of the three persons. In the last few decades a new appreciation for last-mentioned approach to trinitarian thinking and the formulation of the doctrine of the social trinity developed. Reinders appreciates the views of John Zizioulas on the interdependence of Father, Son and Spirit. Zizioulas argues that God is not caused by a divine substance but by Himself, specifically by the Father. There is not

MacIntyre's post-liberal anthropology of dependent living constitutes a criticism of liberal anthropologies that are dominated by the idea of rationality, autonomy and independence. His work is increasingly attended to in modern-postmodern societies. It is to be appreciated that increasing attention is given to the notion of vulnerability and dependence in contemporary anthropological discourses; see amongst others Eva Kittay (2009) and Judith Butler (2006). 
a divine substance which makes God God. His Name Yahweh, I am what I am, bears witness to this fact. Zizioulas, according to Reinders (1996:33), also reasons that God has an ecstatic character. Ecstasis means that God's being is determined by his radical search for communion with the other. In fact, God is communion. In Jesus Christ, who became human, we are part of this communion. In this communion God finds his true being. This choice of ecstasis, for communion with his creatures, expresses the vulnerability of God.

The vulnerability of God is manifested in the relations of interdependence between Father, Son and Spirit; it reaches its culmination point in the cross of Jesus Christ, and it comes to expression in the compassion, sympathy, concern and solidarity of the triune God with a suffering world. From this vulnerable God, whose essence is that of vulnerability in Christ, and whose mission to the world culminates in the vulnerability of the cross, the church receives its essence and mission.

\section{On vulnerable humans}

Vulnerability is part of the essence of being human. We can indeed speak of an anthropology of vulnerability. Hans Reinders and the American theologian Stanley Hauerwas write with remarkable insight about the vulnerability of humans.

Reinders, whose research focuses on mentally disabled people, states that an adequate ethical response to disabled people can only be arrived at if the dependence of human beings is not viewed negatively. This requires a break with the dominant modern anthropology of rationality, autonomy and independence. With an appeal to the ethicist, Joan Tronto, he argues that the one fundamental feature of human beings should not be independence, but care. Care is the result of the acknowledgement that we can never be fully autonomous, that we need each other, that we exist in a condition of interdependence (Reinders 1996:16-17). According to Reinders the idea of human freedom as rational autonomy and independence is an aporia, since human beings are not able to subject all conditions of their existence to their reason. These conditions include the contingent and finite nature of our existence, as well as the external limitation of our freedom in relation to others and the internal limitation of our freedom, which is caused by our lack of self-knowledge $(1996: 32,61)$.

Hauerwas $(1986: 13-14,19)$ shares this plea for the redefinition of human beings in terms of interdependence and care. He is of opinion that the freedom and autonomy, which enable us to decide for ourselves on questions such as when to terminate a pregnancy, prevent us from negotiating the limits (i.e. dependence) and possibilities of this existence in a just and caring fashion. The freedom to merely choose for or against contraception prevents us from discussing the question about why we ought to be open to having and caring for children at all. 
Reinders (1996:37) agrees with Kant that we cannot derive specific moral rules from the trinity. He, however, reckons that the trinity does offer a normative framework for understanding our identity and purpose as human beings. This self-understanding helps us to understand who the disabled person is and this knowledge of who we are and who the disabled are determines the way we fulfil our ethical responsibility with regard to disabled people.

Reinders (1996:34-35, 43) argues that true humanity is not defined by independence and rationality, but by the willingness to enter into relationships with others. In this relationship with the other you do not discover a replica of yourself, as Aristotle taught. In the interaction with the other, in the communion, in the relationship, I find my essence and being. I receive my being from the other. We receive our existence out of the hands of the other and my existence is meaningful because there are others who want to share their existence with me. Reinders (1996:17, 42-43) reckons that we need hermeneutical skills to appropriately understand the other, especially people with disabilities, who are viewed as inferior in terms of the modernistic paradigm. These skills enable us to view the other as someone who helps to constitute my essence as person. It resists denying the uniqueness of the other and it resists the modernistic temptation to see our task with regard to the disabled as one of determining and developing their potential for rational and independent living, as the pedagogic approach to the disabled strove to do in the past.

Reinders (1996:38-39) continues that to receive my being, my personhood from the other implies that I am dependent and vulnerable. Those who live so ecstatically can merely trust that this ecstatic living does not imply the loss of myself but the true finding of myself. Hauerwas's (1986:13; 1987:592) view of God as the God of sacrifice, of weakness and suffering who draws people to Him not by coercive power, but by sacrificial love, comes to mind. This genuine weakness lures us from our pretentious attempt to make our lives meaningful through power and violence. This weakness also entails that we do acknowledge that our attempt to eliminate the suffering of sick and disabled people - instead of being present to them, being available for them and personally caring for them - is merely a demonstration of our quest to affirm our own significance through power.

\section{On vulnerability and leadership of humble assertiveness}

This section of this essay argues that where there is a constructive response to vulnerability, anxiety and arrogance are overcome; there life and leadership are exercised in humble assertiveness that flows from the strength of realistic and resilient hope.

The very influential Stellenbosch University theologian, Reinhold Niebuhr (1949:163-213), argued decades ago that individual human beings, and even groups and nations, respond to our vulnerability with anxiety. We struggle to accept our vulnerabilities 
and to live constructively with them. He even argues that we hide our anxieties in various forms of arrogance and pride, namely the pride of power, intellect, morality and religiosity. This pride is often the cause of personal and public expressions of aggression and violence.

Another famous American theologian, Paul Tillich (1961:37-51), identified three forms of anxiety that we as vulnerable human beings live with. His typology exercises great influence to this day, and in fact receives renewed attention in modern-postmodern societies with high levels of anxiety. These anxieties are the anxiety of fate and death, emptiness and meaninglessness, guilt and condemnation. We are sinners and we have the status of being guilty, and we therefore face the risk of condemnation and rejection. We are finite beings who are exposed to the threat of fate, tragedy, contingency and death. The most severe form of anxiety is the anxiety of emptiness and meaninglessness.

Tillich (1961:53-59) argues that we simultaneously experience all these anxieties which are inter-related. Sometimes one of them is prominent but the others are also present. These types of anxiety manifest in the personal biographies of individuals, but also in the historical periods of broader societies and civilisations. Up until the Middle Ages fate and death were the prominent sources of anxiety. During the late Middle Ages and Reformation period guilt and condemnation had to be addressed, and in the modern period since the Enlightenment the anxiety of meaninglessness and purposelessness has to be dealt with.

Anxieties experienced by people as vulnerable beings people might lead to despair, which can only be overcome by courage and fortitude that flow from hope.

German theologian Gerhard Sauter (2000:211-216) describes hope as realistic hope. He develops a so-called realistic eschatology. Sauter (2000:211) bases hope in the promises and actions of the triune God. Hope means trust in the good that God has promised and provided. Hope is rooted in God's promises and through it in the confidence in God's providence (Sauter 2000:211). Hope, according to Sauter (2000:212), is not only based in the historical act of the resurrection of Christ, but more so in the communion with the resurrected Christ who is present through his Spirit. This communion with the resurrected Christ who, as One seated at the right hand of the Father, enjoys inner-Trinitarian communion, is the basis of our hope. This inner-Trinitarian communion between Father, Son and Spirit is why Christ is present with us, why we enjoy communion with Him, and why we have reason to hope. Sauter (2000:214) also writes about God's act of hoping. God namely waits patiently and tirelessly that we put confidence in his promises and acting, that we leave room for his redeeming activity. On this hope of God for us, our hope rests! ${ }^{3}$ Sauter bases our hope in the communion with the resurrected, ascended and reigning Christ.

3 For a more extensive account of Sauter's views on eschatology and the Trinitarian roots of hope, see Sauter (1999). 
Realistic hope also rests in and grows from the reality of our communion with the living Christ, who is also the crucified Lord. In the cross of Christ, we see God's ultimate identification and solidarity with vulnerable and suffering people, with people having to live with disabilities. In the cross of Jesus Christ God reveals Himself as the God of compassion, the vulnerable God, even the disabled God.

Realistic hope does not call us to a withdrawal from the world with all its challenges. Realistic hope sees the reality of this world, but also imagines and envisages new possibilities. Famous Brazilian theologian Rubem Alves (1972:194) also describes hope as realistic hope.

What is hope? It is the presentiment that imagination is more real and reality less real than it looks. It is the hunch that the overwhelming brutality of facts that oppress and repress is not the last word. It is the suspicion that Reality is much more complex than realism wants us to believe; that the frontiers of the possible are not determined by the limits of the actual, and that in a miraculous and unexpected way life is preparing the creative event which will open the way to freedom and resurrection.

Decades ago German theologian Eberhard Jüngel (1969:417-442) argued that hope enables us to imagine what is possible in the midst of the old broken reality. Realistic hope enables us to consistently distinguish between current reality and envisaged possibility. Applied to the theme of this chapter, we can argue that realistic hope enables us to acknowledge the struggles and suffering of vulnerable people, especially people with disabilities, as well as the prejudices, wrongs and injustices against them. Simultaneously realistic hope enables us to imagine, envision and work for the actualisation of new possibilities where all people, especially people with vulnerabilities and disabilities, experience justice, peace and joy.

One also needs to emphasise that realistic hopes resides in the reality of the presence of the resurrected Lord who is also the crucified Lord. Exactly the central Christian conviction that Jesus Christ had experienced specific vulnerability, suffering and even the ultimate specific disability of god-forsakenness, communicates the hopeful reality of heavenly solidarity with people with disabilities.

This realistic hope is also resilient hope that enables us to live with patience amidst vulnerability, fragility and disability; with courage amidst suffering; with fortitude amidst injustice and dehumanisation.

Paul Tillich's (1961) notion of courage and fortitude might be viewed as a manifestation of resilient hope. He pleads for a courage that is both ethical and ontological. Courage as a human act, as a matter of valuation, is an ethical concept. Courage as the universal and essential self-affirmation of one's being is an ontological concept. The courage to be is the ethical act in which man (sic) affirms his own being in spite of those elements of his existence which conflict with his essential self-affirmation. The courage that 
is an expression of resilient hope is the courage to be, the courage to act morally and to accept your being amidst many threats to that being. This courage to be is manifested in the realisation that I am part of a whole, that I can also be alone, and that I receive my courage from a transcendent being, in the case of Christianity from the triune God. And where I live with this courage to be, I overcome despair which is especially the outcome of the anxiety of meaninglessness and purposelessness.

Stanley Hauerwas and his colleague Charles Pinches (1997:175-176) argue that the virtue of patience is the most neglected and most needed virtue in contemporary societies. They reckon patience is the most neglected virtue in modern societies where the levels of addiction to hyperactivity are very high. Where people are aware of the presence and involvement of God in the world, they oppose the impatience of Eve and Adam which made them break God's commandment, and the impatience of Cain which made him become the killer instead of the shepherd of his brother, and the impatience which makes us desert our suffering brothers and sisters, because we impatiently reckon that if we cannot immediately cure, we can also not patiently care.

American theologian Joel Shuman (1999:130-150) identifies various virtues of care. The virtues of dependency and constancy are virtues of the receivers of care. Hospitality and presence are the virtues of caregivers. According to Shuman (1997:131-134) dependence is to let one be cared for by the members of the body of Christ. He uses the phrase 'letting the body be the body' to express the fact that this care is not contractual, but that the body, according to 1 Corinthians 12 , is constituted in such a way that its members live in relationships of dependence and interdependence. The essential nature of the body of Christ implies that its members give care and receive care.

Constancy, according to Shuman (1997:134-135), is the virtue which means that Christians live, in the face of illness, suffering and death, in congruence (consistent) with the good life that we led before. It is the skill which enables suffering and dying people to look back on their lives and to be able to make sense of it, to be able to say it was worth it and we would not have it otherwise. In the exposure to these virtuous people, others acquire these skills as well.

The virtues of the caregivers, which are the more active corollaries of the two patient virtues discussed above, are, according to Shuman (1997:143), hospitality and presence:

Hospitality and presence are in fact not readily separable. Formally, at least, it can be said that hospitality is the name given to the virtue that enables us to welcome others into our lives, whereas presence is an expression of our willingness to enter into and share the lives of others. In this sense these virtues represent our willingness to share our bodies and our sustenance with one another. 
Although these virtues have a long history in the church, in modern times with their emphasis on efficiency, these virtues - which take time and are, in terms of modern managerial science, ineffective, according to Shuman (1997:152-153) - have to be acquired through training. They are after all no longer integral parts of our lives. In acquiring these virtues, we must be aware of the challenge to resist what Shuman (1997:145) calls the gods of the modern world, namely efficiency, hard work, success and the accumulation of private property, private wealth, private space and private time. Hospitality for Christians implies sacrifice. It means taking time and sharing space.

Shuman's thoughts offer liberating perspectives for the nurturing of resilient hope. Resilient hope, with its building-blocks of patience and perseverance, fortitude and courage, dependency and constancy, hospitality and presence, enables us to care even though we cannot always cure. It enables us to survive in the most despairing situations. And this resilience paves the way for caring, penultimate forms of curing as expressed in our quest for dignity, justice and freedom, whilst we realistically, actively and courageously wait upon the dawn of the reign of perfect caring and curing - for people living with vulnerability in general (that is, all people), as well as for people with specific vulnerabilities and disabilities. Resilient hope paves the way for a humble assertiveness, a strange strength, fortitude and patience amidst vulnerability.

\section{On vulnerability and leadership in search of justice}

This section of the essay argues that vulnerability paves the way for advancing the quest for justice. A vulnerability perspective ensures that the quest for justice for the most vulnerable is prioritised; and where justice for the most vulnerable is prioritised, justice for all is served.

The theme of God's special identification with vulnerable and suffering people runs like a golden thread through Scripture. This theme is not referred to coincidentally. It cannot be ignored. Neither can it be countered with other evidence from Scripture. Vast biblical evidence shows that this theme has to do with the heart of the Christian faith.

This confession of God's special identification with the marginalised, the poor, the destitute and the wronged received attention in specifically the Reformed tradition. The South African Reformed theologian, John de Gruchy (1991:74-76), explains how this notion was prominent at the birth of the Reformed tradition. De Gruchy shows that this was the case because many of the earliest Reformed theologians and pastors, as well as congregations, were persecuted, and that the heart of Reformed theology was conceived in exile, in poverty, amidst adversity and in the struggle against social and ecclesiastical tyranny. According to De Gruchy, this theologising from the perspective of the destitute faded, as Reformed Christians became part of 
the so-called middle and upper classes, where the dominant political power also resided. It regained prominence in Reformed theology as a result of the challenge posed by Liberation and Black Theology concerning God's preferential option for the poor. De Gruchy is of the opinion that Liberation and Black Theology's real challenge to Reformed theology, however, was to rediscover and to revalue the notion of the preferential option, which was so central at the birth of Reformed theology. This prophetic challenge was namely to express its commitment to the public square from the perspective and in the interest of the victims of oppressive power.

De Gruchy (1991:133-134) explains, with an appeal to liberation theologian, Gustavo Gutierrez, that the notion of the preferential option for the poor and marginalised should not be interpreted in an exclusive way, as if God chooses against some. This option for the poor indicates how God works in the world, namely from the particular to the universal. The option for the poor, therefore, also does not imply that even the poor are ends in themselves. In the redemption and liberation of the poor and wronged, God is working towards the liberation of all, including those we name as oppressors. Gutierrez (1974:25-26) confirms this preference of the most vulnerable. He argues that they enjoy primary attention from God, but not exclusive attention. Gutiérrez states that the destitute, poor and wronged, i.e. all people who experience misery, ${ }^{4}$ do have first, but not exclusive, right to our solidarity. He pleads that we simultaneously confess the universality of God's love and his special identification with the suffering in specific situations. If we fail to do this, we do grave injustice to the Christian message.

Where this solidarity with the most vulnerability exists, there the quest for justice prioritises these needs; and where the needs of the most vulnerable are prioritised and addressed, the common good of all is served to a higher extent.

\section{Conclusion}

We are privileged to have journeyed with a cherished colleague who embodies leadership in vulnerability, leadership as vulnerable being, leadership in dependence upon the vulnerable God, leadership in interdependence upon other vulnerable humans, leadership in humble assertiveness that grows from realistic and resilient hope, leadership in search of justice for the most vulnerable, and therefore for all.

$4 \quad$ Gutiérrez (1974:248-249) warns that the understanding that poverty does not only have a material connotation, but also a spiritual one, should not be abused to change exceptions into rules. He refers to exceptions like poor people who strive anxiously for wealth, and rich people who are not attached to their wealth. Where such exceptions become the rule, a relaxed attitude and a protection of the status quo of injustice is fostered in line with the function of rules. This abuse is a play with words and with people. South African theologian, David Bosch (1991:99), also pleads that the secondary use of poverty to refer to all forms of misery not be abused to neglect the primary meaning of poverty as concrete and visible material poverty. 


\section{Bibliography}

Alves, R. 1972. Tomorrow's Child. Imagination, Creativity, and the Rebirth of Culture, New York, Evanston, San Francisco, London: Harper \& Row Publishers.

Bosch, D. 1991. Transforming Mission: Paradigm Shifts in Theology of Mission, Maryknoll, New York: Orbis Books.

Buitenweg, R. 2001. Recht op een menswaardig bestaan. Een humanistieke reflectie op social-economische mensenrechten, Utrecht: Uitgeverij de Graaff.

Butler, J. 2006. Precarious Life: The Powers of Mourning and Violence, New York: Verso.

De Gruchy, J. 1991. Liberating Reformed Theology: A South African Contribution to an Ecumenical Debate, Grand Rapids: William B. Eerdmans.

Durand, J. 1976. Die Lewende God, Pretoria: NGK Uitgewers.

Gutiérrez, G. 1974. Theologie van de Bevrijding, Baarn: Ten Have.

Hauerwas, S \& Pinches, C. 1997.

Christians among the Virtues. Theological Conversations with Ancient and Modern Ethics, Notre Dame: University of Notre Dame Press.
Jüngel, E. 1968. Die Welt als

Möglichkeit und Wirklichkeit, in Evangelische Theologie, 29: 417-424.

Kittay, E. 2009. The personal is philosophical is political: a philosopher and a mother of a cognitively disabled person sends notes from the battlefield, Metaphilosophy, 40: 606-607. https://doi.org/10.1111/j.14679973.2009.01600.x

Koopman, N. 2003. The dis(otherly) abled and public morality, Scriptura: International Journal of Bible, Religion and Theology in Southern Africa, 1:72-81.

Koopman, N. 2008. Vulnerable Church in a Vulnerable World? Towards an Ecclesiology of Vulnerability, Journal of Reformed Theology, 2(3):240-254.

Koopman, N. 2009. Endgültige Heilung? Vorläufige Heilung? Fürsorge? Christliche Hoffnung und Krankheit, in G Thomas \& I Karle (eds.), Krankheitsdeutung in der postsäkularen Gesellschaft. Theologische Ansätze im interdisziplinären Gespräch, Stuttgart: Verlag W. Kohlhammer, 393-407.

Koopman, N. 2013. Hope, vulnerability and disability? A theological perspective, in J Claassens \& L Swartz (eds.), Searching for Dignity: Conversations on Human Dignity, Theology and Disability, Stellenbosch: AFRICAN SUN MeDIA, 43-54. 
MacIntyre, A. 1999. Dependent Rational Animals. Why Human Beings Need the Virtues, London: Duckworth.

Maslow, A. 1954. Motivation and Personality. First Edition, New York: Harper \& Row.

Niebuhr, R. 1949. The Nature and Destiny of Man. A Christian Interpretation, 2, New York: Scribner.

Reinders, J. 1996. Wat niets kan worden, stelt niets voor. Mensen met een ernstige verstandelijke handicap in het licht van de hedendaagse gezondheidsethiek, Amsterdam: Vrije Universiteit.

Reynolds, T E. 2008. Vulnerable Communion. A Theology of Disability and Hospitality, Grand Rapids: Brazos Press.
Sauter, G. 1999. What Dare We Hope? Reconsidering Eschatology, Harrisburg: Trinity Pres International.

Sauter, G. 2000. Our reasons for hope, in J Polkinghorne \& M Welker (eds.), The End of the World and the Ends of God. Science and Theology on Eschatology, Harrisburg: Trinity Press International.

Shuman, J. 1999. The Body of Compassion. Ethics, Medicine and the Church, Boulder, Colorado: Westview Press.

Tillich, P. 1952. The Courage To Be, Repr. 1961, Digswell Place: James Nisbet and Company Limited.

Van de Beek, A. 1984. Waarom? Over lijden, schuld en God, Baarn: Nijkerk: Uitgeverij G.F. Callenbach BV. 


\title{
Chapter 16
}

\section{Funerary Customs in First-century Mediterranean Culture}

\author{
Highlighting the role of women
}

Birgit Taylor

\section{Introduction}

According to Jewish tradition, two of the most important commandments regarding human relations are to honour the dead and to comfort the mourner (Num. 23:10; cf. Tobit 1) (Levine 2015). Hence it is to be expected that the culture would have evolved definite customs regarding the disposal of the bodies of the deceased, which would have involved prescribed roles for members of the family and the wider community in order to ensure that the dead were properly honoured. These roles, and the funerary rites in general, would in all likelihood reflect the culture of the society as well as the status of the deceased. An assessment of the canonical passion and empty tomb narratives ${ }^{1}$ suggests that women played a key role within the socio-cultural context of the $1^{\text {st }}$ century Mediterranean society. While an investigation of the role of women in the funerary rites that honour the dead and comfort the bereaved in Ancient Judaism provides a basis for a comparison between the portrayed behaviour by the women in the gospels and socially expected funerary behaviour, this chapter will concentrate primarily on the role of women in the funerary rites.

For the purposes of this chapter, the investigation into the funerary rites of $1^{\text {st }}$ century Mediterranean society will focus on Ancient Judaism. First, a brief backdrop will be provided in a discussion of the development of Early Christianity in relation to Judaism. At the time of the construction of the canonical gospels, Christianity had manifested

The assessment can be found in the author's MA dissertation submitted at the University of Cape Town in 2004, see http://open.uct.ac.za/handle/11427/6737. 
itself as a distinctive movement within Judaism (cf. Chilton \& Neusner 1995; Dunn 1991). Although the extent to which the evangelists and their communities remained integrated within Judaism is debatable, it is apparent that tensions that would lead to the separation of Christianity from Judaism were manifested from an early date (cf. Dunn 1991) (also see 3 John 1:9). Even before the appearance of Christianity, Judaism included a variety of different strands and opposing factions with competing interests (cf. Sanders 1992). By the end of the $1^{\text {st }}$ century CE most urban Christian communities established in areas outside Palestine had become socially independent of Judaism (Meeks 1983). The process of Christianity's separation from Judaism continued at different times and at different rates, manifested in various forms and locations. By the end of the $2^{\text {nd }}$ century CE very little clear evidence of common identity between Gentile Christianity and Judaism, or even between Christian and other Jewish groups, was noticeable (see Paul's admonishing in Gal. 1:6-7). Although a dynamic process in which Christianity in its different forms emerged from Judaism prevailed in the first two centuries CE, the social conduct of $1^{\text {st }}$ century Mediterranean society depended greatly on Jewish customs at that time. ${ }^{2}$ Since the early traditions portrayed in the canonical gospels emerged and circulated in the middle of the $1^{\text {st }}$ century CE, they have been extensively impacted on by Ancient Jewish conventions. In order to investigate the mourning rituals performed at the time, culturally assigned roles and expectations regarding burial of the dead will be explored (cf. McCane 2003:29). To that end, this chapter will cover issues such as the preparation and honourable disposal of the body, providing comfort to the bereaved, and preserving the respectable memory of the deceased.

Mediterranean Jewish funerary customs are critically examined in two works, one by McCane (2003) and the other by Crossan and Reed (2001). Both observe the increasing usage of the ossuary for secondary burials, during which the remaining bones of a deceased are inserted into a box. This tendency was in all likelihood influenced by Hellenism, and appears to have increased chiefly among the upper classes of the society, as archaeological evidence points out in the activities of the more affluent section of society. Considering its economic nature, the poorer segment of $1^{\text {st }}$ century Mediterranean society would inevitably have left fewer archaeological records. Although it appears that the traditional customs would have prevailed among the less affluent, the archaeological records to not provide sufficient evidence for this claim. Nevertheless, archaeological evidence has been useful in the understanding of New Testament references of certain burial practices and graves, for example, the brief burial of Lazarus (see John 11) ties in with extant archaeological evidence. ${ }^{3}$

2 The Talmud consists of the Mishnah and Gemara. The Mishnah was compiled around 200 CE and contains the oral law and various commentaries on the Torah. It was imperative to have a written collection after the destruction of the Temple in 70 CE and the following diaspora. The Mishnah consists of legal opinions and debates. The Gemara was written around $500 \mathrm{CE}$ and consists of further commentaries and discussions, chiefly on the Mishnah, in an effort to elucidate the information provided in the Mishnah and therefore the understanding of the Torah.

3 See http://www.bibleodyssey.org/people/related-articles/burial-practices-in-first-century-palestine.aspx (Retrieved 12 May 2017). 
Even though not a great deal of information on the subject of the tradition of Jewish female mourners is available, a sufficient number of sources are accessible to provide an impression of how the Jewish women responded to death and what their mourning practices were. The following comprise the primary sources of information: the Hebrew Bible, intertestamental Jewish writings, the New Testament and other early Christian writings. The rabbinic writings, although recorded a few centuries later, have codified earlier traditions of some historical value, which can be used with care (cf. Kee 1973:54-55). In addition to these sources, early historians such as the Roman historian Tacitus and the Church historian Eusebius provide useful comparative material.

\section{Funerary rites in $1^{\text {st }}$ century Judaism}

The funerary customs in Ancient Judaism sought to provide a ritual that disengaged the deceased from the society of the living in an honourable fashion, and established his or her position in the community of the deceased (McCane 2003:13). A direct consequence of the death and mourning process is the transformation in the social networks of the family and friends, which is facilitated by traditions and customs that give meaning to death and provide comfort to the living. A number of these will be introduced briefly below.

The hot climate of the $1^{\text {st }}$ century Mediterranean surroundings required that, if all possible, the deceased should be buried on the day of death. Hence burial customs were predictably influenced by environmental considerations (cf. John 11:38-44; Acts 5:6,10, 8:2; mSanh. 6:5; bSanh. 47a) (McCane 2003:94; Rabinowicz 1964: 22). Jewish tradition forbade cremation or embalming, since the Hebrew Bible contains passages stipulating that the body should not to be altered in any way (Gen. 3:19; Deut. 21:23; Yoreh De'ah 348:1) (Levine 2015:81; Rabinowicz 1964:25). Occasionally law-breakers and enemies were cremated as a symbol of dishonour, but in general the body of a deceased Israelite was treated with a great deal of respect, while simultaneously being considered as a source of ritual contamination (Num. 19:11). Regarding the burial sites, bodies were regularly deposited into natural caves (cf. Gen. 25:9), as well as caves that had been cut into rock faces (John 11:38) (cf. Gonen 1992).

According to Jewish tradition, the body of the deceased was purified by washing, dressing and anointing procedures (Levine 2015:81). After washing the body, it was wrapped in plain white linen (Rabinowicz 1964:39-40; Hyman 1941:319; cf. Levine 2015:81). The head had a separate wrapping. The washing of the corpse as well as dressing the body in white linen symbolised a process of purification ( $m$ Shab. 23:5; Heilman 2001:50-51). The forehead was also anointed with a mixture of vinegar and egg white in order to signify the Jewish status of the body, although this was not necessary if the funeral did not take place within Israel (Heilman 2001: 58). In general, the preparation of the body was overseen and conducted by women, 
specifically those who could no longer bear children and were seen as sexless, while on the whole the washing and clothing of the body was done by the same sex as that of the body to respect the privacy of the deceased (cf. McCane 2003:32; Heilman 2001: 30-31, 34). The funeral shrouds were also prepared by women (Hyman 1941:318; Levine 2015:81).

As for activities linked to the funeral procession and burial, a starting point to note is that the already mentioned impure status of a corpse lead to the tradition stating that it was forbidden to handle a corpse on the Sabbath or to mourn publicly on the Sabbath or any other feast day (High Sabbath) (bSanh. 46b; Yoreh De'ah 400:1; Hyman 1941:315, 317, Rabinowicz 1964:42). The body of the deceased was not left alone right up to the point of burial (Heilman 2001:43, 79; Rabinowicz 1964: 21). Usually family members took it upon themselves to watch the body in turn (Levine 2015:92). While family and friends and other adults in the area joined the funeral procession (Luke 7:12; Heilman 2001:73; Hyman 1941:316; Levine 2015: 84), women usually formed the head of these processions (cf. Edersheim 1876: 170). Lamenting and wailing of the bereaved formed a significant aspect of funeral processions (mB.Bat. 6:7). Frequently, women were hired as professional mourners to wail and grieve (cf. Mark 5:38). During the physical burial procedure, the body of the deceased was laid onto its resting place, for example a shelf inside a cave, without any worldly goods except the linen wrapping around the body and the head wrapping. After the burial, family and friends often visited the burial sites to mourn, especially on the anniversary of the death (Yahrtzeit, see Levine 2015:89).

Evidently the death and mourning rituals in Ancient Judaism involved a number of different activities that had to be performed in a particular way and in a specific sequence. Nevertheless, the apparent androcentric and patriarchal nature of $1^{\text {st }}$ century Mediterranean society (Schüssler Fiorenza 1983) downplays the importance of women with regard to funerary practices. An example of this patriarchal nature is seen in the cases of ossuaries, which had regularly been labelled with the name of the husband only, although the bones of both the husband and the wife had been placed in the ossuary (McCane 2003:53).

\section{Funerary customs pertaining to women in Ancient Judaism}

\section{Preparation of the body}

After being convinced that death has occurred, the eyes of the deceased were closed, if they were not already closed. After that a designated group of women washed the body of the deceased as a purification ritual, although occasionally washed male corpses, as mentioned earlier men (McCane 2003:32; cf. Levine 2015:81). Wrapping the body completed this ritual of purification. The Jewish funerary customs advise wrapping the body of the deceased in a plain shroud or linen (Gospel of Peter 6:24; Adam and Eve 9:5, 12:14; mShab. 23:4), where the colour of these garments is mostly 
described as white (Yoreh De'ah 352:2). For example, John 11:44-45 describes the deceased Lazarus as having been bound with strips of linen, and that his face had been covered by a cloth. The canonical passion narratives describe similar grave clothes for Jesus (Mat. 27:59; Mark 15:46; Luke 23:53, 24:12; John 19:40, 20:5-7). Furthermore, John 19:40 states that wrapping the body of a deceased was indeed a Jewish burial custom, which suggests that in all likelihood non-Jews acted differently during this period.

\section{Anointing}

Anointing the body of a deceased person for burial formed a key aspect of the funerary tradition. However, anointing was practised in different ways with varying applications, which we can glean from the varying anointing traditions associated with the death of Jesus. The Hebrew Bible indicates that anointing was used as a form of consecration to their specific divinely ordained roles, for example, for those who were priests (Ex. 30:30; Lev. 4:5), prophets (1 Kings 19:16), leaders (1 Sam. 9:16, 10:1; 1 Chron. 29:22) and kings (Jud. 9:8; 1 Sam. 15:1, 16:13; 2 Sam. 2:4; 1 Kings 1:34; 2 Kings 9:3,12; bK.R. 53a). Similarly, the Mishnah refers to the anointing of high priests (Hor. 3:4). In this context, anointing someone with oil or perfume referred to pouring the liquid on the person, as a rule on the person's head (Lev. 21:10). Moreover, sick persons were anointed as recorded in Hebrew Bible and the New Testament (Isa. 1:6; Mark 6:13; Luke 10:34; James. 5:14). According to the Mishnah, anointing wounds with oil was a widespread Jewish tradition (bShab. 53b; 128a).

Although not overtly related to the processes of anointing, it is significant that Jesus, as the Christ, is the Xpıбós (Acts 4:26-27, 10:38). There is a link between anointing and Messianic activities, since the Hebrew word משיח. Messiah, means the anointed one. Thus Jesus' messianic status may affect our later interpretation of the anointing of Jesus, particularly as recounted in Mark 14:3-9.

A further observation regarding the customs of anointing with regard to formal

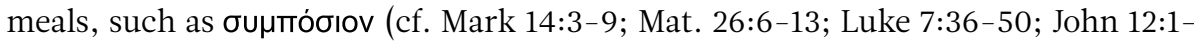
8 ), has to be made. The head of a person arriving as guest was anointed as a means of honouring him or her, though in most cases this would have been a male visitor. It may also have had a practical application, that of removing any lingering unpleasant odours before reclining together at a meal. Although this activity is not part of the funerary custom, it is a custom nonetheless. And it does impact on the discussions around the traditions featuring women anointing Jesus (Mark 14:3-9; Mat. 26:6-13).

Having discussed the various forms of anointing into an office or for a specific task including healing, the second category of anointing has to be examined. For this category rabbinic writings shed significant light on the issue of anointing prior to burial. The Talmud, which consists of the Mishnah and the Gemara, is a compilation of instructions and comments based on Jewish law and various Hebrew Bible passages. 
The Mishnah consists of a codification of Jewish law, in particular oral Jewish law, up to the end of the $2^{\text {nd }}$ century CE, and the Gemara is a collection of further commentaries by various rabbis on the Mishnah, written between 200 and 500 CE. Therefore the Talmud provides not only the basis for Jewish law, but also affords an insight into Jewish interpretation of the Hebrew Bible. With regard to anointing, it is written in the Babylonian Talmud that a corpse may be anointed with oil, provided that the limbs of the body remain stationary (bShab. 151b). The anointing of the dead is also mentioned in the Mishnah (Shab. 23:5). These references, added to biblical and post-biblical references (2 Chron. 16:14; Josephus, Ant. 15.61), indicate a high probability that in $1^{\text {st }}$ century Mediterranean society the body of a deceased person was customarily anointed before burial as part of the preparation for burial. Schottroff (1993:181) observes that aromatic essences were placed next to the deceased in order to show honour to the deceased. As this took place prior to the burial, the location of the anointing would have been the home of the deceased (McCane 2003:48).

In summary, the New Testament and the Talmud, as well as ancient Greco-Roman authors such as Josephus, indicate that the acts of mourning were performed to a large extent by the women (Luke 23:48; bKet. 46b; bM.K. 28b; Yoreh De'ah 344:3; Josephus, Ant.4.320; Solon 21.4; Sawicki1994:255; Malina \& Rohrbaugh1992:408-409). We can therefore conclude firstly that anointing the body of the deceased for burial was a vital part of the funerary customs in Ancient Judaism. Secondly, women were predominantly responsible for the anointing, since anointing the body of the deceased formed a part of the mourning tradition, which was performed chiefly by women (cf. Sawicki 1994:255-257, 272).

\section{Funeral processions}

The Hebrew Bible narrates that Joseph (the son of Jacob and Rachel), together with a large number of relatives, the elders of the land of Egypt, and all of Pharaoh's officials as well as chariots and horsemen, proceeded from Egypt to a cave near Mamre in Canaan to bury Jacob (Gen. 50:6-14). Likewise, the body of Joseph was carried from Egypt to his final resting place by the Israelites and the mixed multitudes joining them, upon leaving Egypt to enter the Promised Land (Gen. 50:25; Ex. 13:19; Josh. 24:32). There are further episodes during which a great number of people assembled in connection with the placement of a newly deceased into a cave or tomb, so that they could honour the deceased and mourn their loss (1 Sam. 25:1, 31:11-13; 2 Chron. $16: 14 ; 32: 33 ; 35: 24)$.

Other early sources state that frequently a reasonably simple burial is preceded by a large procession (bKet. 17a-b; Josephus, C. Ap. 2.205). The Talmud and the Mishnah describe the transportation of a deceased body on a bier as a necessity for a funeral (bSanh. 20a; Ket. 4:4). With reference to women, Rabbi Judah states in the Babylonian Talmud that women are, in fact, to precede the funeral bier (bSanh. 20a). Within ancient Greco-Roman writings there are similar references 
to funerary processions. For example, Plutarch mentions a funeral procession with a bier (Timoleon 39.2-3). Therefore the funerary rites in Ancient Judaism included a procession of the dead to transport the body of the deceased and to offer family and friends a ritualised opportunity to mourn the death of their family-member or friend. On a more practical level, a procession would have given most people in the village or town the possibility to learn the news of a person's death and to have the opportunity to honour the deceased and to mourn by following the procession for some time. Communication systems were vastly different from modern methods of communication, and the villages and towns were quite compact. Since the procession applied to a cross-section of the society, women certainly took part in these funeral processions. The most significant function of the processions was to facilitate an honourable transportation of the body of the deceased from his or her home to his or her grave (McCane 2003:32).

\section{Mourning}

This section deals firstly with the observation that public mourning is a female role, after which a dishonourable burial will be discussed, given that Jesus was crucified as a criminal and therefore apparently given a dishonourable burial.

Several biblical and apocryphal cases illustrate that the lament is a prominent part of the mourning custom (Deut. 34:8; Jud. 11:40; 2 Sam. 1:19; Jer. 22:18; Mark 5:38-39; Sir. 38:16-17; 2 Adam and Eve 9:6, 10:8). The Mishnah refers to women wailing in the context of a mourning rite (mKet. $4: 4 ; 6)$. Tacitus, a Roman historian, also refers to lamenting within the framework of mourning (Ann. 3.4). Nevertheless, the description of the act of the lament varies. Occasionally it is merely described as mourning or lamenting, but at other times this is elaborated on by the use of words such as crying and wailing. Yet in each case the act of lamenting is applied as a public form of the portrayal of grief at a funeral. This public portrayal of grief appears to form an important part of the mourning process to assist family and friends to adjust to the change in the structure of their society (Yoreh De'ah 344). In many cases professional lamenting women were hired for a funeral, seemingly to augment the expression of grief (bSanh. 47a; Yoreh De'ah 344:4; Solon 21.4). Furthermore, female lamenters were often joined by women who clapped their hands (mM.Kat 3: 8-9).

It is thus evident that women played a prominent role when it came to lamenting (4Q179, fr.2; mM.K. 28b; bKet. 46b, 48a). Josephus writes, "The women, too, with beating of the breast manifested their emotion at his approaching death" (Ant. 4.320). In Sawicki's (1994:255-257, 272) opinion, mourning was largely a feminine activity, since the women were judged to be in contact with major life transitions and were thus able to give meaning to death and expression to the associated grief.

Nevertheless, in some cases the deceased was given a dishonourable death, as it had been in the case of Jesus. In a world based on honour and shame, unsurprisingly, ancient sources tell us that executed persons were not honoured with a decent 
burial (2 Macc 13:7: bSanh. 47a-b; Eusebius H.E. 5.1.59) (Crossan \& Reed 2001:246). However, Crossan and Reed (2001:246) observe that archaeologists have found the exceptional case of a family burial having been performed for an executed person, even though the Talmud states that there should be no public mourning for executed persons (bSanh. 46a). Jeroboam, for example, was refused an honourable burial on account of having defied the inspired instruction of the prophet (1 Kings 13:21-22). Schottroff (1993:171) notes that the refusal of an honourable burial constituted a part of the criminal's punishment, thereby further removing any shred of honour from the death and burial of society's unwanted members. Slain Israelites were buried without shrouds (Yoreh De'ah 364:4), which is a further example of showing dishonour to the deceased, since the custom calls for careful washing, anointing and wrapping of the body in plain shrouds so that the purity laws could be upheld. Thus men, women and children who have been scourged and crucified (B.J. 2.307) were not given an honourable burial. Although the executed were on the whole not buried, or buried in a dishonourable way, it was possible to make a request for a burial (Yoreh De'ah 375:5), which is exactly what Joseph of Arimathea did (Mat. 27:57; Mark. 15:43; Luke 23:52; John 19:38). Moreover, Deuteronomy 21:22-23 states that the deceased body of a hanged person ought to be buried by sunset, which reinforces the view that members of society who had been crucified were still rather buried dishonourably than not at all. Furthermore, a dishonourable death would mean that the corpse would not have been laid in the family tomb, and all mourning rites would have been withheld (McCane 2003:96). This would be extended to relatives having been forbidden to mourn publicly at an execution (Philo, In Flaccum 72; Tacitus, Ann. 6.19; cf. McCane 2003:95). Therefore the public lament formed a significant part of honouring the dead and of the remaining family members recognising and sharing their grief and acknowledging the status of honour or dishonour of the deceased.

In conclusion, public mourning appears to have fallen into the domain of the women. Even though the Mishnah refers to men following the bier in the funeral procession behind women (Sanh. 2:2) and connects private mourning to men (Sanh. 6:6), public mourning was habitually performed by women in Ancient Judaism.

\section{Return to the burial site}

According to the rabbinic writings, it was the custom for Jews to return to the tomb $\mathrm{b}^{4}$ to examine the body of the deceased within three days in case the body was still alive thus ensuring the status of death of the body (mBer. 3:2; bSanh. 47a). In John (11:31) Mary of Bethany is shown to have returned to Lazarus' grave to mourn. The Gospel of Peter (12:50-51) also shows Mary Magdalene returning to the tomb, to weep and lament at Jesus' sepulchre. As explained earlier, family and friends were not allowed to mourn openly for someone who had been crucified, so that the 
deceased's death would be dishonoured. The Acts of Pilate illustrates this in 13:2 (cf. Gospel of Peter 21:52), as the Jews asked the guards why they had not seized the women waiting at the tomb. Witherington (1988:165) also observes that it seems likely that the women would have wanted to return to the tomb, so that they could mourn and thereby bestow honour on what they assumed would be the deceased body of Jesus. The clandestine visit to the grave was assumed to be safe, since the norm was to be in mourning during the first seven days of shiv'ah (mM.Kat. 3:5; cf. Levine 2015:84-85). Thus, a person leaving home during this time would not have been assumed to be carrying out a return visit to the burial site of the deceased, since the person would not have been going about their daily activities during that period (McCane 2003:38).

\section{Conclusion}

Funerary rites in Ancient Judaism were fairly elaborate but vital to honour the deceased. These practices enabled the remaining family and friends to voice their grief and to comfort the mourning family members and friends. ${ }^{5}$ The discussion around the funerary rites in Ancient Judaism has demonstrated that women played an essential role in the death and mourning customs in Ancient Judaism. Apart from preparing the body for burial, women grieved loudly in a lamenting act during a funeral procession (Sautter 2010:119), thereby giving voice to society's grief. This indicates that, although in general the public domain belonged to men, in the funerary rites the domain of public mourning belonged to the women, as also evidenced by the occasional hiring of professional female lamenters (b.Sanh. 47a) in order to enhance the wailing and expression of grief.

5 See Levine (2015: 90) pertaining to the expression of grief. 


\section{Bibliography}

\section{Primary Sources}

Apocrypha and Pseudepigrapha

Acts of Pilate

Adam and Eve

2 Adam and Eve

Gospel of Peter

Sirach

Tobit

Dead Sea Scrolls

4Q179, fr.2

Talmud

bKet.

$b K . R$

bSanh.

bShab.

Mishnah

mB.Bat.

mBer.

mHor.

mKet.

mM.Kat.

mSanh.

mShab.

Yoreh De'ah (Joseph Karo, Shulchan Arukh)

Eusebius H. E. (Church History)

Greco-Roman

Josephus, Ant. (Antiquities)

Josephus, B.J. (War of the Jews)

Josephus, C. Ap. (Against Apion)

Philo, In Flaccum

Plutarch, Timoleon

Solon

Tacitus, Ann. (Annals)

\section{Secondary Sources}

Chilton, B \& Neusner, J. 1995. Judaism in the New Testament: Practices and Beliefs, London and New York: Routledge.

Crossan, J D \& Reed, J L. 2001. Excavating Jesus: Beneath the Stonesm Behind the Text, London: SPCK.

Dunn, J D G. 1991. The Partings of the Ways between Christianity and Judaism and their Significance for the Character of Christianity, London: SCM.

Edersheim, A. 1876. Sketches of Jewish Social Life in the Days of Christ, London: Religious Tract Society.

Gonen, R. 1992. Burial Patterns and Cultural Diversity in Late Bronze Age Canaan, American Schools of Oriental Research Dissertation Series, 7, Winona Lake, Ind: Eisenbrauns.

Heilman, S C. 2001. When a Jew Dies: The Ethnography of a Bereaved Son, Berkeley: University of California Press.

Hyman, G E. 1941. The Jewish Woman and her Home, New York: Hebrew Publishers.

Kee, H C. 1973. The Origins of Christianity, New Jersey, USA: Prentice-Hall. 
Levine, E. 2015. Jewish Views and Customs on Death, in Death and Bereavement Across Cultures, 2nd Ed, C M Parkes, P Laugani, \& B Young, London and New York: Routledge, 76-93.

Malina, B \& Richard, L R. 1992. Social Science Commentary on the Synoptic Gospels, Minneapolis: Fortress Press.

McCane, B R. 2003. Roll Back the Stone: Death and Burial in the World of Jesus, Harrisburg: Trinity Press International.

Meeks, W A. 1983. The First Urban Christians: The Social World of the Apostle Paul, New Haven: Yale University Press.

Rabinowicz, T. 1964. A Guide to Life: Jewish Laws and Customs of Mourning, London: Jewish Chronicle Publications.
Sanders, E P. 1992. Judaism: Practice and Belief, 63 BCE-66 CE, London: SCM/ Philadelphia: Trinity.

Sauter, C. 2010. The Miriam Tradition: Teaching Embodied Torah, Urbana, Chicago and Springfield: University of Illinois Press.

Sawicki, M. 1994. Seeing the Lord: Resurrection and Early Christian Practices, Minneapolis: Fortress Press.

Schottroff, L. 1993 [1991]. Let the Oppressed Go Free: Feminist Perspectives on the New Testament, Trans. A S Kidder, Louisville, Kentucky: Westminster/John Knox Press.

Schüssler Fiorenza, E. 1983. In Memory of Her: A Feminist Theological Reconstruction of Christian Origins, London: SCM Press.

Witherington, B. 1988. Women in the Earliest Churches, Cambridge: New York, Cambridge University Press. https://doi.org/10.1017/ CBO9780511520495 


\section{Chapter 17 \\ Plotting Pauline Travels in an Imperial Setting}

Jeremy Punt

\section{The importance of travel in the New Testament (NT)}

It is probably proper to end a volume dedicated to the life and work of Elna Mouton with a chapter on travelling and the NT. ${ }^{1}$ Elna's life, as also described in various ways in the chapters above, is marked by many travels of various kinds. Moreover, the relationship between the New Testament and travel is strong. Reading through the NT, its texts recount endless movement. ${ }^{2}$ The NT recounts how Joseph and Mary fled with Jesus to Egypt (Mat. 2); later Jesus and his disciples are constantly on the move, albeit in the Synoptics in the general direction of Jerusalem; ${ }^{3}$ finally the in-group

1 In honour of, and with immense appreciation for, my colleague Elna Mouton, I offer this paper which addresses notions which Elna has embodied for so many years as a travelling or - to use her word journeying partner in the pursuit of making sense of and investigating the ethical potential and value of NT texts, when these writings are read right.

2 The NT continues the biblical narratives on migration (Abraham, Joseph, the exodus), and is in line with other early Jewish interpretations of migration in Israel (Dead Sea Scrolls, rabbinic Midrash) and in Diaspora contexts (Philo, Josephus). Other kinds of travels, e.g. divine travels such as portrayals of Jesus Christ, or supra-human travels in other dimensions than in daily, physical reality (such as "a man", maybe Paul himself, in 2 Cor. 12:2-4), and with different agency (e.g. ápாаүर́vтa in 2 Cor. 12:2), are not considered here.

3 The transitory nature of the epistles is matched by the transitory situations of the Jesus movement and their Jewish homeland settings in some gospels; e.g. the Lucan travel narrative (Luke 9:51-19:44) starts with the anticipation of Jesus' ascension (Luke 9:51) and closes with his lament over Jerusalem (Luke 19:41-44), and Luke-Acts emphasis on hospitality is related to and invokes relations between stranger-native, insider-outsider, guest-host (see Denaux 1999:255-279, also for the notion of divine travels or visits); cf. Luke's Jesus is homeless, unlike Mark's Jesus (Mark 2:1; 3:20). 
flees (Mark 16), are sent away (Mat. 28) or Jesus departs (Luke 24). ${ }^{4}$ The movement (both as group and as mobility) continues in Acts, after the scattering of people in various directions (Acts 8), especially through first Peter and then Paul. The one particular designation of Jesus followers in Acts, a reference to travelling, $\dot{n}$ ódós (the Way, e g. Acts 9:2; 19:9, 23; 22:4, and 24:14; cf. John 14:6), fits with their profile. Even NT letters result from past travels or call forth future travels, or in themselves act as placeholders or substitutes for actual travelling. Also the Pauline letters and legacy, our focus here, are framed by and shot through with travelling, or, to use a modern notion, migration.

Trying to avoid narrow understandings of migration, ${ }^{5}$ and given the interrelationships and connections between travelling and the NT, a focus on migration may impact upon Pauline research with new angles of investigation. ${ }^{6}$ So too, Pauline studies may contribute - albeit in limited and fractured ways - to (the framing of) work on migration in religious research. Linking up with reflections upon reciprocity and theoretical shifts in migration studies, travels in relation to the Pauline letters are considered in their ancient, imperial setting but from the perspective of migration.

\section{Migration as complex notion: theoretical shifts}

Thinking about the mutual benefit of reciprocal work on travelling or migration in ancient texts and modern contexts starts with three theoretical shifts in migration studies. The move away from the idea of migration as a singular movement of a homogenous group of people from one predefined geographical area to another has meant the growing realisation that migration is a more complex phenomenon than it was (often) made out to be in the past. Similarly, the notion that acculturation among migrants is generally only a matter of time has been shown to be inaccurate, since acculturation typically reaches across several generations among migrants. A third important but rather new acknowledgement is that religious persuasions and behaviours have always played an important role in migration, particularly in how migrants - and others - construct and understand their identity.

4 Denaux (1996:255-279) identified four aspects of divine travels in relation to human hospitality in Luke-Acts: ethical, with Lk presenting a position in tension with contemporary host-guest relationships (Luke 14:7-14 and 14:15-24); christological, with Jesus' earthly life and ministry as divine visit (esp. Luke 9:51-19, 44); mission, where the disciples modelled Jesus' ministry in an ecclesiological setting (Luke 9-10; Acts's accounts on Paul); and, eschatological, with hospitality as Luke's metaphor for the Kingdom of God (Luke 13:22-30).

5 Such as the general, popular view found on the internet: "Human migration is the movement by people from one place to another with the intentions of settling temporarily or permanently in the new location. The movement is often over long distances and from one country to another, but internal migration is also possible; indeed, this is the dominant form globally. Migration may be individuals, family units or in large groups" (https://en.wikipedia.org/wiki/Human_migration).

6 In any case, because of the prevailing conditions in the $1^{\text {st }}$ century, travels generally implied longer periods of time and also extended stays, with the modern distinction between travels and migrations becoming blurred. Pilgrimage - and connections with e.g. Gal. 1-2 - should probably be distinguished from migration, since pilgrimage presupposes return to the place of origin, which is not necessarily the case with migration. 
In Acts Paul is explicitly portrayed and in his letters more sublimely indicated as a migrant - at least, when migration is understood as long-distance travel, a lengthy or permanent stay at the destination, in the presence of social networks of receiving communities. ${ }^{7}$ In the past, ideas about migration or diaspora often rested on the notion of movement away from a fixed centre. But this notion of centre is misleading: "Already in antiquity, the relationship between center and diaspora was ambivalent, a push-pull dichotomy of yearning and rejection, that usually turned the center and the longing for it into a symbol, if it had not yet been forgotten" (Rozen 2008a:27). ${ }^{8}$ For describing the ancient context, the notion of migration in terms of distant peripheries removed from a centre located elsewhere tends to be anachronistic, inclined to presuppose the historical context of nation states and their accompanying ideological priorities (Kitromilides 2008:324). These and other recent views on migration can benefit the understanding of ancient travels, diaspora and exile - including Pauline travels.

After many years of lacklustre attention to migration in ancient times, a new appreciation of mobility among the ancients and its significance is developing maybe induced also by developments in the modern world. Benmajor and Skotnes (1994:4) claim that "migration is a basic feature of social life throughout the world today". But both in popular opinion as well as in official responses by governments, migrations have been treated as "isolated, random events, outside the central thrust of social development ... accidents of history, the result of unusual circumstances, catastrophes, deviations from the norm". ${ }^{9}$ Such thinking in modern times fails to acknowledge how countries worldwide can be explained only with reference to migration, with the USA as prime example of a country defined by migrations and remigrations; how interventions elsewhere in the world often contribute to and in fact stimulate a country's migration; and how identities of immigrants as dangerous, deviant and disruptive persons have been formed, while, conversely, nation states were idealised as culturally homogeneous and territorially distinct. ${ }^{10}$

Modern obliviousness, by and large, to migratory phenomena and trends finds a counterpart in the study of migration of old. Even if travelling was less common in ancient times, and not a daily event nor expectation, most people would have been

$7 \quad$ Notwithstanding the inconclusive debate on whether and how the depiction of Paul in Acts can be correlated with his self-presentation in the letters, our focus here remains on the letters, in order to understand Pauline travels within their rhetorical context. For the more traditional, Acts-based approach to missionary activities ascribed to Paul, see Prill (2009: 332-346).

8 "Modern nationalism rendered the problem more acute. It demanded identification of a center, loyalty toward it, and action on its behalf" (Rozen 2008b:28).

9 For more detailed discussions on reasons for modern-day migrations, see the contributions in Portes and DeWind (2007), as well as the very useful introductory chapter in Portes and DeWind (2007:3-26).

10 Claims about "biblical perspectives" on migration, that the Bible "speaks clearly on public policy" and finding the challenge in the "conundrum of finding and applying the right, timeless principles to a modern policy issue in a specific nation" (Edwards 2009), notwithstanding the good intentions, are neither helpful nor responsible. 
familiar with those who did travel or who had met travellers in their place of stay (Laurence 2001:169). Maybe it is understandable then that the systematic study of ancient migration has been slow in developing (e.g. De Ligt and Tacoma 2016), ${ }^{11}$ and that NT texts are mostly still not read with reference to migration, notwithstanding the centrality of travelling in them. ${ }^{12}$ Without eliding the differences between travelling and migration altogether, it is the similarities between the two that caution against the dismissal of NT texts when it comes to migration. The neglect of the NT, and also early Christian source materials, with regard to issues of migration may be due to different conceptual frameworks (such as mission history). When travels do get attention, it is as romanticised journeys of discovery and sentimentalised missionary travels, which tend to privilege the explicit or ascribed ideological convictions of the travellers of old, neglecting the travels' migratory significance. Such hermeneutic-theological frameworks privilege scholarly interests, in any case, to the detriment of (an appreciation of) the fuller picture.

As mentioned above, quite detrimental for understanding the connection between text and migration is the longstanding definition of migration as a single movement in time and space toward assimilation (see Benmayor and Skotnes 1994:3-11). ${ }^{13}$ Newer theoretical positions may assist in avoiding the impasses induced by conventional theoretical and methodological positions. Collar, for example, presents network theory as an approach with which to understand religious diffusion in the Roman Empire, believing that an "ultra-modern" theory can illuminate the ancient world. Network theory is grounded in connectivity, "the power of the dynamic, fluid interactions that form and dissolve networks to affect cultural change and influence the success and failure of ideas" (Collar 2013:1). ${ }^{14}$ But in the end it is not so much about a particular theoretical approach, but rather about hermeneutical accountability. Here Gaertner's (2007:20) argument on exile, that its treatment "depends not so much on personal experience as on literary, and more generally

11 The contributions in De Ligt and Tacoma work from the assumption that state-organised, forced (including slaves and conscripts) and voluntary (e.g. merchants or traders) mobility and migration were interlinked and need to be considered together. Paul was probably aware of the banishment or exile of the Jewish community from Rome under Claudius in 49 CE, and in any case shared in ancient Israel's narrative of enslavement in and exodus from Egypt (e.g. 1 Cor. 10:1-5; cf Rom. 8:18-29), and Israel's exile (e.g. use of Isa. 52 in Rom. 2:24; 10:15; 15:21).

12 The broader context for NT texts is probably the relocation settings of Jewish Diaspora communities as portrayed in contemporary literature such as Philo (Embassy 155-6, 281-2) and Josephus (JW 7.43-45; Ag Ap 1.186; Ant 14.114-118).

13 Koet (2006: esp. 11-24) points to the fluctuating situations of migration in Luke-Acts, as narrated (persecution Acts 8:1; 11:19; mission; and political trial Acts 22:22-28:31) and as envisioned (war Luke 21:8-36; references to Jewish diaspora communities and the influx of Gentiles in these communities).

14 Two other emerging concerns cannot be addressed here: travelling and agency (losing voice in strange contexts; the need to establish oneself, to find voice again - to what extent were these issues in ancient times? Maybe "having voice" was differently conceived in ancient times?); and communities and the value of non-travelling or staying put (the trouble[s] with travelling, matters such as hospitality, and so forth). 
cultural, canons”, is equally appropriate for migration - past and present. In fact, vastly different perceptions pertaining to geography as much as to peoples require commensurate respect for a different understanding and framing of travel in general and migration, in particular, in ancient times. And, to add to literary and cultural canons, the interrelationships between scholarship and its national settings are complex and fraught with difficulties (Whitelam 2011).

With these sentiments in mind, a final restraint for now is that Pauline travel-discourse has to be understood in connection with the way texts framed the space in which such travels took place. Paul actively constructed the world which he addressed in his letters, including the different situational contexts of his letters, their socio-cultural and theological frameworks, and the tensions between the community of the faithful and the world portrayed in the texts. The traditional,

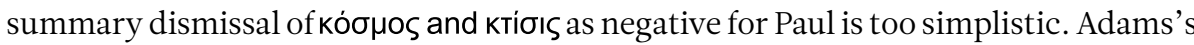
(2000:246) conclusion that "Pauline symbolizations served to create community, not primarily to reflect it" is accurate but limited. Not only created the communities' immediate symbolic universe, the letters created the broader world, too, as they were addressing it. ${ }^{15}$ And pointing to such constructive endeavours in the letters sits well with two emphases in migration studies: the negotiation of identity and acculturation, both of which illuminate Pauline travels.

\section{Migration and identity formation/construction}

According to its own founding narratives, the Jesus movement was migratory from its earliest beginnings - a "movement" in more than one sense - invoking traditions and narratives of ancient Israel in support of its migratory nature. In its increasingly diasporic settings, the Jesus movement relied on and developed interpretive traditions that focused on the movement's itinerant nature. As far as the Pauline letters are concerned, the travelling nature of these early writings' presentation of a relationship of faith in Christ is evident, and the understanding of this relation is bolstered further by reliance on the Scriptures of Israel. In fact, the explicit or embedded use of Israel's Scriptures in the understanding, but also further development, of the formulation or construction and negotiation of a "new identity" in relation to Christ, on the one hand, can be traced through the Pauline letters. On the other hand, Paul clung to his Jewish identity, even where he redeployed and re-evaluated his Jewishness (e.g. Rom. 11:1; Philem. 3:5-6; Gal. 1:13-17). For our investigations here, the role played by Genesis, and narratives of the itinerant

\footnotetext{
15 With an apocalyptic frame of reference in 1 Corinthians, the social and ideological tension between the Jesus community and the world is stressed; emphasising the world as God's good creation and lesser (but not absent) apocalyptic strain, social harmony and good citizenship characterise Romans: proselytising tensions appear to highlight social and religious disunity among Jesus followers in Galatians; but, in 2 Corinthians no specific ideological or social tension seems to determine the use

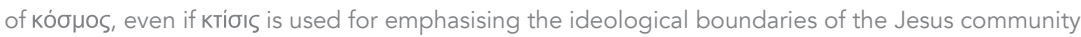
(cf. Adams 2000:85-237).
} 
Abraham in particular, in the framing of the identity of Jesus followers by Paul comes as little surprise (see Punt 2012). ${ }^{16}$ His discursive concern with travels connects intertexually with migration in Israel's Scriptures and in other Jewish interpretive traditions. In recalling the Abraham stories, as for example in Galatians 3-4 and Romans 4, Paul traced a common thread from the past to the experienced realities of the present, both through continuities and breaches, so that also the story about Abraham as told by Paul is neither stable nor closed (see Lieu 2004:97). ${ }^{17}$

The Roman period was characterised by high levels of interregional movement and fluid identity transformations. Evidence reveals significant complexity which meant that everyone who dressed and behaved like an outsider was not necessarily an immigrant in the dynamic social groupings that emerged (e.g. Killgrove 2010a). This was certainly true for Paul's role in the developing Jesus movement as well, given especially the robust Jewish setting and continuing influence on Paul and others. The strong invocation of the narratives of ancient Israel and Paul's intimate association with his Jewish identity cast some doubt on Pauline scholarship's penchant to make

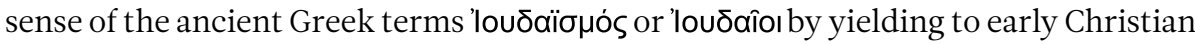
identity studies' tendency to focus on religious separation between Judaism and Christianity (see Holmberg 2008; also Mason 2007). The appropriateness of the use of terms such as "early Christian" and "early Judaism" which some scholars defend (Holmberg 2008:3-5; cf. Runesson 2008:59-92) is hotly debated, while even the suitability of terms like "Christian" or "Judaism" in the $1^{\text {st }}$ century are questioned (e.g. Becker \& Reed 2007:1-33; Lieu 2002:191-209; 2004; cf. Mason 2007).

This is not to rule out the importance of binary thinking in ancient identity constructions and negotiations. Granted, in the $1^{\text {st }}$ century Roman world, binary thinking regarding identity was less typical than what the case was among Greeks and Jews. The Romans were more aware of human diversity, and contrasts made with other peoples as barbarians were mostly on basis of "cultural deficiencies" rather than "with ethnic difference per se" (Stanley 2011:125). Nevertheless, the binary model served identity claims and formulations well, since identity was constructed in contrast, if not always opposition, to the Other. As Collar (2013:30) explains for the Greeks, it was "precisely the act of confrontation between the colonisers and the new people, cultures and religions in the places they colonised that articulated how Greeks saw themselves, and which drive the formation of what came to be understood as collective 'Greek' identity”. To some extent, at least, this is true of the

16 Trebilco (2012:270) relates the use of ódós in Ac to the Scriptures (Isa. 40:3). The NT designation of followers of Jesus as óঠó (the Way, e.g. Acts 9:2; 19:9, 23; 22:4, and 24:14, 22), is of course more than reference to travels, but boils down to an important designation of the identity of Jesus followers (e.g. Trebilco 2012:247-271). However, how the followers of Jesus would fill in this metaphorical self-description in developments towards taking up the name Christianity (Acts 11:26), is not always clear in Acts or, for that matter, in the rest of the NT.

17 An outstanding matter here is about the (different ways of?) understanding intertextuality with regard to the Scriptures of Israel, in relation to ethnic identity, in ancient Israel and among Second Temple Jews? 
travelling Paul and his letters as well: the letters' theological reasoning and moral exhortation took place in the $1^{\text {st }}$ century's whirlpool of change, and are testimony to a concern to negotiate, and at times to impose, a specific identity framework on the addressees of the letters.

\section{Migration and acculturation}

Recent migration studies on acculturation also make for interesting reading when comparing ancient and modern contexts. They play into the question of the extent to which people who created identities, either through coercion or choice, that were distinct from those of the host society, also still maintained their ideological and personal links with their places of origin. Acculturation mostly involves the blending of homeland identity with local cultural life abroad. It constitutes an evolving multigenerational process that includes education and childhood socialisation. In the case of religion and migration, a general pattern of religious support for selective acculturation and transcultural ties has been discerned (Portes \& DeWind 2007:17-20). ${ }^{18}$ This pattern of acculturation relates in many ways to the ancient situation of Jewish Diaspora communities, which were distinctly characterised by strong transcultural ties to Judaea and the ancestral cult in Jerusalem and sometimes by dual citizenship, depending on ancient rules for and systems of affiliation (Josephus, Ag.Ap. 2.38-41; cf. Mason 2007) ${ }^{19}$ Investigating the familial relationship types as found on the epitaphs of foreigners of either civilian or military status in antiquity reveals the extent to which migrants were living in Rome. What is interesting is that, notwithstanding the foreign influences on families, indications are that nuclear families consisting exclusively of immigrants were rare (Noy 2000:67-68). In short, assimilation seems to have been the order of the day in and around Rome.

The $1^{\text {st }}$ century Jesus movement was in many ways related to other Jewish groups, although it should probably not be seen as a Jewish sect in the way that Pharisaism was (cf. Meeks 1985:106). Traditionally it has been concluded that through its internal diversity and apart from Jewish acculturation in the Greek-infused Roman world, "in the long run the gentile world was marginal to the religious cosmos of virtually all Jews in antiquity" (Goldenberg 1997:99-107). From a Jewish perspective, however, there was much more diversity in Jewish attitudes to Gentiles and their religious

\footnotetext{
18 The former neglect of religious concerns in migration studies is changing because of the empirical evidence for the strong and growing presence of religion among the US population, as well as studies showing the importance of religious beliefs and communities in transnational communities, the growth of Islam (Portes and DeWind 2007:17-18).

19 "The re-Judaisation of the Diaspora following the destruction of the Temple in CE 70 and the Bar Kokhba revolt was manifest in the epigraphy through clear statements of Jewish identity. The Jews of the Diaspora reacted to the crisis their faith was undergoing by tightening their ethnic bonds - in sociological terms, the tension they experienced with their environment led to their susceptibility to religious innovation" (Collar 2013:289).
} 
practices, including high levels of tolerance, than is often acknowledged..$^{20}$ Jewish groups like other $1^{\text {st }}$ century groups, including the Jesus movement, maintained connections with the homeland and its cultural ways, including devotion to the "ancestral gods". ${ }^{21}$ "Judean gatherings were, therefore, not alone as ethnic groups with their own distinctive customs and identities that set them apart in certain ways from other groups in the same social setting" (Harland 2009:183). Although the Jesus movement laid no claim to any homeland or ancestral god, Paul at least took his Jewish context seriously, to the extent of going out of his way to garner support for the Jerusalem community (see esp. 2 Cor. 8-9). However, the maintenance of ethnic identities and connections to the homeland, while integrating with host societies, questions traditional notions of rootlessness and detachment among the ancient Mediterranean's immigrant populations. ${ }^{22}$

Not unlike identity issues emerging from Paul's migratory life, considering the presence and extent of acculturation in his letters reveals more about the apostle than the communities he addressed. While Paul's Jewishness was primary, other traditions deriving from the broader $1^{\text {st }}$ century Hellenistic setting also feature in Paul's writings, and probably also influenced Pauline thought. Some scholars argue that as far as acculturation to the Hellenistic world was concerned, "Paul makes little attempt to translate the traditional biblical language of covenant and election into the idiom of Graeco-Roman culture" (Barclay 1995:108). ${ }^{23}$ Barclay describes Paul as a diaspora Jew, highly assimilated (i.e. socially integrated), but comparatively low in acculturation (his mastery of Hellenistic education and Greek) as well as accommodation (subscribing to the Hellenistic conceptual framework). Other scholars, however, have emphasised the opposite, also by showing Paul's invocation and even use of some of the Hellenistic traditions as indication of his acculturation. Scholars then point to Paul's extensive use of the "philosophic tradition of pastoral care" (Malherbe 1987), or his use of other "non-Jewish traditions" such as Menander in 1 Cor. 15:33 (Tuckett 1991:309). The explicit claims regarding assimilation in, for example, 1 Cor. 9:20-23, may be further testimony not only to rhetorical finesse in the interest of his mission, but an indication of Pauline (aspiration to) acculturation. So too do Pauline vitriolic comments against judaising (Gal. 2) raise the question

20 Philo is a good example of strong acculturation, and he "represents a form of Judaism which had come to terms with a high degree of social-cultural and political assimilation and acculturation. Furthermore, it accommodated Judaism to the dominant culture via practices such as allegorical interpretation without abandoning its distinctive traditions and practices" (Winston 1981:12).

21 Minority groups such as Jewish sects and the Jesus movement "also engaged in similar techniques of internal self-definition through stereotyping the 'other,' including other associations" (Harland 2009: 184-185)

22 Harland (2009:183) offers the example of the Judean family at Hierapolis as an example of how both cultural maintenance as well as certain forms of integration within the local society was possible for cultural minority groups. Various affiliations and several identities were possible for the Glykon family, evidently also for the primarily non-Jewish organisations or guilds who explicitly evoked his memory on Jewish as well as Roman holidays.

23 Barclay examines him in his 1st-century Jewish context and concludes that Paul was seen by his fellow Jews as an apostate, a "label [which] fits historical reality" (1995:118). 
whether only religious convictions are of concern here, or whether such polemic need not also be understood in the light of acculturation - especially where religion was not primarily a matter of cognitive content but of active practice, in an imperial context.

\section{Migration in imperial context}

In NT times the Roman Empire impacted heavily on migration through its control by military and other means over the vast areas it controlled. It also did so in direct and indirect ways, by actively moving its military around, creating relatively safe travel routes by sea (fighting piracy) and by land (building roads and bridges), and by attracting people to Rome itself, largely apparently for economic reasons. ${ }^{24}$ To make the point in another way, during imperial times the most important travellers were those involved in the army (Laurence 2001:167). ${ }^{25}$ Rome's imperial designs and the stimulus it provided for travels were not unrelated. In general, links between geographical knowledge and empire (building), and between travels and empire, are well established. ${ }^{26}$ "The need to travel would seem to be part of the experience of the Roman empire, which may partially explain its difference from barbarian lands" (Laurence 2001:169). Ancient literature's functional purpose for geography to plot appropriate travel routes and the widespread use of the travel or journey metaphors also demonstrate the importance of travel and discovery in the wider Roman Empire.

Like most imperial centres, Rome exercised both centripetal and centrifugal forces as far as peoples' movements were concerned. Economic prosperity was an important reason for immigrants to move to Rome, ${ }^{27}$ even when the move was not initially so directed. People often first resided in different places where others of similar religious persuasion or ethnic heritage found themselves, before settling in Rome

24 For a detailed overview of the composition of the types of foreigners and the nature of their lives in Rome, see Noy (2000:157-267).

25 Many contextual factors impact migration in the NT, but the imperial context tends to dominate. The case of Acts is a one example with its uneasiness about possible insurgency (Acts 5:35-39; 21:37-38) against the backdrop of material infringements by Empire signalled or at least anticipated by the Judean census (Luke 2:1-2; Acts 5:37; cf Josephus, Ant. 18.1-10). These sentiments are ostensibly shared by intra-Jewish opposition groups (Luke 2:34; Acts 28:22) and matched in extant contemporary literature (Josephus, Ant. 18.23-24; Philo, Flaccus 86, 92-94). The migratory "messianizing" group of Jesus followers appears hard-pressed to mollify intra-Jewish conceptions of it on the part of Roman authorities (Acts 18:15; 23:28-29)

26 The lingering effects of centuries-long Romanisation prevails in notions such as "those subject to Roman rule, citizen or not, Christian or otherwise, benefited in tangible ways, such as lawful travel within the empire. And temporal citizenship served both God's and early Christians' interests, affording individuals such as Paul certain civil rights and privileges" (Edwards 2009:6). For criticism against Romanisation as a scholarly tradition of emphasising the perceived benefits of Roman rule while neglecting its brutality and domination of other people, see Mattingly (2011) and Punt (2014:81-104).

27 A recent PhD study based on osteological analysis of skeletons found in cemeteries outside Rome begins to cast some light on migration among the lower classes, underlining the diverse composition of migrants to Rome in terms of geographical provenance, distances travelled, demographic composition, and the like (Killgrove 2010a, 2010b). 
(Noy 2000:53-55, 262). ${ }^{28}$ Even if infrequently and for self-interest, Rome at times encouraged foreigners, and doctors and teachers in particular, to move to Rome (Noy 2000:47-48). ${ }^{29}$ The progressive orientation from Jerusalem to Rome in the narratives of Luke-Acts, besides the (imperialist?) expansion narrative of the Jesus communities, and the scope of Paul's letter to the Jesus community in Rome, may betray an attraction to the centre of Empire. ${ }^{30}$ Roman law allowed for foreigners, as persons who were "born outside Italy and moved to Rome, but continued to have a 'home' (in their own thinking or in other peoples) elsewhere” (Noy 2000:xi). Peregrinus was the term for a foreigner or stranger in the sense of non-Roman citizen, with the social status in between slave and citizen (Noy 2000:1, 24). ${ }^{31}$ The province of people's birth rather than of their residence determined their status. In modern times our use of foreigners or migrants reaches much further than in ancient times.

Different kinds of movement originated in and moved away from Rome. Migration was an imperial mechanism in the $1^{\text {st }}$ century CE, both in forcing migration upon people to move them away from a place typically through banishment or as form of punishment, but also in moving people towards a place such as settling war veterans and in this way starting a new community, settling a buffer community of sorts. Imperial travels undertaken by Rome and its emissaries as conquering journeys of "discovery" and "conquest", meant contact with other peoples, and required the development of imperial mechanisms to portray them as different from the (imperial) norm. In texts and visual representations the concepts of travel are closely associated with conquest (Laurence 2001:168). The palpable economic and other material benefits in usurping people's land and resources were accompanied by a colonising perspective on the conquest and destiny of those involved. Trajan's column in Rome exemplifies Empire on the move: "Roman bridges chain rivers with

28 "Indeed, the urban poor in contemporary developing countries have been described as tied into 'a vicious circle of low training, shortage of work opportunities, and low incomes'; it appears that the situation for the urban poor in Rome was not vastly different" (Holleran 2011:180). Cf. Mason (1997:457-512) on problems relating to racial/ethnic and religious categorisation in ancient history.

29 As much as foreigners felt attracted to move to Rome, political and economic motivation sometimes led to their expulsion from Rome. References to expulsion from the time of the Republic to the fourth century CE repeatedly indicate that food shortages in particular were the determining factor for acting against foreigners. Groups singled out for expulsion typically shared common religious values, nationalities or occupations (Noy 2000:37-47).

30 Luke also prepares the way for the migratory movement, culminating in the final chapters of Acts with a journey to Rome and open-ended two-year stay there (Ac 27:1-28:16). The route to Rome in Acts includes elements (sea of Adria; Puteoli) similar to those found in Josephus' description of a Jewish mission (Life 13-16).

31 Although the distinction between Roman citizens and foreigners gradually blurred for economic reasons, already during the Late Republic some differences legally remained in force. A peregrinus legally had no political rights, had to live intestate, and was barred from the military. Peregrini could only become legal heirs through Roman soldiers' wills, with few having the legal right to marry (conubium) or to engage in commercial transactions (commercium) (see Gardner 1993:186-188). 
their cooperation, roads gird the mountains and force through the Carpathian passes. Forests are cleared so that the army may move inexorably forwards (and upwards) in ordered columns. The conflict is not simply between Romans and Dacians, Trajan and Decebalus. It is also a contest between Romans and barbarians, disciplina and perturbatio, labor and inertia, imperial virtues and enemy perfidy, civilisation and untamed nature, urbanisation and wilderness. The depictions of transport and travel on the column not only gave structure to the Dacian wars, but also fully contributed to these actual and symbolic conflicts" (Coulston 2001:129-130).

As was explained more fully elsewhere (Punt 2015:145-147), a popular colonial trope was travel to distant lands and the triumph over indigenous people. In 1 Thessalonians Paul refers to his experiences in Philippi (2:2), encounters with assemblies in Judea (2:14), and the Thessalonian community's role in Achaia and Macedonia (1:7-8). In 2:18, Paul expressed his frustration in not having been able to visit the Thessalonians, but referred to Timothy who travelled as Paul's substitute. ${ }^{32}$ The apocalyptic nature of Paul's letters helps to clarify how Paul was using conquering travel. On the one hand, apocalyptic with its ultimate, final, radical scenarios presents divine conquering travels (4:14-17), sudden and unexpected (5:2). On the other hand, Paul presents himself as the eminent emissary, as the ultimate traveller within an apocalyptic context collecting and leading the others toward the final journey (4:16-17). Even as he offers praise for and appeals to communal love and support (4:9-12) in their own land, it is in anticipation of "conquering" other communities that Paul travelled and invited others to follow suit (as 1:8 seems to suggest already happened). While these and other images could be viewed as anti-imperial in one sense, Paul still tends to speak in the same terms as the empire, repeating or perhaps perpetuating an imperial discourse - and in the process he does not so much destabilise empire as he replaces one with another.

In biblical studies the mission narratives of many biblical texts (and the cultures that carried the texts with them on their journeys) can often be read as imperialist, sanctioning authoritative travellers and reducing all nations to obedient student disciples of Jesus or the apostles (and thus their new representatives among the colonisers) (Dube 2000:140-141). The biblical views of travel involved not only cultural imposition but also enlisted support for political and economic submission to an empire, elements interlinked with religious sentiment. The push and pull of empire meant that the imperial framework rubbed off, and this may go some way towards explaining the forceful language or messages communicated by Paul in referring to his travels to the communities he addressed. Paul could exert pressure, such as in Philemon, where he asks that a room be prepared in expectation of his

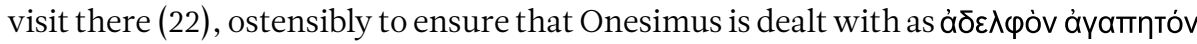

32 Earlier the Thessalonians themselves apparently also travelled (1:8). The letter itself forms part of Paul's broader programme of missionary travels, acting as substitute for Paul's conquering presence and maintaining the dominance of his voice as expressed in the letter. See Stirewalt (2003) on the nature of Paul's letters, particularly their formal, ambassadorial style, and on the authority Paul assumed in the letters. 
(16). In other instances, the threat is pronounced, as in 1 Cor. 4:21 ( $\dot{\varepsilon} \vee \dot{\rho} \alpha \dot{\beta} \delta \omega \tilde{\varepsilon} \wedge \theta \omega$ прò ú uâs). In fact, many Pauline letters refer to completed and impending visits. It remains to ask about the letters of Paul themselves: to what extent do these documents serve Pauline travels not only in the cause of identity (mind you, not acculturation) and imperialism? Are they in some sense exporting pre-packaged knowledge to "the colonies", for dissemination and adapting, while dismissing the indigenous, home-grown as unimportant, secondary, of lesser quality? Not only were Empire and migration cross-linked and the one dependent upon and regulated by the other, they both appear to have left their mark on Paul as traveller, the migrant apostle.

\section{Conclusion}

The NT, of course, does not discuss or entertain migration in its modern conceptualisation(s), but using this modern concept as heuristic interface renders interesting results. Our (post)modern world, often described as a global village or even a glocal world, is facing an enormous crisis with people on the move often through no choice of their own. ${ }^{33}$ Globalisation as such brings along demographic changes which includes migration, with the result that mainstream cultures are impacted upon and even reformatted by diasporic communities (Gabriel 2008:3). The extent of refugees on the African continent has taken on epidemic proportions, at a time when the world's attention seems to be focused on the refugee crisis in Europe. Different levels of attention devoted to refugees, and the vastly disparate reactions when similar events happen in Africa and in Europe, are evidence of dissimilar spatial and socio-political perceptions, illustrating how geography and travels are ideologically informed. Tim Whitmarsh (2016), professor of Greek Culture at Cambridge, writes in April 2016 amidst the recent sharp increase of migrants: "It is too easy to assume that frontiers between continents are stable, permanent and essentially resistant to crossing," especially since continents are not natural givens, but "the products of human political devising”. Mesopotamian, Israelite, Egyptian and Greek writings refer to the world not as "continents" but as "political territories, empires and states, the frontiers of which were ever expanding and contracting across seas, rivers and mountain ranges". ${ }^{34}$ While modern migration studies have a thing or two to teach

33 At times, the effects are clearer than the reasons, e.g. the German Bundesliga started on 26 August 1963 with three foreigners playing for German clubs. Five decades later, in the same league footballers with German citizenship were outnumbered 235 to 194 in the 2015/2016 season (http://newsletter.alumniportal-deutschland.org/-viewonline2/1688/2719/22689/81865/ A06K5pODrn/1).

34 Whitmarsh (2016) illustrates his point with reference to the Hellespont, which in the past was seen as connecting measure, but in the present as a point of division. The boundary between Europe and Asia is obscure, at any rate given the extent of land in common to the north that reaches beyond the tiny sliver of sea that divides them in the Hellespont region. But what today is seen as measure of distinction, division and separation was in ancient times no barrier at all, certainly not a boundary between the two continents of Europe and Asia but the opposite - a waterway connection facilitating travel, connecting the Aegean and the Black Sea. 
present-day scholars of antiquity, maybe studies of antiquity at times can deconstruct some modern notions about geography and migration ${ }^{35}$

The NT's characterisation of Jesus followers as "the Way", of those associated to Jesus Christ as "followers" (among other renderings), highlights the dynamic self-understanding of the movement at the time. Paul's travels were hardly unique, even if generally more extensive in reach and broader in scope than many others. In the Message for the 95th World Day of Migrants and Refugees in 2009, Pope Benedict XVI referred to the apostle Paul as "a migrant by vocation". Linking up with Paul's endeavours, "The proclamation of the kerygma [which] caused him to cross the seas of the Near East and to travel the roads of Europe until he reached Rome", the Pope argued that "This is the mission of the Church and of every baptised person in our time too, even in the era of globalisation; a mission that with attentive pastoral solicitude is also directed to the variegated universe of migrants - students far from home, immigrants, refugees, displaced people, evacuees - including for example, the victims of modern forms of slavery, and of human trafficking". ${ }^{36}$ If the Pope's remark reflects the ecclesial situation, a final sobering comment about the academic world is appropriate for our discussion on the topic of migration: "All discussion of the ancient world is about negotiating the relationships in our world through debating relationships in and to that world" (Penner and Lopez 2011:173) - also in making sense of Pauline travels and their implications in our modern world marked, and at times defined, by migration.

35 The NT has neither the notion of "invading hordes" of "yellow" or "brown" people which so occupied the media and white minds for long, nor of course the "hysterical fear of Islamization" so prevalent in Western Europe (Benmajor \& Skotnes 1994:1).

36 The Pope further urged, "May the teaching and example of St Paul, a great and humble Apostle and a migrant, an evangelizer of peoples and cultures, spur us to understand that the exercise of charity is the culmination and synthesis of the whole of Christian life" (Benedictus PP XVI 2008). Making direct comparisons between ancient and modern contexts (e.g. Holleran 2011:180) is always risky, but ignoring obvious analogies is equally detrimental to proper research. 


\section{Bibliography}

Adams, E. 2000. Constructing the World: A Study in Paul's Cosmological Language. Studies of the New Testament and Its World, London: Bloomsbury Academic.

Adams, C \& Laurence, R (eds.). 2001. Travel and Geography in the Roman Empire, London: Routledge.

Barclay, J M G. 1995. Paul among Diaspora Jews: Anomaly or Apostate? JSNT, 60: 89-120.

Becker, A H \& Reed, A Y. 2007. Introduction: Traditional Models and New Directions, in The Ways That Never Parted. Jews and Christians in Late Antiquity and the Early Middle Ages, A H Becker and A Y Reed (eds.), Minneapolis: Fortress, 1-33.

Benedictus PP XVI. 2008. Message of his Holiness Benedict XVI for the 95th World Day of Migrants and Refugees (2009): Theme: St Paul migrant, 'Apostle of the peoples'. https://w2.vatican.va/content/ benedict-xvi/en/messages/ migration/documents/hf_benxvi_mes_20080824_worldmigrants-day.html. [Retrieved 23 May 2016].

Benmayor, R \& Skotnes, A. 1994. Some Reflections on Migration and Identity, in International Yearbook of Oral History and Life Stories, III: Migration and Identity, R Benmayor \& A Skotnes (eds.), Oxford: Oxford University Press, 1-18.
Carling, J; Erdal, M D \& Ezzati, R. 2014. Beyond the insider-outsider divide in migration research, Migration Studies, 2(1): 36-54. https://doi.org/10.1093/ migration/mnt022

Collar, A. 2013. Religious Networks in the Roman Empire. The Spread of New Ideas, Cambridge: Cambridge University Press. https://doi.org/10.1017/ CBO9781107338364

Coulston, J. 2001. Transport and Travel on the Column of Trajan, in Travel and Geography in the Roman Empire, C Adams \& R Laurence (eds.), London: Routledge, 106-37.

Denaux, A J. 1999. The Theme of Divine Visits and Human (In)hospitality in Luke-Acts, in The Unity of Luke-Acts, J Verheyden (ed.), Bibliotheca Ephemeridum Theologicarum Lovaniensium, 142, Leuven: Peeters, 255-79.

Dube, M W. 2000. Postcolonial Feminist Interpretation of the Bible, St Louis: Chalice.

Edwards, J R. 2009. Center for Immigration Studies Backgrounder: A Biblical Perspective on Immigration Policy. http://cis.org/sites/ cis.org/files/articles/2009/ immigration-biblicalperspective.pdf. [Retrieved 24 May 2016]. 
Gabriel, J. 1998. Whitewash: Racialised Politics and the Media, London: Routledge.

Gaertner, J F. 2007. The Discourse of Displacement in Greco-Roman Antiquity, in Writing Exile: The Discourse of Displacement in Greco-Roman Antiquity and Beyond, J F Gaertner (ed.), Mnemosyne: Bibliotheca Classica Batava, 83, Leiden: Brill, 1-20.

Gardner, J. 1993. Being a Roman Citizen, London: Routledge.

Goldenberg, R. 1997. The Nations that Know Thee not. Ancient Jewish Attitudes towards Other Religions, Biblical Seminar, 52, Sheffield: Sheffield Academic Press.

Harland, P A. 2009. Dynamics of Identity in the World of the Early Christians, New York, London: T \& T Clark.

Holleran, C. 2011. Migration and the Urban Economy of Rome, in Demography and the Graeco-Roman World. New Insights and Approaches, C Holleran and A Pudsey (eds.), Cambridge: Cambridge University Press, 155-80. https://doi.org/10.1017/ CBO9780511863295
Holmberg, B. 2008. Understanding the First Hundred Years of Christian Identity, in Exploring Early Christian Identity, B Holmberg (ed.), Wissenschaftliche Untersuchungen zum Neuen Testament, 226, Tübingen: Mohr Siebeck, 1-32.

Killgrove, K. 2010a. Identifying Immigrants to Imperial Rome Using Strontium Isotope Analysis, in Roman Diasporas. Archaeological Approaches to Mobility and Diversity in the Roman Empire, H Eckardt (ed.), JRA Supplement, 78, Portsmouth: JRA, 157-74.

Killgrove, K. 2010b. Migration and Mobility in Imperial Rome, Unpublished Phd dissertation, Chapel Hill: University of North Carolina. https:// www.academia.edu/245988/ Migration_and_Mobility_in_ Imperial_Rome. [Retrieved 25 May 2016].

Koet, B J. 2006. Dreams and Scripture in Luke-Acts, Collected Essays, Contributions to Theology and Exegesis, 42, Leuven: Peeters.

Laurence, R. 2001. Afterword: travel and empire, in Travel and Geography in the Roman Empire, C Adams \& R Laurence (eds.), London: Routledge, 167-176.

Lieu, J M. 2002. Neither Jew nor Greek. Constructing Early Christianity. Studies of the New Testament and Its World, London: T \& T Clark. 
Lieu, J M 2004. Christian Identity in the Jewish and Graeco-Roman World, Oxford: Oxford University Press. https://doi.org/10.1093/ 0199262896.001.0001

Malherbe, A J. 1987. Paul and the Thessalonians. The Philosophic Tradition of Pastoral Care, Philadelphia: Fortress.

Mason, S. 2007. Jews, Judaeans, Judaizing, Judaism: Problems of Categorization in Ancient History, Journal for the Study of Judaism, 38: 457-512. https://doi. org/10.1163/156851507X193108

Mattingly, D J. 2011. Imperialism, Power, and Identity: Experiencing the Roman Empire (Miriam S Balmuth Lectures in Ancient History and Archaeology), Princeton \& Oxford: Princeton University Press.

Meeks, W A. 1985. Breaking Away: Three New Testament Pictures of Christianity's Separation from the Jewish Communities, in 'To See Ourselves as Others See Us': Christians, Jews, 'Others' in Late Antiquity, J Neusner \& E S Frerichs (eds.), Chico: Scholars, 93-115.

Noy, D. 2000. Foreigners at Rome: Citizens and Strangers, London: Gerald Duckworth.
Penner, T \& Lopez, D C. 2011. Homelessness as a Way Home: A Methodological Reflection and Proposal, in Holy Land as Homeland? Models for Constructing the Historic Landscapes of Jesus, K W Whitelam (ed.), The Social World of Biblical Antiquity, 2/7, Sheffield: Sheffield Phoenix, 151-76.

Portes, A \& DeWind, J. 2007.

A Cross-Atlantic Dialogue: The Progress of Research and Theory in the Study of International Migration, in Rethinking Migration: New Theoretical and Empirical Perspectives, A Portes \& J DeWind (eds.), New York, Oxford: Berghahn, 3-26.

Prill, T. 2009. Migration, Mission and the Multi-ethnic Church, Evangelical Review of Theology, 33(4): 332-346.

Punt, J. 2012. Identity, memory and scriptural warrant, Arguing Paul's case, in Paul and Scripture: Extending the Conversation, C Stanley (ed.), Early Christianity and Its Literature, 9, Atlanta: SBL, 25-53.

Punt, J. 2014. Identity claims, scriptures and Rome in Galatians, Acta Theologica Suppl, 19: 81-104. http://dx.doi.org/10.4314/actat. v33i2S.5

Punt, J. 2015. Postcolonial Biblical Interpretation. Reframing Paul, STAR, 20. Leiden: Brill.https:// doi.org/10.1163/9789004288461 
Rozen, M. 2008a. People of the Book, People of the Sea: Mirror Images of the Soul, in Homelands and Diasporas. Greeks, Jews and Their Migrations, M Rozen (ed.), International Library of Migration Studies, 2, London: IB Taurus, 35-81.

Rozen, M. 2008b. Preface, in Homelands and Diasporas. Greeks, Jews and Their Migrations, M Rozen (ed.), International Library of Migration Studies, 2, London: IB Taurus, 21-32.

Runesson, A. 2008. Inventing Christian Identity: Paul, Ignatius, and Theodosius I, in Exploring Early Christian Identity, B Holmberg (ed.), Wissenschaftliche Untersuchungen zum Neuen Testament, 226, Tübingen: Mohr Siebeck, 59-92.

Stanley, C D. 2011. Paul the Ethnic Hybrid? Postcolonial Perspectives on Paul's Ethnic Categorizations, in The Colonized Apostle. Paul through Postcolonial Eyes, C D Stanley (ed.), Paul in Critical Contexts, Minneapolis: Fortress, 110-126.

Stirewalt, M L. 2003. Paul, the Letter Writer, Grand Rapids: William B. Eerdmans.
Trebilco, P R. 2012. Self-Designations and Group Identity in the New Testament, Cambridge: Cambridge University Press.

Tuckett, C M. 1991. Paul, Tradition and Freedom, Theologische Zeitschrift, 47(4): 307325.

Whitelam, K W (ed.). 2011. Holy Land as Homeland? Models for Constructing the Historic Landscapes of Jesus. The Social World of Biblical Antiquity, Second Series, 7, Sheffield: Sheffield Phoenix Press.

Whitmarsh, T. 2016. Bridging the Hellespont. https://aeon.co/ essays/the-boundary-betweeneurope-and-asia-is-a-culturalfiction. [Retrieved 27 April 2016].

Winston, D. 1981. Philo of Alexandria: The Contemplative Life, Giants and Selections, The Classics of Western Spirituality. London: SPCK.

Zetterholm, M. 2012. 'Will the Real Gentile-Christian Please Stand Up!' Torah and the Crisis of Identity Formation, in The Making of Christianity. Conflicts, Contacts, and Constructions: Essays in Honor of Bengt Holmberg, M Zetterholm \& S Byrskog (eds.), Coniectanea Biblica New Testament Series, Winona Lake: Eisenbrauns, 373-93. 